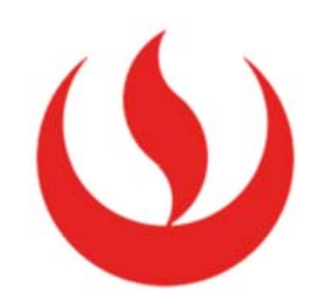

UNIVERSIDAD PERUANA DE CIENCIAS APLICADAS

FACULTAD DE ARQUITECTURA

CARRERA DE ARQUITECTURA

\title{
CENTRO DE DÍA CON ALOJAMIENTO PARA PERSONAS CON ALZHEIMER
}

\author{
TESIS
}

Para optar el título profesional de Arquitecto

\begin{abstract}
AUTOR
Francesca Delia Ramos Matta (0000-0002-1022-6965)

ASESOR DE TESIS

Jorge Garrido Lecca Barandiarán (0000-0002-4083-6852)
\end{abstract}

Lima, 08 de Setiembre de 2018 
Al Arq. Jorge Garrido Lecca, mi asesor de tesis, por el apoyo que me brindó durante el desarrollo de mi proyecto.

A mis padres Miguel y Delia y mi abuelo Filiberto, por su gran amor, apoyo y aliento en todo momento desde el inicio de mi vida profesional.

A mi abuela Cristina, por quererme tanto y por haberme enseñado mucho sobre ella y el Azheimer, ya que sin ella, no hubiera sido posible realizar esta tesis.

A mis hermanos, Miguel y Renzo, por su apoyo constante desde siempre.

A Melissa, mi gran amiga, por haberme alentado a seguir adelante y haber confiado en mí.

A José Antonio, por creer en mí y ser parte de mi motivación. A mis amigos Diego, Margarita y Eduardo por su aporte y apoyo durante este proceso. 


\section{RESUMEN}

En la siguiente tesis se desarrollará un estudio acerca de las características principales que debe tener el centro de día donde se realizarán procesos de rehabilitación para personas con el mal de Alzheimer. Este centro será diurno en donde los familiares puedan dejar a los pacientes a partir de las 8:00 am. hasta las 4:00 pm. Se realizarán terapias para así poder retrasar el avance drástico de la enfermedad. Ademas, las personas que necesiten de alojamiento por temas de desarrollo del tratamiento o como alojo temporal reemplazando los cuidados de su familia.

Se realizó un estudio sobre algunos centros de día para rehabilitar a personas con dicha enfermedad en el mundo para poder establecer un análisis de las características que poseen y los ambientes y así puedan ser parte del nuevo Centro en el Perú. Estas, son características sobre ambientes, materiales constructivos, acabados y otras características en general, que serán tomadas en cuenta para el Centro de día.

Palabras claves: Centro de día; Alzheimer; Rehabilitación; Adulto mayor; Alojamiento. 


\section{DAY CENTER WITH ACCOMMODATION FOR PEOPLE WITH ALZHEIMER}

\section{ABSTRACT}

In the following thesis a study will be developed about the main characteristics that the day center where rehabilitation processes will be carried out for people with Alzheimer's disease. This center will be a day center where relatives can leave patients from 8:00 a.m. until 4:00 p.m. various types of teraphy will be carried out in order to suppress the drastic growth of the disease. In addition, people who need accommodation for treatment development issues or as a temporary shelter replacing the care of their family.

A study was conducted on a few day centers to rehabilitate people with this disease in the world in order to establish an analysis of the characteristics patiens possess and the environments and thus they can be applied to the new Center in Peru. These are characteristics about environments, constructive materials, finishes and other characteristics in general, which will be taken into account for the development of the Day Center.

Keywords : Day Center; Alzheimer ; Rehabilitation ; Elderly People ; Accommodation. 


\section{TABLA DE CONTENIDOS}

ÍNDICE

¡Error! Marcador no definido.

Capítulo 1: INTRODUCCIÓN

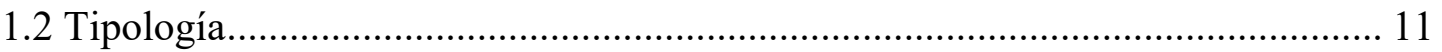

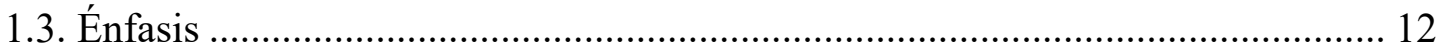

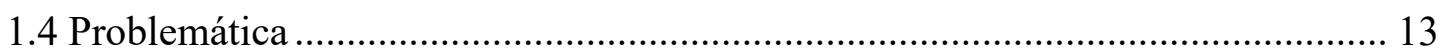

1.4.1 Problemática principal.............................................................................. 13

1.4.2 Problemas secundarios .......................................................................... 13

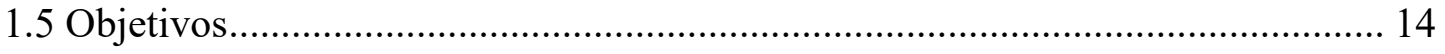

1.5.1 Objetivo principal de la investigación ........................................................ 14

1.5.2 Objetivo principal del proyecto ................................................................ 14

1.5.3 Objetivos secundarios........................................................................... 14

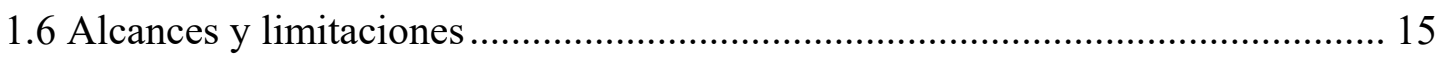

Capítulo 2 : MARCO TEÓRICO Y REFERENCIAL ................................................. 16

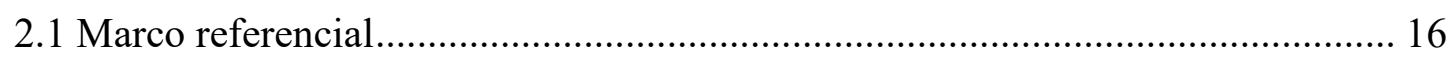

2.1.1 Enfermedad del Alzheimer..................................................................... 16

2.1.2 El impacto de la enfermedad en los pacientes .............................................. 16

2.1.3 Adulto mayor y sus problemas ..................................................................... 17

2.1.4 Comportamiento de los pacientes con esa enfermedad .................................. 17

2.1.5 Etapas en la enfermedad de Alzheimer .................................................... 19

2.1.6 El Alzheimer en el Perú.......................................................................... 19

2.1.7 Discapacitado con enfermedad de Alzheimer .............................................. 21

2.1.8 Grado de incapacidad física de la Cruz Roja................................................. 21

2.1.9 Tipos de centros de cuidado para personas de la tercera edad ..................... 22

2.1.10 Situación, avances y perspectivas en la atención a personas con discapacidad por trastornos mentales en el Perú...................................................................... 23

2.1.11 Centros de Alzheimer actuales del Perú ................................................... 24

2.1.12 Necesidades que tiene un paciente con la enfermedad de Alzheimer (EA) 25

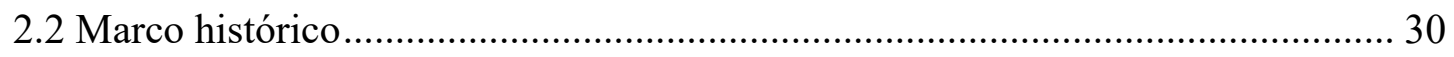


2.2.1 Evolución Histórica del tratamiento de la terapia ocupación en los centros de rehabilitación 30

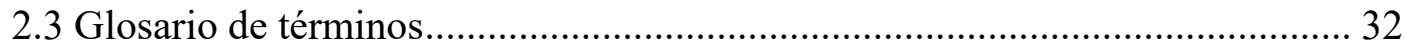

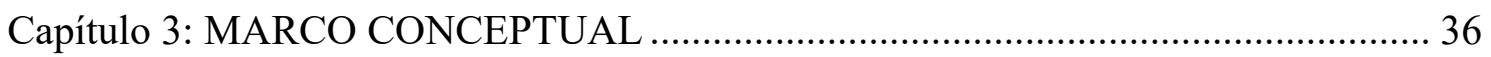

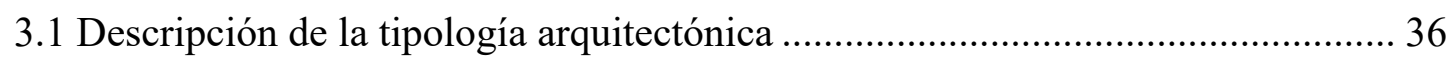

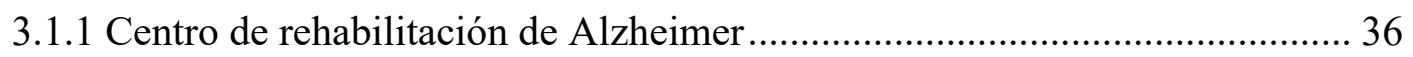

3.1.2 Dependencias de un Centro de rehabilitación para personas afectadas de

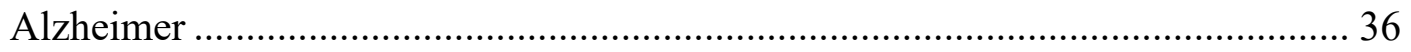

3.1.3 Características generales de la edificación ................................................... 40

3.1.4 Cómo se involucra el diseño con la enfermedad de Alzheimer .................... 41

3.1.5 Características de la distribución arquitectónica (DA) ................................ 42

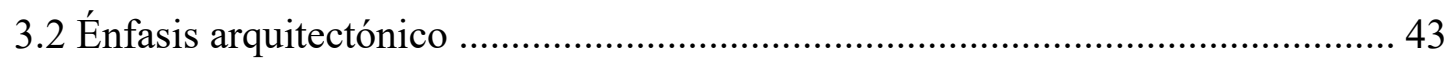

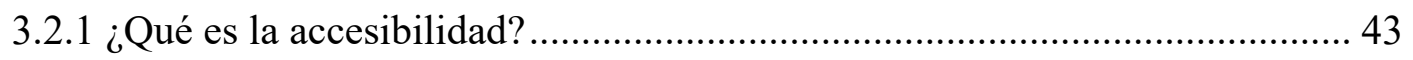

3.2.2 La accesibilidad en las personas con el mal de Alzheimer........................... 44

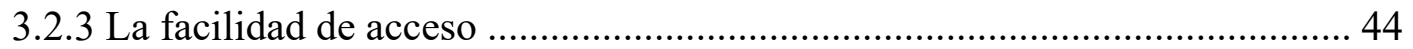

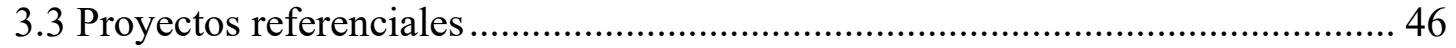

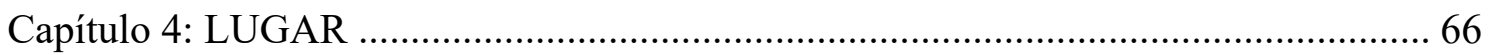

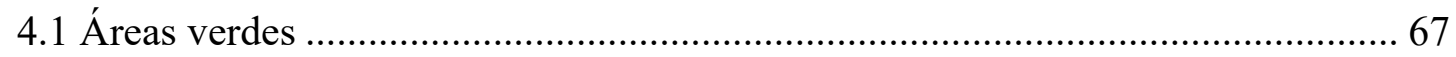

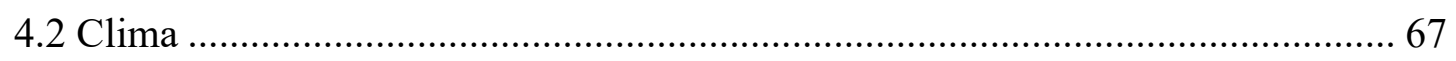

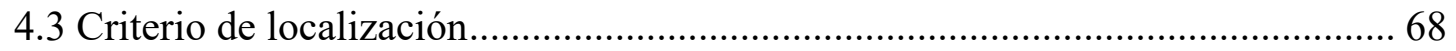

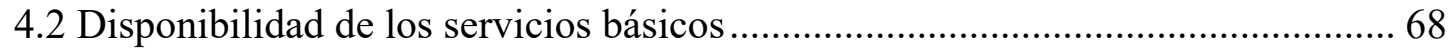

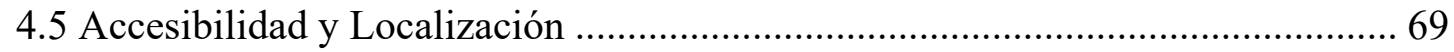

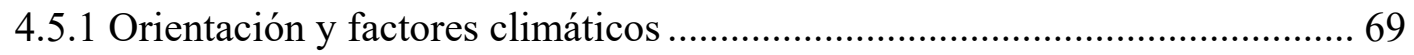

4.5.2 Condiciones físicas del terreno................................................................ 70

4.5.3 Disponibilidad del área del terreno.................................................... 70

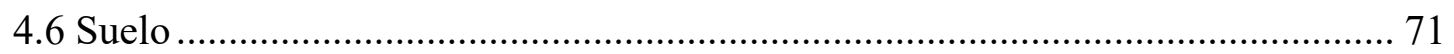

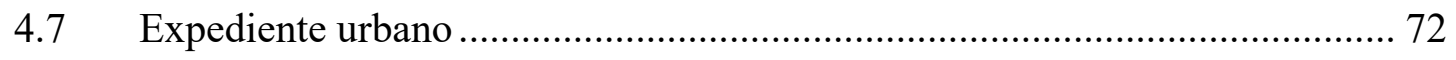

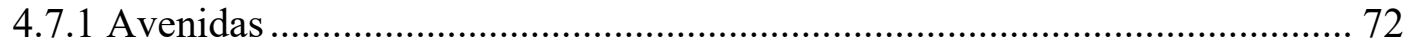

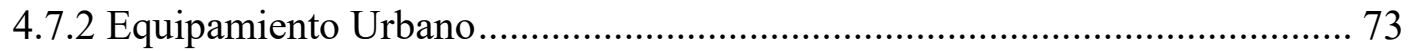

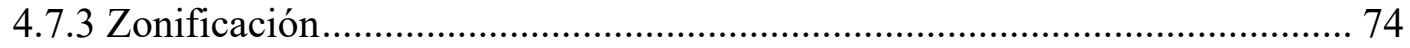

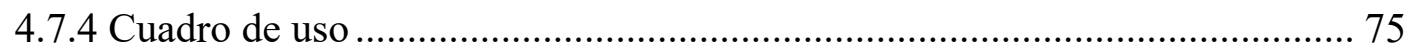

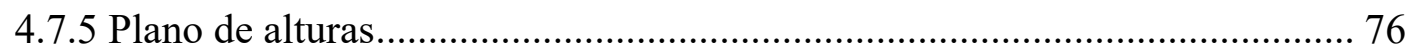

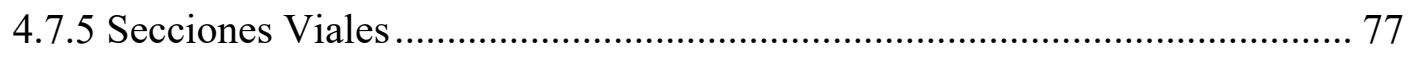

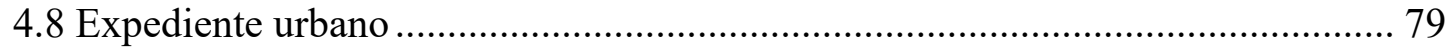




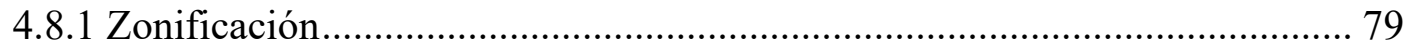

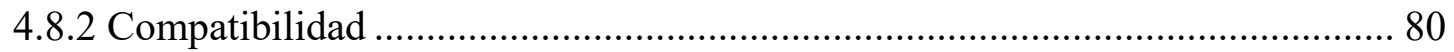

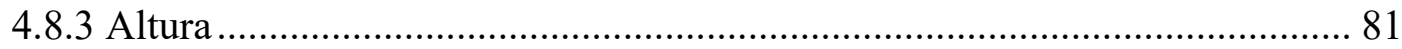

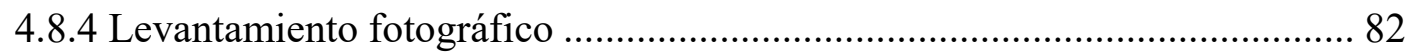

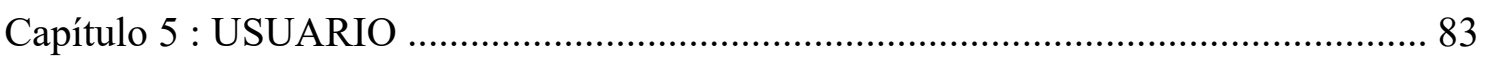

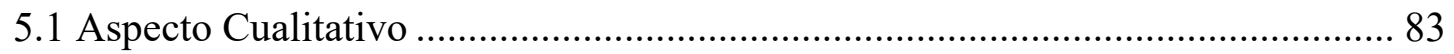

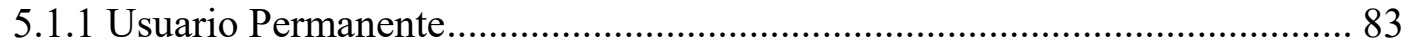

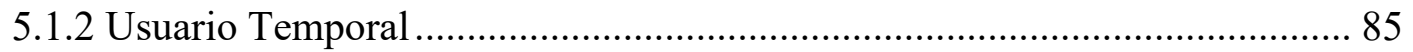

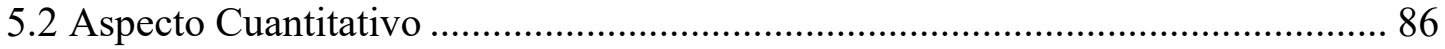

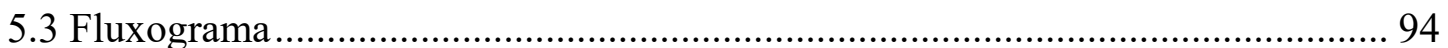

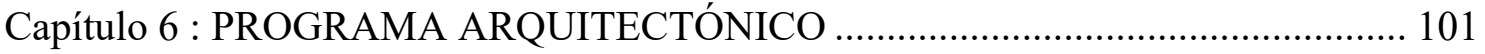

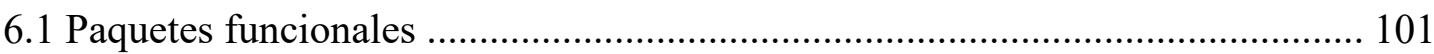

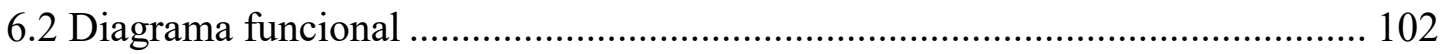

6.3 Cuadro de Compatibilidad............................................................................ 102

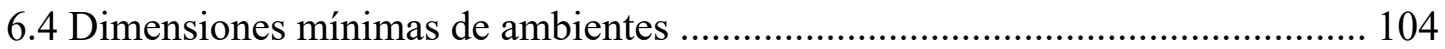

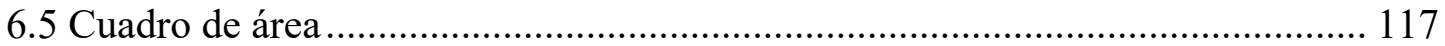

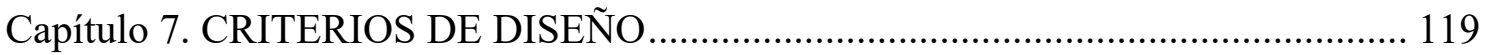

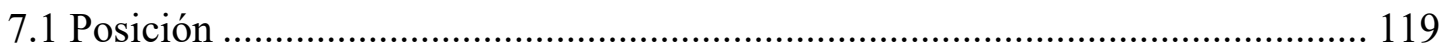

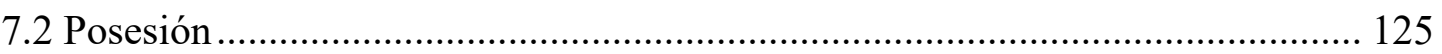

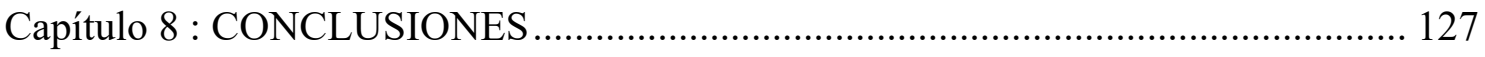

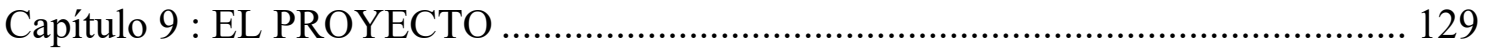

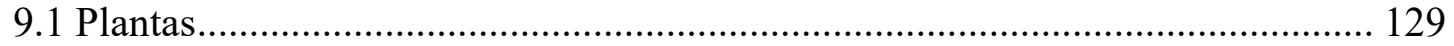

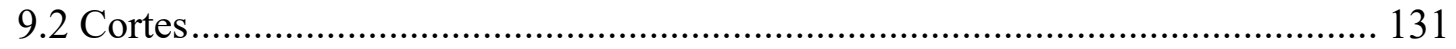

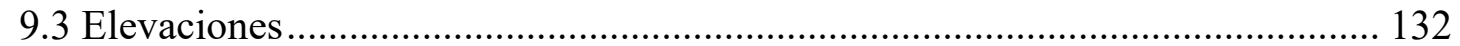

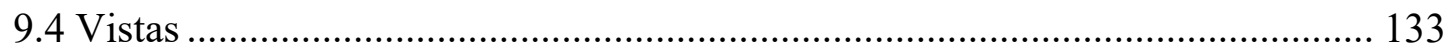

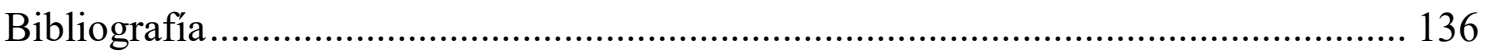




\section{INDICE DE TABLAS}

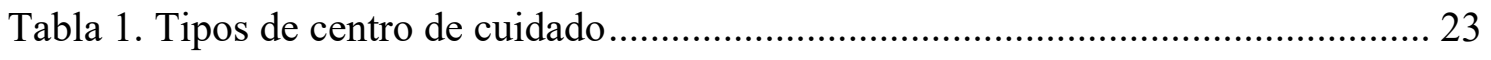

Tabla 2. Terapias no farmacológicas (TNF) por afectados ....................................... 26

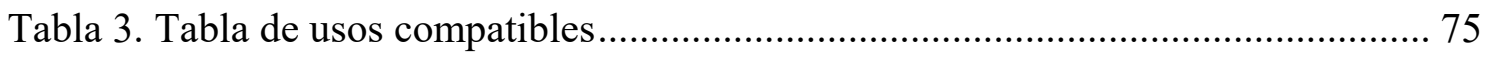

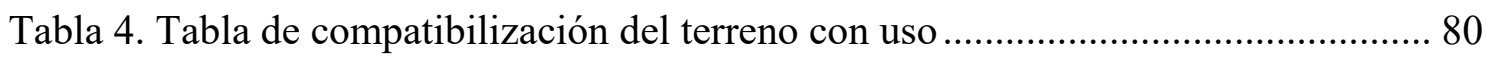

Tabla 5. Población total según año, sexo y grupos de edad $2020-2050$...................... 87

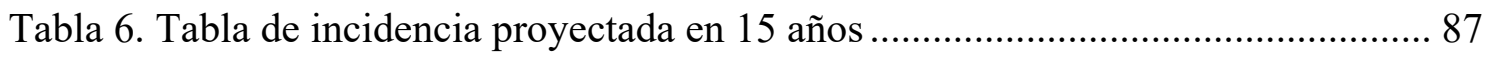

Tabla 7. Tabla de personas asistentes a los centros de rehabilitación actuales ............... 88

Tabla 8. Tabla de Aforo total por centros actuales de rehabilitación para personas con

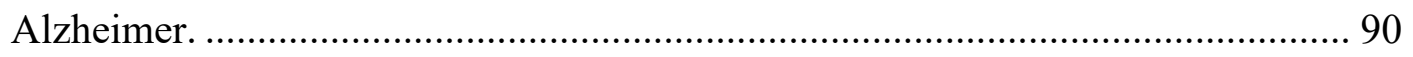

Tabla 9. Pacientes asistentes al centro con demencia de Alzheimer ............................ 92

Tabla 10. Pacientes atendidos de fase crítica de Alzheimer en San Martín de Porres ... 92

Tabla 11. Tabla de características por tipo de terapias............................................... 93 


\section{INDICE DE FIGURAS}

Figura 1. Incremento Absoluto de la Población Adulta Mayor en el Perú..................... 20

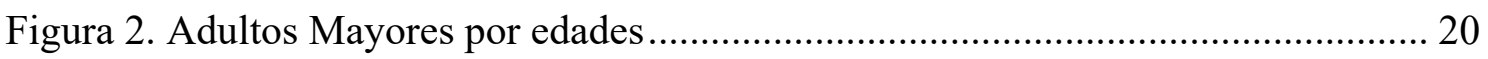

Figura 3. Porcentaje de población adulta con al menos una discapacidad o inhabilidad.

Figura 4.Actitues frente a personas con transtorno mental ......................................... 24

Figura 5. Diagramas de funcionamiento referencial .................................................. 38

Figura 6. Porcentaje adultos mayores en los distritos de Lima ..................................... 66

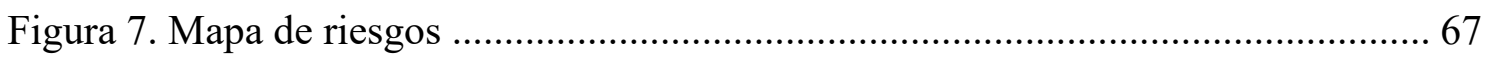

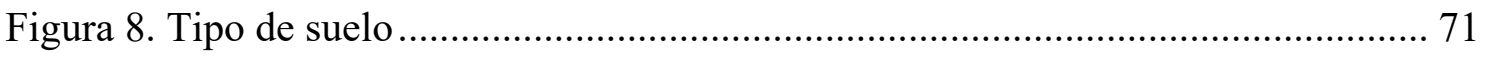

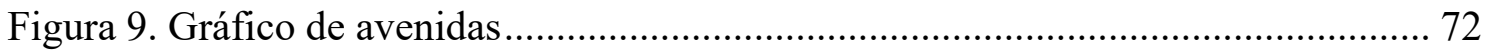

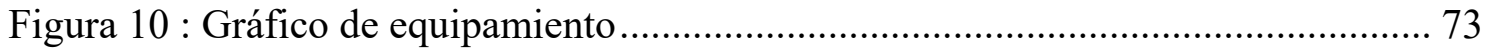

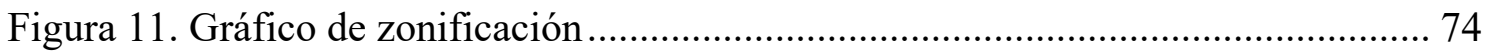

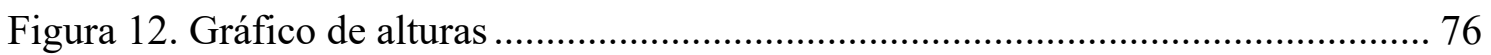

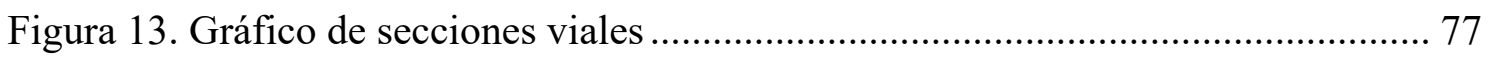

Figura 14.Gráfico de zonificación del terreno......................................................... 79

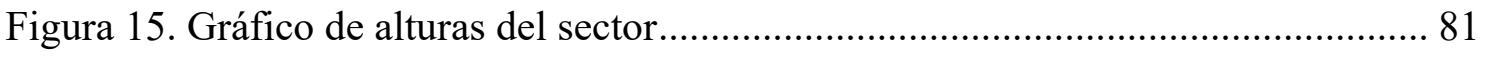

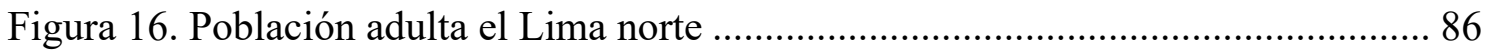

Figura 17. Gráfico de asistentes al Instituto Nacional de Ciencias Neurológicas ........... 88

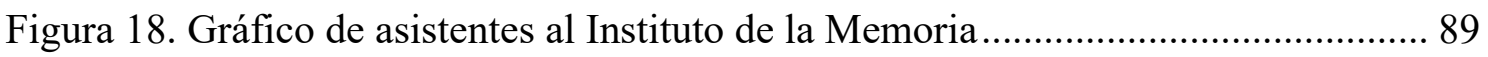

Figura 19. Gráfico de asistentes a la Asociación Peruana de Alzheimer y otras Demencias

Figura 20. Vista exterior : Fachada Av. Canta Callao ................................................. 133

Figura 21. Vista exterior : Fachada calle Huascar..................................................... 133

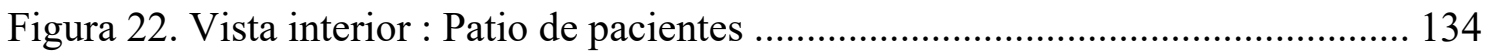

Figura 23. Vista interior : Terraza de pacientes.......................................................... 134

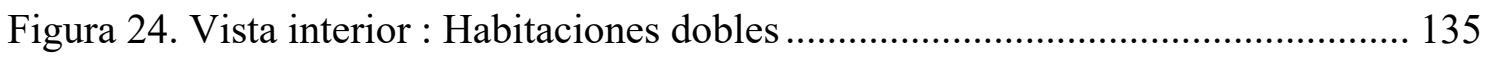

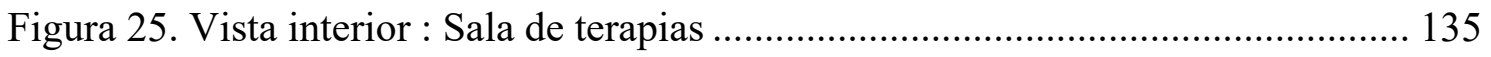




\section{Capítulo 1: INTRODUCCIÓN}

"Su cabeza recubierta por cabello blanco y clavada en su pecho le impedían mirar a plenitud los acontecimientos a su alrededor. Sus movimientos lentos, su hablar y la expresión contenida de su rostro clamaba el esfuerzo inmenso que tenía que hacer para estar presente, aun cuando su voluntad y sus sentimientos fueran tan grandes e intensos, todavía así eran insuficientes para sostener sin pesar su envejecido y encorvado cuerpo..." (Esquivel, 2002)

Así como él, existen muchas personas en el mundo que sufren distintas enfermedades crónicas degenerativas como lo es el Alzheimer, que los limita mental y/o físicamente y acaban con su independencia, haciendo que muchos afectados sean víctimas de maltratos, marginación y abandono.

La enfermedad de Alzheimer (EA) es una enfermedad neurodegenerativa que se caracteriza por un deterioro cognitivo progresivo y es el tipo de demencia más común. Para el 2013 la Asociación Americana de Psiquiatría incorporó la demencia bajo la categoría de enfermedades neurocognitivas moderadas y mayores. El desorden cognitivo mayor es el deterioro de la memoria, en el lenguaje y aprendizaje que interfiere con la independencia y actividades diarias de la persona mientras que el desorden cognitivo moderado se refiere a una pérdida de las capacidades que no interfieren con las tareas diarias, pero sí en actividades que requieran un mayor esfuerzo mental.

Un estudio realizado por la Alzheimer Association Women and Alzheimer Poll, encontró que, aunque las enfermedades del corazón son la primera causa de muerte, la enfermedad que los adultos más temen desarrollar es el Alzheimer. El estudio se hizo con 3,102 personas y reportó que al 35\% le preocupaba sufrir de Alzheimer, el 23\% de cáncer y el $15 \%$ de un ataque al corazón. (Alzheimer Association, 2014). 
Debido a la carencia de lugares especializados en Alzheimer en la ciudad de Lima, surge la necesidad de apoyar a los afectados y sus familiares ante esta problemática. Los enfermos de Alzheimer requieren y merecen la mejora de su calidad de vida dentro de un ambiente que les brinde un cuidado especializado. Es así, como se busca enfatizar el tema de accesibilidad para que facilite el desplazamiento interior y exteriormente para que se sientan identificados con el lugar y aporte proceso de rehabilitación.

Por otro lado, se dice que el aceite de coco se está utilizando en la actualidad con diversos usos, incluyendo para la pérdida de memoria. Aunque eso no está comprobado por completo, el aceite de coco contiene gran cantidad de ácidos grasos de cadena mediana (MCT) que a su vez son fuentes de cuerpos cetónicos, que ayuda a restaurar y renovar las neuronas. La Dra. Newport presentó un estudio de caso donde utilizó 2 cucharadas de aceite de coco diarias con su esposo, paciente que fue diagnosticado con Alzheimer a la edad de 51 años con resultados de mejoría en la memoria y tareas diarias. La Dra. Newport junto al USF Health Byrd Alzheimer's Institute comenzó en el 2013 una investigación para probar su teoría.

Por lo anterior expuesto, el presente trabajo busca generar una propuesta espacial que beneficie y abastezca a un paciente con Alzheimer, así como ser una referencia para quienes, en un futuro, deseen conocer que tan importante es el diseño como una herramienta terapéutica para el cuidado de estas personas. 


\subsection{Tipología}

\section{Centro de Rehabilitación}

Se define como un Centro de rehabilitación como “El establecimiento público, social o privado que proporciona alternativas a los adultos mayores para la ocupación creativa y productiva del tiempo libre mediante actividades culturales, recreativas y de estímulo, donde se promueve tanto la dignificación de esta etapa de la vida, como la promoción y autocuidado de la salud" (NOM-167-SSA1-1997).

Los pacientes con Alzheimer poseen dos tipos de terapias: las farmacológicas y las no farmacológicas (TNF). En este tipo de centro se realizará intervenciones no farmacológicas que son "intervenciones no químicas, teóricamente sustentadas, focalizadas y replicables, realizada sobre el paciente o el cuidador y potencialmente capaz de obtener un beneficio relevante". (Olazarán et al., 2010). Si bien la enfermedad no es curable, las terapias brindadas evitarán el

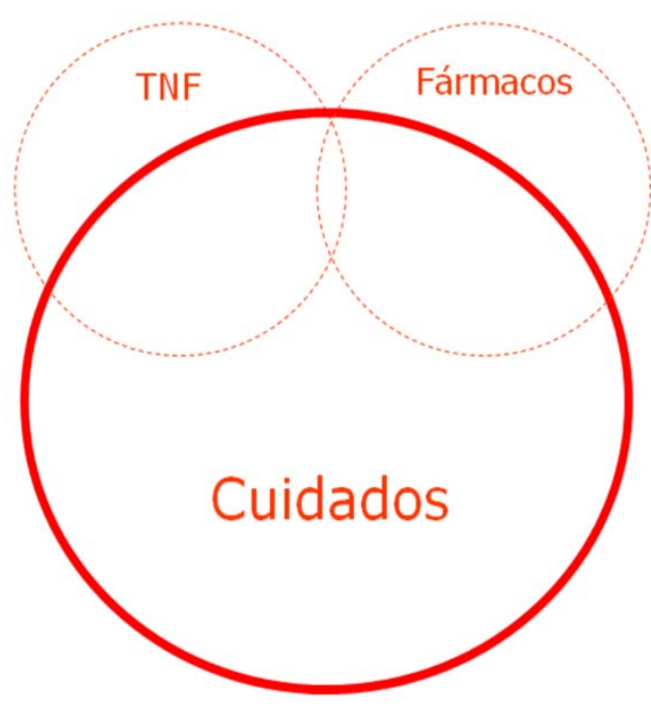
rápido desarrollo de esta en los pacientes, además de buscar aliviar los síntomas y mejorar la calidad de vida de las personas afectadas y sus familiares. Contará también con una zona de asesoramiento y apoyo al cuidador. (Muñiz, y Olazarán, 2010). 


\section{3. Énfasis}

La accesibilidad del usuario es el énfasis que se tomará en cuenta en el Centro de Rehabilitación para personas con Alzheimer y en el área de alojamiento. Esta, es una característica básica del entorno construido, es la condición que posibilita a las personas el llegar, entrar, salir y utilizar el espacio para el objetivo con el que fueron construidos, además de poseer condiciones adecuadas para evacuar.

También se define por accesibilidad como: "la condición de acceso que presta la arquitectura urbanística y arquitectónica para facilitar la movilidad y el desplazamiento autónomo de la persona con discapacidad, propiciando su integración y la equiparación de oportunidades para el desarrollo de sus actividades cotidianas, en condiciones de seguridad" (Yanguas, 2008).

Las personas con Alzheimer, al ser gran parte de los pacientes adultos mayores y al ir perdiendo la capacidad de movimiento y comunicación, tienen dificultades para su desplazamiento, siendo esta una de las características más importantes que se tiene que desarrollar es este tipo de edificios. 


\subsection{Problemática}

Actualmente, en el Perú, sólo tres asociaciones de salud se encargan de la Enfermedad de Alzheimer (EA): El Instituto de la Memoria (IMEDER), el Instituto Nacional de Ciencias Neurológicas (INCN) y la Asociación Peruana de Enfermedad de Alzheimer y otras Demencias (APEAD). Estas, se encargan de orientar y brindar información clara y segura de esta enfermedad a las personas, además de realizar algunas terapias que no son eficientes ni suficientes y actividades gratuitas por un conjunto de personas voluntarias, ya que estos centros requieren de características propias y específicas para el usuario; sin embargo, no existe ningún centro especializado en rehabilitación con los tratamientos requeridos para esta enfermedad en el Perú. Por otro lado, estos centros no tienen las medidas necesarias de accesibilidad para los pacientes con algún tipo de discapacidad según el "Modelo de Centro de Día para la atención a personas con enfermedad de Alzheimer".

\subsubsection{Problemática principal}

¿Cómo la accesibilidad define a un centro de rehabilitación para personas con Alzheimer en el distrito de San Martín de Porres?

\subsubsection{Problemas secundarios}

- ¿De qué manera influyen las condiciones de accesibilidad de dicha infraestructura en los usuarios?

- ¿Cuáles son las necesidades de los pacientes y sus familiares?

- ¿Qué características debe tener la edificación para complementar las técnicas de rehabilitación con respecto a la arquitectura? 


\subsection{Objetivos}

\subsubsection{Objetivo principal de la investigación}

- Recopilar información acerca del diseño de un centro de rehabilitación de Alzheimer enfatizando la accesibilidad del usuario.

- Realizar un estudio urbano con el fin de obtener la mejor ubicación del centro en Lima, para que pueda ser accesible para los pacientes de otros distritos.

\subsubsection{Objetivo principal del proyecto}

Desarrollar un proyecto arquitectónico de un Centro de Rehabilitación para personas con Alzheimer en el distrito de San Martín de Porres para brindar servicios indispensables aplicando las recomendaciones de diseño obtenidas a través de fuentes sobre el tema de accesibilidad donde se realizarán todo tipo de terapias especializadas con el fin de evitar el rápido desarrollo de la enfermedad.

\subsubsection{Objetivos secundarios}

- Investigar sobre la importancia de la accesibilidad para este tipo de usuario

- Conocer las necesidades de los pacientes y familiares

- Investigar qué aspectos arquitectónicos contribuyen a un buen tratamiento para la EA. 


\subsection{Alcances y limitaciones}

El proyecto no busca curar la enfermedad ya que esta no tiene cura cuando ya está muy avanzada. En caso de las personas que se les ha detectado recién el mal de Alzheimer, este centro lograría ayudar a curar la enfermedad por medio de actividades relacionadas con las terapias de rehabilitación (terapias no farmacológicas) y por otros tipos de cuidados como la doctora Mary Newport lo detalla en su libro. Lo que se busca es tener un centro de rehabilitación que tenga los espacios con dimensiones y usos necesarios para realizar las terapias que varían según el punto de vista de cada especialista. En el siguiente capítulo, se explicará la enfermedad, la situación de esta en el Perú y cuáles son las terapias no farmacológicas necesarias para un paciente con la enfermedad del Alzheimer (EA) según tres especialistas. En el caso de las personas que no logren curar la enfermedad, se le realizarán terapias especiales hasta que estas no puedan realizarlas por dificultades que presenten por la edad, por lo cual ya no tendrían la necesidad de acudir al centro de día. 


\section{Capítulo 2 : MARCO TEÓRICO Y REFERENCIAL}

\subsection{Marco referencial}

\subsubsection{Enfermedad del Alzheimer}

En lo últimos años, el termino Alzheimer se ha utilizado con mayor frecuenta entre los distintos medios de comunicación como la televisión, el radio, el internet y el periódico; así como en el lugar de trabajo en la escuela o entre los familiares y amigos. A pesar de esto, no se tiene un conocimiento suficiente sobre lo que esta enfermedad significa.

El siguiente centro de rehabilitación está dirigido para las personas que poseen la enfermedad de Alzheimer y sus familiares, ya que estos cumplen con un rol importante durante el tratamiento de la enfermedad. El usuario son personas mayores que podrían tener hasta alguna dificultad física (pacientes con silla de ruedas) o ya sea los propios problemas de la edad con problemas para su desplazamiento.

Para poder lograr un mejor entendimiento de esta enfermedad es necesario poder definir el término demencia. La organización mundial de la salud (OMS) define como demencia: "síndrome debido a una enfermedad del cerebro, generalmente de naturaleza crónica o progresiva, en la que hay déficit de múltiples funciones corticales superiores, entre ellas la memoria, el pensamiento, la orientación, la comprensión, el cálculo, la capacidad de aprendizaje, el lenguaje y el juicio. La conciencia permanece clara. El déficit cognoscitivo se acompaña de deterioro y control emocional, del comportamiento o de la motivación".

\subsubsection{El impacto de la enfermedad en los pacientes}

Para entender lo que es la enfermedad del Alzheimer (EA) se explicará definiendo demencia. La demencia son alteraciones que afectan la memoria, el lenguaje, la orientación, entre otros, causando problemas emocionales y de conducta. La demencia puede ser adquirida con el paso de los años y puede también ser la causa de muchas enfermedades, siendo la más frecuente la enfermedad de Alzheimer.

La EA es un trastorno neurodegenerativo (mueren las neuronas en el cerebro), produce el deterioro de las personas en el aspecto laboral, familiar y social. La EA también afecta al 
cuidador y a la familia. Antes de descubrir esta enfermedad, era conocida como "demencia senil", "ateroesclerosis" o "falta de lucidez". La presentación de esta enfermedad es más frecuente a partir de los 65 años. El 30\% de las personas de 80 años en adelante desarrollan esta enfermedad, es decir, 1 de cada 3 personas. Por otro lado, así como la EA se presenta en personas mayores de 65, también se puede presentar entre los 30 y 50 años de edad que es provocada, en el mayor de los caso, por antecedentes familiares (Martinez, 2009).

\subsubsection{Adulto mayor y sus problemas}

Se define como adulto mayor a personas con avanzada edad aproximadamente a partir de los 60 o 65 años de vida. Anciano, viejo, personas de la tercera edad, son algunos de los calificativos que, actualmente, han sido sustituidos por el de adulto mayor. Actualmente, no se tiene una cantidad exacta pero existe gran cantidad de adultos mayores en nuestro país e influyen en la población por su constante participación en la sociedad. (Fuente: Diario el comercio, 2015).

Entre los problemas más comunes de salud se puede mencionar la pérdida normal de audición, visión y memoria, enfermedad de Alzheimer y la mayor incidencia de enfermedades crónicas. Estas enfermedades varían de acuerdo al individuo. Algunas personas no padecen este tipo de pérdidas hasta edades avanzadas (aproximadamente 80 años), y la gran mayoría se adapta a las limitaciones de sus problemas de salud. Hoy en día, la salud de las personas mayores es mejor que antes por el avance tecnológico, lo que ayuda a mejorar el estilo de vida de los ancianos (Martinez, 2009).

\subsubsection{Comportamiento de los pacientes con esa enfermedad}

Estas personas disminuyen el interés por aprender. En ocasiones, presentan desorientación espacial, sintiéndose perdidos tanto en su propio barrio como en los pasillos de su propio hogar. Esto, va de la mano con un cambio total en su comportamiento que los hace más irritables y huraños. A continuación se mencionarán 10 signos de alarma de la enfermedad del Alzheimer (EA):

- Pérdida de memoria que afecta a la capacidad laboral.

- Dificultad para llevar a cabo tareas familiares.

- Problemas con el lenguaje. 
- Desorientación en tiempo y lugar.

- Juicio pobre o disminuido.

- Problemas con el pensamiento abstracto.

- Cosas colocadas en lugares erróneos.

- Cambios en el humor o en el comportamiento.

- Cambios en la personalidad.

- Pérdida de iniciativa

Fuente: Martinez, 2009.

Algunos estudios han demostrado que el ambiente también influye en el comportamiento de los pacientes, es por eso que los centros de Alzheimer deben tener espacios bien diseñados que puedan mejorar la calidad de vida del enfermo. (Brawley, E.1997).

Los adultos mayores que no tienen enfermedades neurodegenerativas como lo es el Alzheimer, son capaces de realizar cualquier tipo de actividades como una persona normal hasta presentar problemas naturales de su envejecimiento. Esto, no los hace en mayoría de estos caso, dependientes al 100\% de alguien, ya que, gracias a la tecnología, existen medios técnicos que permiten aliviar gran parte de los problemas de estas personas. Los Adultos mayores que poseen esta enfermedad presentan deterioro progresivo de la memoria, el lenguaje, el conocimiento y la personalidad, que termina en una amnesia total y una reducción de las funciones motoras. El Alzheimer no es una enfermedad mortal pero de una vez que se diagnostica el paciente morirá con ese mal. Esto quiere decir que el padecer de Alzheimer aumenta las posibilidades que pueden causar la muerte. Por ejemplo, tienen mayor riesgo de accidentes urbanos y domésticos al perder la capacidad cognitiva y aumento de enfermedades adquiridas como las infecciones (Martinez, 2009). 


\subsubsection{Etapas en la enfermedad de Alzheimer}

El Alzheimer se manifiesta de maneras distintas en las personas por lo que el avance en cada persona no es lo mismo en todos los pacientes. Sin embargo, la evolución de esta enfermedad, por lo general, suele dividirse en tres etapas: inicial, intermedia y avanzada, esto varía según la progresión de la muerte neuronal que produce efectos en la memoria, en el pensamiento y en la capacidad del paciente para atender sus necesidades básicas.

La segunda fase se La primera fase es denominada como Alzheimer inicial o leve que se caracteriza por tener poca pérdida de la memoria. Sufren también problemas en su expresión oral lo que afecta la relación social con las personas y cambio de carácter al no poder superar estas deficiencias intelectuales.

Se denomina como Alzheimer intermedia o moderada en donde el paciente empieza a sufrir mayores fallos en la memoria como la desorientación. En esta fase, los pacientes pueden recordar etapas de su niñez como si lo hubiesen vivido ayer y dejan de reconocer a los miembros más pequeños de la familia.

En la tercera etapa de la enfermedad o Alzheimer avanzado, el paciente ha perdido su contacto con el entorno, volviéndose dependiente a los demás. Hasta este punto, se han olvidado hasta las habilidades más básicas de alimentación, higiene, y necesitan los mismos cuidados de un niño pequeño. Incluso vuelven a tener posturas que recuerdan al estado fetal. Sus movimientos en esta etapa son muy reducidos, por lo que requieren en la mayoría de ocasiones silla de ruedas y elementos ortopédicos para facilitar su desplazamiento (Martinez, 2009).

\subsubsection{El Alzheimer en el Perú}

Según un estudio realizado en el Perú por el Instituto Nacional de Estadística e Informática (INEI), en relación a la población de adultos mayores peruanos, la población mayor de sesenta años asciende a 796300 personas en el Perú. Se estima que este número seguirá creciendo potencialmente de manera que, para el año 2025, habrá una persona adulta mayor por cada dos niños de 14 años o menos, como se muestra en la siguiente imagen: 
Figura 1. Incremento Absoluto de la Población Adulta Mayor en el Perú

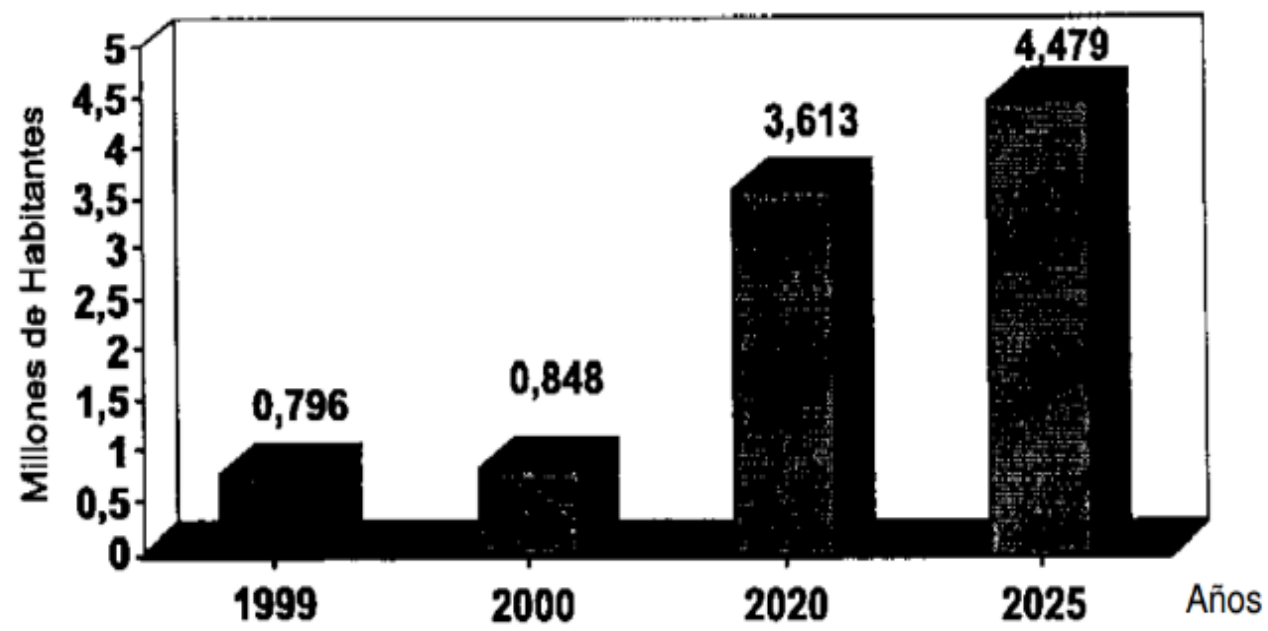

Fuente: Benavides, 2013

Así mismo, se ha demostrado mediante un estudio elaborado por EURODEM sobre la prevalencia de las demencias, que estas aumentan exponencialmente con la edad, tal como se mostrará a continuación:

Figura 2. Adultos Mayores por edades

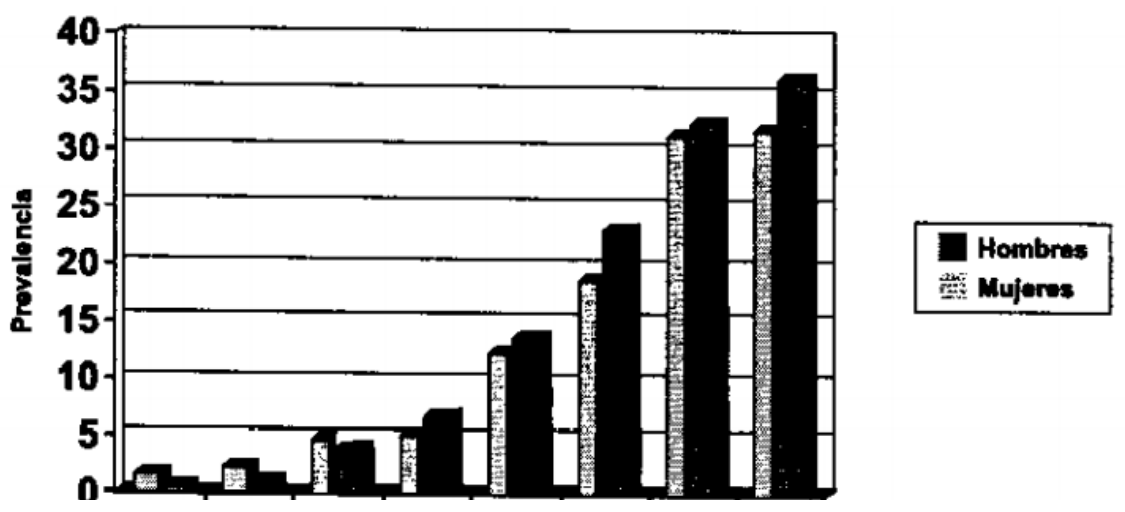

Fuente: Benavides, 2013

Grupo do Edad

De esta manera se puede concluir que el aumento de la población de adultos mayores y su esperanza de vida hace que el aumento de la demencia se incremente. De cada rango de edades, entre el 50\% y 60\% corresponden al mal de Alzheimer (Benavides, 2013). 


\subsubsection{Discapacitado con enfermedad de Alzheimer}

Las personas con la enfermedad de Alzheimer que poseen al mismo tiempo algún tipo de discapacidad física, poseen distintas necesidades en el tratamiento que los demás pacientes, lo cual dificulta las mejoras del paciente.

Según la Organización Mundial de la Salud (OMS), en la clasificación Internacional de deficiencias, discapacidades y Minusvalías (CIDDM), publicada en el año 1980, se define como discapacidad a toda restricción o ausencia de la capacidad para realizar actividades en la forma o dentro del margen que se considera normal para un ser humano. En la nueva Clasificación Mundial del Funcionamiento, de la discapacidad y de la Salud (CIF), que fue aprobada en el año 2011, discapacidad se define como un término baúl para déficit, limitaciones en la actividad y restricciones en la participación. Denota los aspectos negativos de la interacción entre el individuo (con una condición de salud) y de sus factores contextuales individuales (factores ambientales y personales).

\subsubsection{Grado de incapacidad física de la Cruz Roja}

- Grado 0

Se vale por sí mismo, anda con normalidad.

- Grado 1

Realiza suficientemente los actos de la vida diaria.

Deambula con alguna dificultad.

Continencia total.

- Grado 2

Cierta dificultad en los actos diarios, que le obligan a valerse de ayuda.

Deambula con bastón o algún otro apoyo.

Continencia total o rara incontinencia.

- Grado 3

Grave dificultad en bastantes actos de la vida diaria. 
Deambula con mucha dificultad, ayudando por al menos dos personas.

Incontinencia habitual.

- Grado 4

Necesita ayuda para casi cualquier acto.

Deambula con mucha dificultad, ayudado por al menos dos personas.

Incontinencia habitual.

- Grado 5

Inmovilidad en cama o sillón.

Necesita cuidados constantes de enfermería.

Incontinencia total.

\subsubsection{Tipos de centros de cuidado para personas de la tercera edad}

El incremento de la población adulta trajo la necesidad de crear una infraestructura dirigida a ellos. Estos espacios varían dependiendo de los tipos de cuidado que requieren los ancianos. Es así como se encuentra la clasificación del usuario según los topos de residencia (Enciclopedia Plazola, 1997). 
Tabla 1. Tipos de centro de cuidado

\begin{tabular}{|l|l|l|l|l|l|l|}
\hline \multirow{3}{*}{ EDIFICIO } & \multicolumn{5}{|c|}{ ANCIANOS } \\
\cline { 2 - 7 } & \multicolumn{2}{|c|}{ SANOS } & \multicolumn{2}{c|}{ ENFERMOS } & \multicolumn{2}{c|}{ INVALIDOS } \\
\hline & $\begin{array}{l}\text { Menes- } \\
\text { terosos }\end{array}$ & $\begin{array}{l}\text { Autofinan- } \\
\text { ciamiento }\end{array}$ & Menores & Mayores & Físicos & Psíquicos \\
\hline Asilos & & & & & & \\
\hline $\begin{array}{l}\text { Residencias } \\
\text { Villas y Clubes }\end{array}$ & & & & & & \\
\hline Casas de Reposo & & & & & & \\
\hline $\begin{array}{l}\text { Clínicasy } \\
\text { Hospitales } \\
\text { Geriátricos }\end{array}$ & & & & & & \\
\hline Granjas & & & & & & \\
\hline
\end{tabular}

Fuente: Hernández, 2006.

\subsubsection{Situación, avances y perspectivas en la atención a personas con discapacidad por trastornos mentales en el Perú}

Según los estudios Epidemiólogos en Salud mental (EESM) que desarrolla el INSM "HDHN" desde el año 2002, el promedio de la población con al menos una discapacidad o inhabilidad en la población general del Perú es en promedio un 14\%, teniendo Lima y Callao la mayor cantidad de afectados como se muestra en el siguiente gráfico:

Figura 3. Porcentaje de población adulta con al menos una discapacidad o inhabilidad.

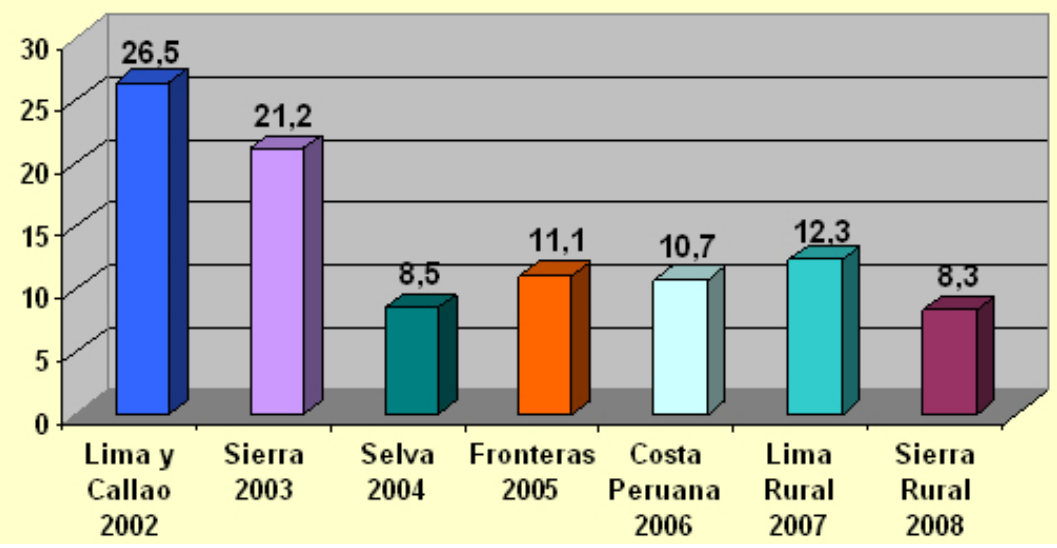

Fuente imagen: http://www.insm.gob.pe

Estas cifras muestran que 1 de cada 7 peruanos (3 950907 personas) tienen algún tipo de discapacidad que dificulta su desempeño personal, familiar, académico, laboral y/o social. 
Instituto Nacional de Estadística e Informática (INEI). Censos Nacionales 2007: XI de población y VI de vivienda. Perú: Crecimiento y distribución de la población- Primeros resultados.

A continuación, se mostrará el comportamiento de estos pacientes en el Perú:

Figura 4.Actitues frente a personas con transtorno mental

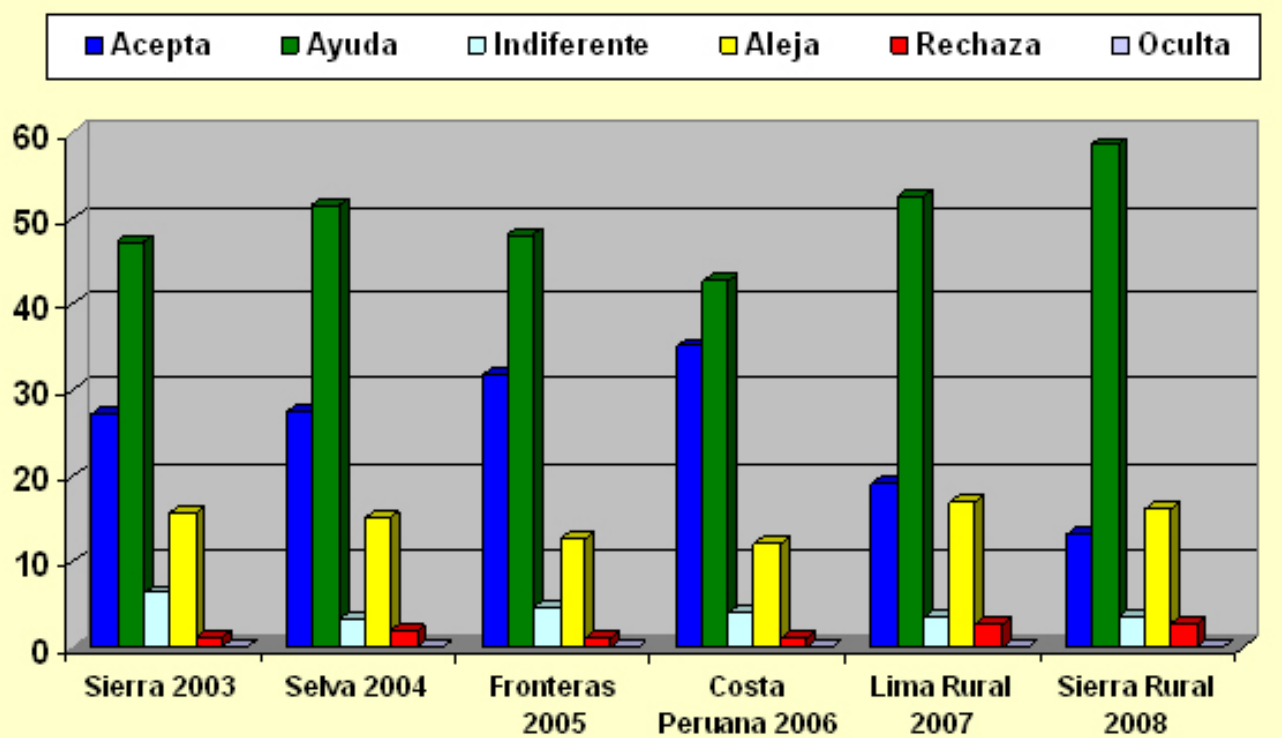

Fuente imagen: http://www.insm.gob.pe

A pesar de esto, el tratamiento dado a estas personas no se da en un $80 \%$, es decir, cada 8 de cada 10 personas no reciben el tratamiento adecuado. Instituto Nacional de Salud Mental “Honorio Delgado - Hideyo Noguchi” (INSM “HD-HN”). Estudios Epidemiológicos en Salud Mental. 2002 - 2010. Lima-Perú.

\subsubsection{Centros de Alzheimer actuales del Perú}

El Instituto Nacional de Ciencias Neurológicas (INCN), en el cual se atiende también a todo tipo de pacientes con enfermedades distintas como un hospital en donde se evalúa el avance de la enfermedad de un paciente con Alzheimer y algunos taller para controlar el desarrollo de la enfermedad, El Instituto de la Memoria (IMEDER), en donde se desarrollan consultas médicas, despistaje de depresión, memoria y otras enfermedades relacionadas al cerebro, evaluaciones neuropsicológicas y psicológicas, talleres de estimulación cognitivas, psicoterapia individual, familiar y grupal y capacitaciones a profesionales de salud; y La Asociación Peruana de Enfermedad de Alzheimer y otras 
Demencias (APEAD) que se dedica a brindar información a los familiares y pacientes sobre la enfermedad por medio de charlas gratuitas, además de realizar algunos taller de estimulación desarrollados por personas voluntarias que están informados sobre esta enfermedad. En conclusión, no existe ningún centro que se encargue únicamente en terapias de rehabilitación para poder controlar la enfermedad. Los hospitales también brindan servicios para esta enfermedad a través de medicinas que complementan los tratamientos de rehabilitación para los pacientes. A pesar de eso, estos lugares existentes para el cuidado de las personas de la tercera edad tienen un carácter institucional, es decir son parecidos a hospitales, siendo inapropiados para dicho fin, ya que son, por lo general, casas adaptadas lo que resulta incómodo y poco funcional.

\subsubsection{Necesidades que tiene un paciente con la enfermedad de} Alzheimer (EA)

La EA es una enfermedad que requiere un elevado gasto económico por parte del paciente debido a los medicamentos y citas médicas necesarias para el tratamiento, además debe tratarse con dos tipos de tratamiento: Farmacológico (a pesar de no haber cura) y el no farmacológico.

Los tratamientos no farmacológicos han demostrado que las intervenciones psicosociales son tan o más efectivas que el uso de fármacos para mejorar la calidad de vida de los pacientes con demencia y sus cuidadores y para el tratamiento de los principales síntomas de la enfermedad (Muñiz y Olazarán, 2010)

Los tratamientos no farmacológicos (TNF) comenzaron a aplicarse de una forma sistemática en las demencias realizadas por grupos de profesionales: terapeutas ocupacionales, fisioterapias y psicólogos. Es también un intento de paliar los efectos a falta de tratamientos curativos.

El siguiente cuadro muestra las intervenciones no farmacológicas de cada afectado, siento I las intervenciones y AVD las actividades de la vida diaria: 
Tabla 2. Terapias no farmacológicas (TNF) por afectados

\begin{tabular}{|c|c|c|}
\hline \multicolumn{3}{|c|}{ TNF clasificadas por afectados } \\
\hline Paciente & Familiar cuidador & Cuidador profesional \\
\hline Estimulación cognitiva & Apoyo al cuidador & $\begin{array}{l}\text { Entrenamiento en los } \\
\text { cuidados generalos }\end{array}$ \\
\hline Entrenamiento cognitivo & Educación y entrenamiento & $\begin{array}{l}\text { Prevención sujeciones } \\
\text { fisicas o quimicas }\end{array}$ \\
\hline Rehabilitación cognitiva & $\begin{array}{l}\text { Asesoramiento y gestión de } \\
\text { casos }\end{array}$ & \\
\hline Ayudas externas & Cuidados de respiro & \\
\hline Entrenamiento AVD & $\begin{array}{l}\text { I. multi-componente para el } \\
\text { cuidador }\end{array}$ & \\
\hline Reminiscencia & $\begin{array}{l}\text { I. multi-componente para } \\
\text { paciente y cuidador }\end{array}$ & \\
\hline \multicolumn{3}{|l|}{ Validación } \\
\hline \multicolumn{3}{|l|}{ Musicoterapia } \\
\hline \multicolumn{3}{|l|}{ Apoyo y psicoterapia } \\
\hline \multicolumn{3}{|l|}{ I. conductuales } \\
\hline \multicolumn{3}{|l|}{ I. sensoriales } \\
\hline \multicolumn{3}{|l|}{ Ejercicio fisico } \\
\hline \multirow{2}{*}{\multicolumn{3}{|c|}{$\begin{array}{l}\text { Estimulación eléctrica } \\
\text { transcutánea } \\
\text { Terapla de luz }\end{array}$}} \\
\hline & & \\
\hline \multicolumn{3}{|l|}{ Relajación } \\
\hline \multicolumn{3}{|l|}{ Masaje y tacto } \\
\hline \multicolumn{3}{|l|}{ Acupuntura } \\
\hline \multicolumn{3}{|l|}{ Terapia con animales } \\
\hline \multicolumn{3}{|l|}{ Arteterapia } \\
\hline \multicolumn{3}{|l|}{ Terapia recreativa } \\
\hline $\begin{array}{l}\text { 1. multi-componente para } \\
\text { ol paciente }\end{array}$ & & \\
\hline
\end{tabular}

Fuente: Muñiz, R. y Olazarán, J. (2010).

A continuación se describirán las TNF orientadas al enfermo según Muñiz y Olazarán:

- Estimulación psicomotriz

- Rehabilitación del miembro superior

- Roboterapia

- Masaje y tacto

- Acupuntura

- Terapia con animales

- Estimulación sensorial Snozelen 
- Programa de educación integral

- Programa Gradior

- Wii terapia

- Musicoterapia

- Danza terapéutica

- Reminiscencia

- Arteterapia

- Laborterapia

- Psicoestimulación cognitiva

- Terapia de luz

- Relajación

- Acupuntura

- Terapia con animales

- Arte terapia

- Terapia recreativa

- Intervenciones multi-componente para el paciente

TNF orientadas al cuidador

- Apoyo al cuidador. Provisión de información relacionada con la demencia y sus causas, y de apoyo poco estructurado (vías para la descarga o refuerzo afectivo). Subtipos: grupos de autoayuda, dispositivos electrónicos para proveer información o establecer redes de cuidadores. 
- Educación y entrenamiento. Aprendizaje de técnicas de tipo cognitivo-conductual dirigidas a manejar el estrés derivado del papel de cuidador (resolución de problemas, reestructuración cognitiva).

- Asesoramiento y gestión de casos. Se educa progresivamente al cuidador en la existencia y utilización de servicios sociales y sanitarios que pueden aliviar la carga.

- Cuidados de respiro. Aplicación rutinaria de servicios dirigidos a aliviar la carga (ayuda en el domicilio, ingreso de respiro, centro de día, etc.) de forma no individualizada.

- Intervención multi-componente.

- Intervenciones multi-componente para el paciente y el cuidador.

\section{TNF orientadas al cuidador profesional}

- Entrenamiento en los cuidados generales. Se educa al personal implicado en el cuidado directo de los pacientes (auxiliares, enfermeros, etc.) en la demencia, sus causas, y su tratamiento desde una perspectiva no farmacológica (comunicación con el paciente, manejo conductual, etc.). El entrenamiento se realiza mediante sesiones teóricas, talleres prácticos y supervisión en el trabajo.

- Prevención de sujeciones físicas o químicas. Intervenciones basadas en los cuidados centrados en la persona, dirigidas a la búsqueda de alternativas dignas y seguras que permitan reducir las sujeciones físicas y el uso de neurolépticos y de fármacos sedantes.

Terapias según la Doctora Mary Newport:

- Aceite de coco: Según la Dra. Mary Newport, del Spring Hill Regional Hospital, el aceite de coco podría ayudar a mantener saludables las células cerebrales, deteniendo de esa forma el avance de la enfermedad e incluso puede revertir algunos de los síntomas. Al respecto la profesional explicó: 
"Parece que todo el problema comienza con algo como una diabetes en el cerebro: las neuronas se vuelven resistentes a la insulina, por lo que no pueden aprovechar la glucosa, y eventualmente se quedan sin energía y mueren

Una fuente de energía que no demande de insulina podrían ser las cetonas, un tipo de grasa que es común en el aceite de coco”. Newport, 2012.

- Artes: Este tipo de terapia ha sido utilizada en el tratamiento de afecciones de salud mental como depresión, ansiedad, así como para otros problemas emocionales. Además ha sido usada en el tratamiento de Alzheimer con resultados positivos: Mejoría de las emociones negativas y comportamientos problemáticos.

- Tai Chi: una investigación realizada sobre el Tai Chi y el Alzheimer demostró que, quienes toman clases de Tai Chi, tenían un cerebro un poco más grande luego de 40 semanas, y tenían también una mayor habilidad cognitiva y una mejor memoria.

- Terapia con animales: La terapia con animales también sería beneficiosa en pacientes con Alzheimer, ya que la compañía de una mascota estimula comportamientos positivos como el contacto físico, la sonrisa, la verbalización de adjetivos cariñosos, etc. 


\subsection{Marco histórico}

\subsubsection{Evolución Histórica del tratamiento de la terapia ocupación en los centros de rehabilitación}

- Las técnicas y terapias ocupacionales tienen raíces históricas. Así, como la historia familiar es parte de la vida privada, el conocimiento de la historia profesional, es parte de la vida laboral. El desarrollo de la terapia ocupacional se mezcla con la historia humana, pero el este se enriquece en el siglo XIX y comienzos del siglo XX. La ocupación ha tenido un papel central en la existencia humana desde el comienzo de los tiempos mezclándose con la historia humana.

- La salud y la ocupación están vinculadas debido a la pérdida de salud que disminuye la capacidad para comprometerse en la ocupación. El uso terapéutico de la actividad y del movimiento, ha sido apreciado desde los inicios de las civilizaciones de las siguientes maneras:

- En el 2600 a.C., los chinos pensaban que la enfermedad era generada por la inactividad orgánica y utilizaban el entrenamiento físico, mediante ejercicios gimnásticos, para promover la salud e incluso, según sus creencias, para asegurar la inmortalidad.

- Alrededor del 2000 a.C., los egipcios alzaron templos donde los depresivos acudían en gran número para aliviar su enfermedad y en los cuales, el uso del juego y actividades recreativas eran la actividad característica.

- En la Grecia clásica, por el 600 a.C., Escupalio, funda el hospital de la ciudad de Pérgamo, donde aliviaban el delirio con canciones, música y literatura.

- Entre el 600 a.C. y el 200 d.C., Pitágoras, Tales de Mileto y Orfeo, utilizaron la música, como remedio para distintos males.

- Hipócrates recomendaba la lucha libre, la lectura y el trabajo para mantener el estado de salud. 
- Cornelio Celso, (14-37 d.C.), recomendaba la música, la conversación, la lectura, y ejercicios hasta el punto de llegar a la fatiga, para mejorar las mentes trastornadas. Para problemas de estómago, recomendó lecturas en voz alta.

- Séneca (55 a.C.-39 d.C.), recomendaba el trabajo para cualquier tipo de agitación mental.

- Galeno (129-199) defendía el tratamiento mediante la ocupación, señalando que el "empleo es la mejor medicina natural y es esencial para la felicidad humana"

- Durante la Edad Media, apenas se desarrolla la idea de la ocupación, con fines terapéuticos.

- Entre 1250 y el 1700, el interés científico, se dirigió al análisis del movimiento y autores como Leonardo, Descartes, y Bacon, prestaban atención al ritmo, la postura, y el gasto de energía.

- Ramazzini resalta la importancia de la prevención, frente al tratamiento, y la importancia de observar al paciente en su lugar de trabajo.

- Sanctorius (médico), señaló cómo los ejercicios ocupacionales y la recreación, podían incrementar la vitalidad.

- Durante los siglos XVIII y XIX tuvo lugar, un rápido desarrollo de la psicología, la anatomía, y la fisiología, lo que contribuyó a que fueran apareciendo los patrones de la fisioterapia y de la terapia ocupacional.

- En 1780, Tissot clasificó el ejercicio ocupacional en activo, pasivo y mixto.

- En 1789, Pinel introdujo el tratamiento por el trabajo en el Hospital Asilo de Bicetre, para enfermos mentales prescribiendo ejercicios físicos y ocupaciones manuales en la creencia de que la labor humana ejecutada rigurosamente, era el mejor método de asegurar una buena moral y disciplina.

- En la Segunda Guerra Mundial, se reconoció la Terapia Ocupacional realmente.

- El proyecto Brabazan, introducido en Escocia en 1898, en el asilo de Woodilee, de Lenzie, fue una notable experiencia de la ocupación como tratamiento. Esta 
consistía en "enseñar a los residentes enfermos y tullidos, a emplear sus manos de modo útil”.

- El primer centro de tratamiento de la Enfermedad de Alzheimer (1958) estaba dirigida para mejorar las actividades sociales y domésticas que tenía el nombre de “tratamiento experimental de la confusión senil persistente”. Pocos años después (1966), aparecieron las estimulaciones cognitivas que tenían que ver con comunicaciones acerca de los efectos beneficiosos de la orientación a la realidad. En el año 1977, se clasificaron las intervenciones en los ancianos: orientación a la realidad, programas de estimulación y actividades y tratamiento ambiental e intervenciones conductuales. Desde ese entonces hasta el día de hoy, se han ido desarrollando otras intervenciones que solo se centraban en el paciente. Desde los años 80 , se desarrollan distintos programas dedicados a la "carga del cuidador", procedente de la psiquiatría que comienza aplicarse en las demencias a través de programas de apoyo a los cuidadores familiares. Finalmente, surgieron grupos de cuidadores profesionales en las personas con demencia por medio de intervenciones no farmacológicas.

Fuente: Berrocal, 2008.

\subsection{Glosario de términos}

- Estimulación cognitiva. Facilitación general y temática de operaciones cognitivas basada en evocación, relación y procesamiento. Se persigue la orientación, dentro de las posibilidades de cada paciente, y la mejoría afectiva.

- Entrenamiento cognitivo. Aprendizaje o refuerzo de operaciones cognitivas específicas; p.e., asociación de nombres y caras a través de la elaboración de relaciones semánticas por parte del propio paciente.

- Rehabilitación cognitiva. Aprendizaje o refuerzo de operaciones cognitivas altamente individualizado, dirigido a mantener o a recuperar capacidades funcionales o sociales relevantes para el enfermo.

- Ayudas externas. Utilización de material o dispositivos que sustituyen alguna de las capacidades cognitivas perdidas, con el fin de recuperar o 
mantener alguna actividad funcional o social relevante para el enfermo como uso de agendas para recordar las citas, o uso de avisadores para tomar la medicación.

- Entrenamiento AVD. Práctica guiada mediante la mínima ayuda necesaria, ofrecida de forma gradual (estímulo verbal, visual o físico) de alguna AVD, con el fin de mantener la mayor autonomía posible en dicha actividad.

- Reminiscencia. Elaboración cognitiva y afectiva a partir de acontecimientos o experiencias del pasado remoto (acontecimientos vividos, hechos del pasado, canciones antiguas, etc.). Técnica específica: elaboración del libro de la vida.

- Validación. Combinación de distintas técnicas (reminiscencia, orientación y tacto.) con el fin de empatizar de forma afectiva con el paciente.

- Musicoterapia. Utilización de la música de forma activa o pasiva, dirigida a estimular capacidades cognitivas, a provocar un refuerzo afectivo y a mejorar el estado físico.

- Apoyo y psicoterapia. Aprendizaje de estrategias cognitivo-conductuales para soportar el estrés derivado de la pérdida de capacidades cognitivas.

- Intervenciones conductuales. Actuaciones basadas en el análisis de los antecedentes y consecuencias de la conducta, con vistas a reforzar las conductas adaptadas o que generan placer, y a modificar las conductas desadaptadas o que generan sufrimiento. La modificación de los antecedentes de la conducta es preferible a la de las consecuencias.

- Intervenciones sensoriales. Utilización de estímulos dirigidos a alguno de los sentidos, con el fin de favorecer las operaciones cognitivas o de mejorar la afectividad o la conducta. Subtipos: utilización de masaje y tacto, uso de la luz, olores, sonidos, estimulación multi-sensorial. 
- Ejercicio físico. Ejecución guiada (mediante indicación verbal o por imitación) de ejercicio aerobio dirigido a mejorar la resistencia, la flexibilidad el equilibrio y la coordinación.

- Estimulación eléctrica transcutánea. Utilización de corriente eléctrica para facilitar funciones cognitivas, mejorar el sueño o mejorar la conducta. Subtipos: estimulación nerviosa eléctrica transcutánea (TENS), estimulación eléctrica craneal.

- Terapia de luz. Utilización de luz en distintas frecuencias e intensidades para conseguir una mejor sincronización del ritmo circadiario natural de sueño y vigilia.

- Relajación. Intervención de corte físico y cognitivo dirigida a liberar al paciente de la tensión muscular y de la ansiedad.

- Masaje y tacto. Grupo de intervenciones que, a través del contacto físico, buscar la mejoría afectiva y conductual. Subtipos: masaje en las manos, tacto terapéutico.

- Acupuntura. Perforación cutánea mediante agujas gruesas en los puntos marcados por la tradición china, acompañada del uso de ungüentos tradicionales. Se persigue la mejoría cognitiva y afectiva.

- Terapia con animales. Utilización de animales domésticos de compañía para motivar al paciente y provocar una mejoría global (cognitiva, afectiva y social).

- Arte terapia. Elaboración guiada de obras con valor artístico como lo son las pinturas, adaptada a las posibilidades del paciente, dando prioridad al refuerzo afectivo.

- Terapia recreativa. Propuesta y ejecución de actividades lúdicas guiadas o supervisadas, ya sea de forma individual o en grupo, con el fin de provocar una mejoría global (cognitiva, conductual, afectiva y social).

- Intervenciones multi-componente para el paciente. Combinación de alguna de las anteriores, ya sea de forma "rígida" (música y ejercicio físico) o diseñada según las características y necesidad del paciente. 
- Intervención multi-componente. Combinación de alguna de las anteriores, ya sea de una forma "rígida" (asesoramiento y grupos de autoayuda) o individualizada según las características y necesidades del cuidador.

- Intervenciones multi-componente para el paciente y el cuidador. Se suman o se integran intervenciones dirigidas al paciente y al cuidador, ya sea de una forma "rígida" (educación del cuidador y estimulación cognitiva para el paciente) o de una forma individualizada, según las características y necesidades del paciente y del cuidador. Dentro de esta segunda modalidad destacan las intervenciones de asesoramiento en el domicilio, realizadas por terapeutas ocupaciones. 


\section{Capítulo 3: MARCO CONCEPTUAL}

\subsection{Descripción de la tipología arquitectónica}

\subsubsection{Centro de rehabilitación de Alzheimer}

En esta tipología ofrecerá terapias de estimulación adecuadas a este tipo de usuario para que el desarrollo de la enfermedad sea lo menos agresivo posible, promover el mantenimiento de la mayor autonomía personal de la persona con demencia y potenciar las capacidades físicas, cognitivas y funcionales de los usuarios. (Yanguas, J. (2008). Modelo de Atención a las personas con enfermedad de Alzheimer. Barcelona)

\subsubsection{Dependencias de un Centro de rehabilitación para personas} afectadas de Alzheimer

Estos edificios deben tener espacios suficientes para poder albergar tanto a los usuarios, para que puedan abastecer sus necesidades básicas para su rehabilitación, como a los profesionales para que puedan tener las comodidades básicas al realizar su labor. Es por esto que la tipología deberá tener dos zonas o áreas claramente diferenciadas, y a ser posible independientes. La primera está destinada a los profesionales que trabajan en el centro y la segunda a los usuarios del mismo. 


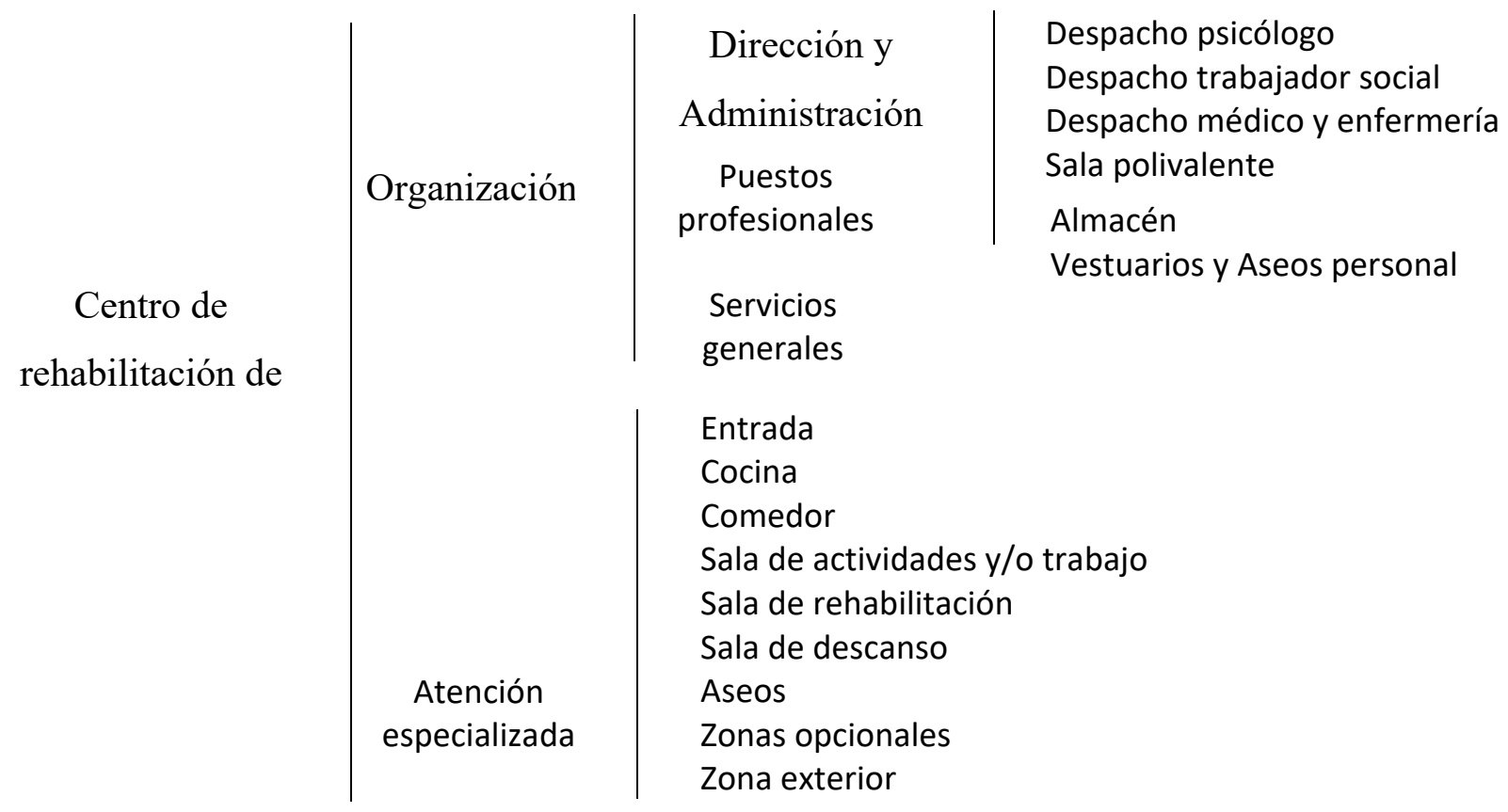

Fuente: Yanguas, J. (2008). Modelo de Atención a las personas con enfermedad de Alzheimer. Barcelona.

Por otro lado, existen otros tipos de diagramas de funcionamiento como el siguiente: 
Figura 5. Diagramas de funcionamiento referencial

\section{Diagrama General de Funcionamiento}

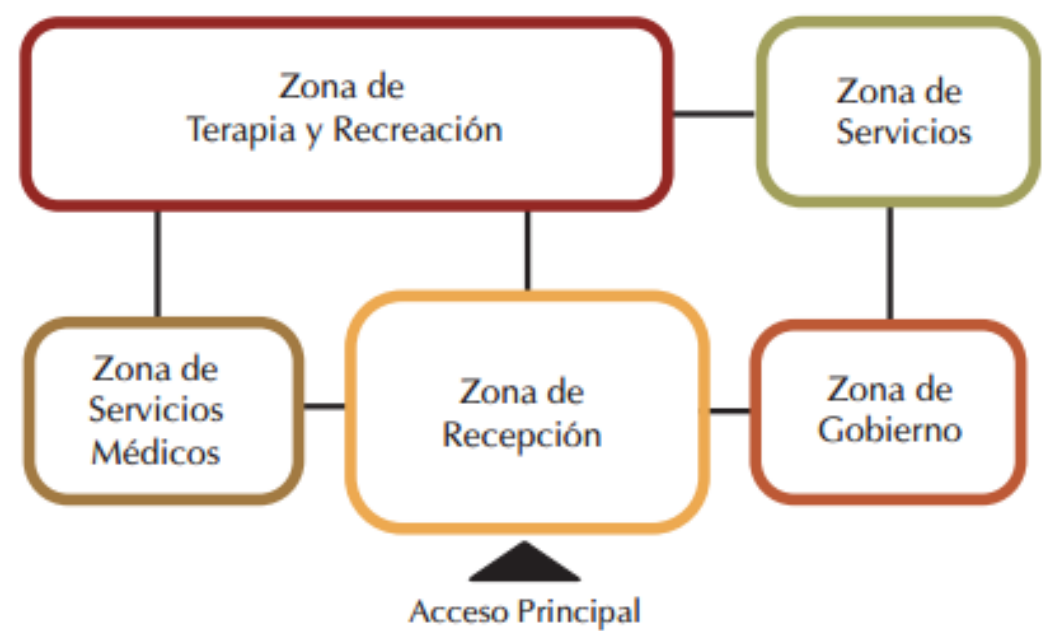

Zona de Recepción

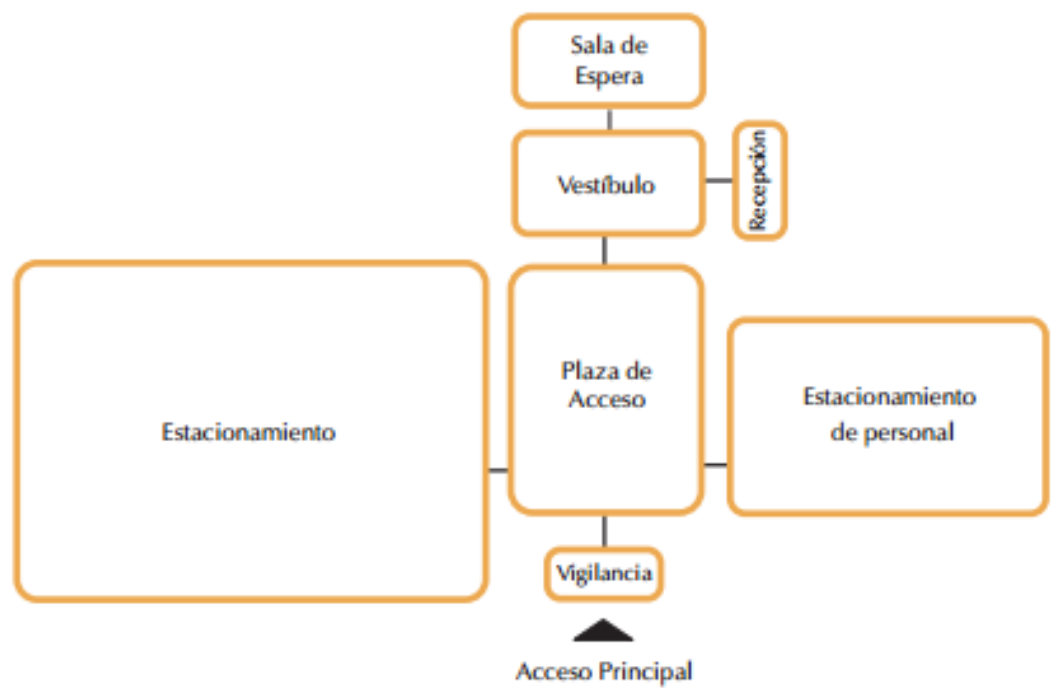

Fuente: Hernández, C. (2006). Centro de asistencia diurno para personas enfermas de Alzheimer en la ciudad de Oaxaca. (Tesis doctoral). Facultad de Ingeniería. Universidad Tecnológica de la Mixteca. 


\section{Zona de Gobierno}

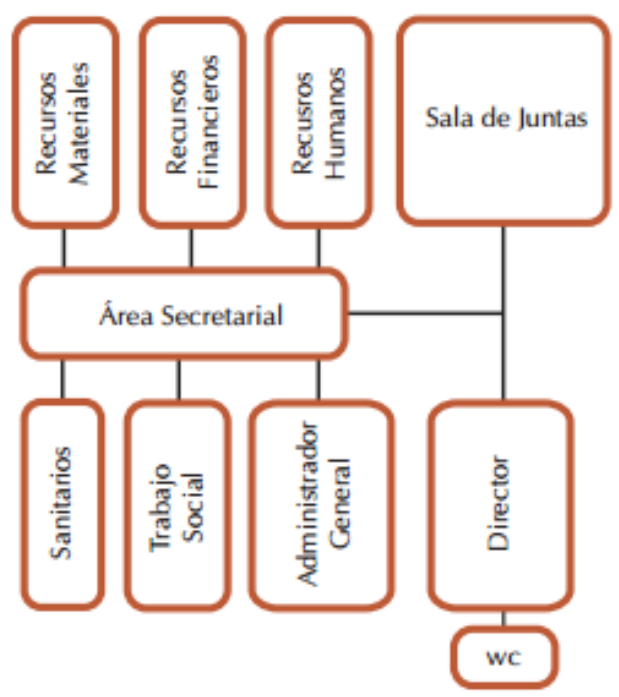

Zona de Servicios Médicos

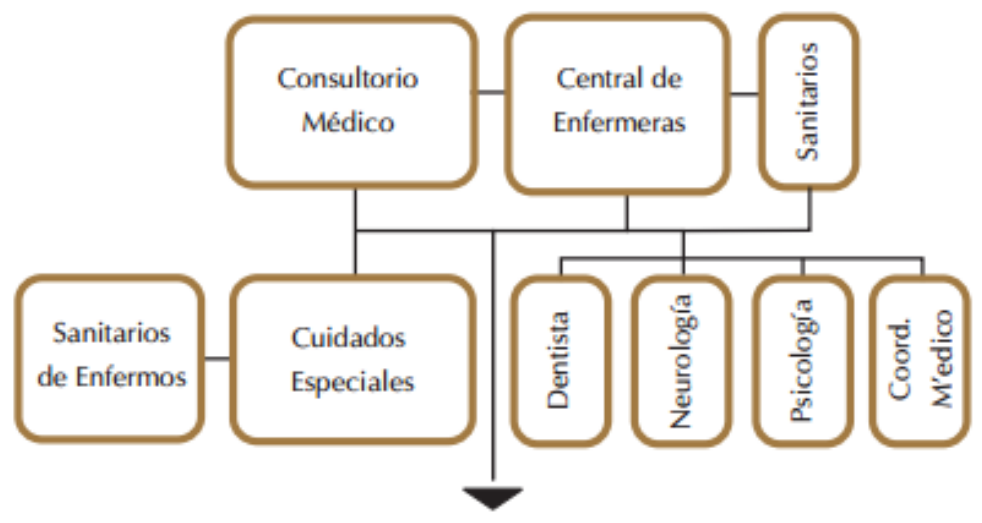

Salida de Emergencia

Zona de Recreación y Terapia

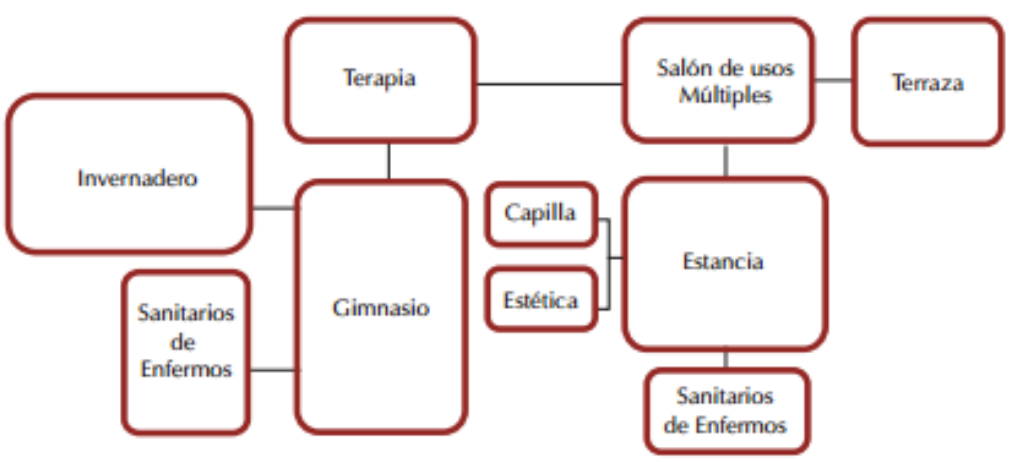

Fuente: Hernández, C. (2006). Centro de asistencia diurno para personas enfermas de Alzheimer en la ciudad de Oaxaca. (Tesis doctoral). Facultad de Ingeniería. Universidad Tecnológica de la Mixteca. 


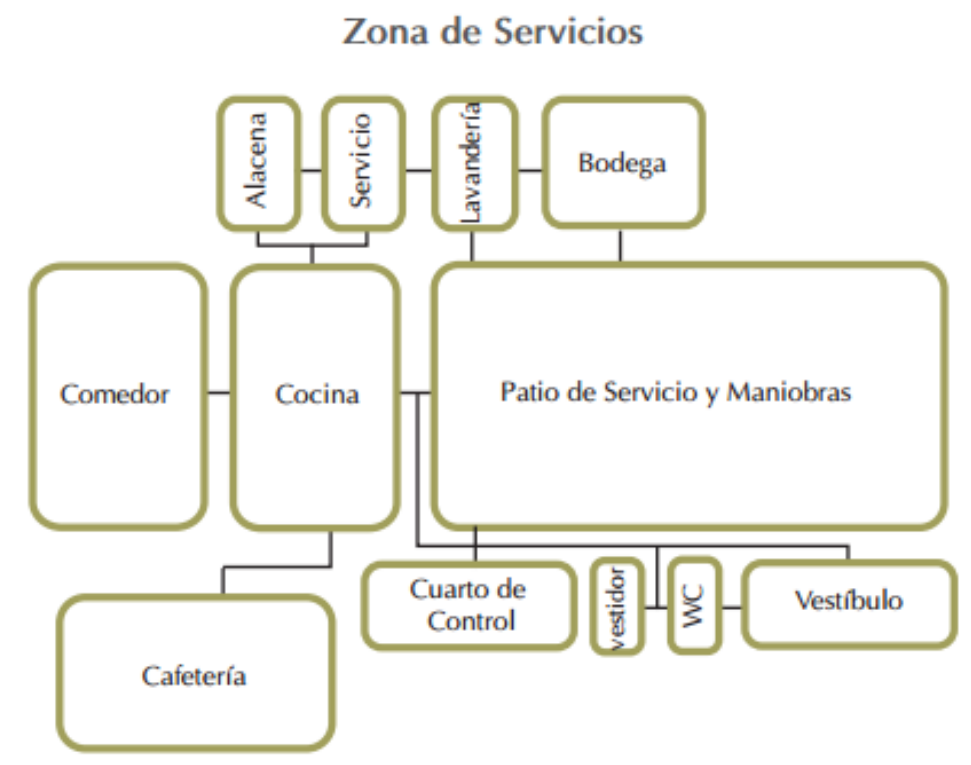

Fuente: Hernández, C. (2006). Centro de asistencia diurno para personas enfermas de Alzheimer en la ciudad de Oaxaca. (Tesis doctoral). Facultad de Ingeniería. Universidad Tecnológica de la Mixteca.

\subsubsection{Características generales de la edificación}

- Deberá ser un espacio soleado y con un máximo aprovechamiento de la luz natural, por los efectos que tiene esta en las personas enfermas y porque podrán visualizar su entorno. Por ello, las ventanas deberán ser amplias, situarse en una altura adecuada y contar con sistemas de seguridad en su apertura.

- Se deben evitar obstáculos en la construcción, creando espacios sencillos y no agobiantes (lo más regulares posibles). La altura de los techos debe estar como mínimo a 2.20 metros del suelo y las salas de trabajo de al menos 3 metros. Con respecto a las zonas de paso, deberán tener no un ancho menor a 1.5 metros y estarán dotados de pasamanos (observando la normativa de accesibilidad).

- Puertas amplias no menos de $.80 \mathrm{~m}$. de ancho y deberán estar construidas con un material aislantes, ligeros y que reflejen a luz.

- Debe contar también con un sistema de calefacción y aire acondicionado que permitan que el centro este a una temperatura moderada. Además los equipos deben alejados para evitar su manipulación por parte del paciente.

- A demás de contar con agua potable, es necesario contar con un regulador de temperatura del agua con el fin de evitar lesiones. 
- El centro debe contar con rampas de acceso, anexas a las escaleras aun así no hayan usuarios con silla de ruedas, estas se deberían situar en la entrada del centro. En caso de contar con escaleras (si es que el centro no es de una planta), de adecuaran a la normativa de accesibilidad: 2 metros de ancho (para que puedan caminar 2 personas), los escalones (entre 0.28 y 0.34 metros), las bandas antideslizantes en los peldaños, etc.

- Finalmente, el centro debe estar comunicado con el exterior, para poder facilitar la comunicación con otros recursos. Yanguas, J. (2008)

\subsubsection{Cómo se involucra el diseño con la enfermedad de Alzheimer}

Los ambientes deben de cubrir las necesidades del albergue y la vez crear un ambiente de seguridad, confortabilidad y cuidado para las personas con dicha enfermedad que ayuden a su independización.

Algunos requerimientos para obtenerlo serían el tamaño de las áreas, el color del ambiente, la fuente de iluminación, el acortamiento de recorridos para caminar y los espacios de aire libre. Para lograr una interacción entre el paciente y sus familiares.

Al entender la relación entre la enfermedad de Alzheimer y el diseño de un espacio adecuado se podrá entender la importancia del potencial terapéutico que tiene un ambiente cuidadosamente planeado y diseñado para albergar a personas que padecen esta enfermedad

"cuando cambiamos la forma en que funciona el ambiente, podemos cambiar de manera significativa la forma en la que funcionan las personas dentro de ese ambiente, especialmente las personas con demencia” (brawlwy,1997)

De lo anterior se enumeran algunas de las formas en que el medio ambiente influye sobre los enfermos de Alzheimer (Eastman, 2003)

- El medio ambiente tiene un efecto emocional y psicológico sobre los que habitan en él. 
- Un ambiente positivo se ve reflejado en la actitud de los residentes y contribuyentes a la satisfacción del personal.

- Los lugares diseñados especialmente ofrecen un mayor número de oportunidad para lograr las metas programadas.

- Un ambiente no institucional es el más apropiado para personas enfermas de Alzheimer, particularmente para aquellos en las primeras etapas.

Yanguas, J. 2008.

\subsubsection{Características de la distribución arquitectónica (DA)}

- DA-1 Usar volados en los techos que eviten que el reflejo de la luz entre a la habitación.

- DA-2 Ubicar las ventanas de tal forma que no queden al final de un pasillo y generen deslumbramiento.

- DA-3 Proveer patios, terrazas y balcones para instar a los residentes a pasar tiempo afuera.

- DA- 4 Procurar cambios graduales en los niveles de iluminación a traves de áreas de transición.

- DA-5 Colocar las puertas de forma que no queden una en frente de otra.

- DA-6 Aumentar la altura de los techos que no queden una en frente de otra.

- DA-7 Separar los locales "ruidosos" (áreas de servicios) de aquellos en donde se encuentren los enfermos.

- DA-8 Brindar una eficiente propagacion del sonido usando formas irregulares ya que los espacios largos de formas rectangulares no lo dispersan de forma correcta.

- DA- 9 Evitar el uso de corredores largos y oscuros.

- DA-10 Evitar largos para el enfermo. 
- DA-11 En corredores o senderos para caminar debe haber áreas para sentarse y descansar cada 6 a $9 \mathrm{~m}$.

- DA-12 Tener un acceso rápido al área médica en caso de accidente o enfermedad.

- DA-13 Localizar un espacio seguro que funcione como punto de reunión en caso de algun siniestro.

- DA-14 Tener acceso directo del área médica a la salida y al estacionamiento.

- DA-15 En el diseño del espacio usar formas definidas fácilmente identificables para una correcta orientación

- DA-16 Colocar ventanas hacia el interior de los locales para la faciles identificacion de los mismos.

- DA-17 Tener vista a los jardimes.

- DA-18 Crear espacios de convivencia para grupos pequeños, por ejemplo terrazas.

- DA-19 Crear espacios intimos que un interes personal como una sala de lectura

- DA-20 Las vistas hacia el estacionamiento o entradas deben disimular ya que estas incitan a los enfermos a irse.

- DA-21 Proveer ilumincación natural mediante tragaluces, patios interiores, caraboya, techos altos y ventanales.

Hernández, C. (2006).

\section{2 Énfasis arquitectónico}

\subsection{1 ¿Qué es la accesibilidad?}

"Se entiende por accesibilidad a la característica del urbanismo, la edificación, el transporte o los medios de comunicación que permite a cualquier persona su utilización y la máxima autonomía personal. 
Una buena accesibilidad es aquella que existe pero que pasa desapercibida para la mayoría de usuarios, excepto evidentemente para las personas con graves problemas en su movilidad y/o con limitaciones sensoriales, visuales y/o auditivas.

Al realizar el diseño de los espacios, elementos, transportes y productos que nos envuelven tendremos siempre presente estas características para mejorar la calidad de vida de todos. Si las actuaciones de mejora de la accesibilidad se realiza en entornos, edificios, transportes y medios de comunicaciones existentes, entonces tendremos que suprimir las barreras arquitectónicas existentes en ellos”. (Rovira; Beleta, 2003.)

\subsubsection{La accesibilidad en las personas con el mal de Alzheimer}

Por accesibilidad se entiende la necesaria exigencia de un centro de Alzheimer para la atención de las personas afectadas por esta enfermedad. Además, deberá cumplir con la normativa vigente a la eliminación de barreras arquitectónicas. Sujetos también, a la normativa donde se ubique el centro; deberá disponer siempre de mecanismos que permitan la accesibilidad al interior del centro. Yanguas, J. (2008).

\subsubsection{La facilidad de acceso}

Los siguientes puntos son importantes mencionar ya que esto ayudara a que los pacientes no sientan ningún tipo de miedo al acceder al lugar.

- Existencia de redes de transporte público que pueda utilizarse.

- Facilidad y comodidad para el acceso independiente de los transportes propios del centro (acompañante de familia y paciente).

- Rapidez en el acceso (no mucho tiempo de desplazamiento interno).

Además, una vez llegado el paciente a la puerta principal del centro, se deberá disponer de accesos adecuados referidos a lo siguiente:

- Facilidad de acceso de los vehículos y cercanía entre sus puntos de parada y el centro.

- Facilidad en el aparcamiento, tanto para los vehículos públicos como para los particulares, procurando no interferir en las esquinas. 
- Distancia a recorrer desde el medio de transporte hasta el edificio.

Además, Teniendo en cuenta los requerimiento de las personas con discapacidad para tener una mejor accesibilidad. Se debe utilizar unas recomendaciones necesarias:

- Antropometría

- Entorno Urbano y espacios descubiertos

- Entorno Urbano y espacios cubiertos

- Señalización y elementos varios

Fuente: Hernández, C. (2006). Centro de asistencia diurno para personas enfermas de Alzheimer en la ciudad de Oaxaca. (Tesis doctoral). Facultad de Ingeniería. Universidad Tecnológica de la Mixteca. 


\subsection{Proyectos referenciales}
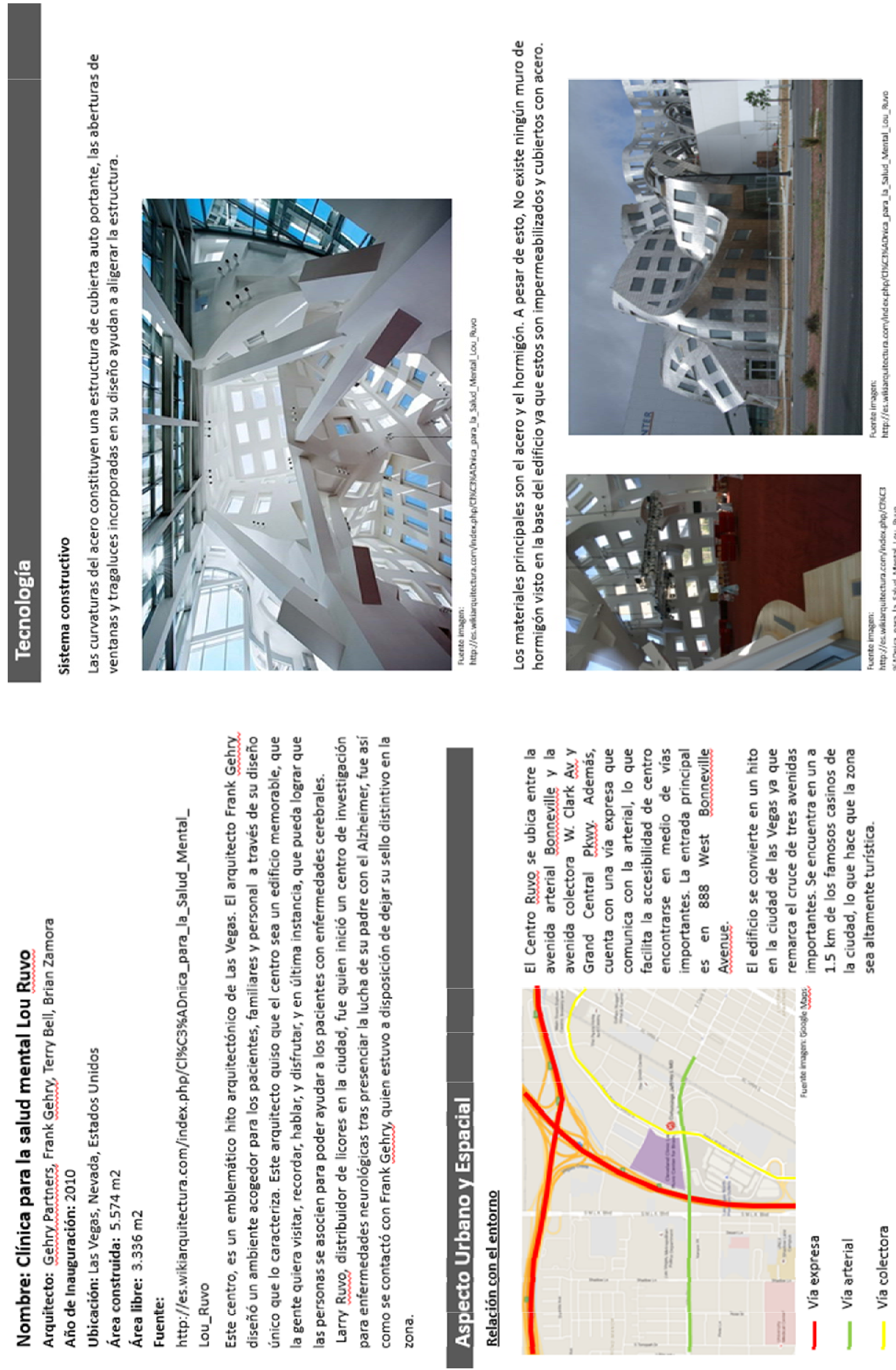

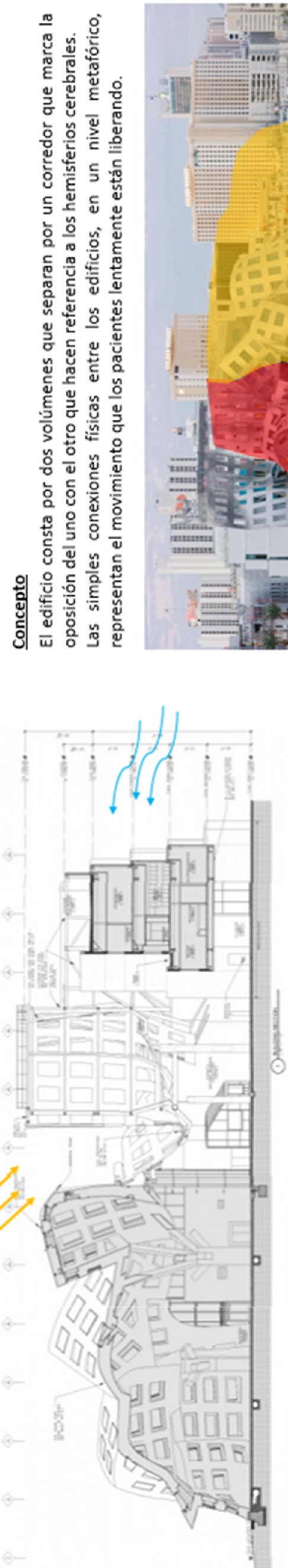
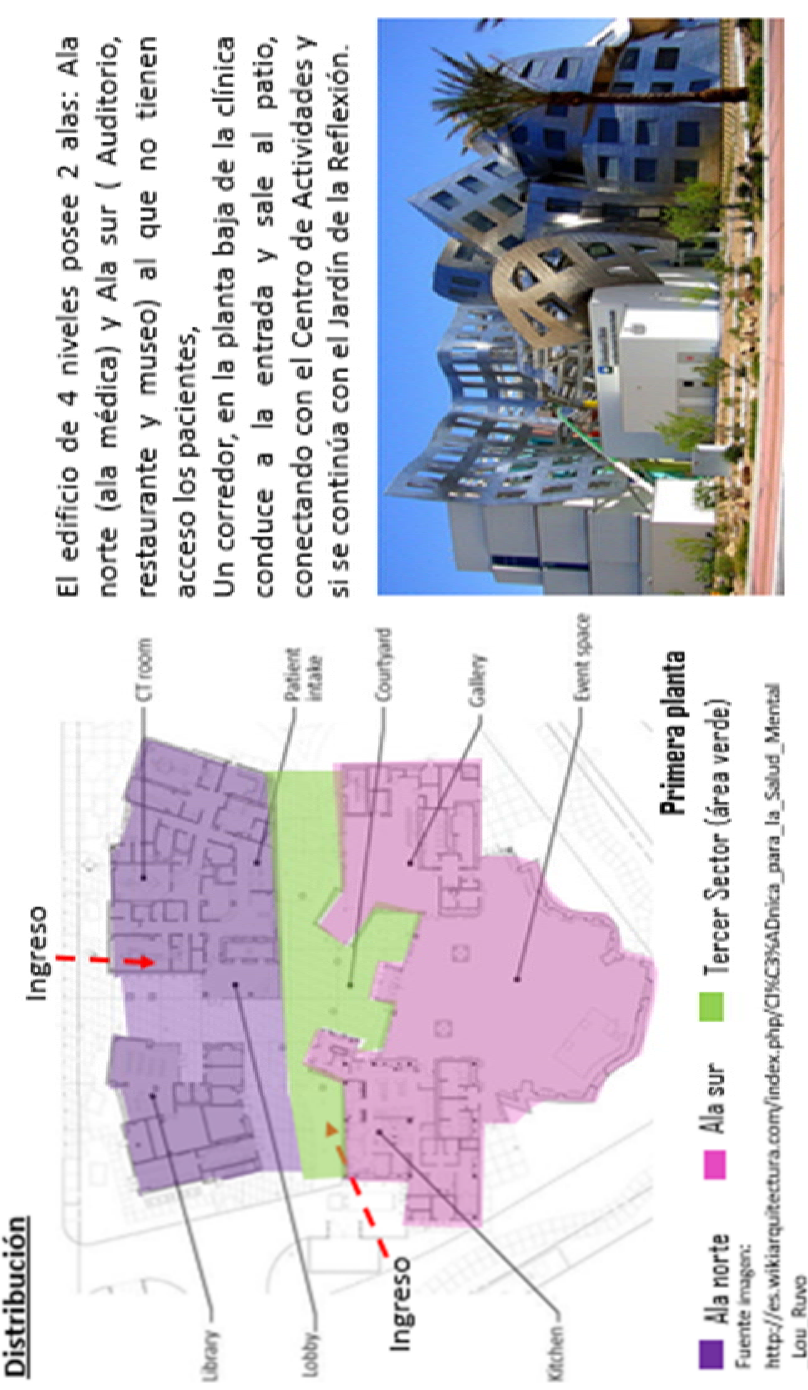

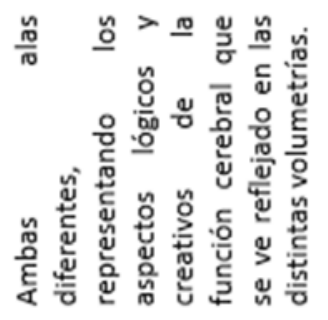

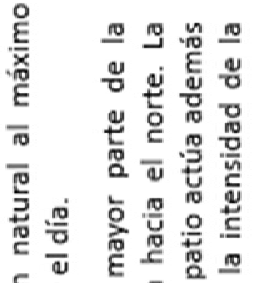

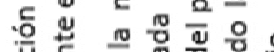

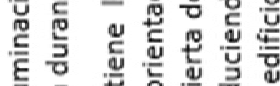

$$
\begin{aligned}
& \text { है }
\end{aligned}
$$

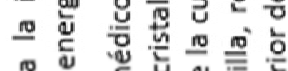

$$
\begin{aligned}
& \text {. } \\
& \text { 次 }
\end{aligned}
$$

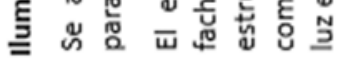

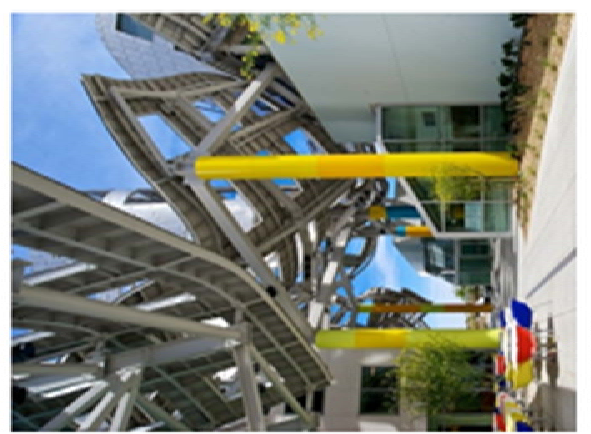

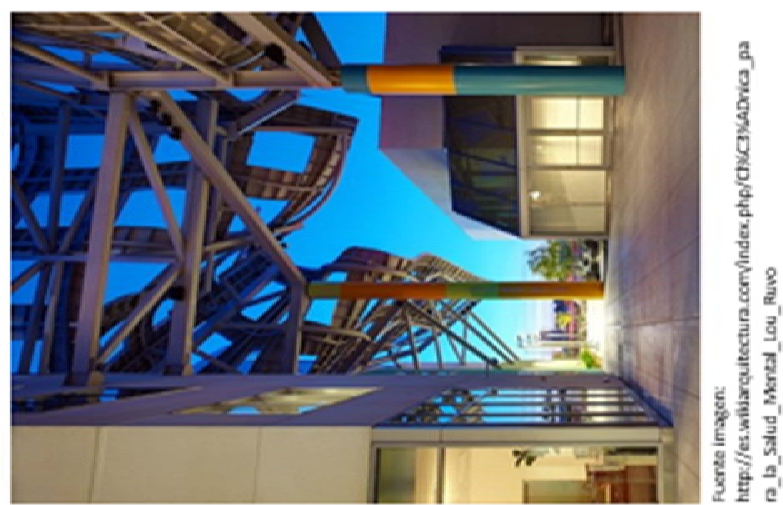

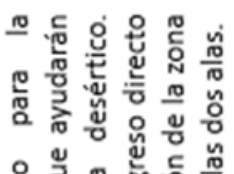

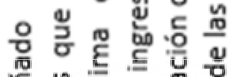

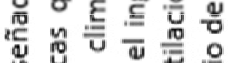

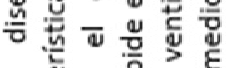

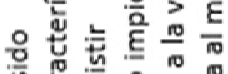
년 원

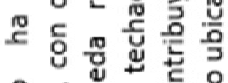

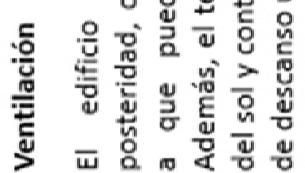



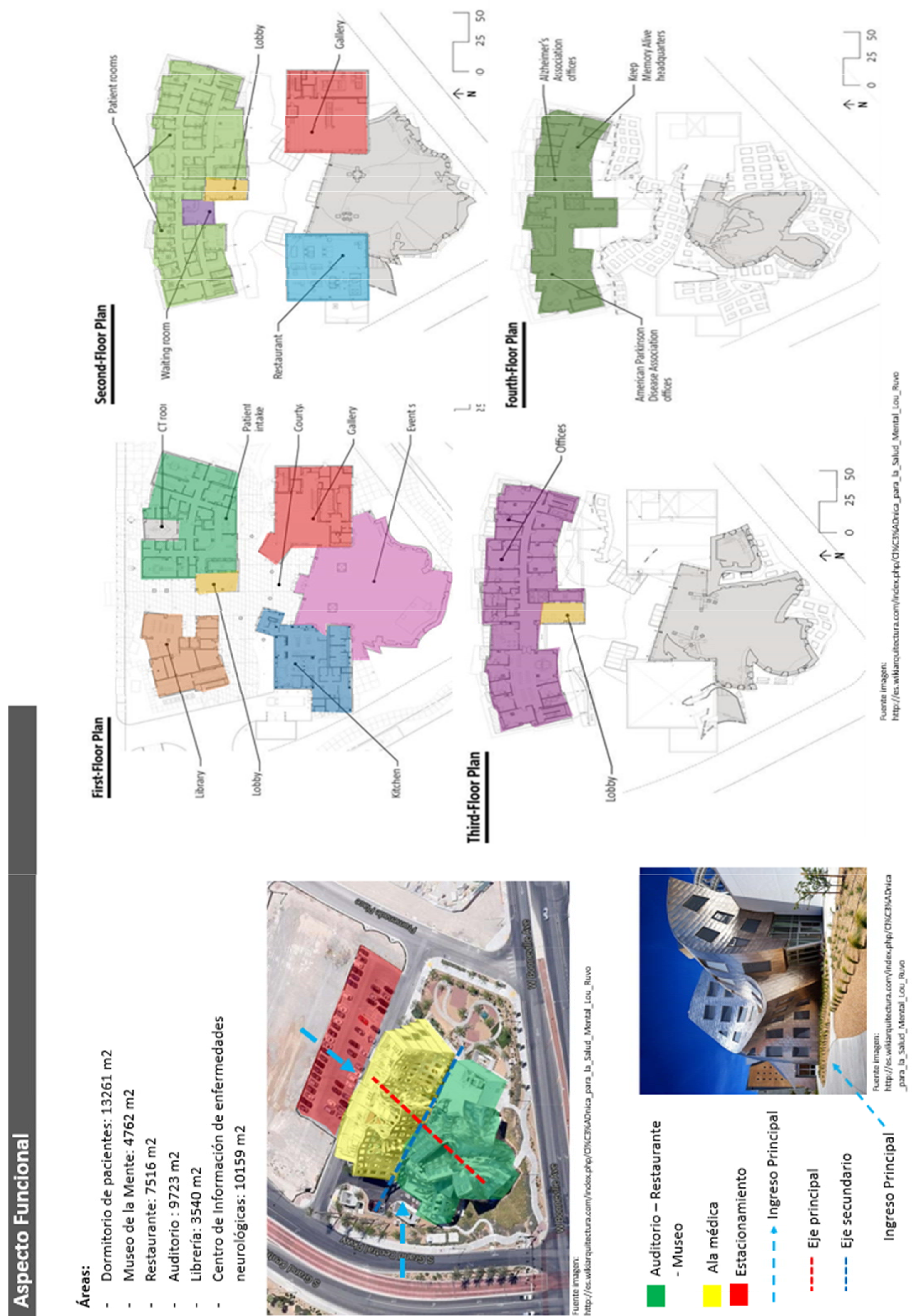

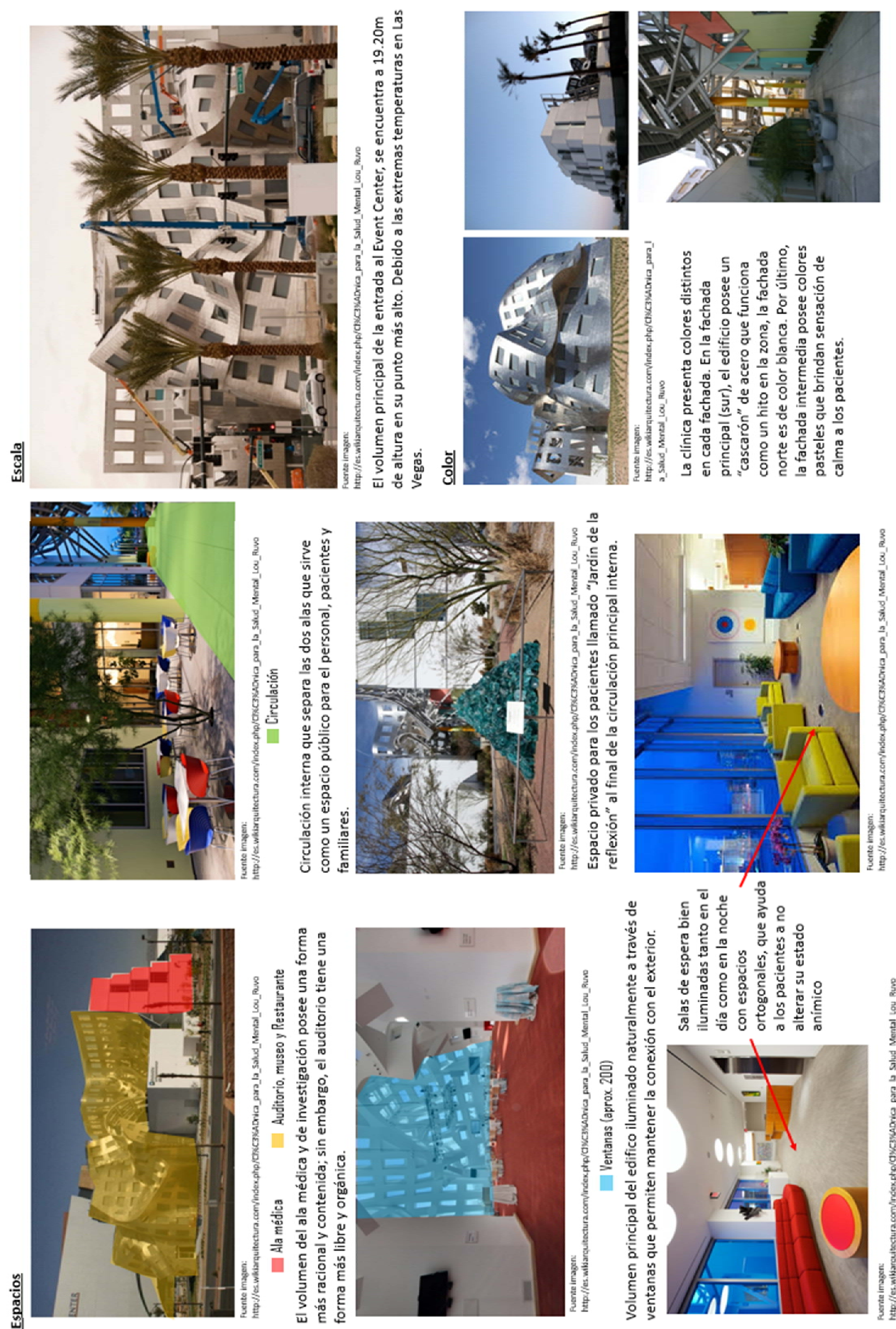


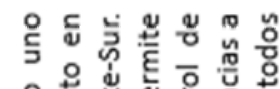

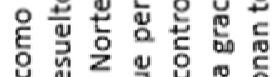

은 넌 흘

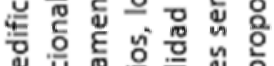

언 을 은 흥 능

于.

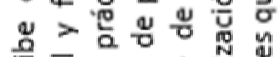

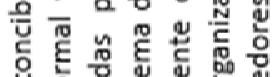

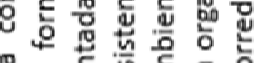

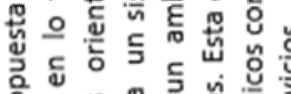

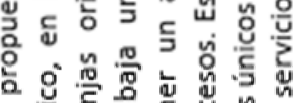

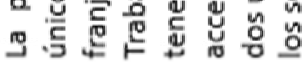
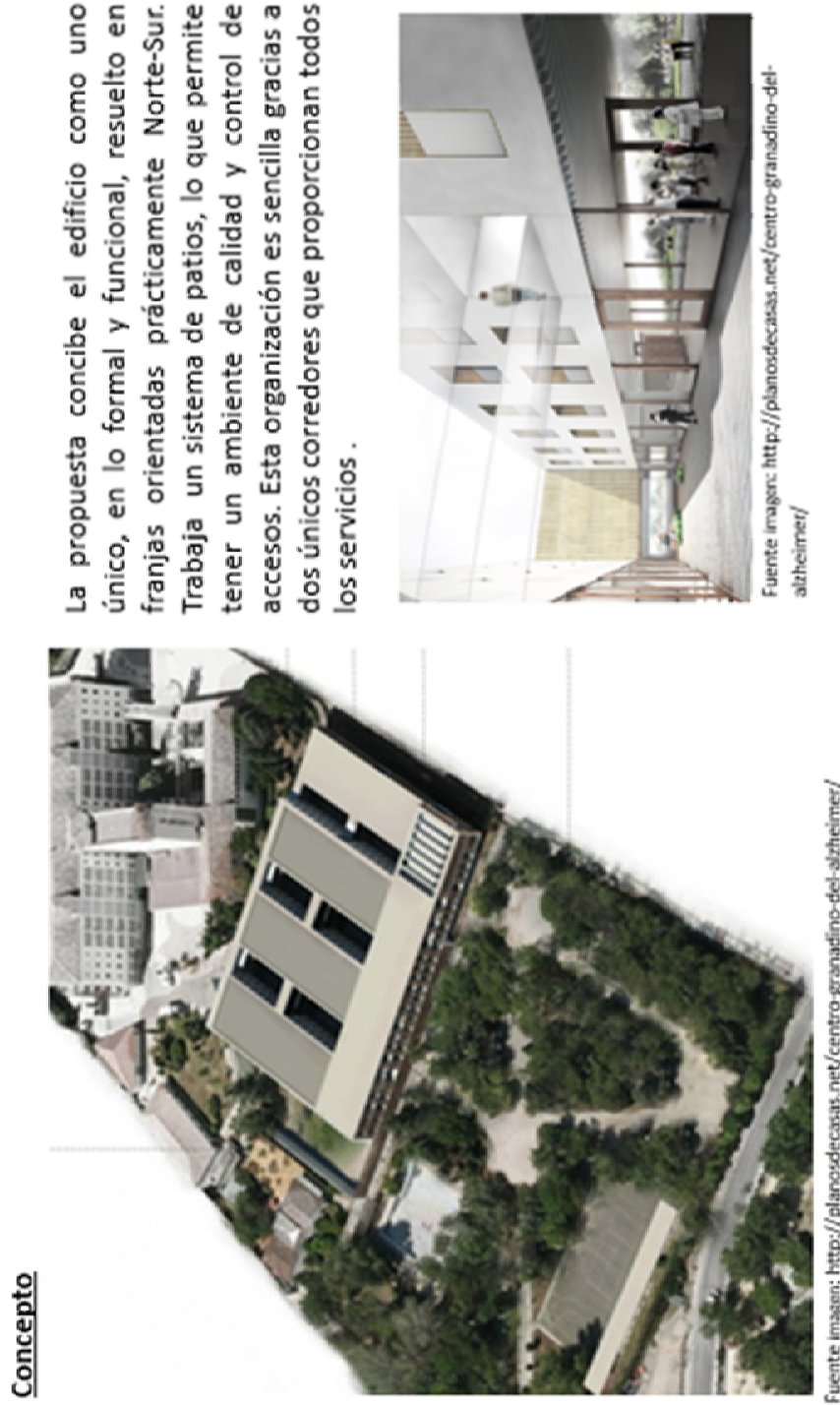

응 눈

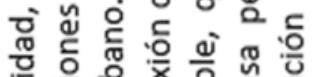

흔 은 옥 希

泮

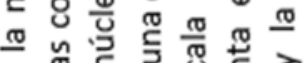

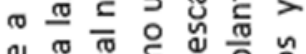

㟧

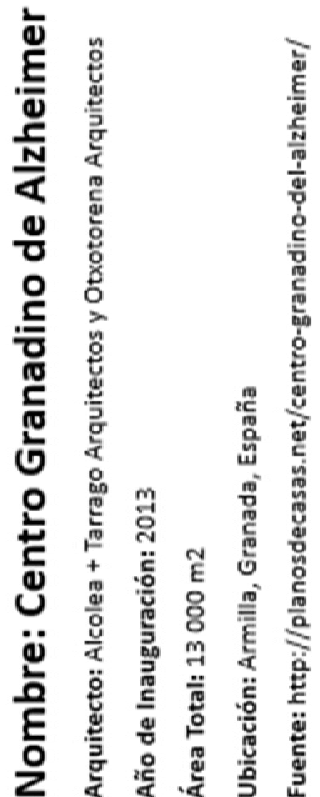

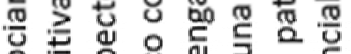

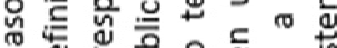

$\circ$ 응

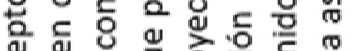

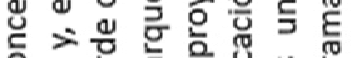

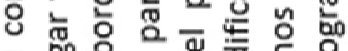

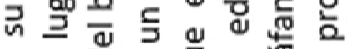

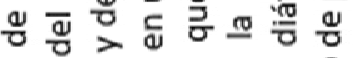

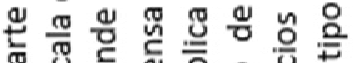

잉

잉

ช

政

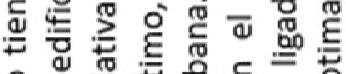

웡 $\frac{\pi}{2}$

这此

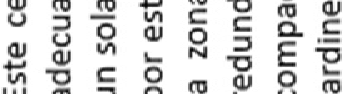

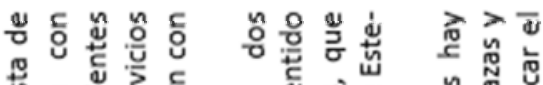

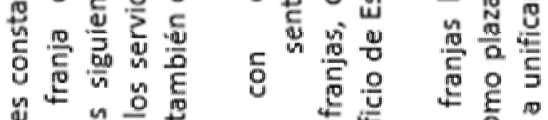

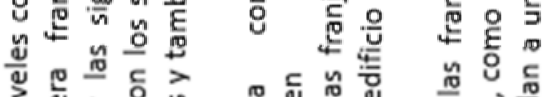

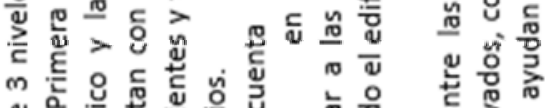

के

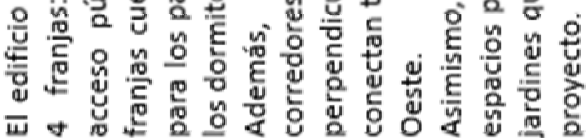

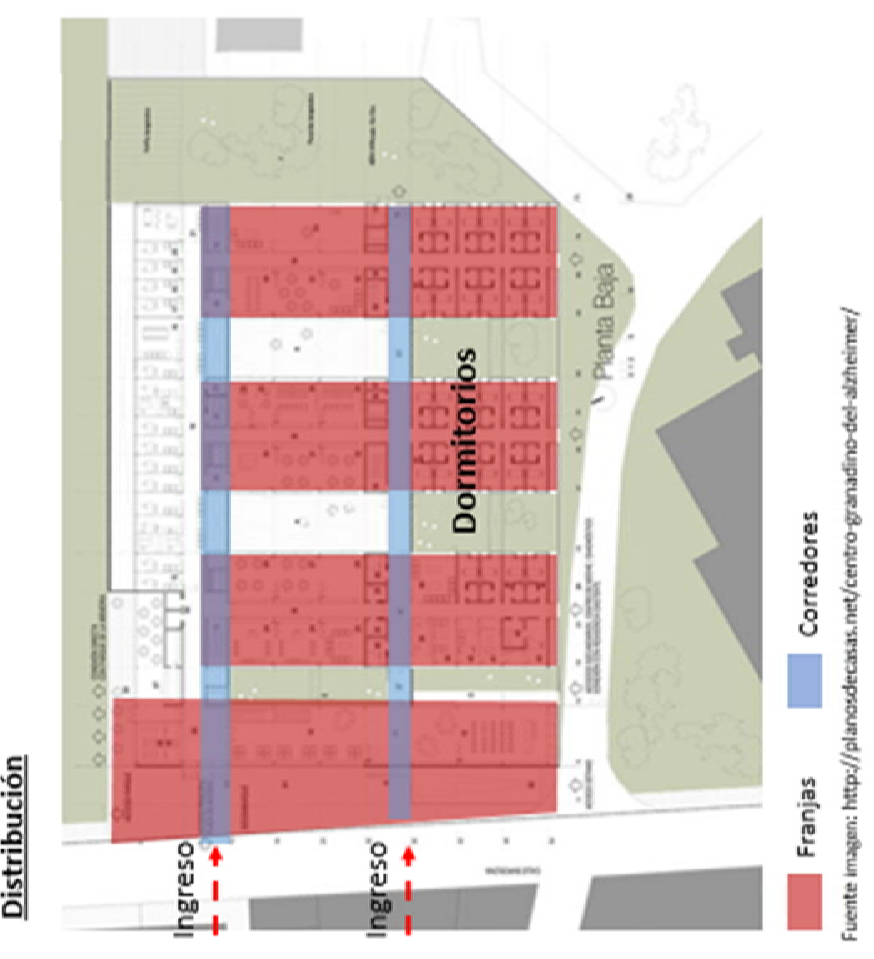

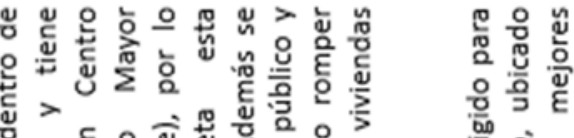

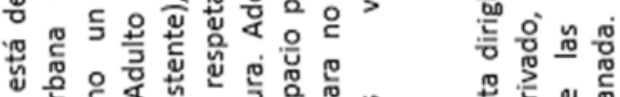

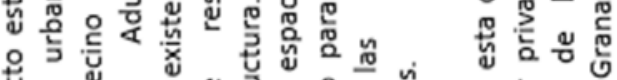

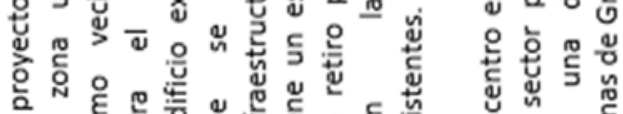

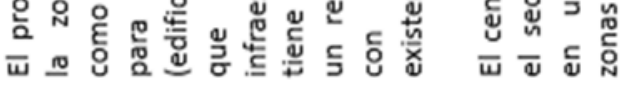

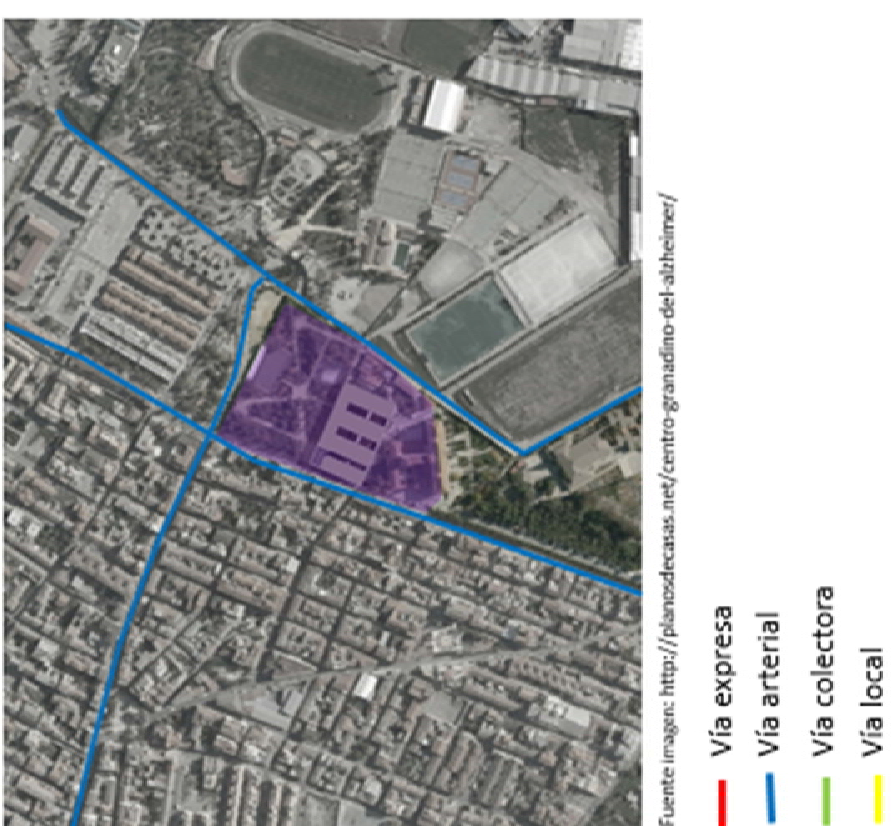




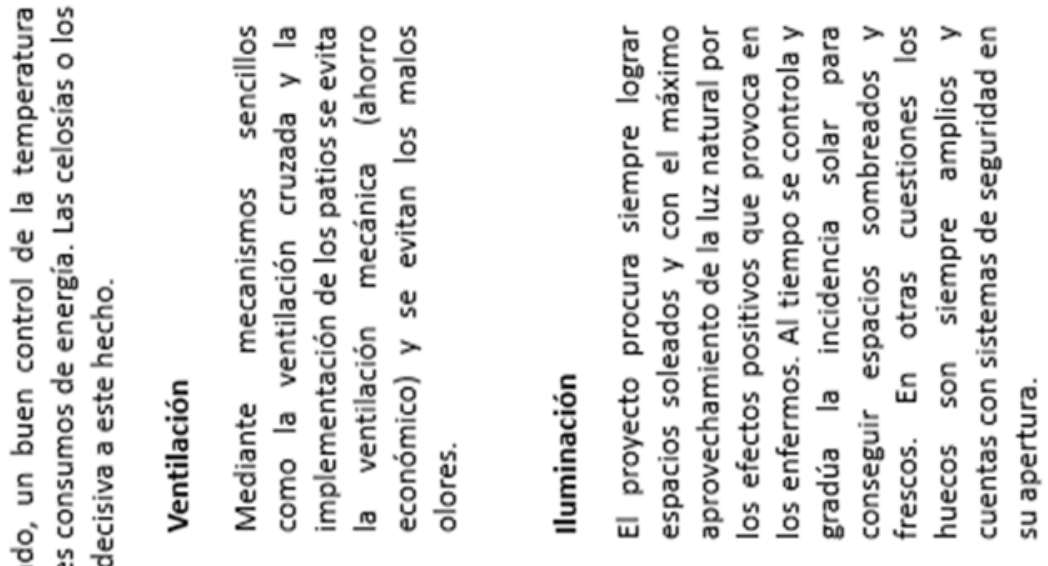

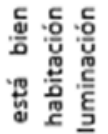

드 흐

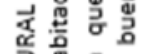

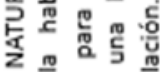

은 웜

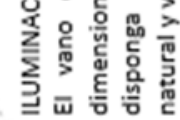

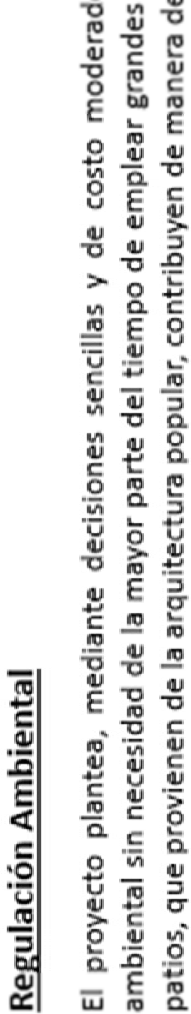

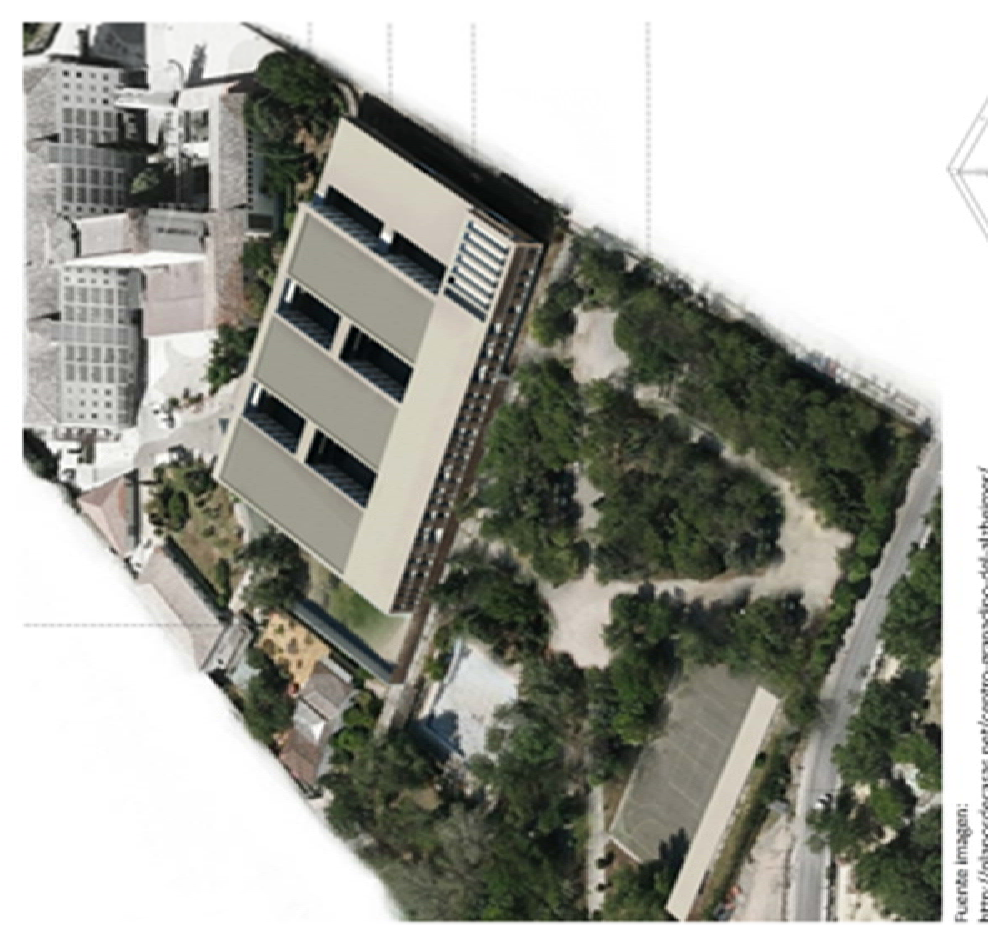

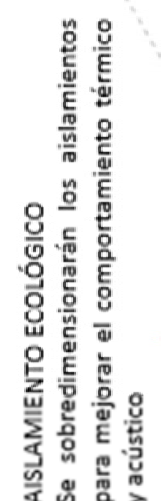
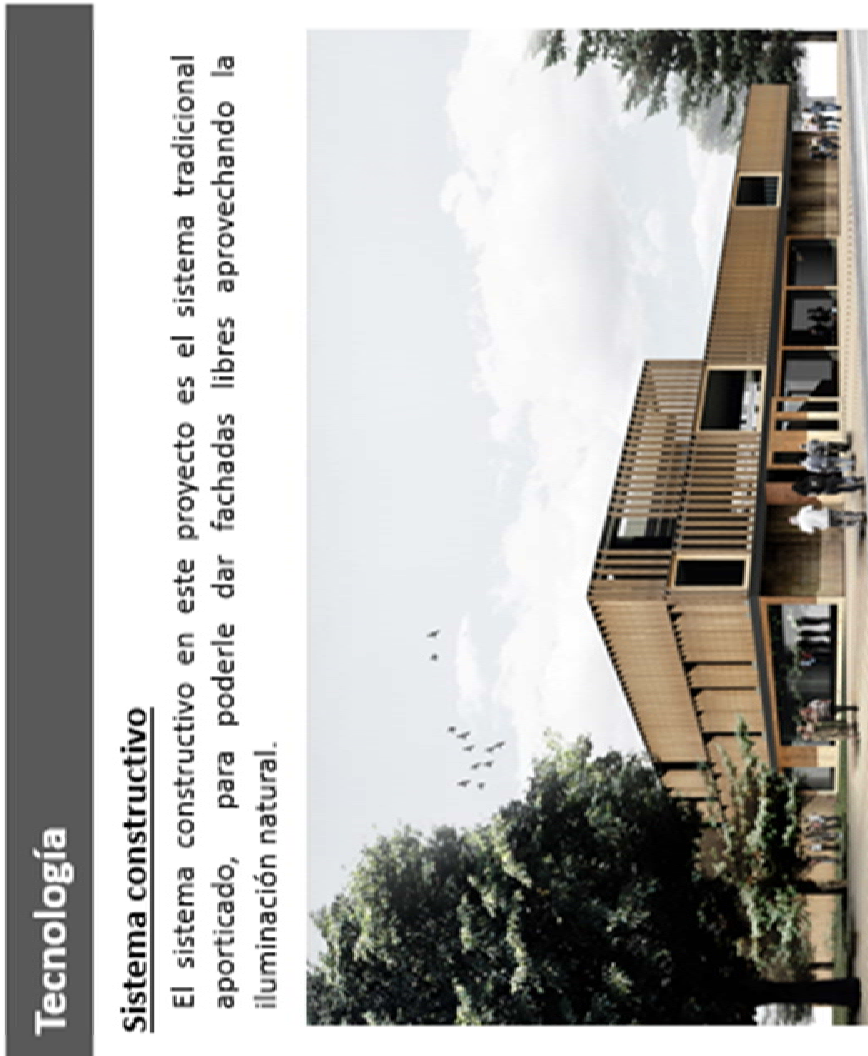

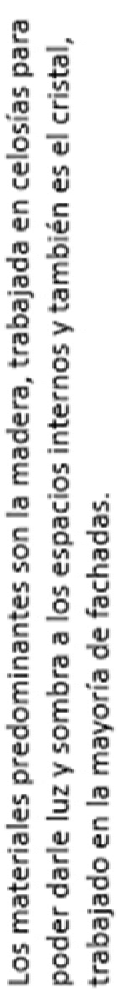

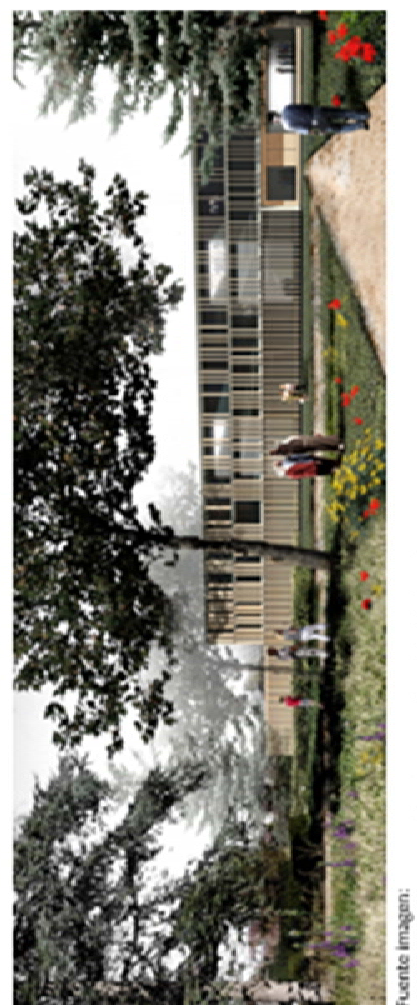

造

ขั ธิ

ป

हु है

ํㅗㅇ

ㅇํㅇ

등 임

원 응

u

ํำ

ㄴํㅇ 능

.ํㅡㄴ

บ

ㄴํㄴ

荡

ह้ํํํํำ

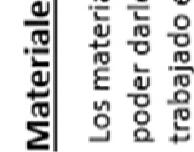

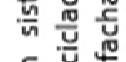



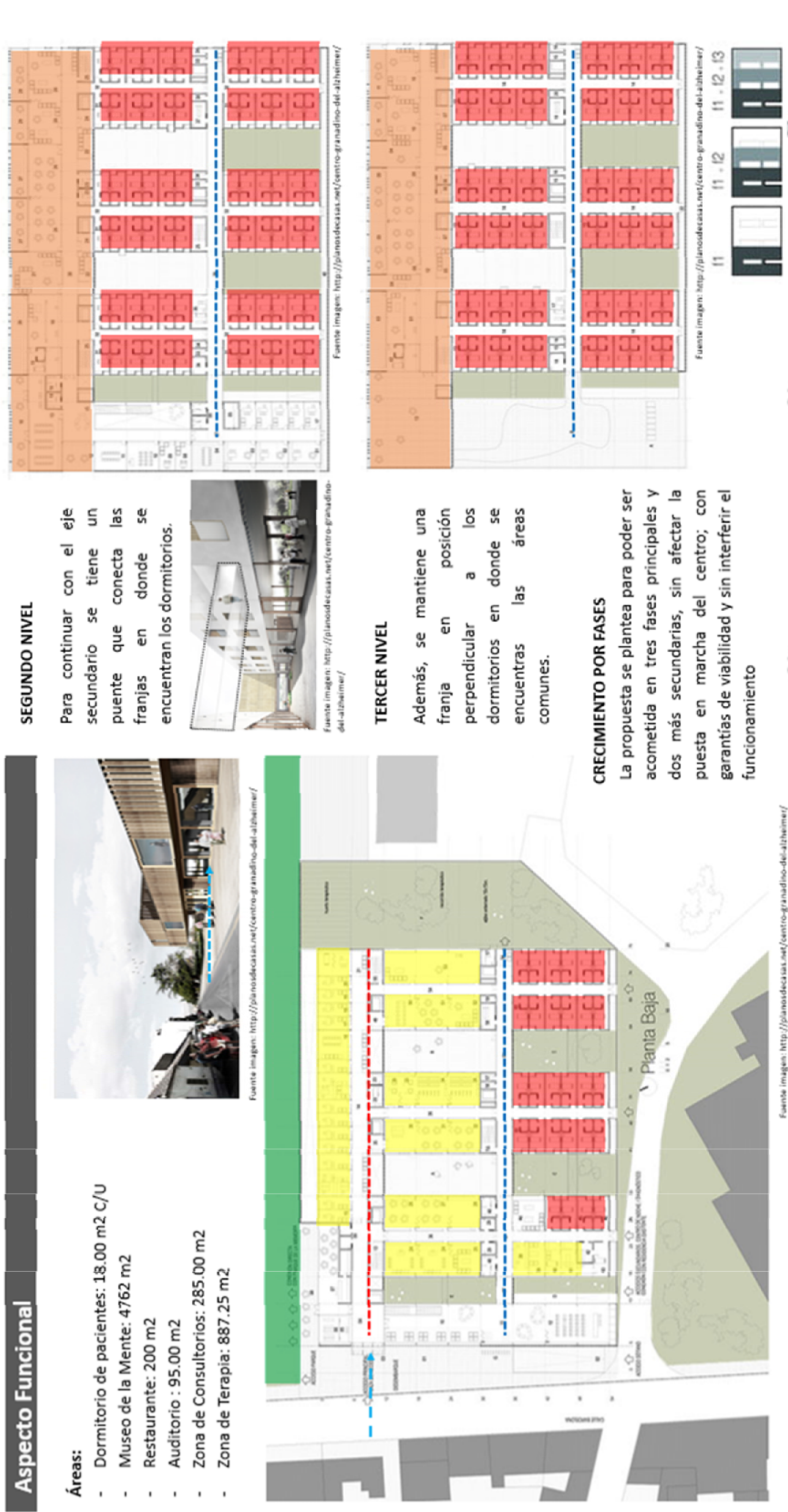

ำ

है

ถี हี พิ ป

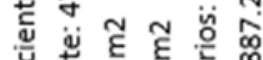
ॠ ข $\sum_{0}$ ฟู 은 능 응

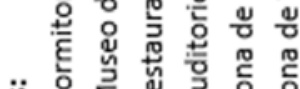

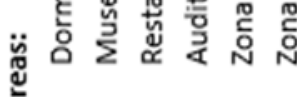

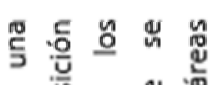

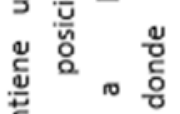
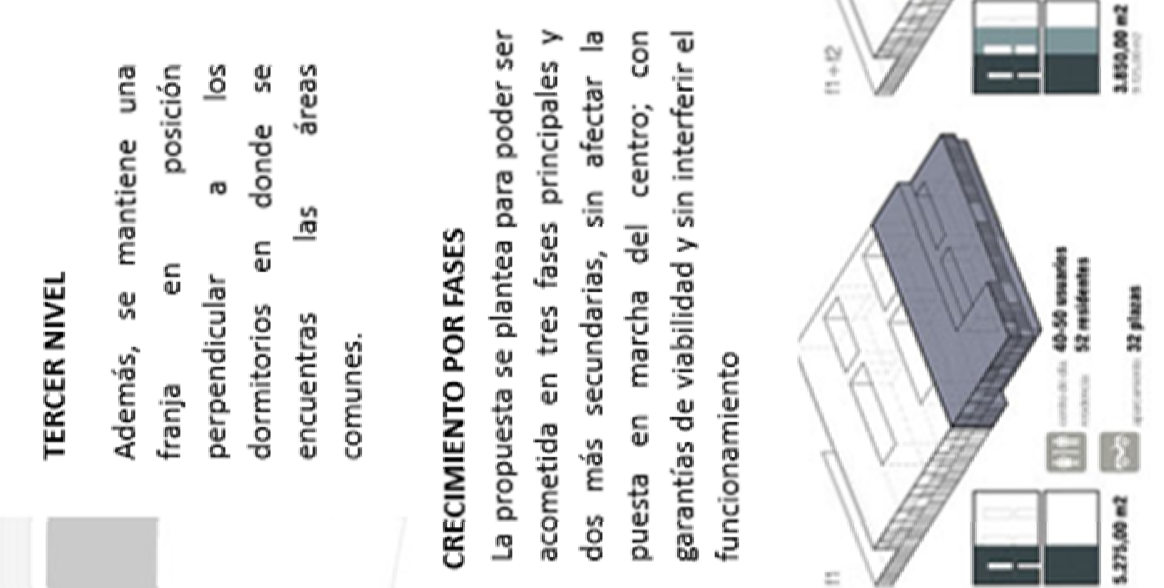

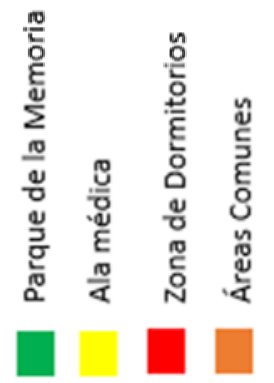



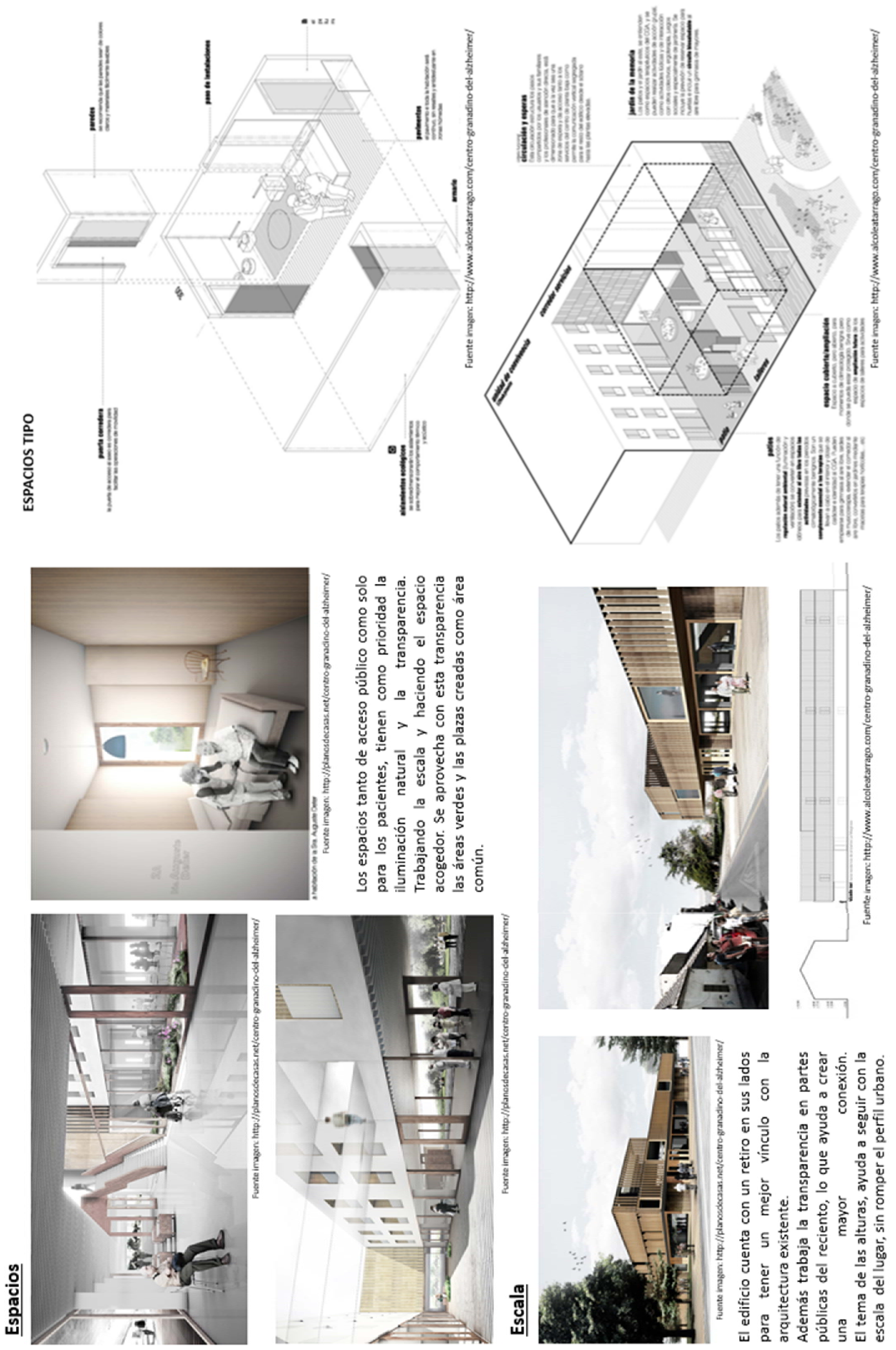

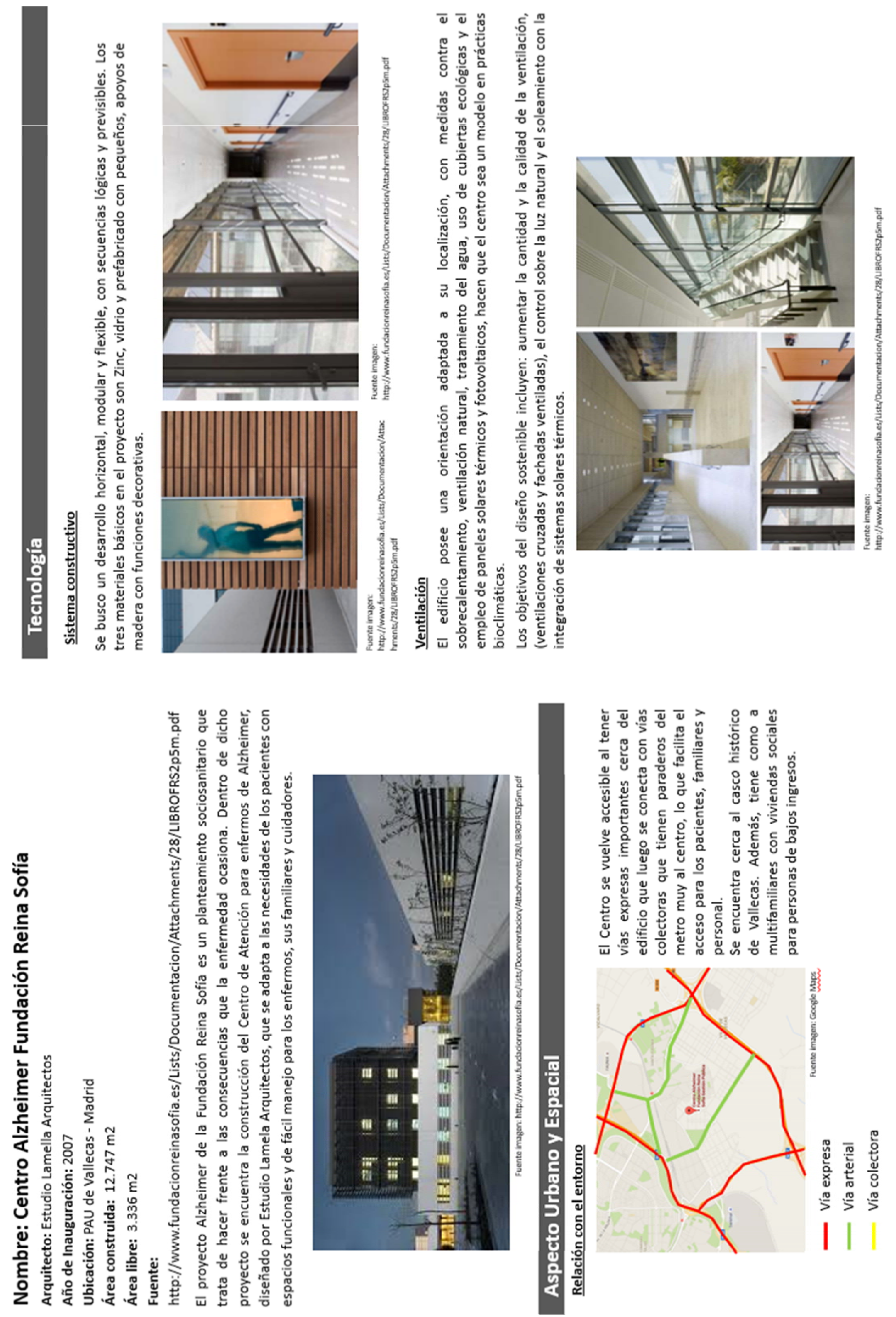


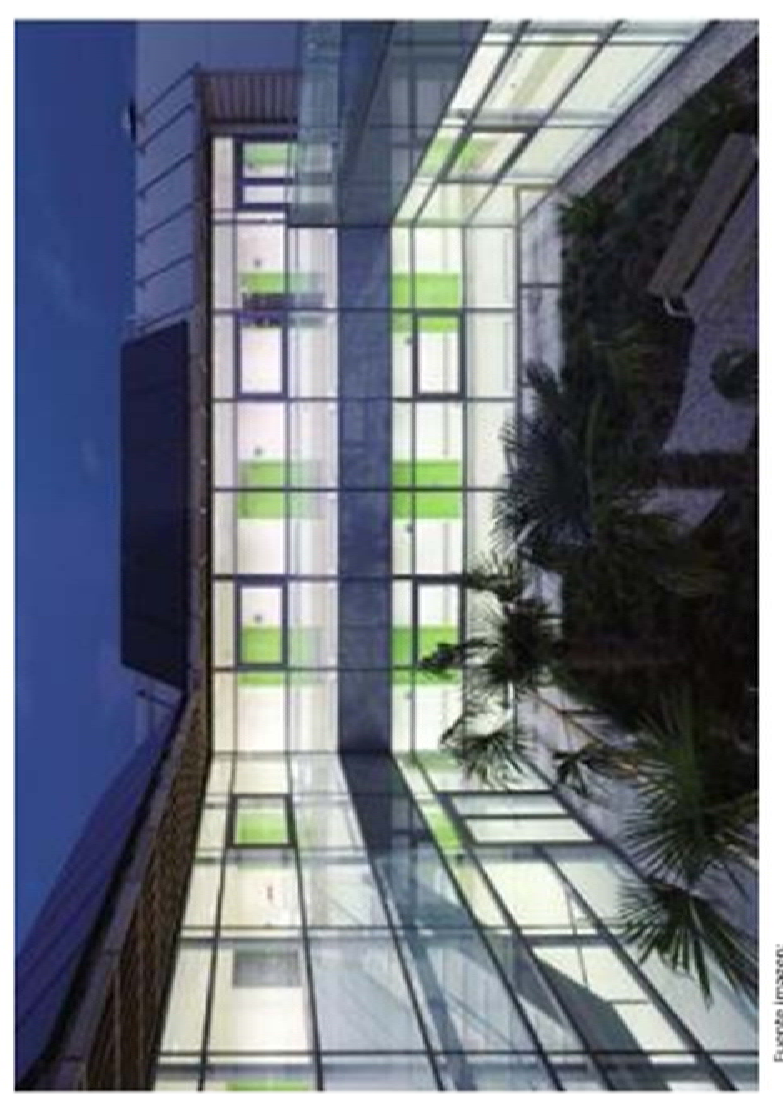

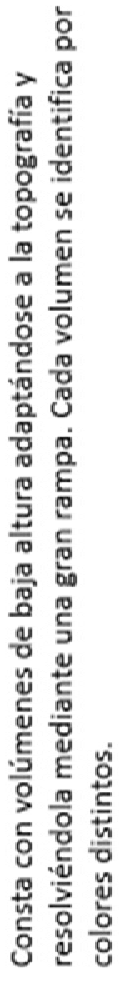
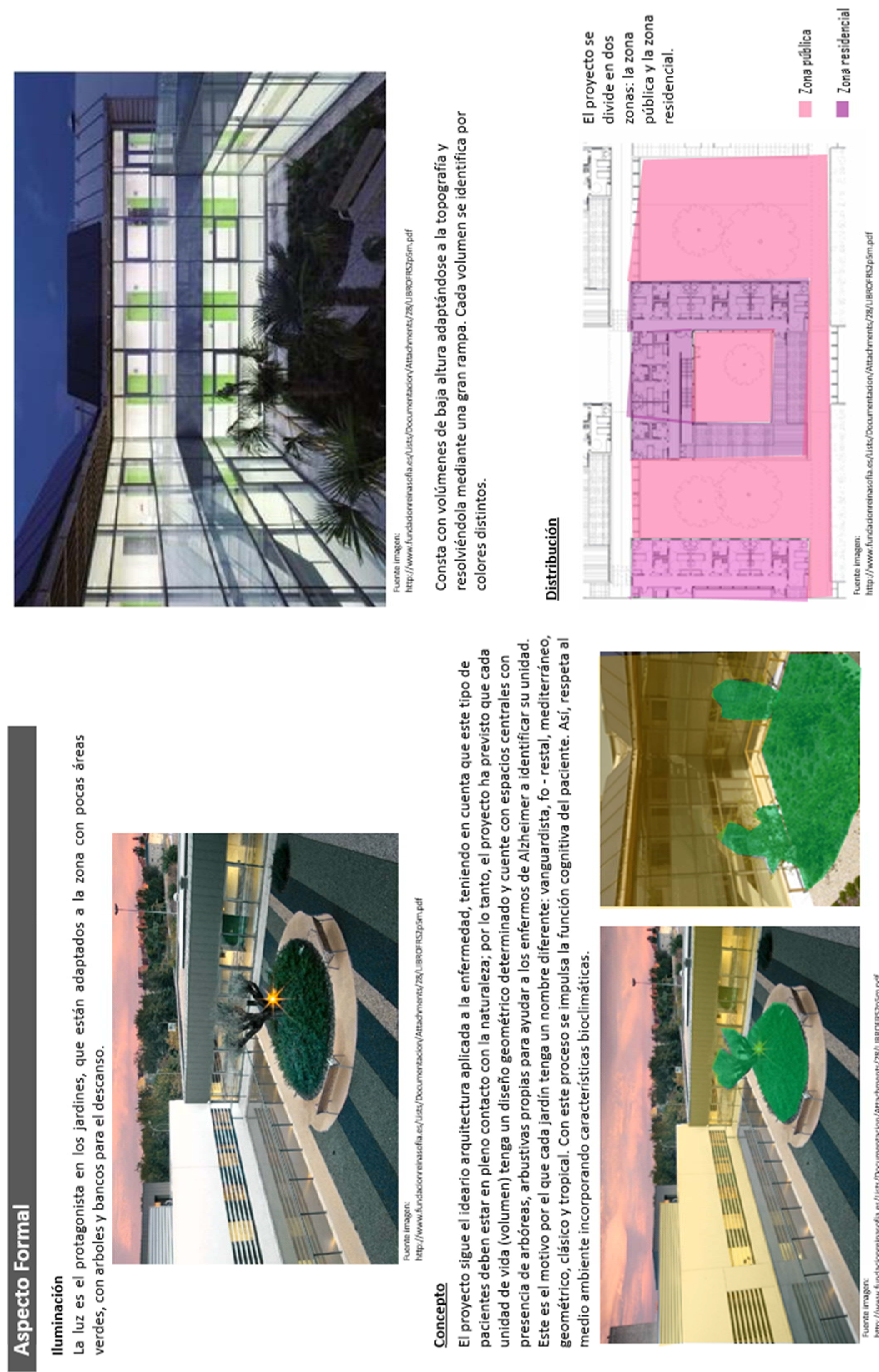

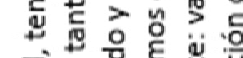

웜은

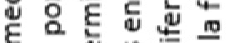

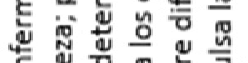

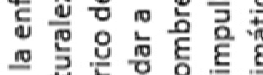

To

증 므

路 ᄃ

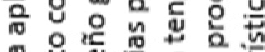

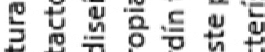

论

产势

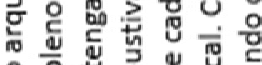

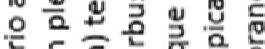

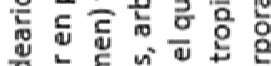

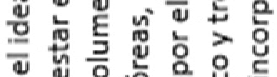

㟧

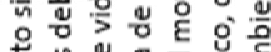

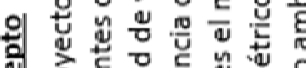

닌

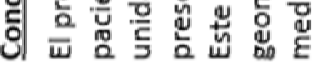

흘

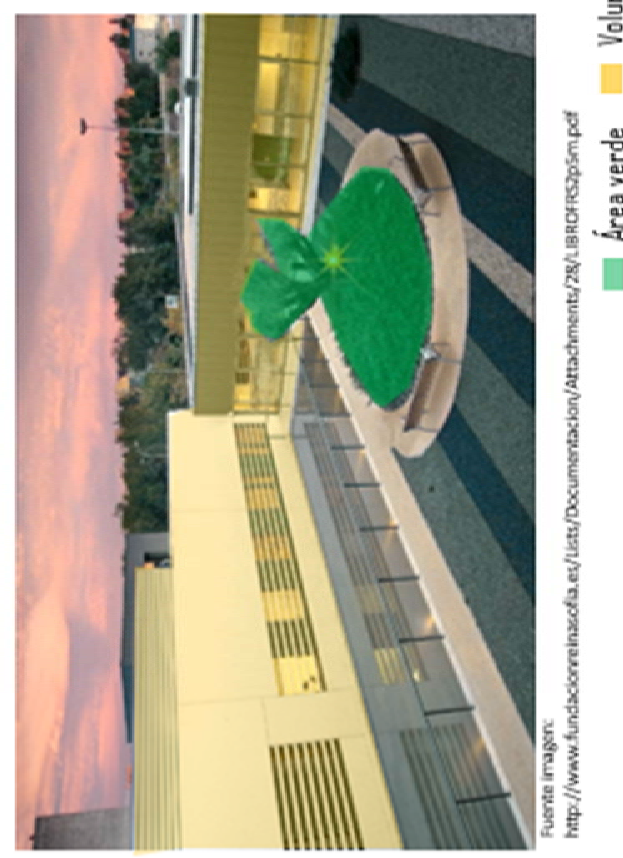




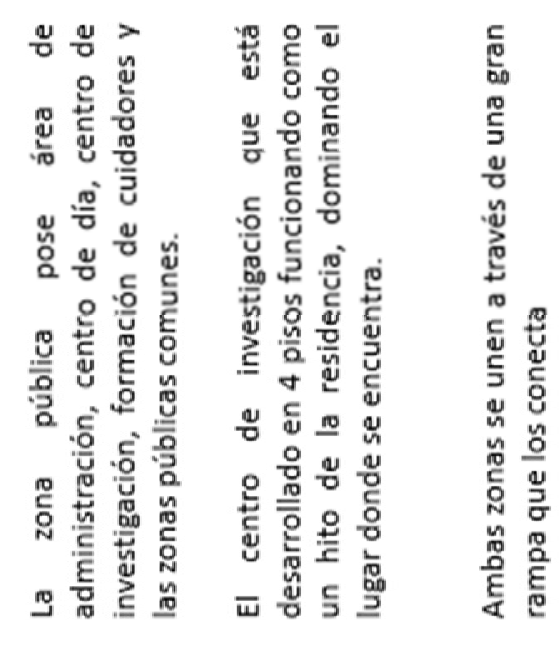

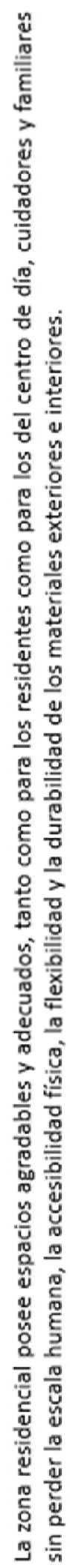
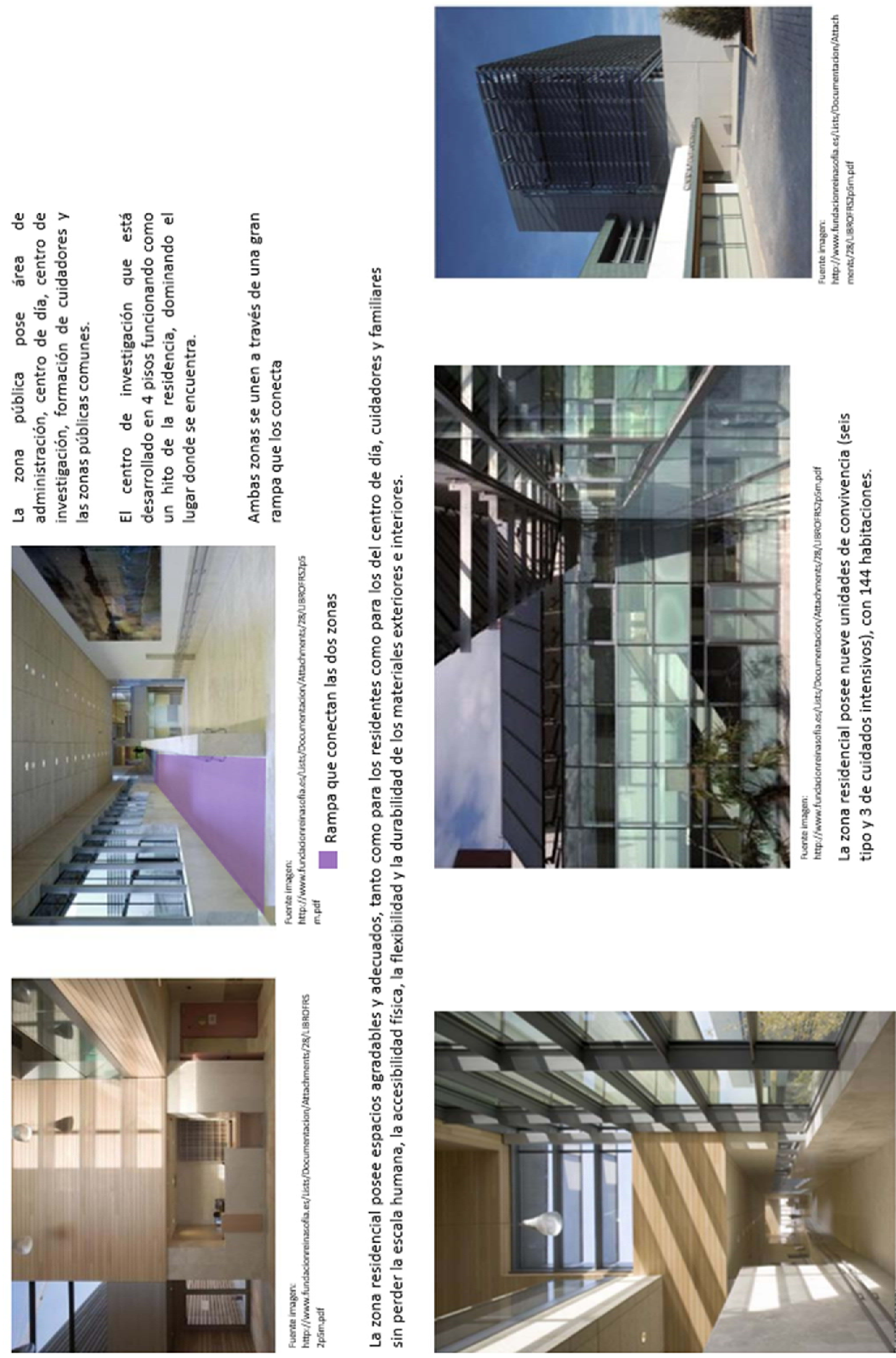

递 

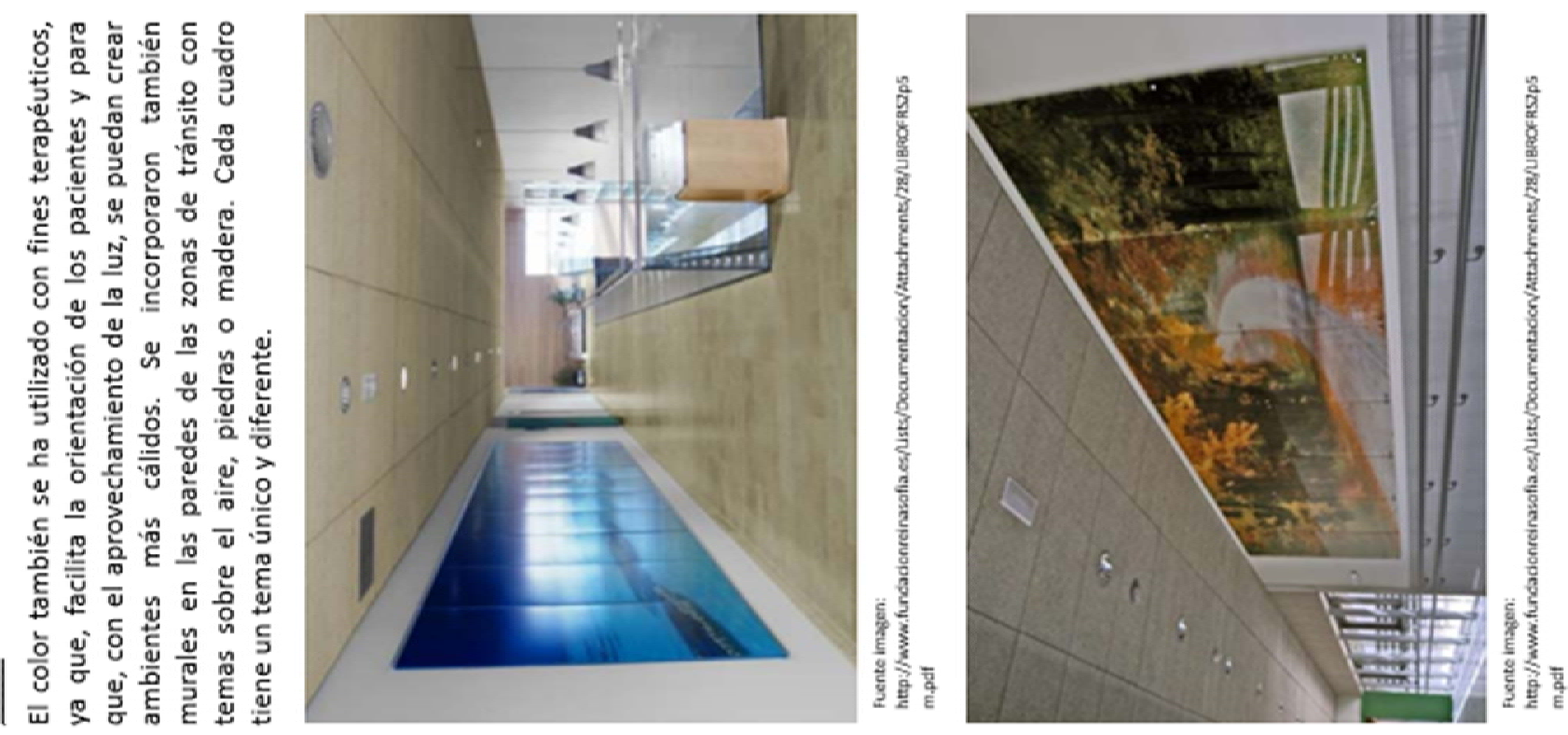

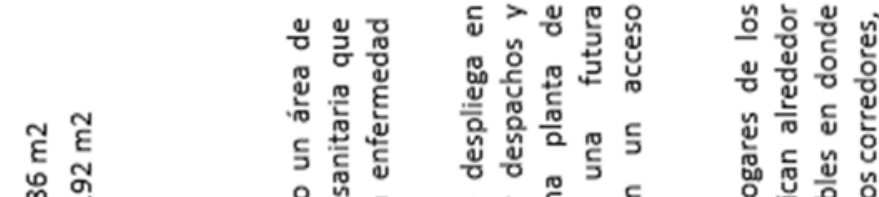

今๊ ने ₹

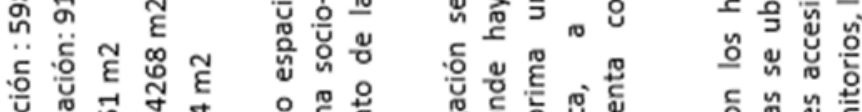

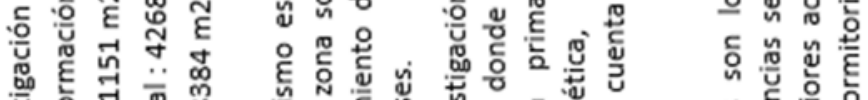

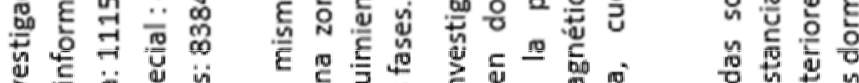

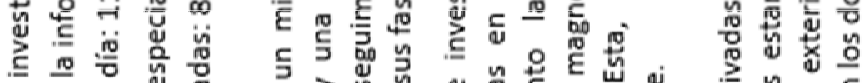

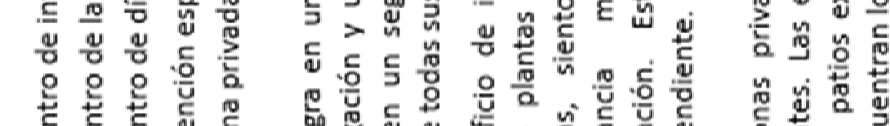

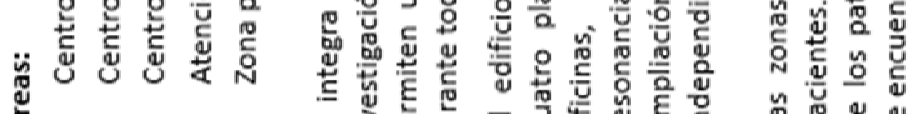

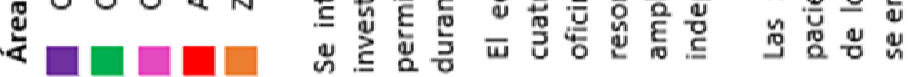
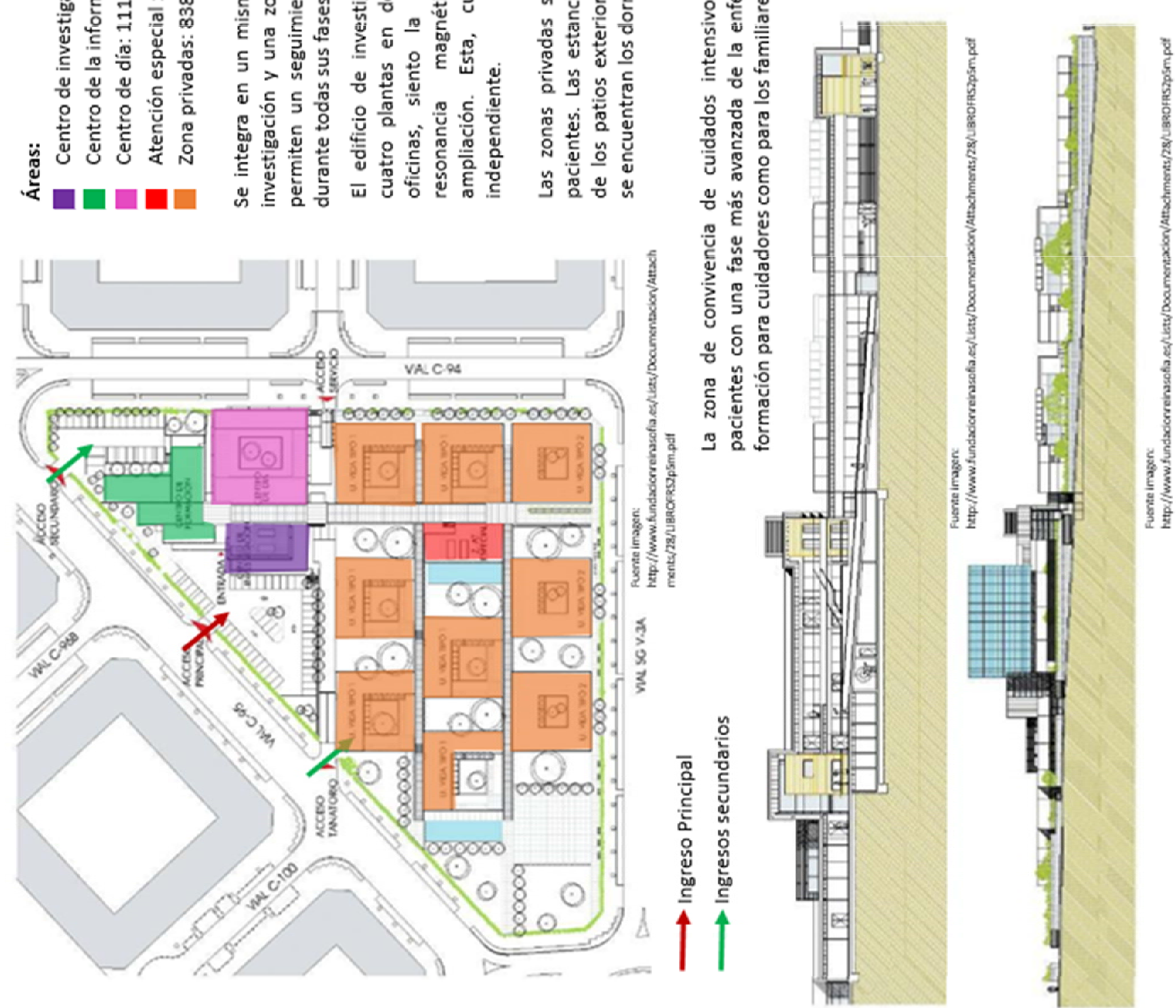

을

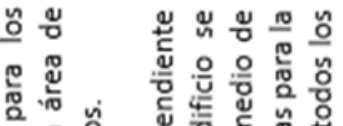

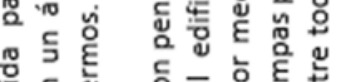

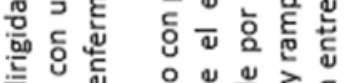

등

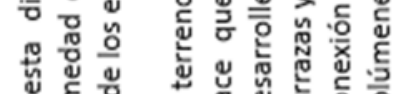

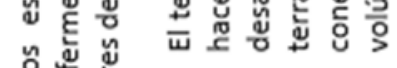



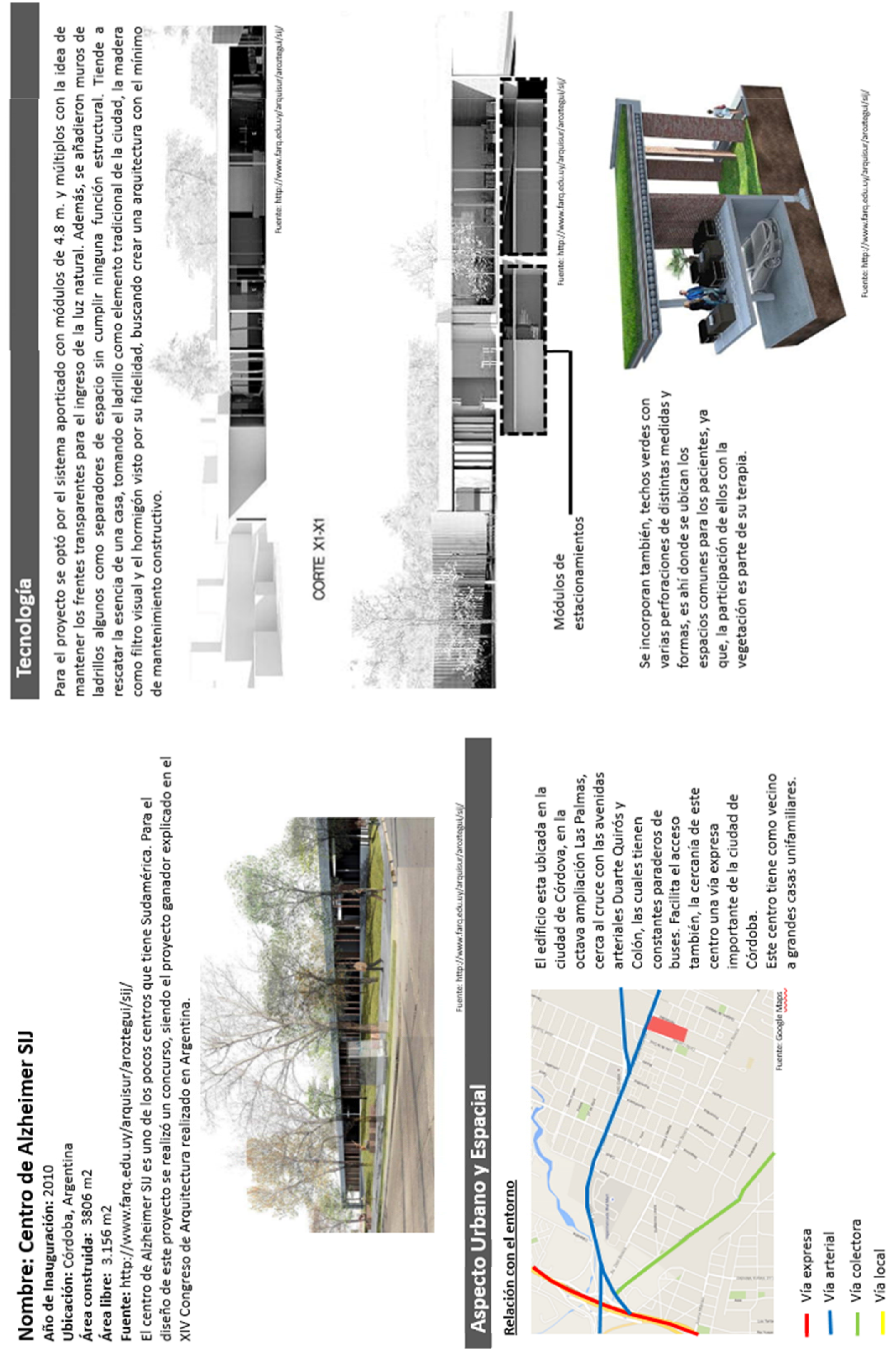

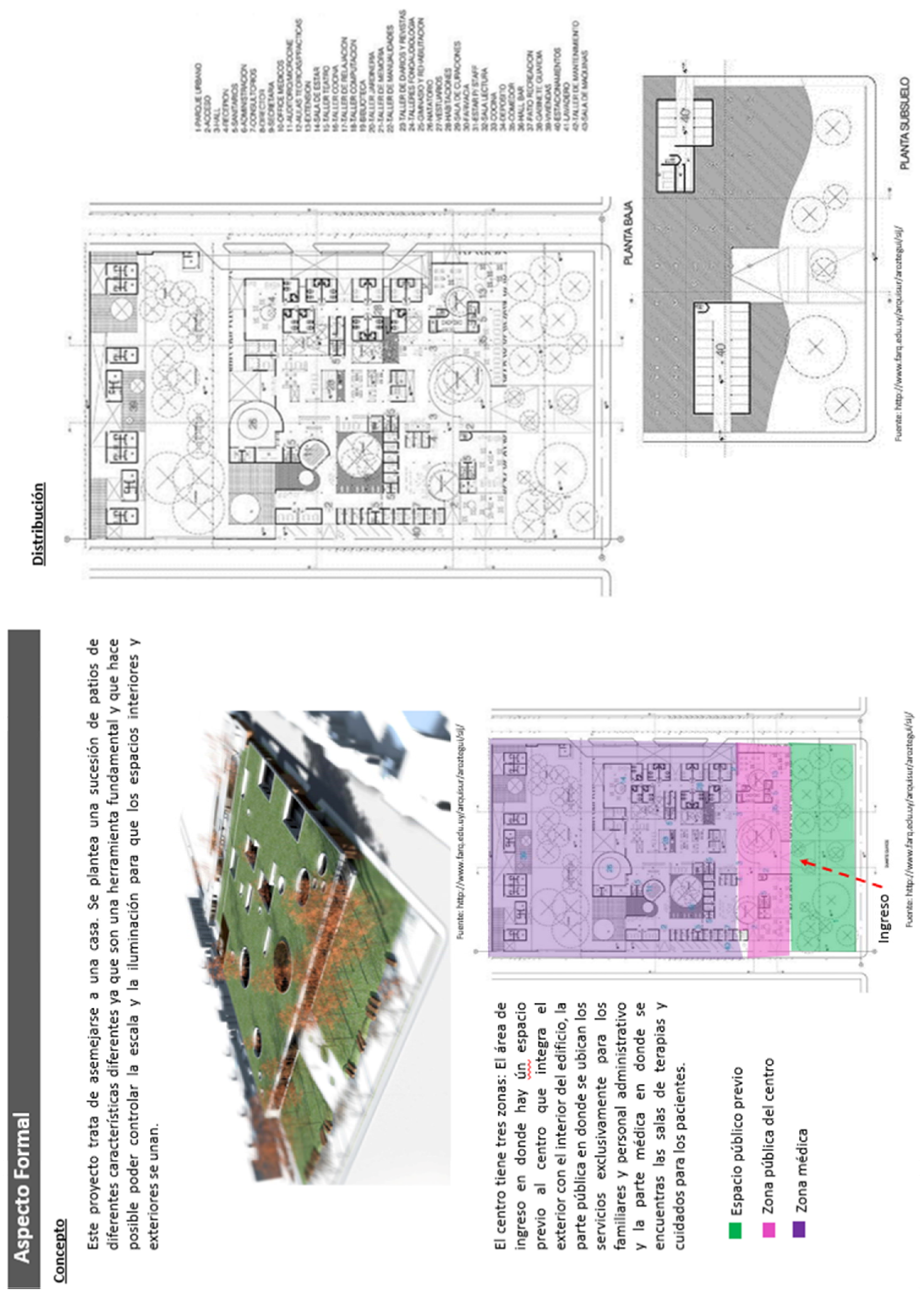

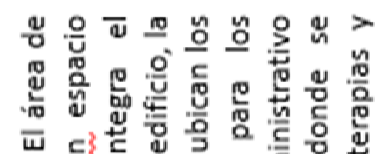

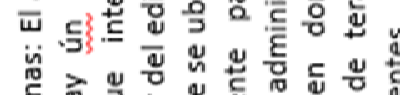

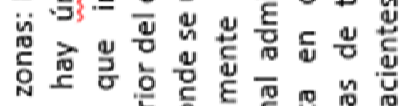

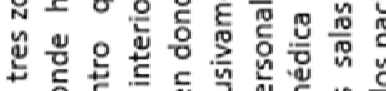

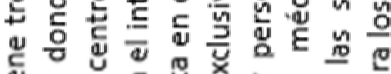

次

웡은

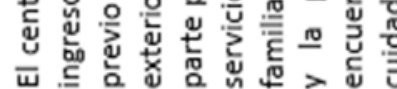

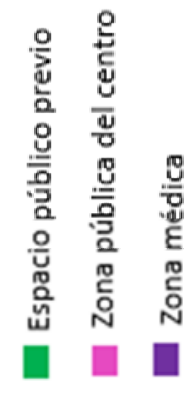



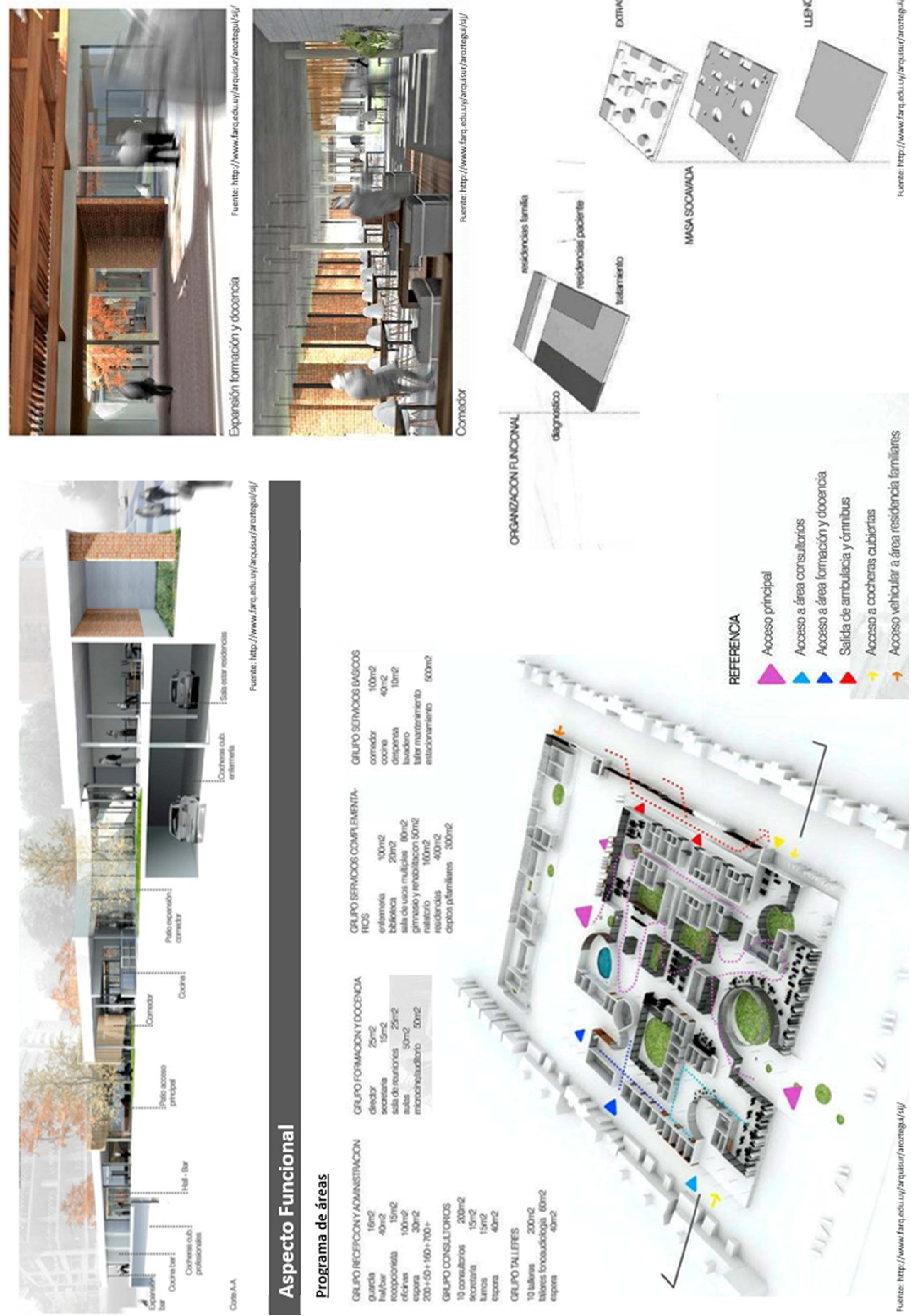

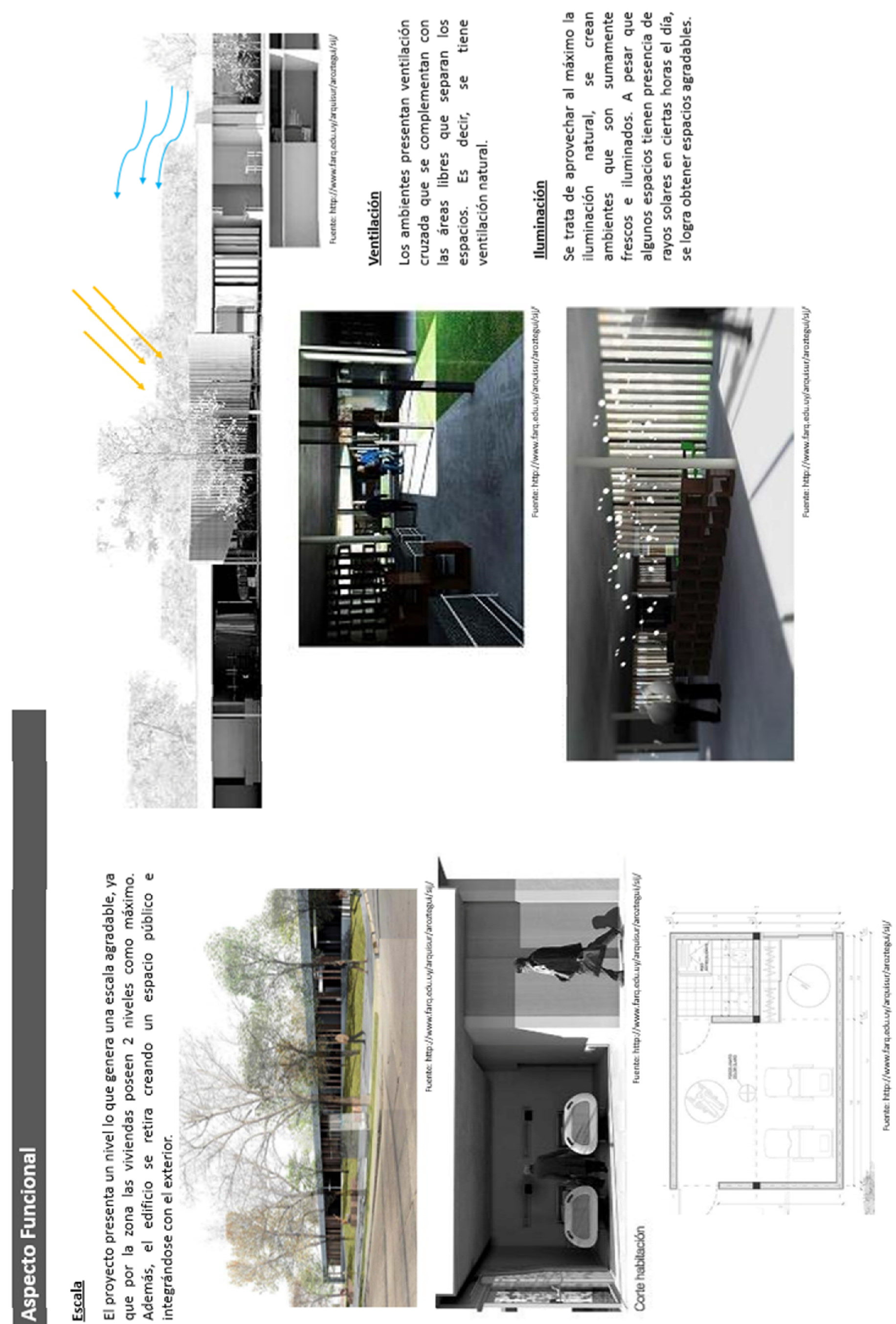
ํํㄴ 등 ํํㅇ 원 으

है

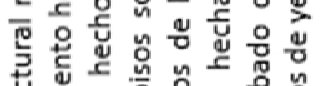

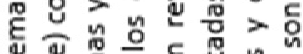

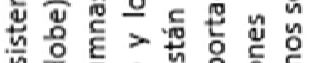

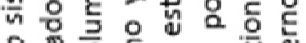

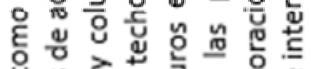

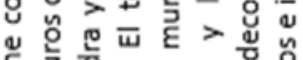

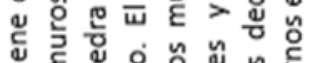

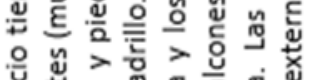

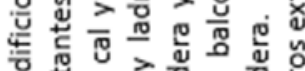
क्ष พ

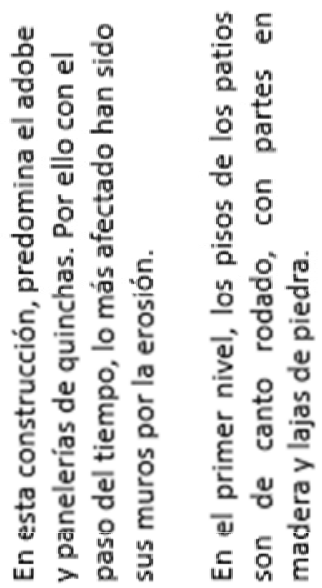

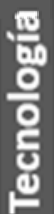

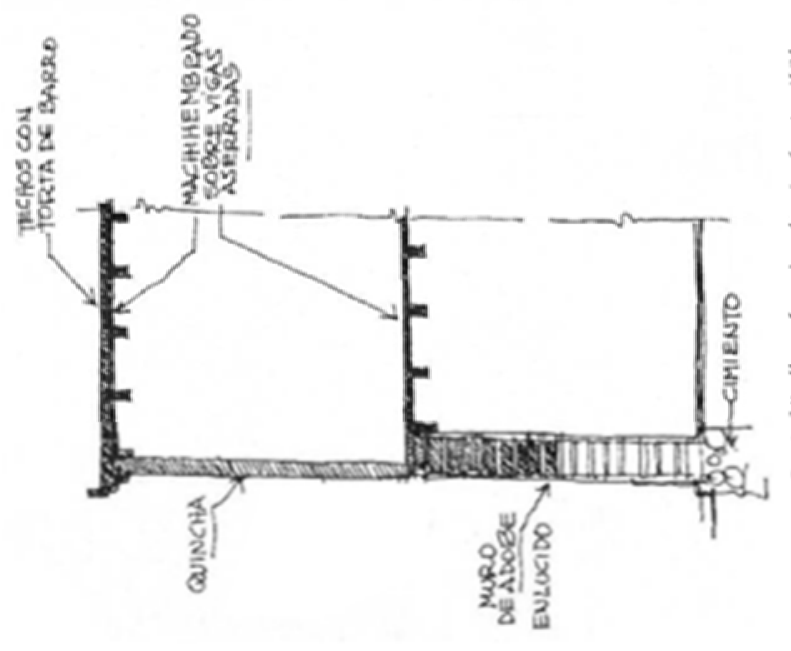

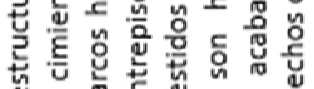

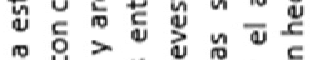

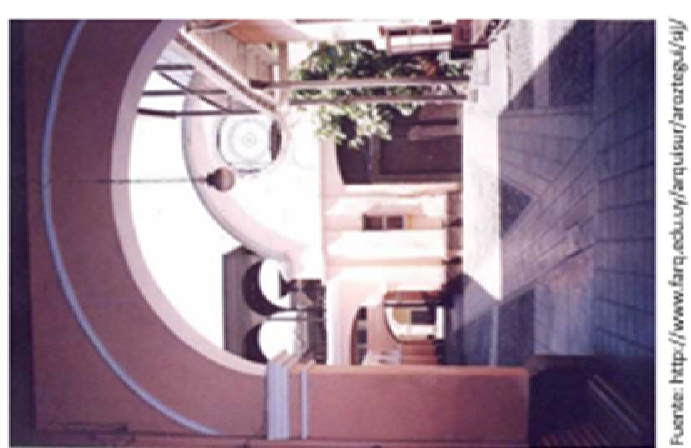

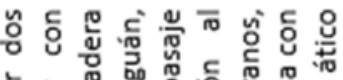

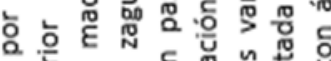

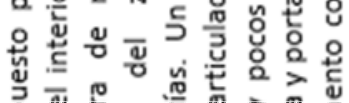

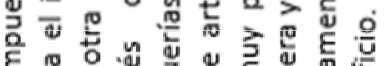
ह

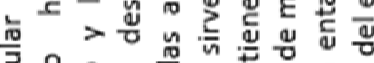
인응

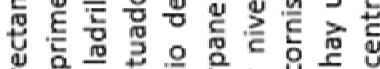

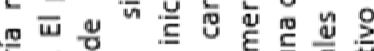
넝 융

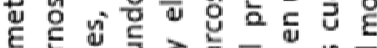

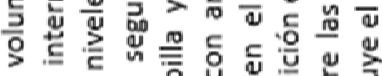

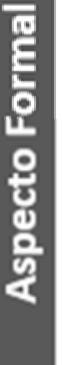

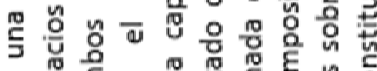

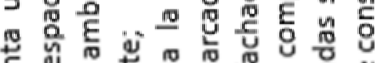

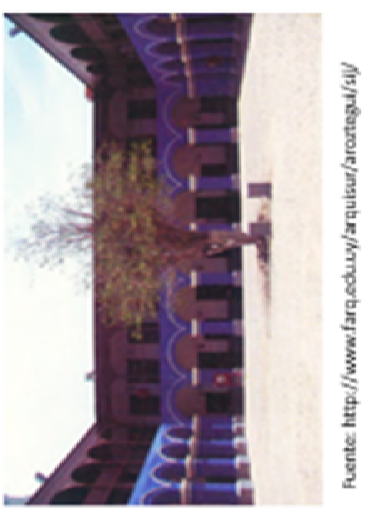
的 凶ั้ 원은

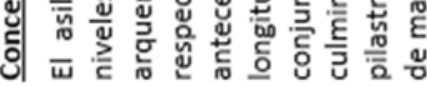

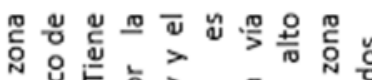

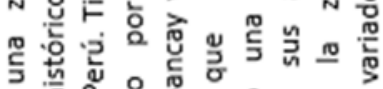

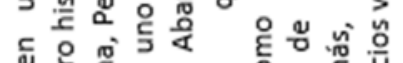

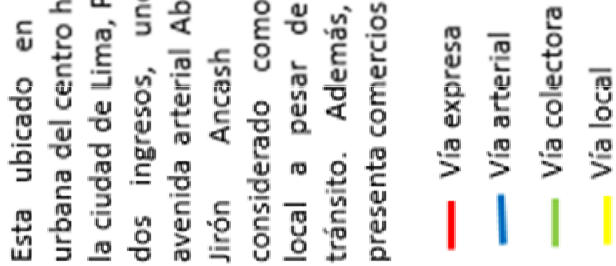

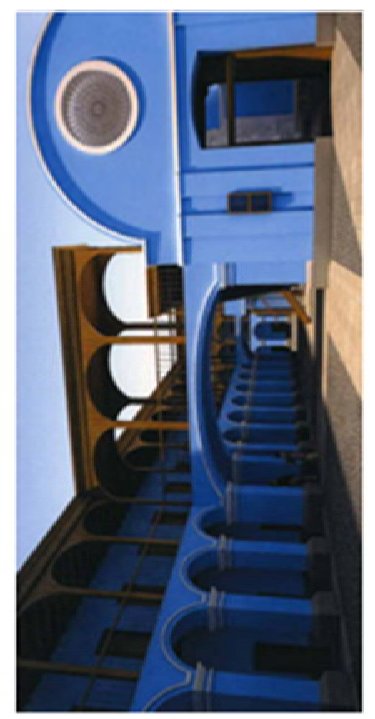

ลิ

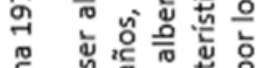

है

प

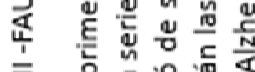

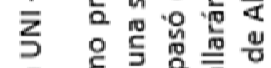

㻤

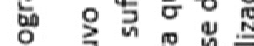

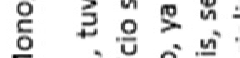

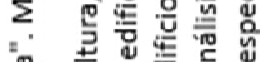

等

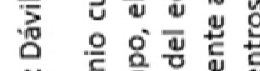

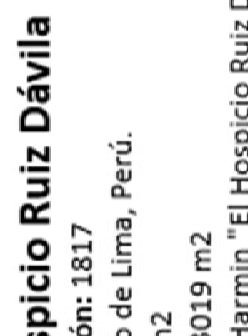

है है

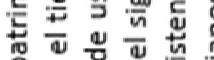

응드은 든

है

윯

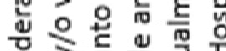

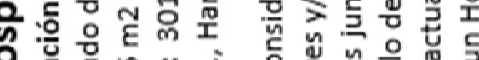

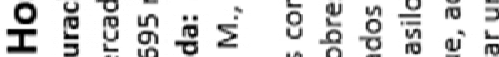

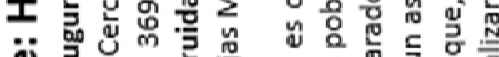

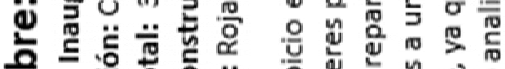

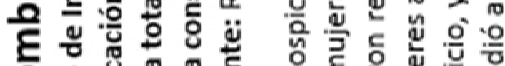

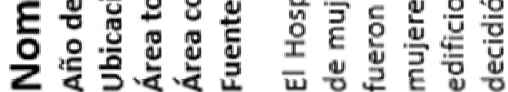
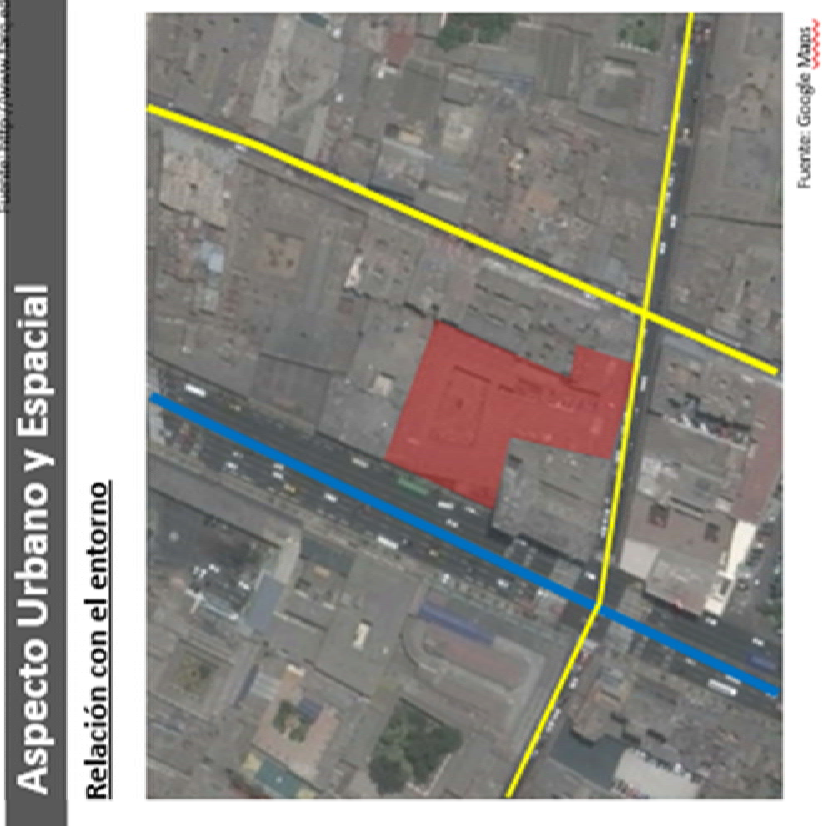

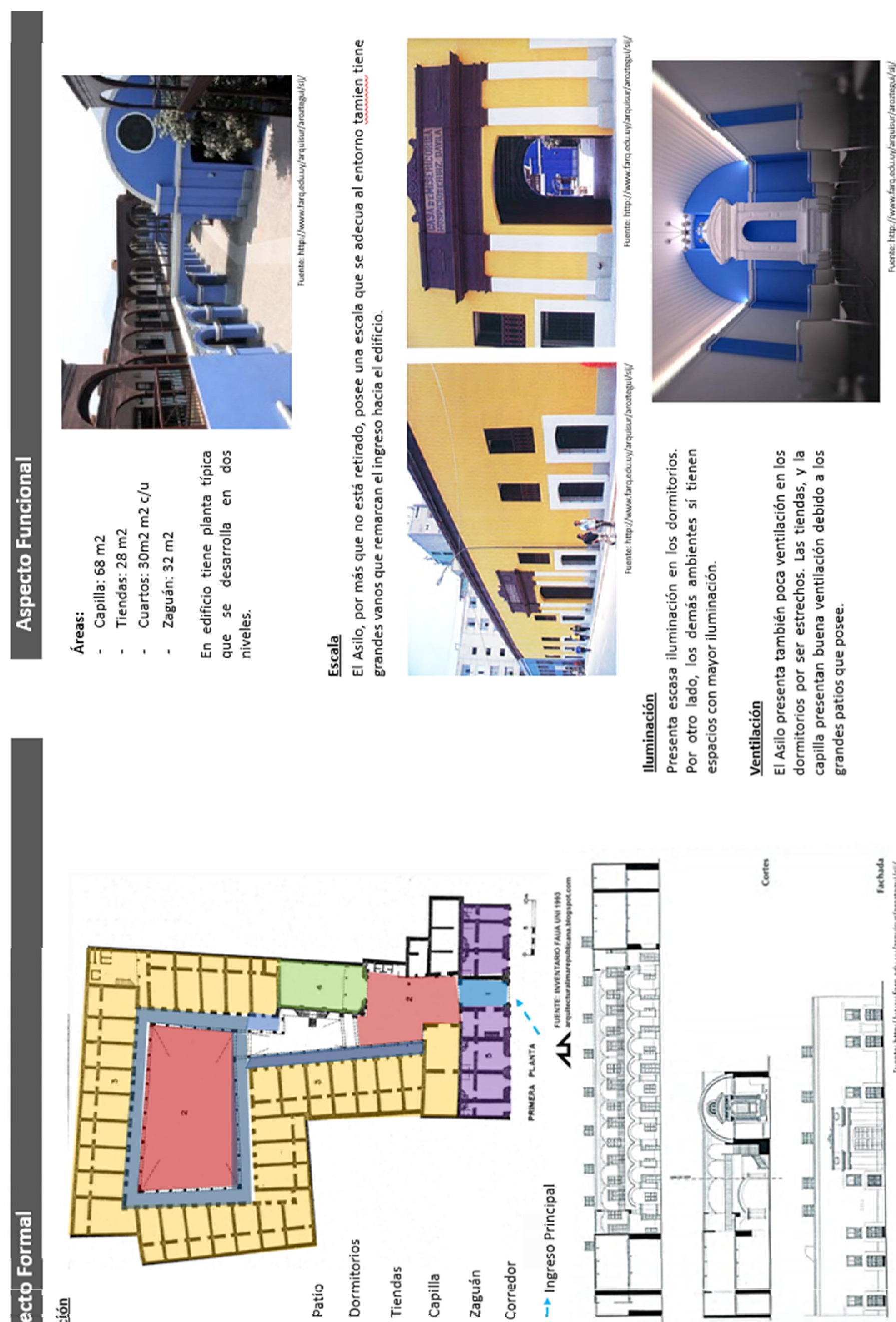


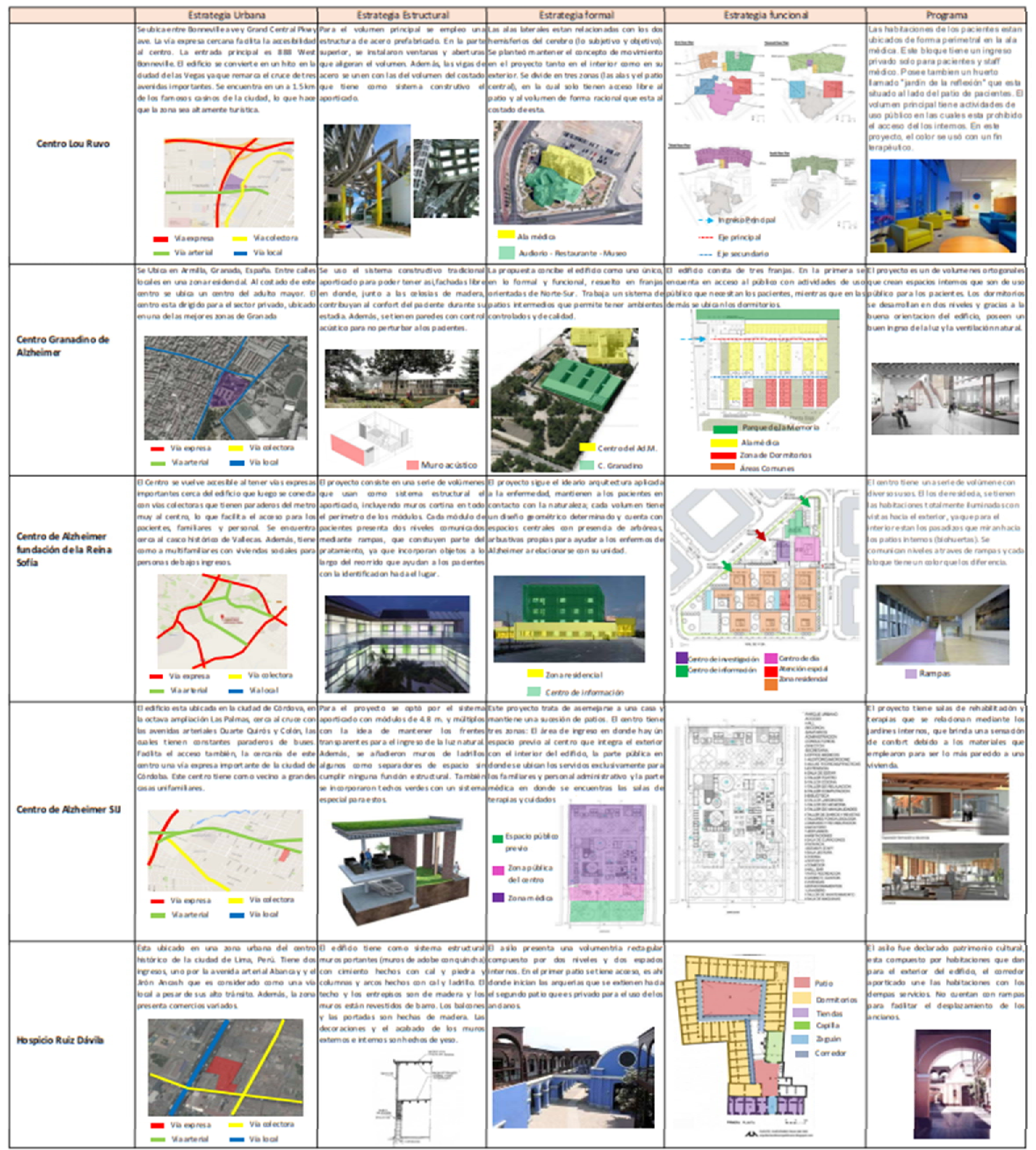




\begin{tabular}{|c|c|c|c|c|}
\hline & Circulación & Escala & Iluminación & Ventilación \\
\hline Centro Lou Ruvo & $\begin{array}{l}\text { El edificio es accesble ya que tiene un solo eje } \\
\text { que reparte a todo el edificia. Este eje, en en } \\
\text { donde se ubica el patio para los pacientes. E } \\
\text { volumen principal presenta tambien ingresos } \\
\text { propios. }\end{array}$ & $\begin{array}{l}\text { El volumen principal de la entrada as } \\
\text { Event Cemter, se encuentra a 19.20m } \\
\text { de altura por las atta temperaturas } \\
\text { en Las Vegas, combirtiendose en un } \\
\text { Hito te la ciudad. }\end{array}$ & $\begin{array}{l}\text { El edficio médico tiene la maycr } \\
\text { parte de la fachada de crista: } \\
\text { orientada haxia el norte. La } \\
\text { estructura de la cubierta del patio } \\
\text { actúa además como sombrilla, } \\
\text { reduciendo la intensidad de la luzz } \\
\text { en el interior deledifcio. } \\
\text { se aprovecha la liuminación } \\
\text { natural al maximo para ahorrar } \\
\text { energia durante el dia. }\end{array}$ & $\begin{array}{l}\text { E edifióo ha sido disefiado para la } \\
\text { posteridad, con caracteristicas que } \\
\text { ayudarán a que pueda resistir el } \\
\text { clima desértico. Además, el techado } \\
\text { impide el ingreso directo del sol y } \\
\text { contribuye a la ventilación de la } \\
\text { zona de descanso ubicada al medio } \\
\text { de las dosalas. }\end{array}$ \\
\hline $\begin{array}{l}\text { Centro Granadino de } \\
\text { Alzheimer }\end{array}$ & 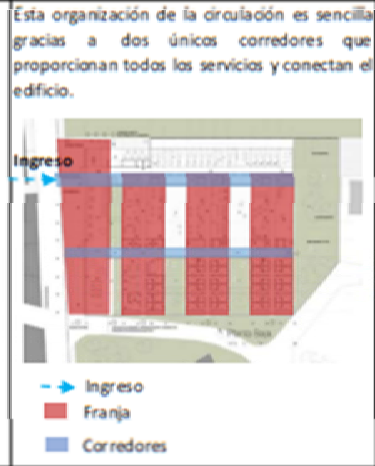 & $\begin{array}{l}\text { La escaia dei edificio de adecua al } \\
\text { lugar ya que, al ser una zona ur bana } \\
\text { con un parque al fente, el edificio se } \\
\text { retetira relacionandose con su entorno, } \\
\text { además de tener solo dos niveles. }\end{array}$ & $\begin{array}{l}\text { Se procura iagras espacios } \\
\text { soleados con el fin de tener } \\
\text { electos positios en las pacientes } \\
\text { se controla la incidencia de los } \\
\text { rayos solares por medio de las } \\
\text { cebsias implementadas en las } \\
\text { tachadas. }\end{array}$ & $\begin{array}{l}\text { Se emplé la ventilacón cruzada y ia } \\
\text { implementacion de patios entre las } \\
\text { franjas para evitar la ventilación } \\
\text { mecánica y evitar los malos olores }\end{array}$ \\
\hline $\begin{array}{l}\text { Centro de Alzheimer } \\
\text { fundación de la Reina } \\
\text { Sofia }\end{array}$ & 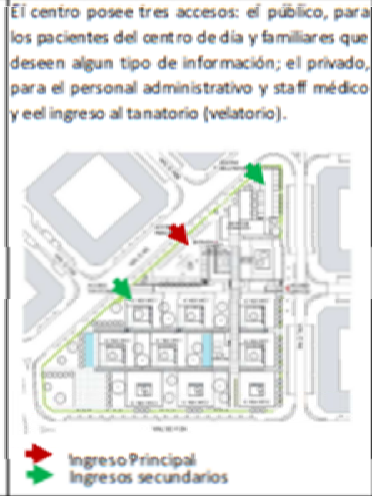 & $\begin{array}{l}\text { Ei volumen se retira por todios su } \\
\text { lados, lo que ayuda a integrarse con } \\
\text { el entorno. Adends, sus volumenes. } \\
\text { con excepcion de uno, son de } 2 \\
\text { niveles como máxima. }\end{array}$ & $\begin{array}{l}\text { ia lie es el protagonista en lios } \\
\text { jardines, que están adaptados a } \\
\text { la zona con pocas dreas verdes. } \\
\text { con arboles y bancos para ef } \\
\text { descanso. }\end{array}$ & $\begin{array}{l}\text { Ê edificio posee una orientación } \\
\text { adaptada a su localizaón, con } \\
\text { medidas contrar el } \\
\text { sobrecalentamiento, ventllación } \\
\text { natural, tratamiento del agua, uso } \\
\text { de cubiertas ecologicas y el empleo } \\
\text { de paneles solares térmicos y } \\
\text { fotovoltacos, hacen que el centro } \\
\text { sea un modeb en prócticas } \\
\text { bioclimáticas. }\end{array}$ \\
\hline Centro de Alzheimer SI & 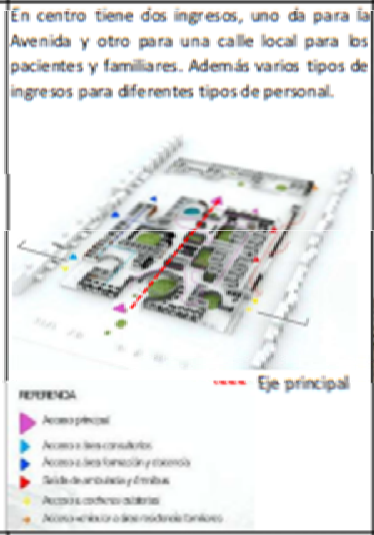 & $\begin{array}{l}\text { Ei proyectio presenta un nivei io que } \\
\text { genera una escala agradable, ya que } \\
\text { por la zona las viviendas poseen } 2 \\
\text { niveles como mírimo. Ademas, el } \\
\text { edifcio se retira creando un espacio } \\
\text { público e integrindose con e| } \\
\text { exterior. }\end{array}$ & $\begin{array}{l}\text { Se trata de aprovechar ai máximo } \\
\text { is iluminación natural, se crean } \\
\text { ambientes que son sumamente } \\
\text { frescos e iluminados. A pesar que } \\
\text { algunos espacios tienen presencia } \\
\text { de rayos solares en ciertas hor as } \\
\text { el dia, se logra obtener espacios } \\
\text { agradables. }\end{array}$ & $\begin{array}{l}\text { Los ambientes presentian ventiación } \\
\text { cruzada que se complementan con } \\
\text { las breas libres que separan los } \\
\text { espacios. Es decir, se tiene } \\
\text { ventilacionn natura. }\end{array}$ \\
\hline Hospicio Ruiz Dávila & $\begin{array}{l}\text { Ei Ásilo tiene un solo ingreso que tiene como } \\
\text { espacio principal un zagian, comunicandolo } \\
\text { con el primer patio en donde se ubica la capits } \\
\text { que tienen acceso público con las personas } \\
\text { ajenas al centro. }\end{array}$ & $\begin{array}{l}\text { El edificio posee una excala que se } \\
\text { adecua a su entorno, consiste en } \\
\text { tener grandes aturas entre piso y } \\
\text { techo. Adends poseen vamos } \\
\text { grandes que remarcan el ingresa. }\end{array}$ & $\begin{array}{l}\text { Presenta excasa liuminación en } \\
\text { los dormitorios. Por otro lado, los } \\
\text { demás ambientes si tienen } \\
\text { espados con mayor iluminación. }\end{array}$ & $\begin{array}{l}\text { E Asilo presenta tambien poca } \\
\text { ventilación en los dormitorios por } \\
\text { ser estrechos. Las tendas, y la } \\
\text { capilla presentan buena ventlación } \\
\text { debido a los grandes patios que } \\
\text { posee. }\end{array}$ \\
\hline
\end{tabular}




\section{Capítulo 4: LUGAR}

Para poder establecer el distrito en donde se enfocará el proyecto, se deberá empezar analizando en dónde se encuentran la mayor cantidad de adultos mayores (tabla 1). La imagen nos muestra que la mayor cantidad de adultos mayores de 65 años se ubica en Lima centro; sin embargo, actualmente existen centros de Alzheimer en dos distritos de ese sector, por lo que los residentes están abastecidos debido al radio de influencia que tienen los centros.

Figura 6. Porcentaje adultos mayores en los distritos de Lima

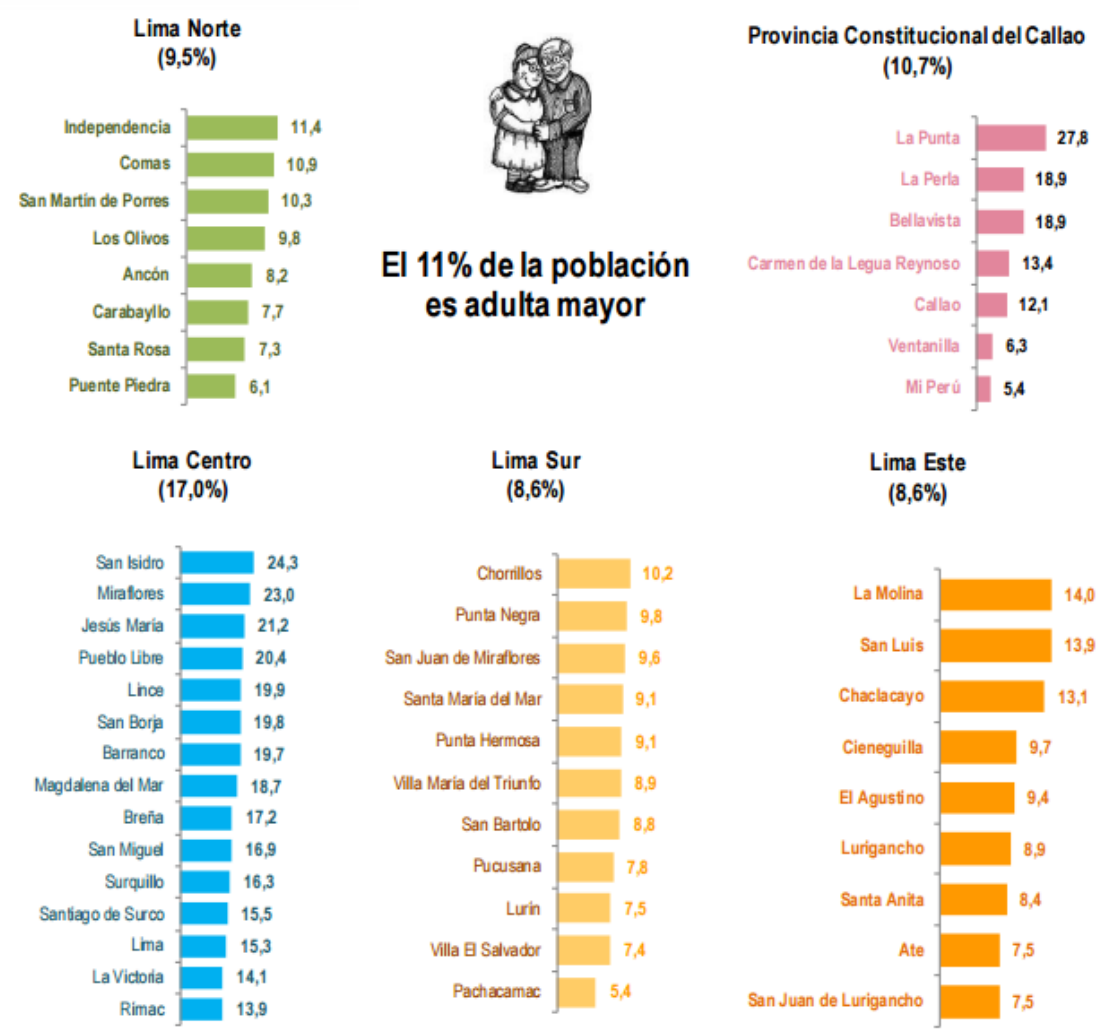

Fuente: Instituto Nacional de Estadística e Informática - Proyecciones de Población por Distritos, 2014

Por otro lado, La provincia del Callao tiene la mayor cantidad de adultos mayores pero no es un buen lugar para la ubicación de esta tipología como la de un centro de rehabilitación para adultos mayores debido a que presenta graves problemas de vulnerabilidad con muy alto nivel de riesgo como lo muestra el siguiente gráfico. 
Figura 7. Mapa de riesgos

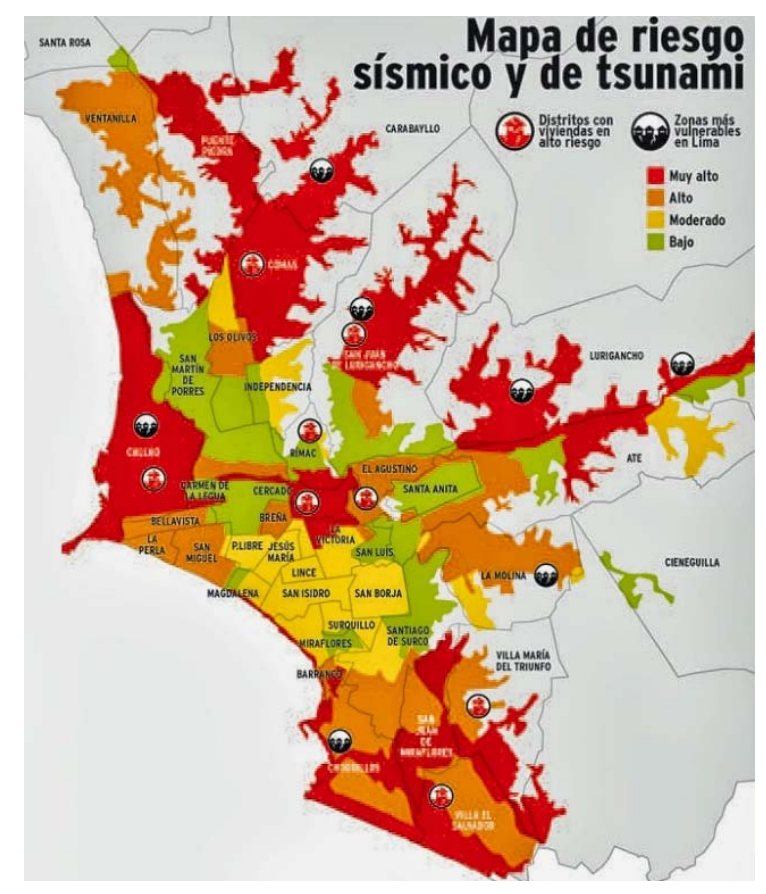

Fuente: INDECI

Es por esas razones que se optó por el sector de lima Norte, además de estar alejado del rango de influencia que tienen los tres centros mencionados anteriormente. Analizando los distritos de ese sector, se eligió San Martín de Porres por tener uno de los mayores índices de adultos mayores y por estar en una zona de baja vulnerabilidad.

\section{1 Áreas verdes}

Actualmente, el distrito carece de áreas verdes. Sin embargo, se han tomado medidas para concientizar a las personas y aprovechar los terrenos sin uso del distrito realizando actividades en donde los habitantes participen con las plantaciones de árboles. Además, se realizó un sistema moderno de riego para las áreas verdes del distrito en las avenidas más importantes.

Fuente: http://www.mdsmp.gob.pe/actividades.php?id=3054

\subsection{Clima}

El clima es templado y cálido en San Martín de Porres. Hasta el mes más seco (Julio) aún tiene mucha lluvia. La temperatura media anual en San Isidro se encuentra a $16.6^{\circ} \mathrm{C}$. La precipitación es de $1006 \mathrm{~mm}$ al año. El mes más caluroso del año con un promedio de $23.3{ }^{\circ} \mathrm{C}$ de enero. El mes más frío del año es de $10.4{ }^{\circ} \mathrm{C}$ en el medio de julio. La diferencia 
en la precipitación entre el mes más seco y el mes más lluvioso es de $60 \mathrm{~mm}$. Las temperaturas medias varían durante el año en un $12.9^{\circ} \mathrm{C}$.

Fuente: http://es.climate-data.org/location/19726/

\subsection{Criterio de localización}

- El proyecto tiene que desarrollarse en un medio urbano, ubicándose en medio de una población desarrollada y ya instalada.

- Es recomendable que los centros de salud no colinden con ningún impedimento físico como: ríos, comtañas, avenidas grandes como las expresas, montañas, etc.

- Se tomará en cuenta el clima, ya que es importante analizar la contaminación visual, sonora y ambiental.

- Analizar las rutas de acceso al terreno. Debe ser con un ingreso de facil acceso para los pacientes, tanto exterior como interiormente.

- El terreno deberá tener una ligera pendiente para ayudar a la evacuación de agua.

Fuente: Normas técnicas para proyectos de arquitectura Hospitalaria. Dirección ejecutiva para normas técnicas para infraestructura de salud. 1996

\subsection{Disponibilidad de los servicios básicos}

Los terrenos designados a la construccion de centros de saluddeberán contar con lo siguiente:

- Abastecimietno de agua potable adecuada en cantidad y calidad

- Disponibilidad de desague y drenaje de aguas pluviales

- Energía eléctrica

- Comunicaciones y red telefónica 
Fuente: Normas técnicas para proyectos de arquitectura Hospitalaria. Dirección ejecutiva para normas técnicas para infraestructura de salud. 1996

\subsection{Accesibilidad y Localización}

Los terrenos deben ser accesibles peatonales y vehicularmente de tal manera que se garantice el fuido efectivo ingreso del público en general al centro. También se evitará la cercanía de áreas de influencia industrial, establos, crematorios, basurales, depósito de combustibles e insecticidas, fertilizantes, morgues, cementerios, mercados o tiendas de comestibles y en general evitar la proximidad a focos de insalubridad e inseguridad. Por último, deberá evitarse la colindancia y proximidad con: grifos, cantinas, bares, restaurantes, prostíbulos y locales de espectáculos.

Fuente: Normas técnicas para proyectos de arquitectura Hospitalaria. Dirección ejecutiva para normas técnicas para infraestructura de salud. 1996

\subsubsection{Orientación y factores climáticos}

Se deberá tomar en cuenta las condiciones atmosféricas para efectos de conceptuar el diseño arquitectónico del futuro dentro de salud tales como:

- Vientos predominantes, temperatura, el clima predominante, precipitacones pluviales, granizada, etc.

- La orientación será de tal manera que permita buena iluminación y ventilación adecuada.

Fuente: Normas técnicas para proyectos de arquitectura Hospitalaria. Dirección ejecutiva para normas técnicas para infraestructura de salud. 1996 


\subsubsection{Condiciones físicas del terreno}

- Tamaño: Debe permitir el desarrollo de los programas de las unidades del hospital a cosntruirm asi como ampliaciones futuras, y los espacios para estacionamiento y área verde (50\%), que permitan la integracion de la vida hospitalaria con los espacios externos.

- Planimetría: Los terrenos deben ser en lo posible de forma regular, casi cuadrados, de superficie plana y con dos accesos como mínimo.

- Condiciones físicas: Se debe tener en cuenta las condiciones físicas del terreno no debe exceder del $30 \%$ del área total.

Fuente: Ministerio de Salud y revisión social. Guía Nacional de diseño y cosntrucción del establecimiento de Salud. 2002

\subsubsection{Disponibilidad del área del terreno}

Se considera de la ocupación del terreno no debe exceder del 30\% del área total. Del 70\% del área libre, el 20\% servirá para futuras ampliaciones, quedando en el futuro el $50 \%$ para área libre.

En el caso de que exista edificios circundantes al terreno, estas estarán ubicadas a una distancia no menor a 9 metros lineales de la edificación hospitalaria.

La volumetría del proyecto, cumpliendo con el seguimiento de las áreas a construir, no deberá provocar conflictos con las zonas colindantes.

Fuente: Ministerio de Salud y revisión social. Guía Nacional de diseño y cosntrucción del establecimiento de Salud. 2002 


\subsection{Suelo}

Según el gráfico mostrado, muestra que el distrito de San Martín de Porres corresponde a la Zona I y es apta para construir por tener un suelo rocoso.

Figura 8. Tipo de suelo

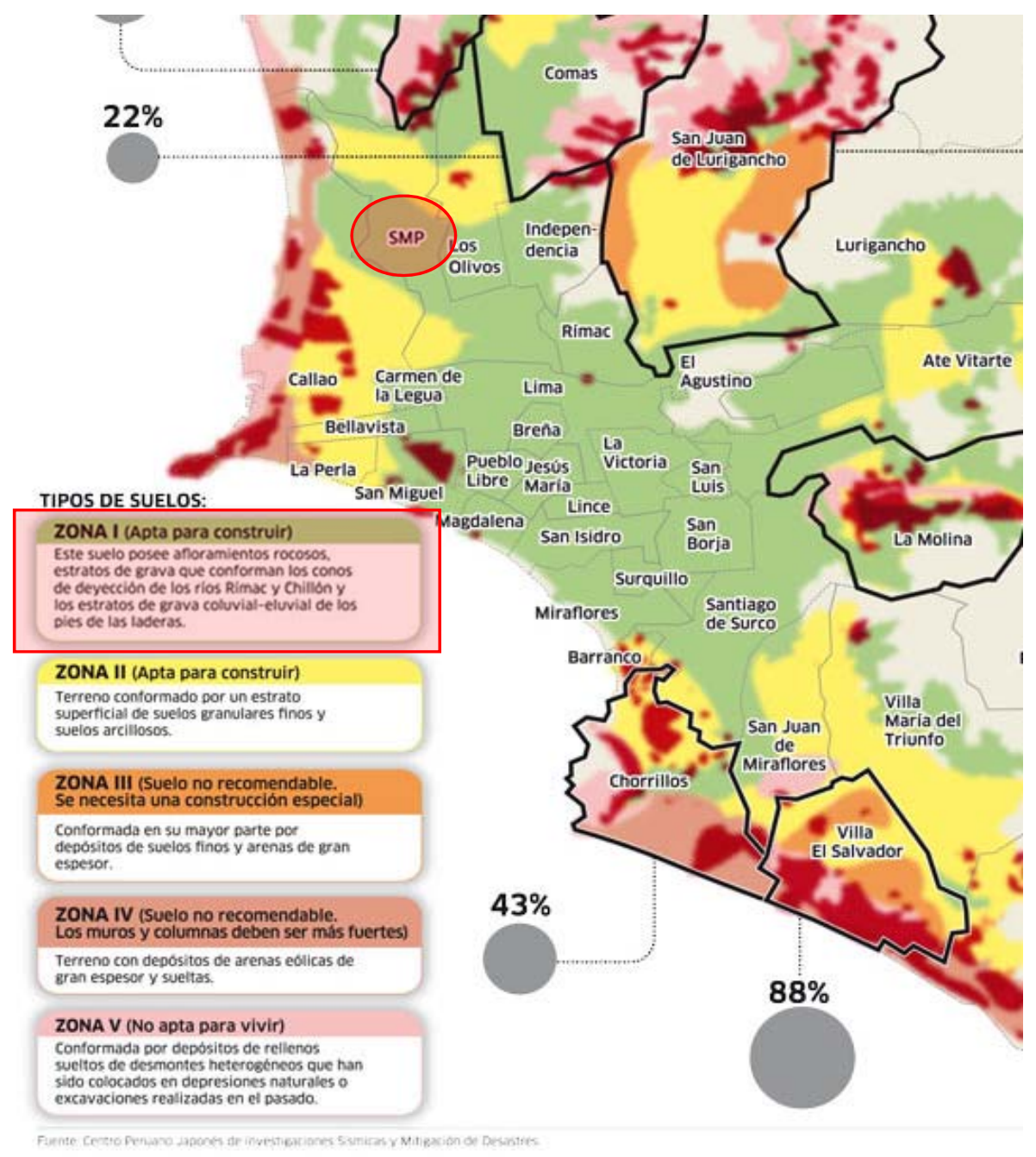

Fuente imagen: http://sinia.minam.gob.pe/mapas/mapa-suelos-distritos-lima 


\subsection{Expediente urbano}

\subsubsection{Avenidas}

Las Avenidas de acceso a la zona son de jerarquía arterial (Av. Canta Callao y Av. Próceres de Huandoy) y colectora (Av. Central, Calle Huascar y Av. Río Marañón). Además, La avenida Canta Callao culmina en la Av. Faucett (muy cerca al aeropuerto, a la policía aérea, la aviación naval y del ejército). Lo que hace que la zona sea totalmente accesible.

Figura 9. Gráfico de avenidas

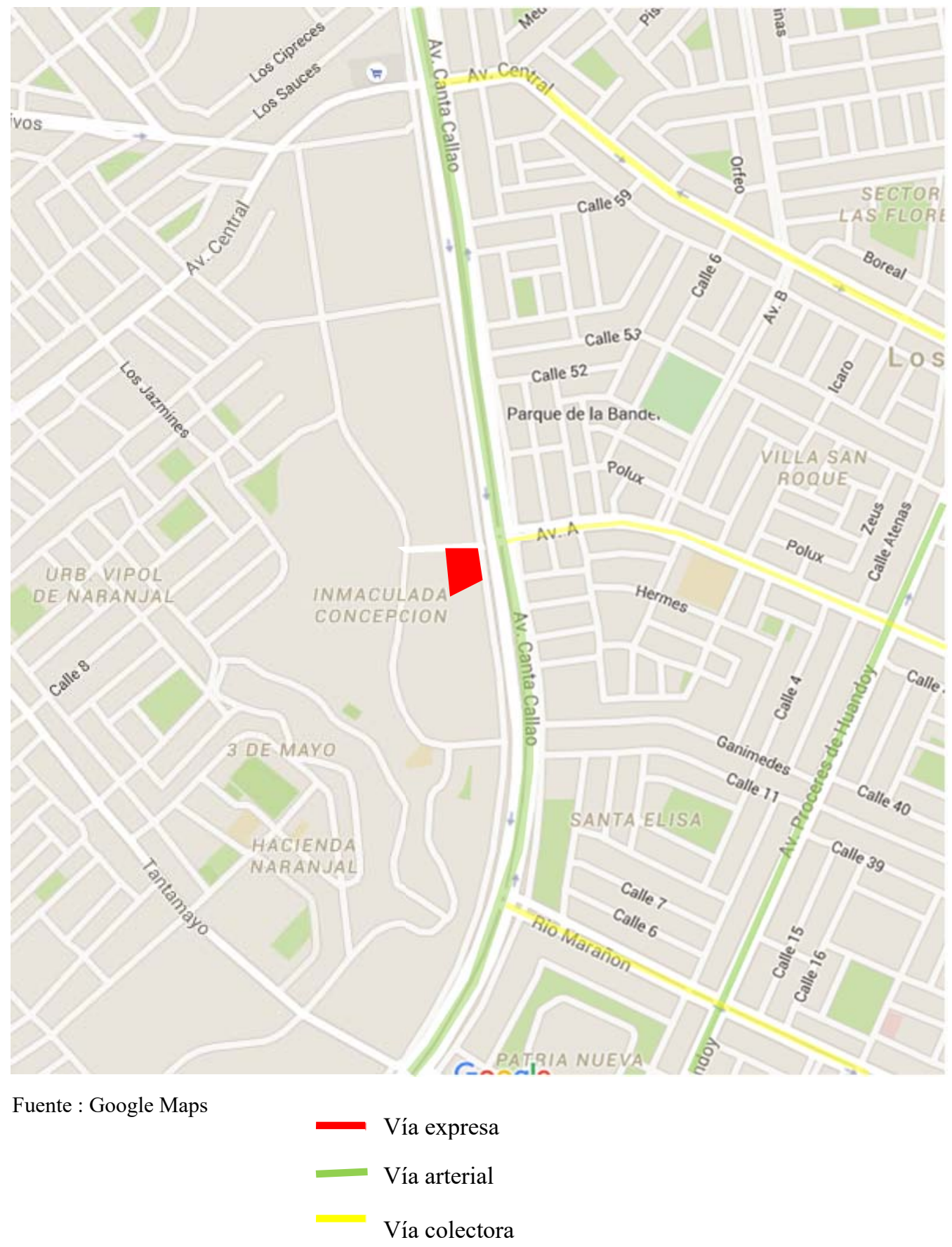




\subsubsection{Equipamiento Urbano}

La zona tiene como equipamiento un Tottus en el cruce de la avenida central con Canta Callao, dos centros de salud cercanos, un mercado modelo de la zona y parques cercanos para los residentes. Para el lado del distrito de Indepedencia ( $\mathrm{Al}$ frente del terreno), existe comercio de todo tipo como: Bodegas, mecánicas, Farmacias y hoteles.

Figura 10 : Gráfico de equipamiento

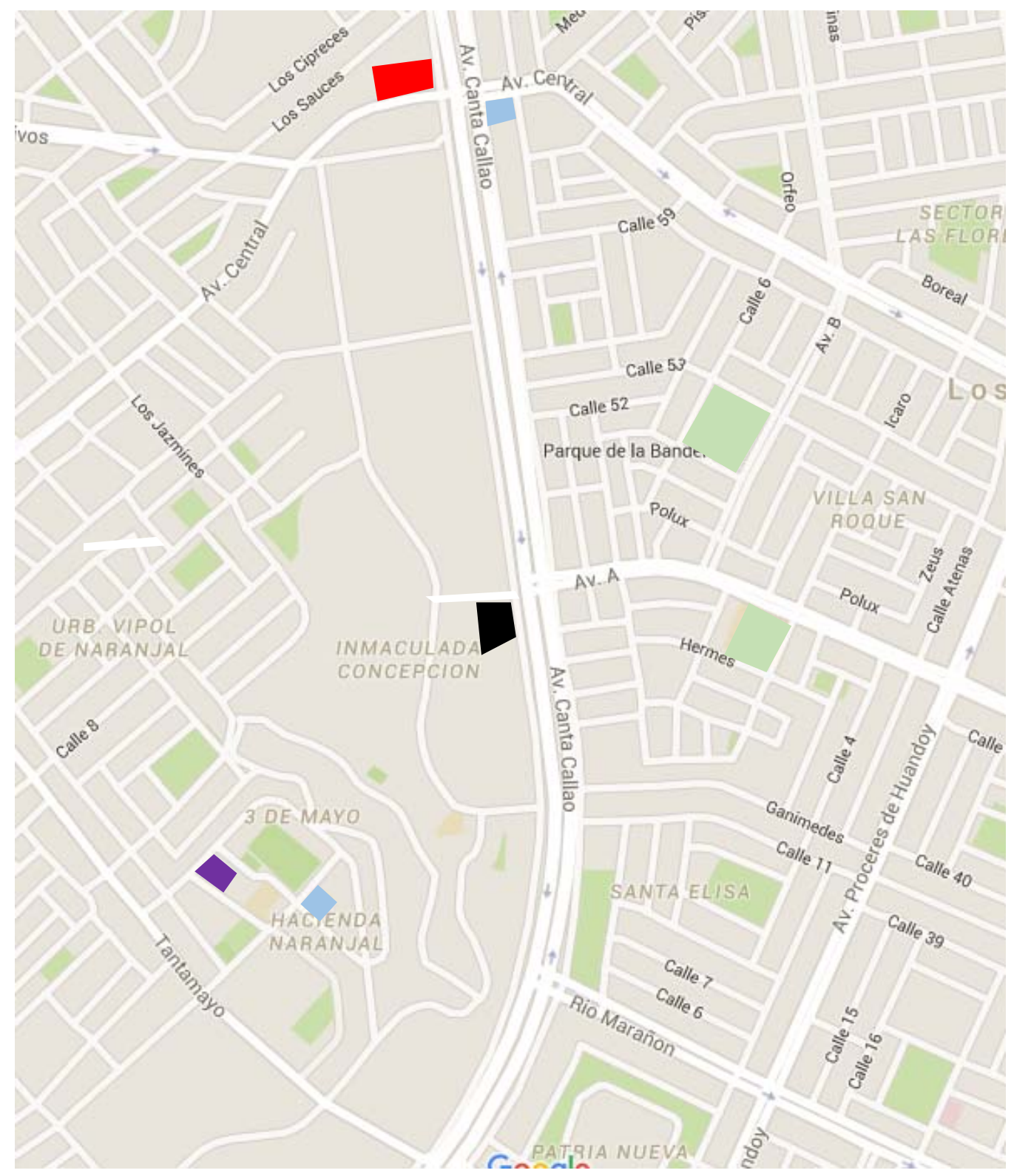

Fuente : Google Maps

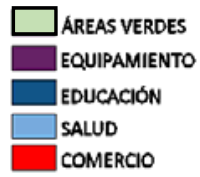




\subsubsection{Zonificación}

La zona, según el cuadro de zonificación, tiene distintos usos como comercio zonal (CZ), residencia de densidad media (RDM), comercio vecinal (CV) y equipamientos como: postas médicas y centros educativos.

Figura 11. Gráfico de zonificación

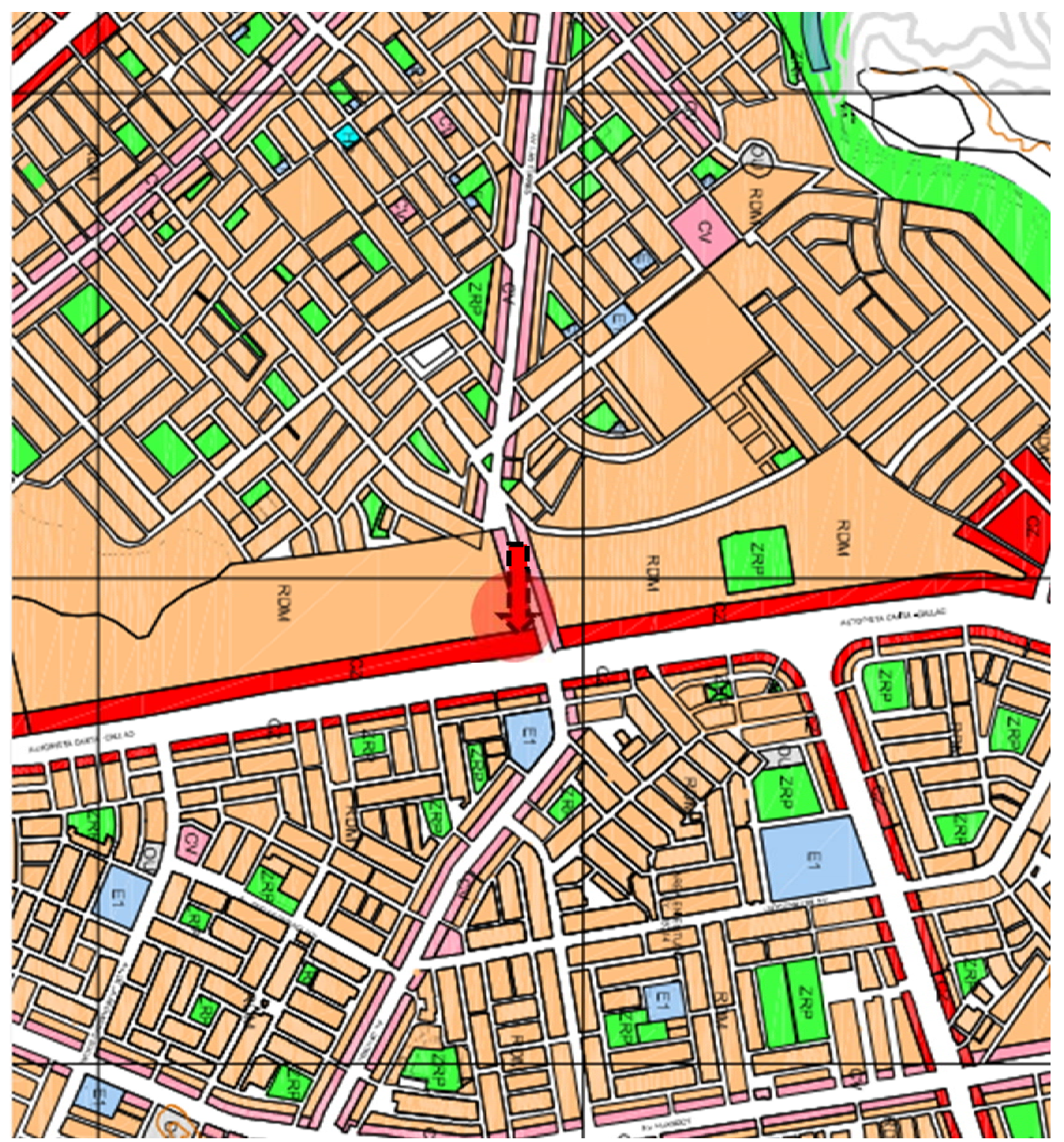

Fuente: Instituto Peruano de Derecho Urbanístico (IPEU) 


\subsubsection{Cuadro de uso}

Los usos mostrados en el plano anterior (Plano de zonificación) y los usos actuales de la zona, muestra que son compatibles entre sí, analizando según la variedad de comercio que hay en la zona, ya que, es el uso que abunda en el sector.

Tabla 3. Tabla de usos compatibles

\begin{tabular}{|c|c|c|c|c|c|c|c|c|c|c|c|c|c|c|}
\hline 345 & 527 & & & NORMAS LEGALE & & & & & & & Wnes & $14 \mathrm{der}$ & maper & le 2007 \\
\hline & & & & HEICE DE USOS PQRAL LA LAICAOCN DE ACTMDACE & gakas & & & & & & & & & \\
\hline & & & & AREA DE TRUTAMENTO NORWATINOI & & & & & & & & & & \\
\hline & & & & & Reoe & row & reas & vT & ov & $\mathrm{cz}$ & cu & m & 12 & th \\
\hline 0 s: & $22^{3}$ & 12 & & VEETA ML POR NENOR DE PROOUCTOS TETLLES PREVOUS DE VESTR CALZZOO, ART. CUERO & & & & & & & & & & \\
\hline $\begin{array}{ll}0.5 & 5 \\
\end{array}$ & 523 & 12 & log & ZAPATESAAS & & 0 & 0 & $\mathbf{x}$ & $\mathbf{x}$ & $\mathrm{x}$ & $\mathrm{x}$ & $\mathbf{x}$ & $\mathrm{x}$ & \\
\hline 0.5 & 523 & 32 & ese & Bountoufs & & 0 & 0 & $\mathrm{x}$ & $\bar{x}$ & $\mathrm{x}$ & $\mathrm{x}$ & $\mathrm{x}$ & $x$ & \\
\hline $\begin{array}{ll}0.5 \\
\end{array}$ & 523 & 2 & ar & VENTA DE TELAS Y TEIODOS & & 0 & 0 & $\mathbf{x}$ & $\mathrm{x}$ & $\mathrm{x}$ & $\mathrm{x}$ & $x$ & $x$ & \\
\hline \begin{tabular}{|l|l}
0 & 5 \\
\end{tabular} & 523 & 32 & & VENTA DE ARTTCULO DE CUERO Y AOCESORIOS DE VWNE & & & & $x$ & $x$ & $\mathrm{x}$ & $\mathrm{x}$ & $x$ & $x$ & \\
\hline $\begin{array}{ll}0 & 5 \\
\end{array}$ & 523 & 32 & es & VEATIA DE PAEROAS DE VESTRR FURACABALEROS & & 0 & 0 & $x$ & $x$ & $x$ & $x$ & $x$ & $x$ & \\
\hline 055 & 523 & 2 & ex & 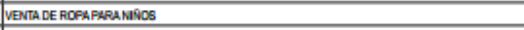 & & 0 & 0 & $x$ & $\bar{x}$ & $\mathrm{x}$ & $x$ & $x$ & $x$ & \\
\hline 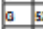 & 523 & 32 & te & VEATAA DE ROFA RARA AEEES & & 0 & 0 & $x$ & $x$ & $\mathrm{x}$ & $x$ & $x$ & $x$ & \\
\hline 0.5 & $52 \sqrt{3}$ & $\sqrt{2}$ & & MELETERIA & & 0 & 0 & $x$ & $x$ & $\mathrm{x}$ & $x$ & $x$ & $x$ & \\
\hline 0.5 & 523 & 2 & & LENCERIA & & 0 & 0 & $x$ & $x$ & $x$ & $x$ & $x$ & $x$ & \\
\hline 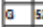 & 523 & 32 & 7 & PEETEERA & & & & $\mathrm{x}$ & $x$ & $\mathrm{x}$ & $\mathrm{x}$ & $x$ & $x$ & \\
\hline 0.5 & $52 \sqrt{3}$ & 32 & 1 & SOUEREREFAL & & & & $x$ & $x$ & $\mathrm{x}$ & $x$ & $x$ & $x$ & \\
\hline 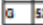 & 523 & 2 & 1 & CASES DE NONOS & & 0 & 0 & $x$ & $x$ & $\mathrm{x}$ & $x$ & $x$ & $x$ & \\
\hline 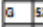 & 523 & 2 & 1 & VENTA DE PAEQUS DE VESTRR FRRA DAUUS & & 0 & 0 & $x$ & $x$ & $x$ & $x$ & $x$ & $x$ & \\
\hline 0.5 & 223 & 3 & & VEVTA AL POR WEVOR APARATOS, RRTTCLOS Y EQUEO DE USO DOWESTTCO & & & & & & & & & & \\
\hline 055 & 523 & 3 & e & VENTA DE ARTEFACTOS DE LUMGUCONY Y ARONCE & & & & $\mathrm{x}$ & $x$ & $x$ & $\mathrm{x}$ & $x$ & $\mathrm{x}$ & \\
\hline 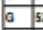 & 523 & 3 & & VENTA DE ARTCU OS Y EOUPO DE USO DOLESTICONCP. & & & & $x$ & $x$ & $x$ & $x$ & $x$ & $x$ & \\
\hline 0.5 & 523 & 3 & te. & VENTA DE CORTNAS Y TRFEES & & & & $x$ & $x$ & $x$ & $x$ & $x$ & $x$ & \\
\hline $\begin{array}{ll}0.5 \\
\end{array}$ & 523 & 3 & & LOCERLS & & & & $x$ & $x$ & $x$ & $x$ & $x$ & $x$ & \\
\hline $\begin{array}{ll}05 \\
05\end{array}$ & 523 & 3 & es & EOUFO DE RECIO Y TELEVESOW & & & & $\mathrm{x}$ & $x$ & $\mathrm{x}$ & $x$ & $x$ & $x$ & \\
\hline \begin{tabular}{|l|l}
05 & 5 \\
& 5
\end{tabular} & 523 & 3 & & RSTRLMENTOS MUSCLES & & & & $\mathrm{x}$ & $x$ & $\mathrm{x}$ & $x$ & $x$ & $x$ & \\
\hline $\begin{array}{ll}0.5 \\
\end{array}$ & 523 & 3 & & COCHONERH & & & & $x$ & $x$ & $x$ & $x$ & $x$ & $x$ & \\
\hline 0.5 & 523 & 3 & ta & MEALEFAA & & & & $x$ & $x$ & $x$ & $x$ & $x$ & $x$ & \\
\hline \begin{tabular}{|l|l}
0 & 5 \\
\end{tabular} & 523 & 3 & te & VEENTA DE LISCOS Y CASSEITES & & & & $x$ & $x$ & $x$ & $x$ & $x$ & $x$ & \\
\hline 05 & 523 & 3 & 1 & VENTA DE UTENSLOS PAPAEE HOQAR & & & & $x$ & $x$ & $\mathrm{x}$ & $x$ & $x$ & $x$ & \\
\hline $\begin{array}{ll}0.5 \\
\end{array}$ & $52 \sqrt{3}$ & 3 & 1 & VEerta DE ELECTROOOMESSTCOS & & & & $x$ & $x$ & $x$ & $x$ & $x$ & $x$ & \\
\hline $\begin{array}{ll}0.5 \\
0\end{array}$ & 523 & 3 & & VIDFIEFUA ESFEJOS Y SMEARES & & & & $\mathrm{x}$ & $x$ & $\mathrm{x}$ & $x$ & $x$ & $x$ & \\
\hline 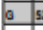 & 523 & 4 & & VEVTA NLL POR NEVOR DE ARTICULOS DE FEREETERIL PIITURA Y YVEO & & & & & & & & & & \\
\hline 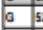 & 523 & 4 & te & FERRETERAAS & & & & $x$ & $x$ & $\mathrm{x}$ & $\mathrm{x}$ & $\mathrm{x}$ & $\mathrm{x}$ & \\
\hline 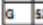 & 523 & 4 & te & VENTA DE PNTURAS, SAFNCES Y LACAS & & & & $x$ & $x$ & $x$ & $x$ & $x$ & $x$ & \\
\hline 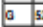 & 523 & 4 & te. & VENTA DE VEFIOS Y ARTCULOS DE VDRD-VDEERLS & & & & $\mathrm{x}$ & $x$ & $\mathrm{x}$ & $\mathrm{x}$ & $x$ & $x$ & \\
\hline 055 & 523 & 34 & & VENTA DE MATERALES Y EOUFO PARA TRABANO DE AFWADOO CASEFO & & & & $\mathrm{x}$ & & $\mathrm{x}$ & $\mathrm{x}$ & $x$ & $\mathrm{x}$ & \\
\hline 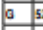 & 523 & 34 & & VEENAA DE SANTLAROG YMANOUCAS & & & & & & $\mathrm{x}$ & $\mathrm{x}$ & $x$ & $x$ & \\
\hline $\begin{array}{ll}0.5 \\
\end{array}$ & 523 & 34 & & VENTA DE MATEFHLES DE CONSTRUCCCON & & & & & & $\mathrm{x}$ & $\mathrm{x}$ & $x$ & $\mathrm{x}$ & \\
\hline 0 & 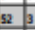 & 9 & & 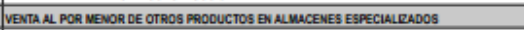 & & & & & & & & & & \\
\hline 05 & 523 & 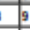 & to & VENTA DE WAUMULS CASEAOS & & & & 0 & & $\mathrm{x}$ & $\mathrm{x}$ & $\mathrm{x}$ & $\mathrm{x}$ & \\
\hline 055 & 523 & 9 & e. & VENTA DE ARTCULOS DE RECUERDO & & 0 & 0 & $\mathrm{x}$ & $x$ & $\mathrm{x}$ & $\mathrm{x}$ & $x$ & $x$ & \\
\hline 055 & 523 & 99 & & VENTA DEARTCULOS DEPOFTINOS & & 0 & 0 & $\mathrm{x}$ & $x$ & $\mathrm{x}$ & $\mathrm{x}$ & $x$ & $x$ & \\
\hline $\begin{array}{l}05 \\
5\end{array}$ & 523 & 9 & & VENTA DE CONPUTAD ORAS Y SOFTMARES & & & & $\mathrm{x}$ & $x$ & $\mathrm{x}$ & $\mathrm{x}$ & $x$ & $x$ & \\
\hline 0 & 523 & 9 & & 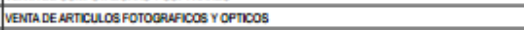 & & 0 & 0 & $x$ & $x$ & $\mathrm{x}$ & $x$ & $x$ & $x$ & \\
\hline 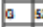 & 523 & 9 & te & VENTA DE PLWNTAS Y FLAES & & 0 & 0 & $\mathrm{x}$ & $x$ & $\mathrm{x}$ & $x$ & $x$ & $x$ & \\
\hline $\begin{array}{ll}0.5 \\
\end{array}$ & 523 & 9 & te & LERERUS & 0 & 0 & 0 & $\mathrm{x}$ & $\mathrm{x}$ & $\mathrm{x}$ & $x$ & $x$ & $x$ & \\
\hline 055 & 523 & 9 & ta & VENTA DE MATERWLES DE LWPEZZA & & & & $\mathrm{x}$ & $x$ & $\mathrm{x}$ & $\mathrm{x}$ & $\mathrm{x}$ & $x$ & \\
\hline 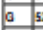 & 523 & 9 & & VENTA DE MATERHWLS Y EOUPO DE OFCNA & & & & $x$ & $x$ & $\mathrm{x}$ & $x$ & $x$ & $x$ & \\
\hline 0 & 523 & 9 & & VEENTA DE JUGUETES & & & & $x$ & $x$ & $\mathrm{x}$ & $x$ & $x$ & $x$ & \\
\hline 0 & 523 & 9 & & VENTA DE OTROS PROOUCTOS NO AUMENMICIOS, MONTURAS CE LENTES & & & & $x$ & $x$ & $\mathrm{x}$ & $x$ & $x$ & $x$ & \\
\hline \begin{tabular}{l|l}
0.5 & 5 \\
\end{tabular} & $52 \sqrt{3}$ & 9 & i. & RELOEERLS Y JORERLS & & 0 & 0 & $\mathrm{x}$ & $x$ & $\mathrm{x}$ & $x$ & $\mathrm{x}$ & $x$ & \\
\hline \begin{tabular}{|l|l}
0 & 5 \\
\end{tabular} & 523 & 99 & & IEFCERALS Y PASQNUNEFUS & & 0 & 0 & $\mathrm{x}$ & $x$ & $\mathrm{x}$ & $x$ & $x$ & $x$ & \\
\hline \begin{tabular}{|l|l}
0 & 5 \\
\end{tabular} & 523 & 99 & & VENTA DE PECES OFNUWENTALES & & & 0 & $\mathrm{x}$ & $x$ & $\mathrm{x}$ & $x$ & $x$ & $x$ & \\
\hline 05 & 523 & 9 & ti & VENTA DE GQS PAOPANO & & & & & $x$ & $x$ & $x$ & $x$ & $x$ & \\
\hline \begin{tabular}{l|l}
0 & 5 \\
\end{tabular} & 523 & 9 & & VEATAA DE RON DE CUEMAR YKEROSENE & & & & & $x$ & $\mathrm{x}$ & $x$ & $x$ & $x$ & \\
\hline \begin{tabular}{l|l}
0 & 5 \\
\end{tabular} & 523 & 9 & 1 & VENTA DE GICOCETRS & & & & $x$ & $x$ & $x$ & $x$ & $x$ & $x$ & \\
\hline $\begin{array}{ll}3 & 5 \\
\end{array}$ & $52 \sqrt{3}$ & 9 & & VENTA DE ARTCU OS APTESQNALES & & 0 & 0 & $x$ & $x$ & $\mathrm{x}$ & $x$ & $x$ & $x$ & \\
\hline \begin{tabular}{|l|l}
0 & 5 \\
\end{tabular} & $52 \sqrt{3}$ & 9 & & PLATERUS & & 0 & 0 & $x$ & $x$ & $x$ & $x$ & $x$ & $x$ & \\
\hline$a$ & 523 & 9 & & VERTA DE ARTCULOS REUGOSOSOS & & 0 & 0 & $\frac{x}{x}$ & $x$ & $\frac{x}{x}$ & $x$ & $\frac{x}{x}$ & $x$ & \\
\hline 0,5 & 523 & 9 & & VENTA DE ARTTCULOSDE PROTECMA & & & & & & & & & & \\
\hline a & 523 & 9 & 2 & VENTA DE DISFraces & & & & $x$ & $x$ & $\mathrm{x}$ & $x$ & $x$ & $x$ & \\
\hline \begin{tabular}{l|l}
0.5 \\
0
\end{tabular} & $52 \sqrt[3]{3} \quad x-30$ & 9 & & VEATIA DE BOLSLS & & & & $\mathrm{x}$ & $x$ & $\mathrm{x}$ & $x$ & $x$ & $x$ & \\
\hline \begin{tabular}{|l|l}
05 & 5 \\
&
\end{tabular} & 523 & 9 & 2 & VENTA DE HELO & & & & $\mathrm{x}$ & $x$ & $\mathrm{x}$ & $x$ & $x$ & $x$ & \\
\hline \begin{tabular}{|l|l}
05 & 5 \\
\end{tabular} & 523 & 9 & & VEATIA DE PLASTICOS & & & & $\mathrm{x}$ & $x$ & $\mathrm{x}$ & $x$ & $x$ & $x$ & \\
\hline $05_{5}$ & 523 & 9 & & VEENTA DE SPAPATOS TELEFONCOS & & & & $\frac{x}{x}$ & $x$ & $\frac{x}{x}$ & $x$ & $x$ & $x$ & \\
\hline 0,5 & 523 & 9 & & VENTA DE PAOOUCTOS ONEESOS, OOTLON, RIATEFRA & & 0 & 0 & $\mathrm{x}$ & $x$ & $\mathrm{x}$ & $x$ & $x$ & $x$ & \\
\hline 0.5 & 523 & 9 & 2 & Aanerius & & & & & & $x$ & $x$ & $x$ & $x$ & \\
\hline 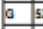 & 523 & 9 & & VENTA DE ALOFFONOS & & & & $\mathrm{x}$ & $x$ & $\mathrm{x}$ & $x$ & $x$ & $x$ & \\
\hline & 523 & 9 & & VENTA DE PAOCUCTOS VETERANAROS & & & & $x$ & $x$ & $x$ & $\mathrm{x}$ & $x$ & $\mathrm{x}$ & \\
\hline
\end{tabular}

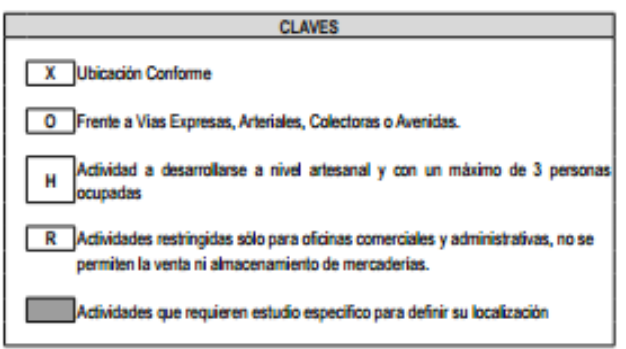

Fuente: http://www.ipdu.pe/ordenanzasyplanos/cononorte/cononorte-indice.pdf 


\subsubsection{Plano de alturas}

Las alturas de los edificios de la zona tienen como máximo 3 niveles. Alguno de estos no tienen ningún tipo de construcción y son usados para sembrar cultivos.

Figura 12. Gráfico de alturas

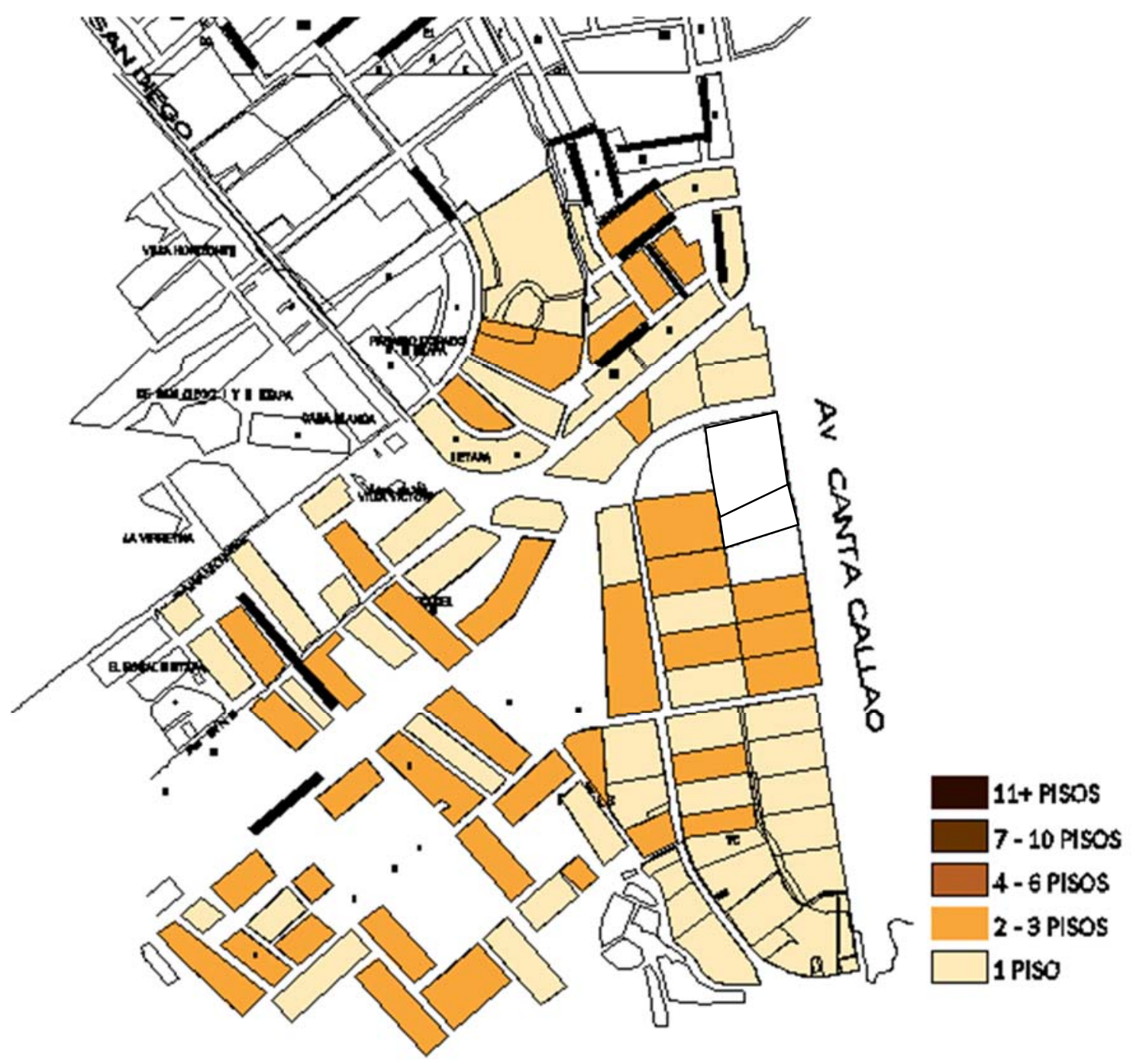

Fuente: Elaboración Propia 


\subsubsection{Secciones Viales}

Figura 13. Gráfico de secciones viales

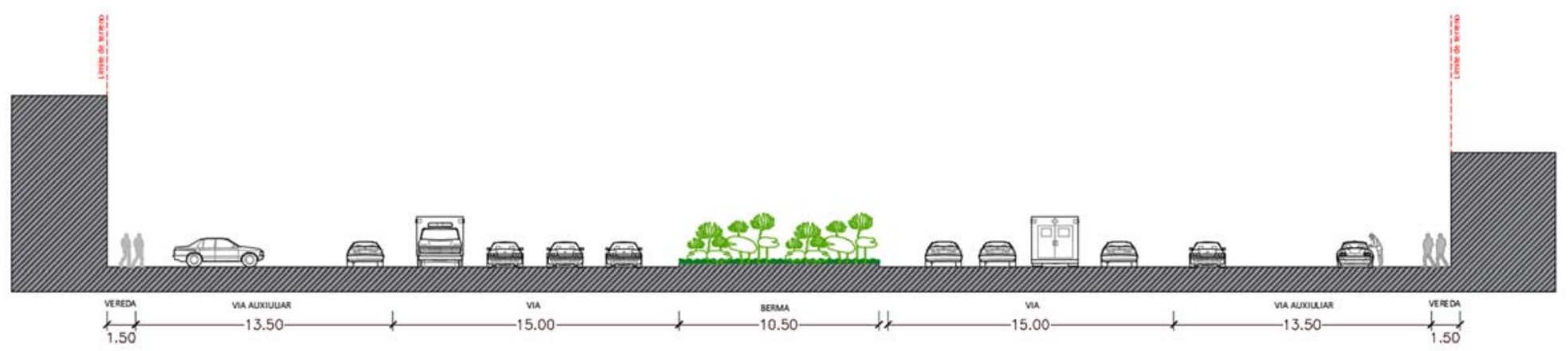

Av. Canta Callao

Fuente: Elaboración Propia

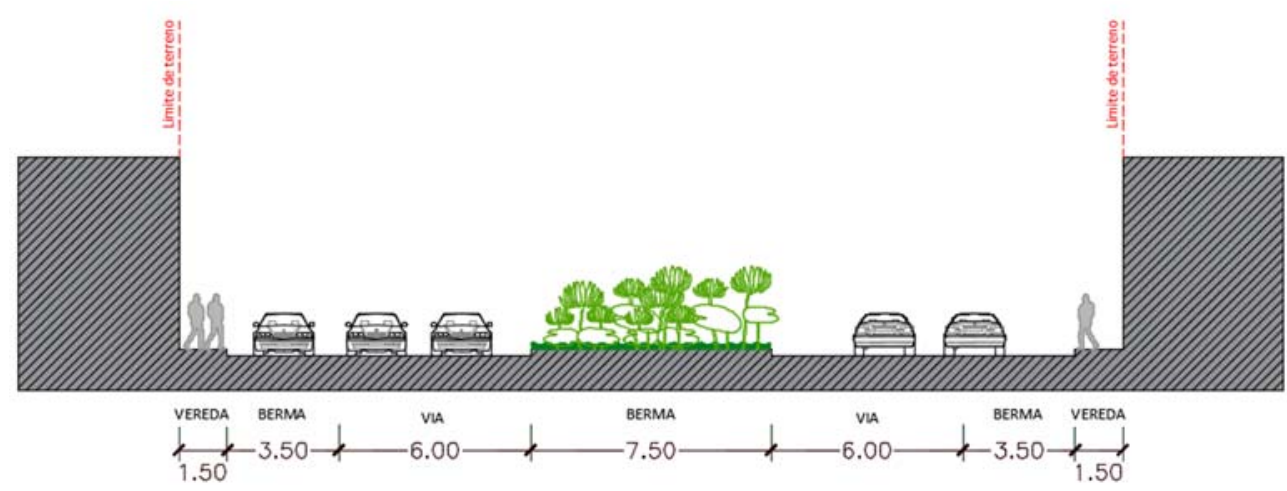

Av. Huáscar

Fuente: Elaboración Propia
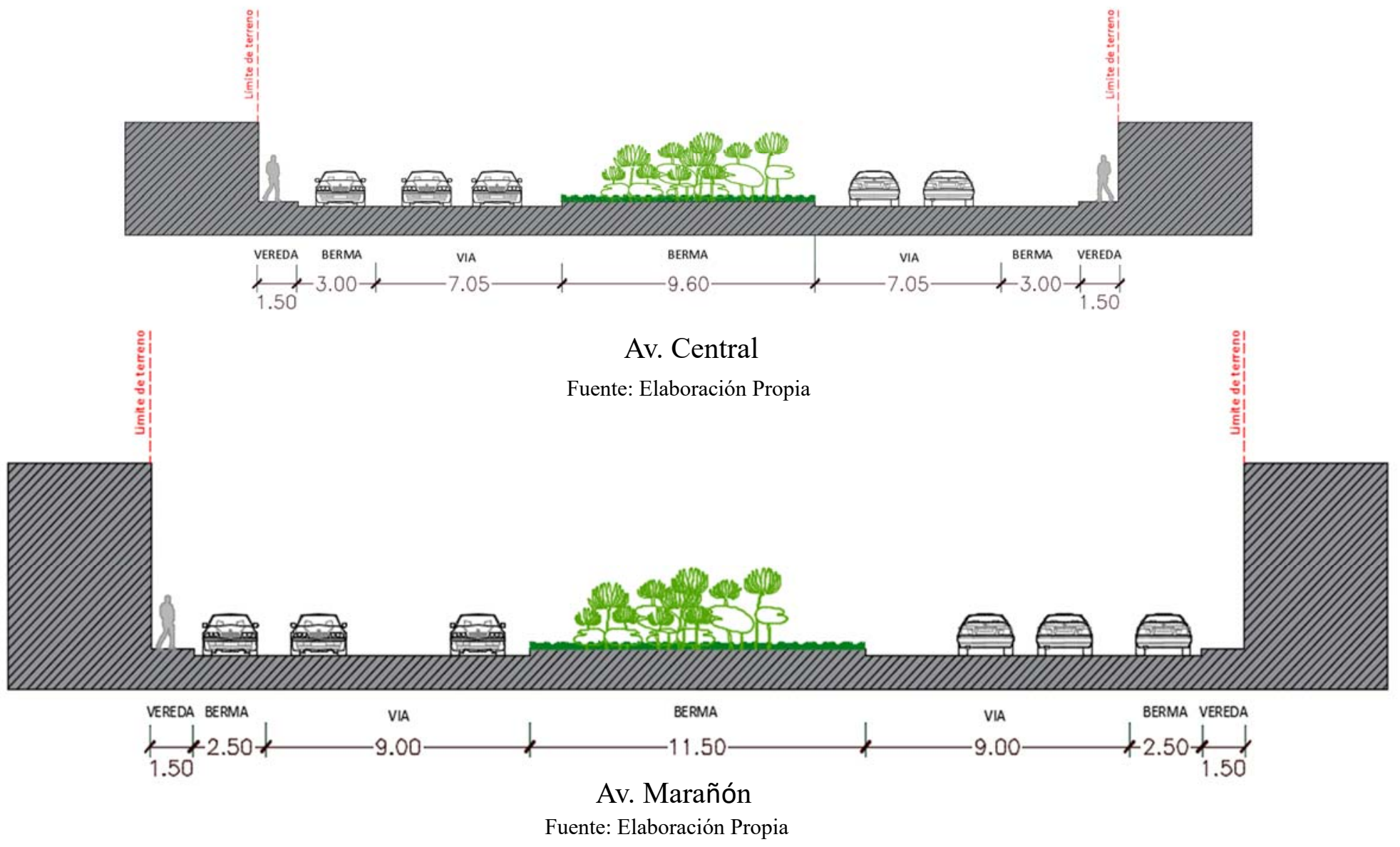


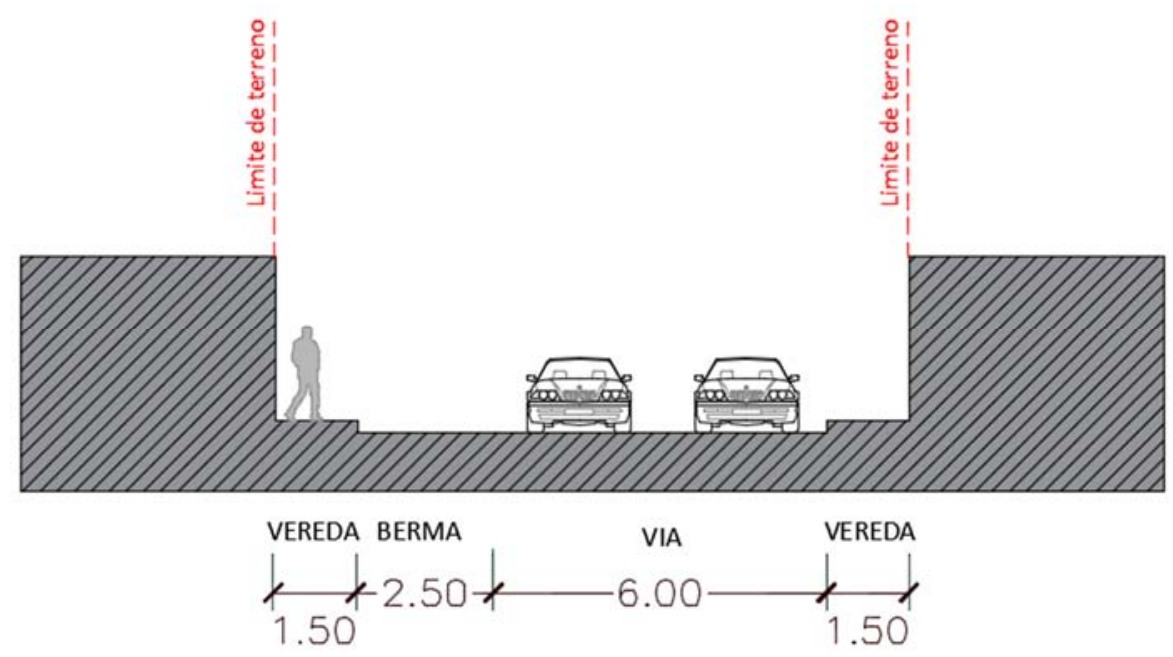

Calle local típica

Fuente: Elaboración Propia 


\subsection{Expediente urbano}

\subsubsection{Zonificación}

El terreno, ubicado en la Av. Canta Callao cruce con calle Huascar Mz. D lote 08 AAHH Horizonte del Naranjal, según el cuadro de zonificación tiene un uso comercio zonal (CZ) y de residencia de densidad media (RDM), ya que está entre los dos usos según el plano mostrado.

Figura 14.Gráfico de zonificación del terreno

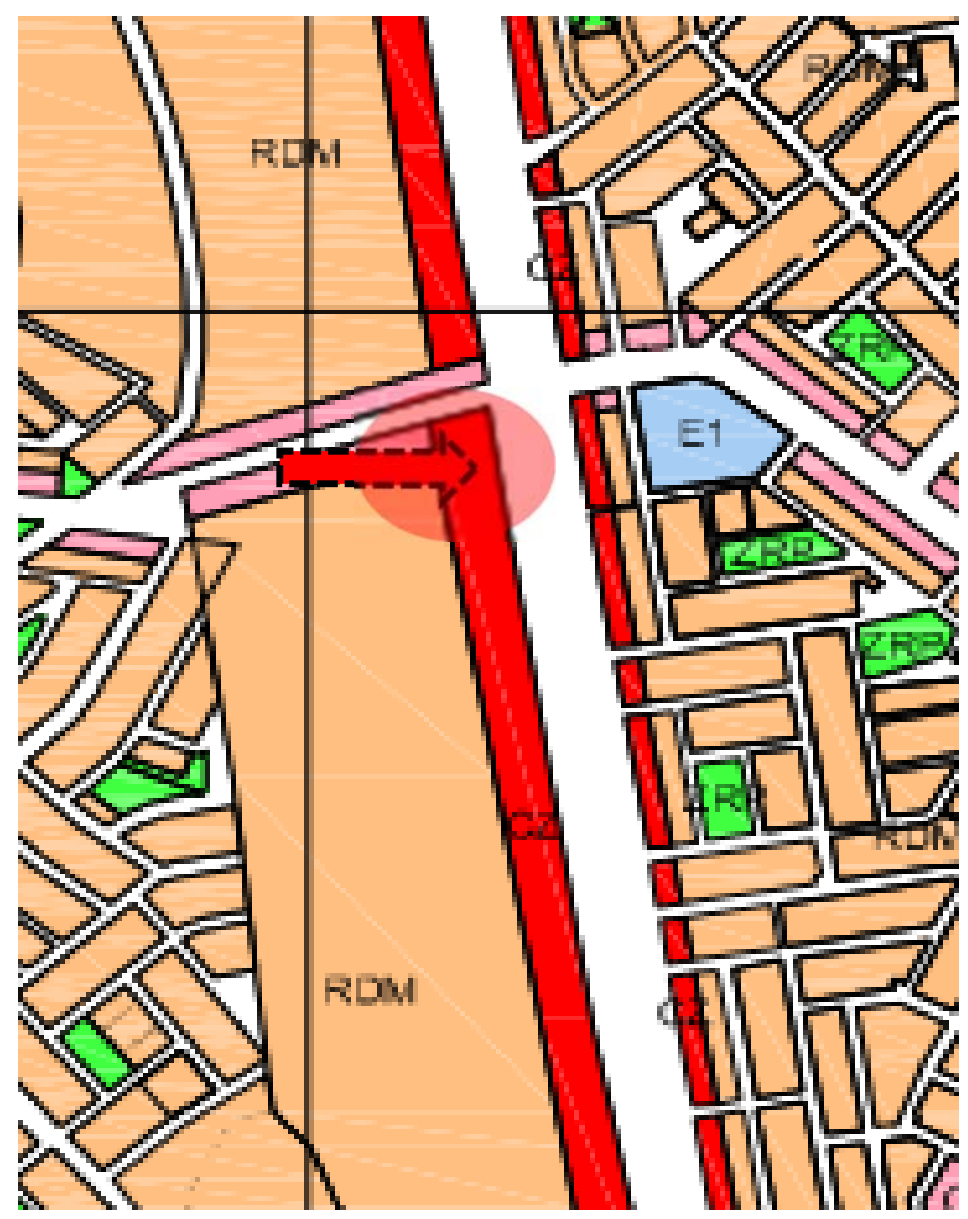

Fuente: Instituto Peruano de Derecho Urbanístico (IPEU) 


\subsubsection{Compatibilidad}

Según el cuadro de compatibilidad de usos, Un centro de rehabilitación es compatible con las residencias de densidad media (RDM) y el comercio zonal.

Tabla 4. Tabla de compatibilización del terreno con uso

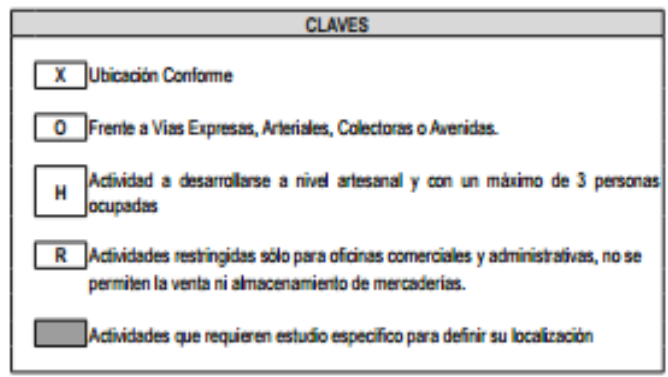

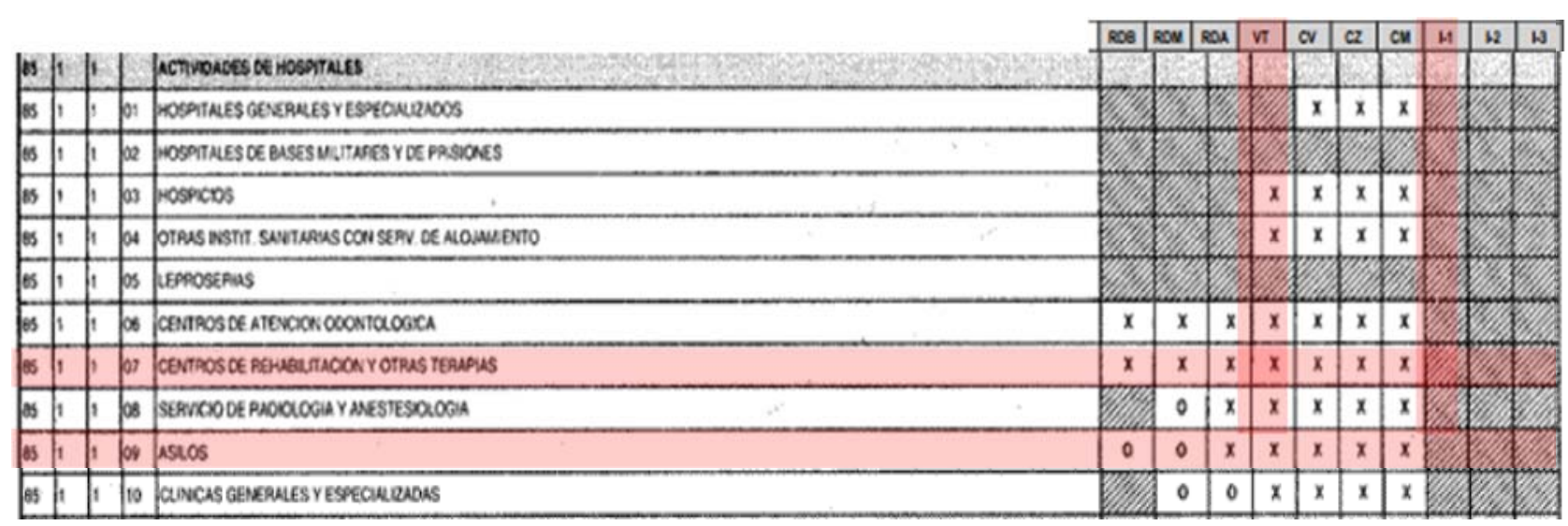

Fuente: http://www.ipdu.pe/ordenanzasyplanos/cononorte/cononorte-indice.pdf 


\subsubsection{Altura}

Los edificios aledaños tienen: por la izquierda, Terreno libre sin uso y por la derecha la calle Huascar.

Figura 15. Gráfico de alturas del sector

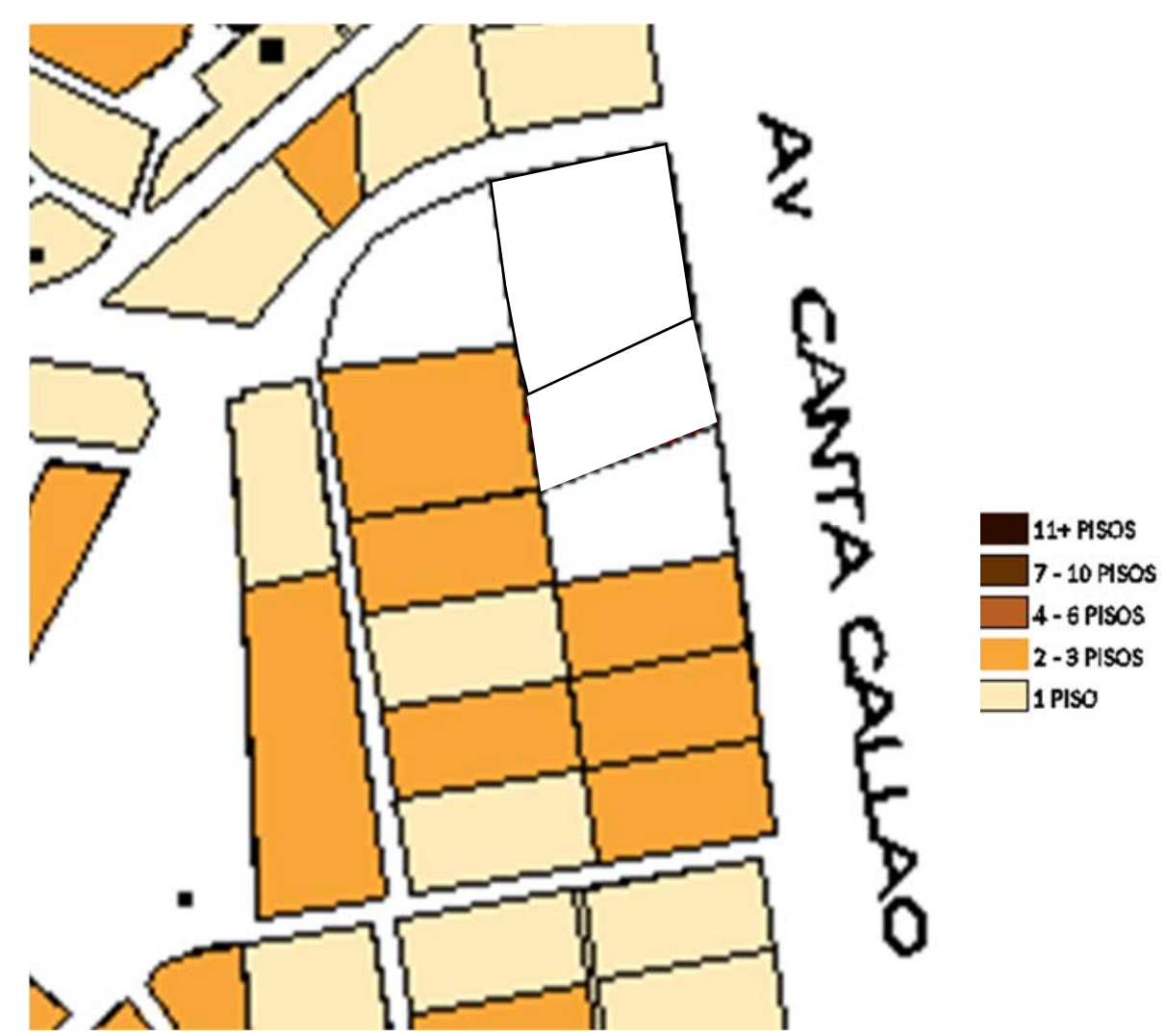

Fuente: Elaboración Propia 


\subsubsection{Levantamiento fotográfico}

Av. Canta Callao

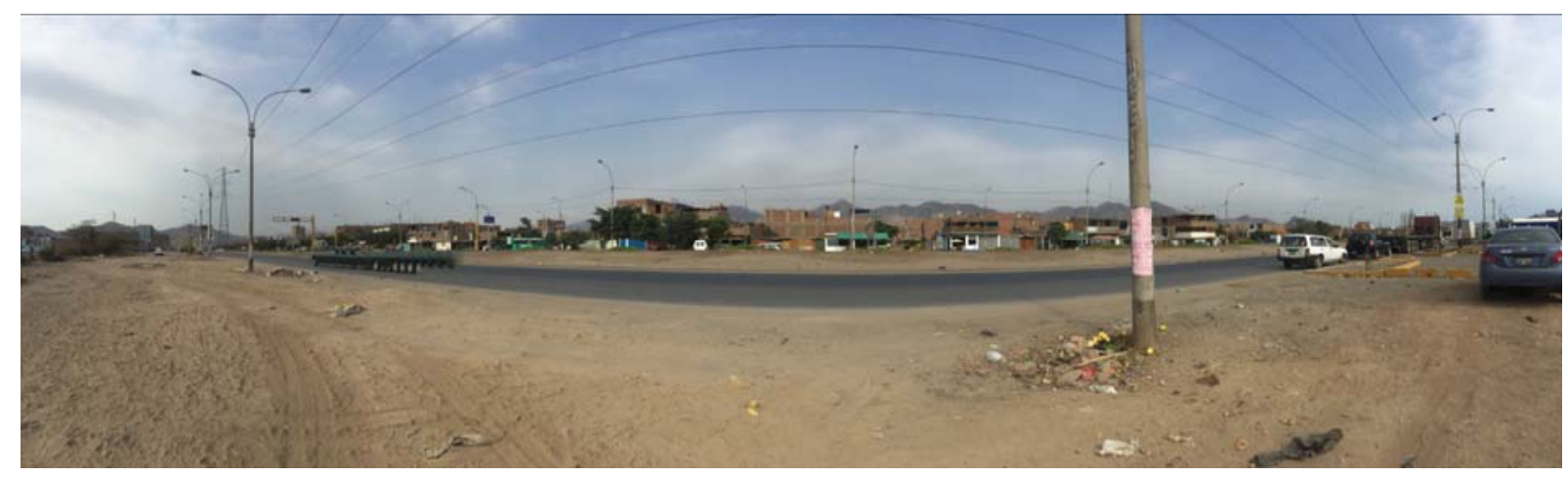

Fuente: Fotografía propia

Vista del terreno desde la Av. Canta Callao

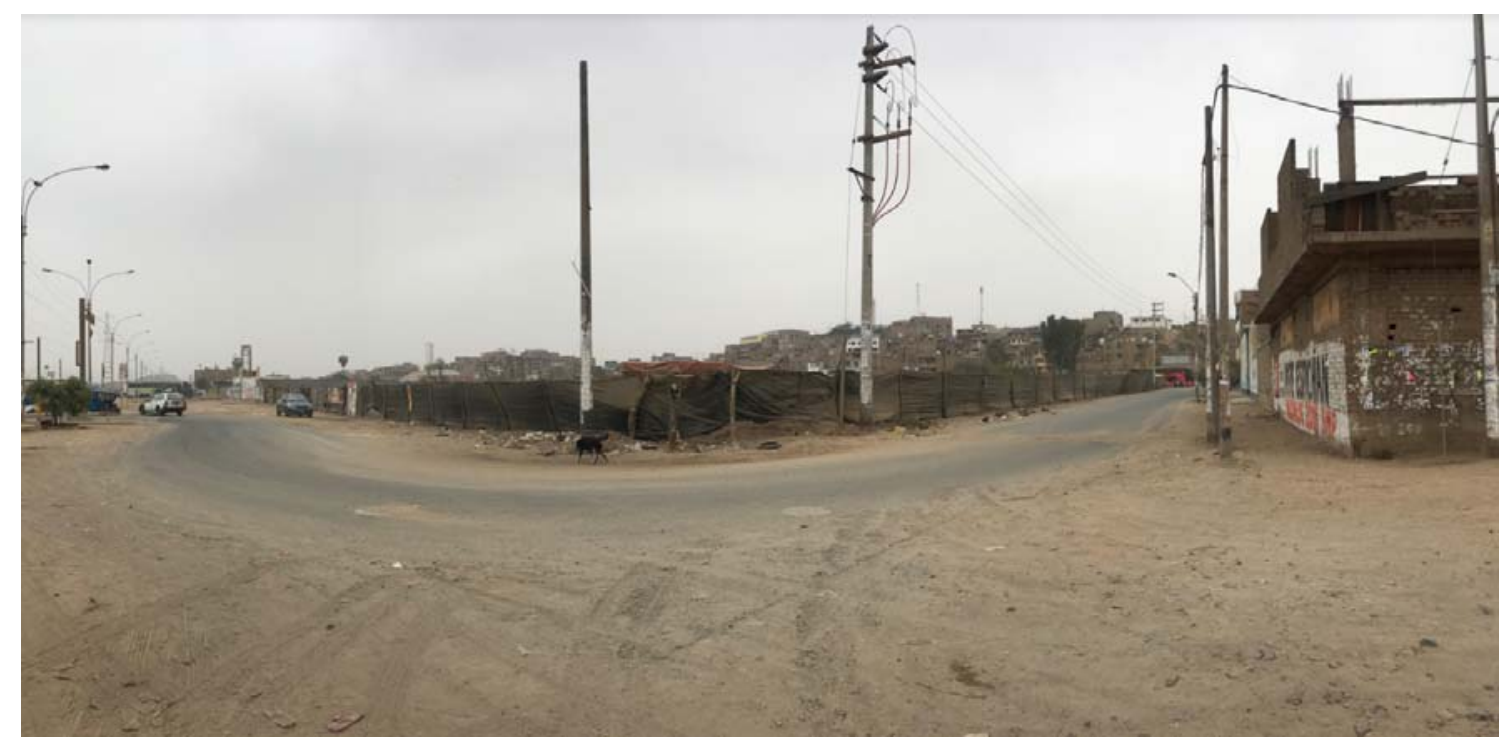

Fuente: Fotografía propia 


\section{Capítulo 5 : USUARIO}

\subsection{Aspecto Cualitativo}

Para poder analizar el usuario se tuvo en cuenta que existen dos tipos de estos: usuarios permanentes y usuarios temporales. En el caso de los usuarios permanentes, se encuentra todo el staff médico, el personal administrativo, el de servicio y los pacientes. Los usuarios temporales son las familias que acudirán al centro para recoger a los pacientes a la hora del cierre del edificio (4 pm.).

\subsubsection{Usuario Permanente}

- Pacientes

Los pacientes con la enfermedad de Alzheimer asistirán al Centro de día a partir de las 8 de la mañana, en donde se les realizará actividades para su rehabilitación y distintos servicios de atención médica. Además de obtener atención médica, podrán relacionarse con los demás pacientes, eso les ayudará mucho en su desarrollo y funcionará como una terapia más (lenguaje, comportamiento y actividades de la vida diaria). Para ello, se requiere estudiar a los tipos de pacientes que asistirán al lugar:

- Pacientes capacitados: Son capaces de realizar cualquier actividad sin ayuda ajena, pero necesitan de asistencias médica temporal.

- Pacientes discapacitados: No son capaces de realizar alguna o varias actividades y necesitan de una asistencia constante.

- También se debe conocer las fases de avance de esta enfermedad para saber qué tipo de terapia recibirán, ya que, una vez que esta esté muy avanzada, lo pacientes ya no podrán asistir al centro de día para ser rehabilitados.

- Etapa Inicial o Fase 1: Esta etapa es caracterizada por tener algunas pérdidas de memoria, se olvidan algunas cosas, pueden perderse, olvidar sus citas o nombres personales. Estás pérdidas de memoria pueden parecer comunes al inicio pero con el tiempo pueden interferir en el día a día de la persona. Además, se observan 
cambios de comportamiento y humor al darse cuenta que pierden el control sobre ellos mismos, mezclan ideas sin relación directa y tienen problemas para encontrar palabras.

- Etapa Intermedia o Fase 2: Esta es la fase en donde no hay duda alguna de su diagnóstico. Disminuye la memoria reciente y empiezan a producirse cambios de comportamiento. El paciente se vuelve más dependiente necesitando ayuda para las tareas básicas y alguna persona quien los supervise. Aún se pueden realizar conversaciones y rutinas superficiales; sin embargo, el lenguaje empieza verse afectado (repiten frases, olvidan palabras, pierden relación al tema de conversación). Además, sus movimientos empiezan a perder el equilibrio, tienen caídas espontáneas y necesitan ayuda para deambular.

- Etapa Avanzada o Fase 3: En esta última fase, el paciente depende por completo de otras personas. Empiezan a requerir ayuda con las tareas más básicas: comer, limpiarse y moverse, no reconocen a los familiares o amigos, comportamientos infantiles, tienen comportamientos agresivos, no controlan esfínteres, desnutrición y presentan heridas por inmovilización. Estas, son las principales causas de la muerte de estos pacientes y pueden llegar a vivir entre 8 y 10 años tras el diagnóstico. (Fundación Reina Sofía, 2007)

\section{- Staff Médico}

Dentro de este grupo se encuentra el cuerpo médico, es decir, los doctores, enfermeros técnicos, etc. Que se encargan de atender a los pacientes. Los médicos deben ser especialistas en la enfermedad de Alzheimer para poder atender en los consultorios a los pacientes y poder asignar las terapias correspondientes al afectado. Por otro lado, se encargan de evaluar a los pacientes hospitalizados. Las enfermeras tomarás las medidas correspondientes según el diagnóstico del médico. Se tienen los siguientes tipos de profesionales en un centro de Alzheimer (Fundación Reina Sofía, 2007): 
- Médico especialista

- Auxiliar de terapias

- Licenciado en enfermería

- Psicólogo

- Terapista

- Personal Administrativo

Está conformado por las personas que encargan de atender a los familiares de los pacientes quienes vienen a inscribirlos para las terapias de rehabilitación: administradores, director, secretarias y recepcionistas.

\section{- Personal de Servicio}

En este grupo de personas, se encuentran los que ayudarán con el mantenimiento del centro como el personal de cocina, de jardinería, limpieza y mantenimiento.

\subsubsection{Usuario Temporal}

- Familiares

Cumplen un rol importante en la vida del paciente con el mal de Alzheimer. Es un nexo que posee el paciente con el exterior por más que algunos de ellos aún puedan desarrollar actividades por si solos. Los familiares deben recibir charlas con especialistas, brindadas en el SUM, para que puedan aprender sobre la enfermedad y poder ser parte del tratamiento en casa, ya que es importante que aprendan cómo relacionarse con el paciente y cómo pueden afrontar los problemas que se puedan dar por el familiar durante el tratamiento. 


\subsection{Aspecto Cuantitativo}

Para poder determinar la cantidad de personas que asistirán al centro de día, se debe empezar analizando la cantidad de adultos mayores, ya que ellos son mayormente quienes presentan este mal, que tiene el distrito de San Martín de Porres y el aforo a base de encuestas realizadas en los proyectos referenciales de Lima.

El distrito de San Martín de Porres, según los datos de la INEI, cuenta con $10.3 \%$ de población adulta en Lima Norte como lo muestra el siguiente gráfico.

Figura 16. Población adulta el Lima norte
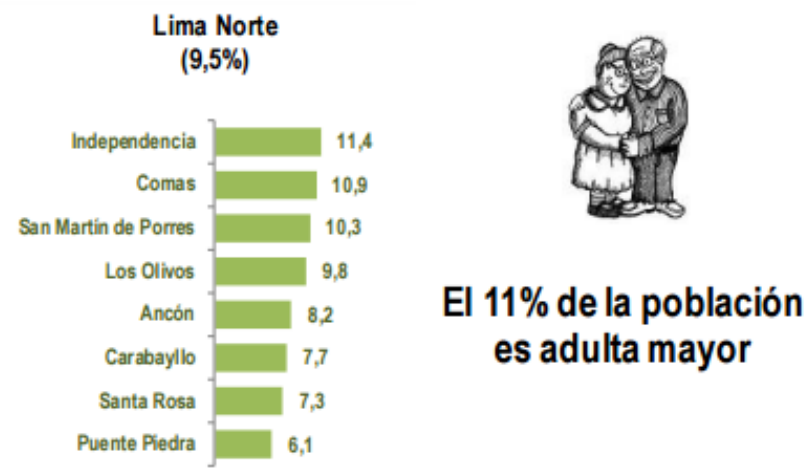

Fuente: Instituto Nacional de Estadística e Informática, Proyecciones de Población por Distritos, 2014

Actualmente, se tiene una cantidad aproximada de 618759 habitantes adultos mayores. Por otro lado, sacando los cálculos necesarios para poder determinar el número de adultos mayores dentro de 15 años, se obtuvo el resultado de 914023 ancianos.

Distintos estudios epidemiológicos sugieren que alrededor de un 5\% de la población adulta mayor actual sufre de esta demencia y que aumenta en unos años a 8\%. (Kay y Bergmann, 1980). 
Tabla 5. Población total según año, sexo y grupos de edad 2020 - 2050

\begin{tabular}{|c|c|c|c|c|c|c|c|}
\hline PERU: PO & CION TOT & L $30 \mathrm{DE}$ & $\begin{array}{r}\text { Cuadro } \\
\text { DE CADA } \\
\text { HIPOTESIS }\end{array}$ & $\begin{array}{l}27 \\
\text { I0, SEGÚ } \\
\text { AEDIA }\end{array}$ & $O Y G R$ & E EDA & D-2050 \\
\hline & & & & & & & Conclusión \\
\hline SEXO Y GRUPOS & & & POBLA & DN AL 30 DE & & & \\
\hline DE EDAD & 2020 & 2025 & 2030 & 2035 & 2040 & 2045 & 2050 \\
\hline TOTAL & 33923224 & 35725458 & 37463580 & 39067037 & 40501750 & 41747214 & 42811226 \\
\hline 0.4 & 2902465 & 2842289 & 2888612 & 2900387 & 2888860 & 2867800 & 2853762 \\
\hline 5.9 & 2902688 & 2873597 & 2817220 & 2865179 & 2878816 & 2869179 & 2849934 \\
\hline $10-14$ & 2909456 & 2890825 & 2863877 & 2808255 & 2856689 & 2870860 & 2861761 \\
\hline $15-19$ & 2916379 & 2898197 & 2881673 & 2855307 & 2800301 & 2849125 & 2863718 \\
\hline $20-24$ & 2956682 & 2898922 & 2884180 & 2868481 & 2842930 & 2788776 & 2838113 \\
\hline $25-29$ & 2914865 & 2933682 & 2880439 & 2866762 & 2852081 & 2827532 & 2774391 \\
\hline $30-34$ & 2709094 & 2889328 & 2912103 & 2860307 & 2847793 & 2834201 & 2810717 \\
\hline $35-39$ & 2478648 & 2683284 & 2865002 & 2888964 & 2838821 & 2827584 & 2815226 \\
\hline $40-44$ & 2316005 & 2448443 & 2653683 & 2835185 & 2860519 & 2812334 & 2802620 \\
\hline $45-49$ & 2018095 & 2278804 & 2411838 & 2616095 & 2797171 & 2824117 & 2778328 \\
\hline 50.54 & 1744674 & 1972491 & 2230422 & 2363097 & 2565832 & 2746054 & 2774940 \\
\hline 55.59 & 1489573 & 1686969 & 1910694 & 2163824 & 2295820 & 2496126 & 2674829 \\
\hline 60.64 & 1189563 & 1416096 & 1607745 & 1824931 & 2071095 & 2201710 & 2398224 \\
\hline 65.69 & 919538 & 1100208 & 1314426 & 1497300 & 1705008 & 1940851 & 2069014 \\
\hline 70.74 & 659000 & 814876 & 980318 & 1177088 & 1347452 & 1541329 & 1762065 \\
\hline 75.79 & 447378 & 549250 & 684529 & 829515 & 1002891 & 1155509 & 1329666 \\
\hline $80+$ & 449121 & 548197 & 676819 & 846360 & 1049671 & 1294127 & 1553918 \\
\hline
\end{tabular}

Fuente:

http://www.inei.gob.pe/media/MenuRecursivo/publicaciones_digitales/Est/Lib0466/Libro.pdfhttp://www.inei.go b.pe/media/MenuRecursivo/publicaciones_digitales/Est/Lib0466/Libro.pdf

Tabla 6. Tabla de incidencia proyectada en 15 años

\begin{tabular}{|l|l|l|l|}
\hline & 65 años a más & $\%$ de incidencia & $\begin{array}{l}\text { Incidencia de la } \\
\text { enfermedad de } \\
\text { Alzheimer }\end{array}$ \\
\hline 2015 & 678759 & 5 & 33937 \\
\hline 2030 & 914023 & 8 & 73121 \\
\hline
\end{tabular}

Fuente imagen: Elaboración Propia

Por otro lado, se realizaron encuestas para saber el número de pacientes que asisten a estos centros que existen actualmente en nuestro país, siendo el referente mas cercano de un « centro de rehabilitación » y teniendo en cuenta que el $70 \%$ va acompañado de sus familiares y esperan por las terapias, obteniendo los siguientes resultados: 
Tabla 7. Tabla de personas asistentes a los centros de rehabilitación actuales

\begin{tabular}{|l|l|l|l|}
\hline $\begin{array}{l}\text { Instituto Nacional } \\
\text { de Ciencias }\end{array}$ & Pacientes & Familiares & \\
Neurológicas & $\mathbf{3 1 5}$ Personas & $\mathbf{1 5}$ Personas & $\mathbf{3 3 0}$ Personas \\
(INCN) & & & \\
\hline $\begin{array}{l}\text { El Instituto de la } \\
\text { Memoria } \\
\text { (IMEDER) }\end{array}$ & $\mathbf{2 9}$ Personas & $\mathbf{1 1 3}$ Personas \\
\hline $\begin{array}{l}\text { La Asociación } \\
\text { Peruana de } \\
\text { Enfermedad de } \\
\text { Alzheimer y otras } \\
\text { Demencias } \\
\text { (APEAD) }\end{array}$ & $\mathbf{5 6}$ Personas & $\mathbf{2 3}$ Personas & $\mathbf{7 9}$ Personas \\
\hline $\begin{array}{l}\text { Honorio Delgado } \\
\text { Hideyo - Noguchi }\end{array}$ & $\mathbf{1 5 0}$ Personas & $\mathbf{3 0}$ Personas & $\mathbf{1 8 0}$ Personas \\
\hline
\end{tabular}

Fuente imagen: Elaboración Propia

Figura 17. Gráfico de asistentes al Instituto Nacional de Ciencias Neurológicas

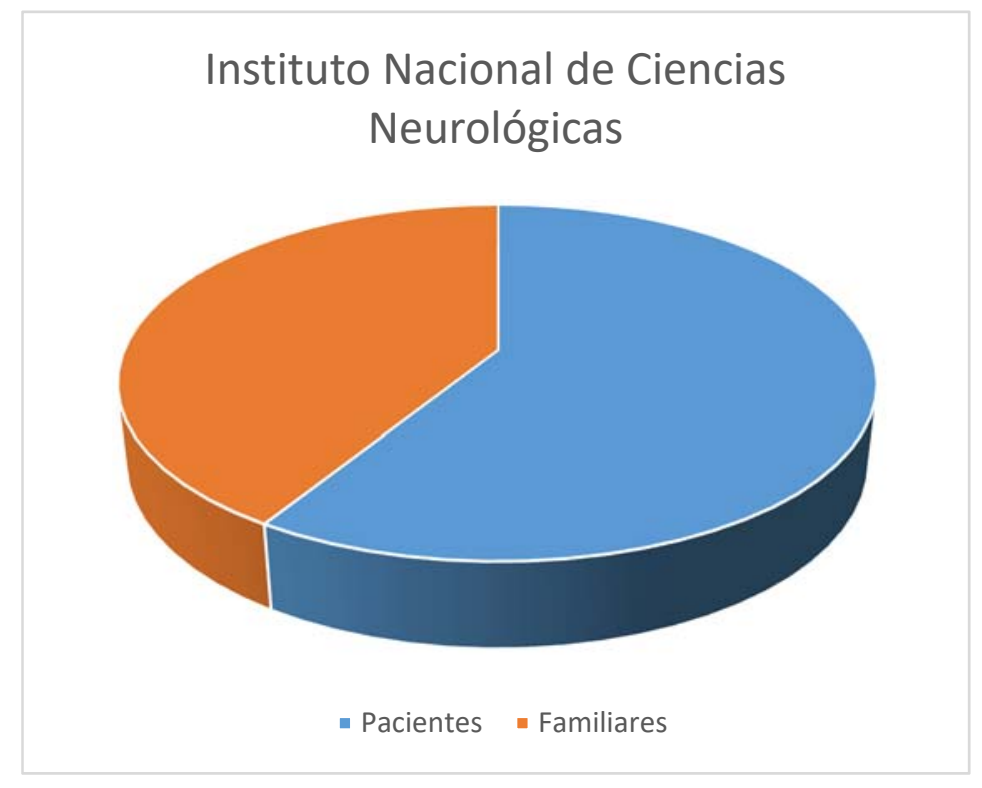

$\underline{\text { Staff de médico y de servicio }}$

Mantenimiento: 2

Limpieza: 3

Recepción: 2

Administración: 7

Fisioterapeuta: 2

Neurólogo: 4

Fuente imagen: Elaboración Propia 
Figura 18. Gráfico de asistentes al Instituto de la Memoria

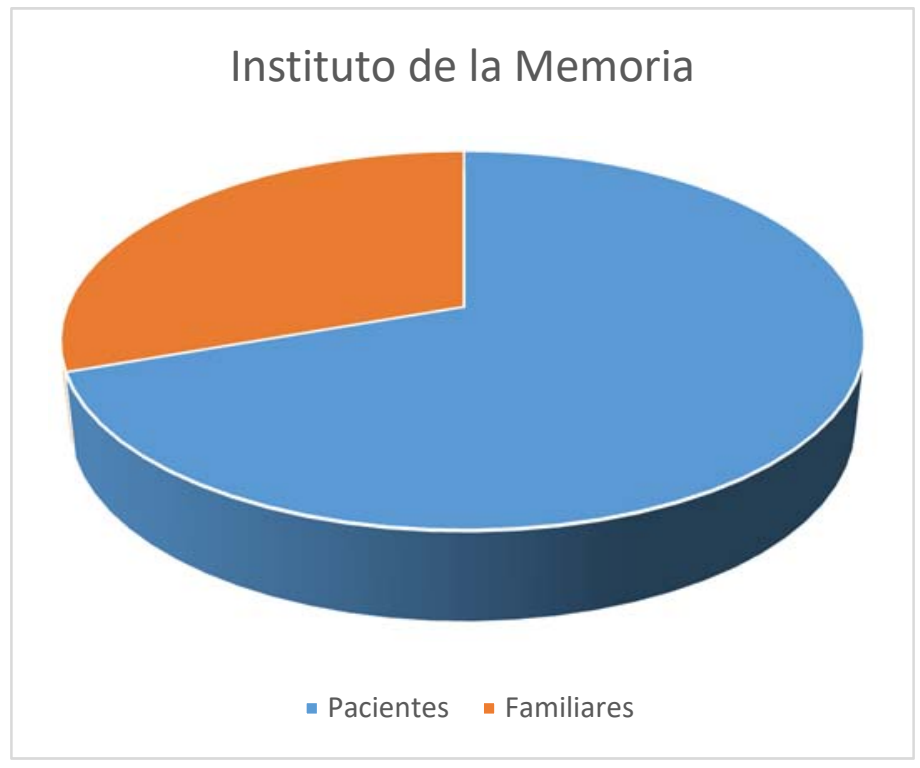

Staff de servicio y médico

Mantenimiento: 3

Limpieza: 3

Recepción: 3

Director: 1

Administración: 8

Terapeuta ocupacional: 2

Fisioterapeuta: 3

Fuente imagen: Elaboración Propia

Figura 19. Gráfico de asistentes a la Asociación Peruana de Alzheimer y otras Demencias

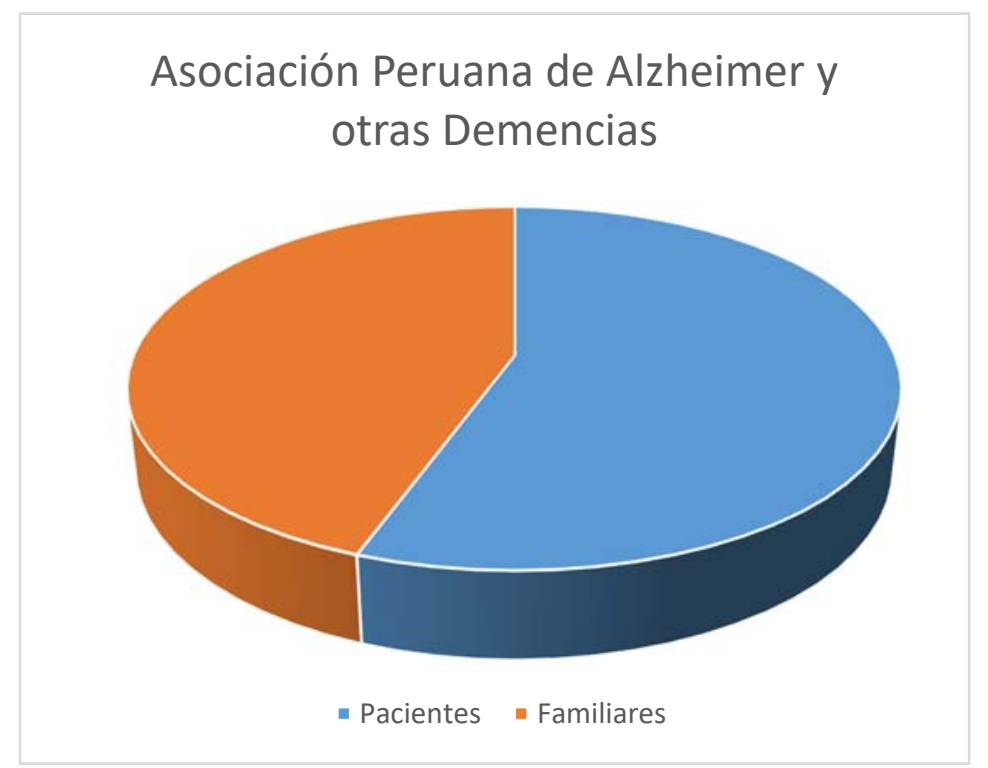

\section{Staff de servicio y médico}

Limpieza: 2

Recepción: 3

Director: 1

Administración: 7

Terapeuta ocupacional: 3

Fuente imagen: Elaboración Propia 
Tabla 8. Tabla de centros actuales de personas con de

Neurológicas Ciencias (INCN)

El Instituto de la Memoria (IMEDER) La Asociación Peruana de Enfermedad de Alzheimer y otras Demencias (APEAD)
Aforo total por rehabilitación para Alzheimer.

Además, los referentes nos llevan a la conclusión que los centros de Alzheimer necesitan un equipo integrado por 79 personas divididas en las siguientes categorías profesionales que deberán ser supervisadas y coordinadas por el equipo de dirección del centro:

- Neurólogo: 3

- Enfermeros: 15 (1c/3 pacientes + jefe $)$

- Psicólogo: 3

- Terapeuta ocupacional: 9

- Fisioterapeuta: 3 
En cuanto el personal de servicio y administrativo, se llegó a la conclusión que se necesitan los siguientes:

- Área de cocina: 5

- Control: 3

- Mantenimiento (lavandería y mantenimiento general) : 5

- Limpieza: 4

- Recepción: 4

- Informes: 4

- Dirección y sub dirección: 3

- Recursos humanos: 1

- Oficina marketing: 3

- Servicio social: 2

- Unidad de investigación : 7

- Personal logística: 5

Se elaboró un análisis para para poder determinar el número de usuarios que asistirán al centro de día. Actualmente existen 125515 habitantes en el norte de Lima de los cuales el 5\% de la población son adultos mayores con el mal de Alzheimer, por lo que se tiene la cantidad de 6276 afectados. Por otro lado, al ya existir un centro en el SMP, Instituto Nacional de Salud Mental "Honorio Delgado Hideyo - Noguchi", la mitad de la población se atenderá en el nuevo centro siento un total 3138 pacientes. Según estudios del centro ya existente, el 7\% de los afectados reciben tratamiento de la enfermedad, es decir, el nuevo centro tendrá una capacidad de 220 pacientes.Por último, el $8 \%$ de los afectados se encuentran en la fase crítica y requerirán del alojamiento temporal siendo 18 adultos mayores. 
Tabla 9. Pacientes asistentes al centro con demencia de Alzheimer

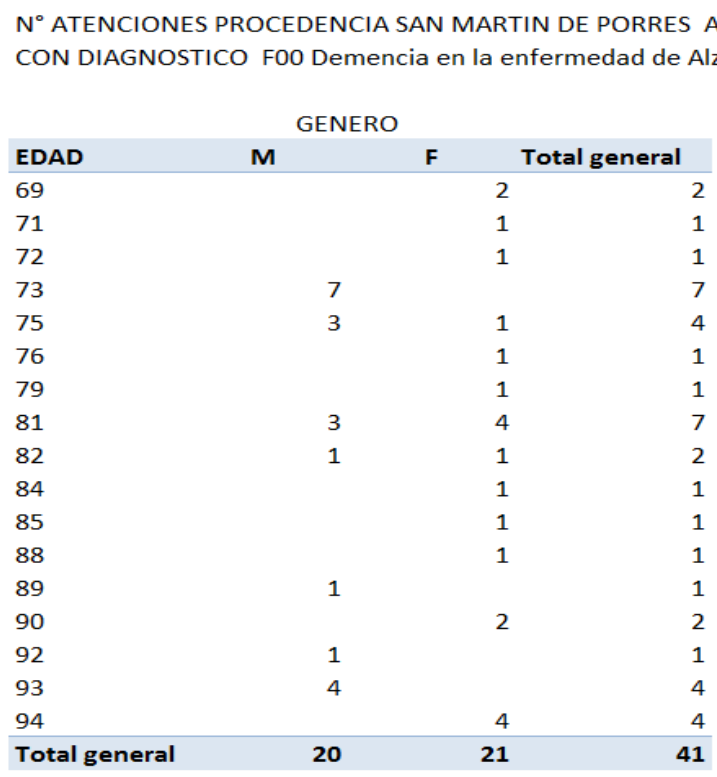

Fuente : Instituto Nacional de Salud Mental « Honorio Delgado - Hideyo Noguchi »

Tabla 10. Pacientes atendidos de fase crítica de Alzheimer en San Martín de Porres N ATENDIDOS FASE CRÍTICA PROCEDENCIA SAN MARTIN DE PORRES AÑO 2016
CON DIAGNOSTICO FO0 Demencia en la enfermedad de Alzheimer

\begin{tabular}{lccr}
\multicolumn{2}{c}{ GENERO } \\
EDAD & M & F & Total general \\
\hline 69 & & 1 & 1 \\
71 & & 1 & 1 \\
73 & 3 & & 3 \\
75 & 1 & 1 & 2 \\
76 & & 1 & 1 \\
79 & & 1 & 1 \\
81 & 1 & 4 & 5 \\
85 & & 1 & 1 \\
88 & & 1 & 1 \\
89 & 1 & & 1 \\
92 & 1 & & 1 \\
94 & & 1 & 1 \\
\hline Total general & $\mathbf{7}$ & $\mathbf{1 2}$ & $\mathbf{1 9}$
\end{tabular}

Fuente : Instituto Nacional de Salud Mental « Honorio Delgado - Hideyo Noguchi » 
Tabla 11. Tabla de características por tipo de terapias

\begin{tabular}{|c|c|c|c|c|c|}
\hline & Fisioterapeuta & Terapeuta & Grupal & Individual & Ambiente \\
\hline $\begin{array}{c}\text { Estimulación sensorial } \\
\text { Snozelen }\end{array}$ & & $\checkmark$ & & $\checkmark$ & Sala de terapias \\
\hline $\begin{array}{c}\text { Estimulación psicomotriz } \\
\text { (gimnasio) }\end{array}$ & $\checkmark$ & & $\checkmark$ & & Sala de terapias \\
\hline Masaje y acupuntura & $\checkmark$ & & & $\checkmark$ & Sala de terapias \\
\hline $\begin{array}{c}\text { Programa de educación } \\
\text { integral }\end{array}$ & & $\checkmark$ & $\checkmark$ & & Sala de terapias \\
\hline $\begin{array}{c}\text { Wiiterapia, musicoterapia y } \\
\text { danza terapeutica }\end{array}$ & & $\checkmark$ & $\checkmark$ & & Sala de terapias \\
\hline Fisioterapia Respiratoria & & $\checkmark$ & $\checkmark$ & & Sala de terapias \\
\hline Psicoestimulación cognitiva & & $\checkmark$ & $\checkmark$ & & Sala de terapias \\
\hline PACID & & $\checkmark$ & $\checkmark$ & & Sala de terapias \\
\hline $\begin{array}{c}\text { Arteterapia, laborterapia y } \\
\text { reminiscencia }\end{array}$ & & $\checkmark$ & $\checkmark$ & & Sala de terapias \\
\hline Terapia con animales & & $\checkmark$ & $\checkmark$ & & Sala de terapias \\
\hline Relajación & $\checkmark$ & $\checkmark$ & $\checkmark$ & & Sala de terapias \\
\hline Paseos al aire libre & - & - & $\checkmark$ & & $\begin{array}{c}\text { Patio e } \\
\text { invernadero }\end{array}$ \\
\hline
\end{tabular}

Fuente imagen: Elaboración Propia 


\subsection{Fluxograma}

- Pacientes de la clínica de día

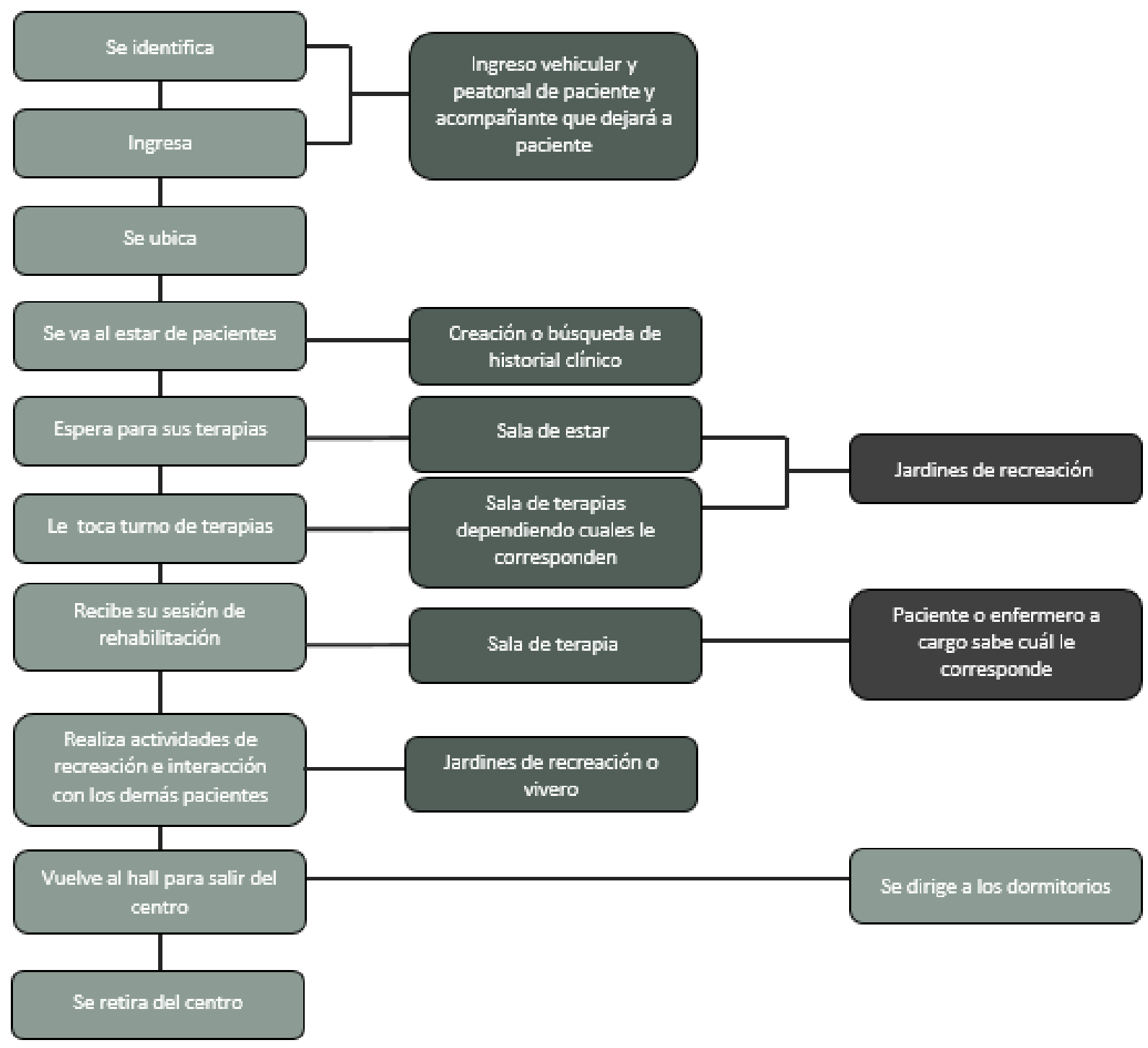

Fuente imagen: Elaboración Propia 
- Médico especialista

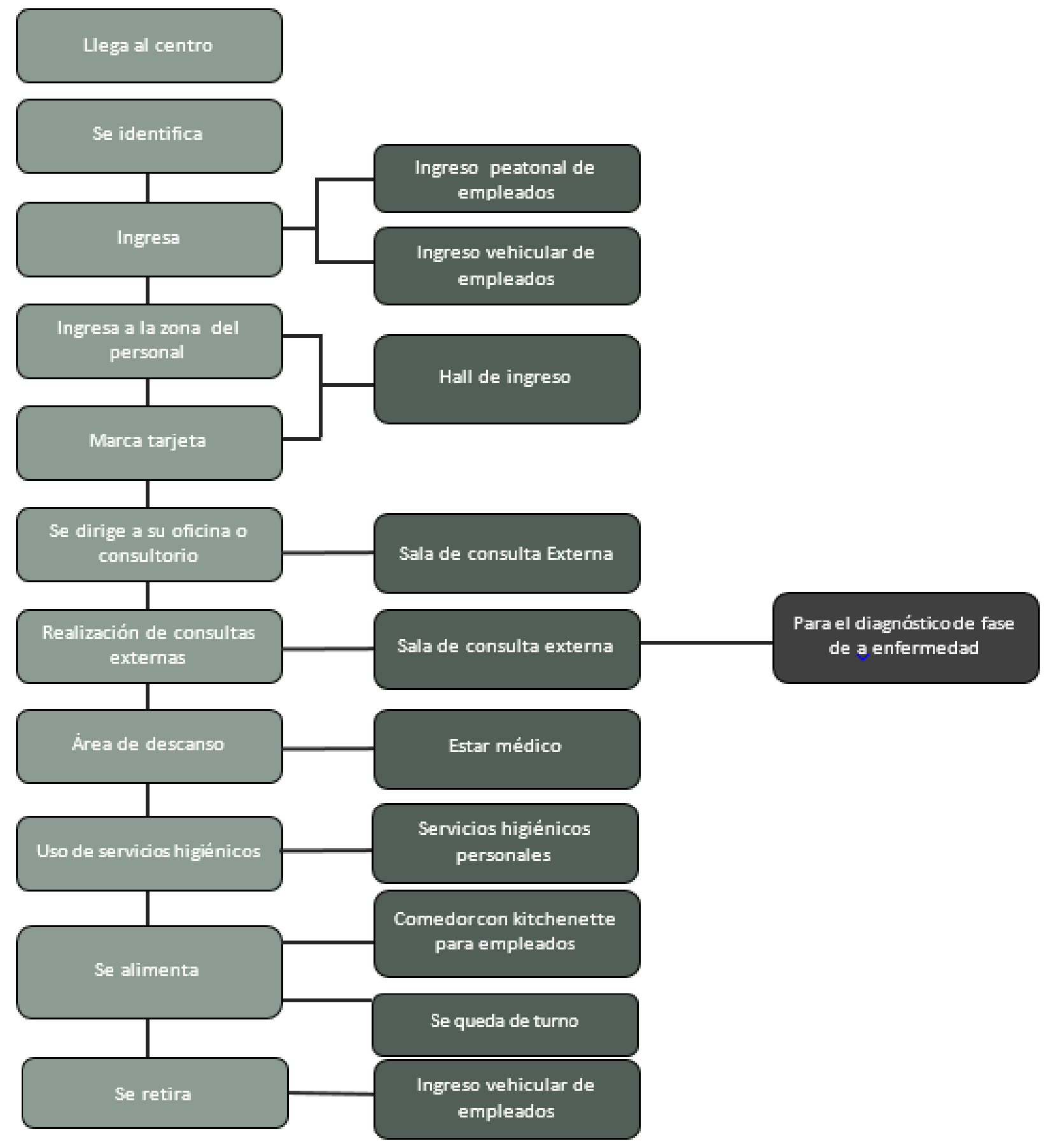

Fuente imagen: Elaboración Propia 
- Terapista 


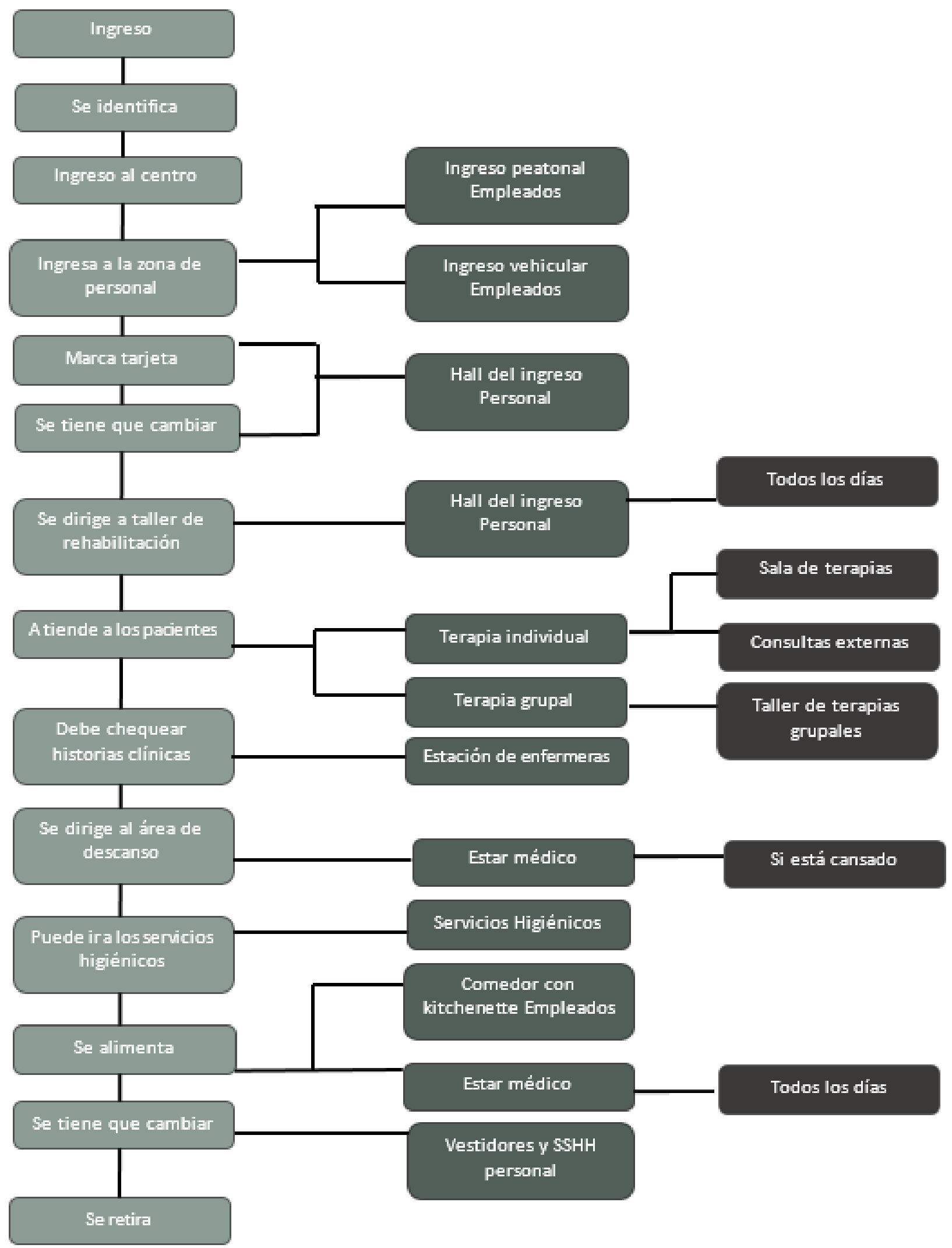

Fuente imagen: Elaboración Propia

- Enfermero 


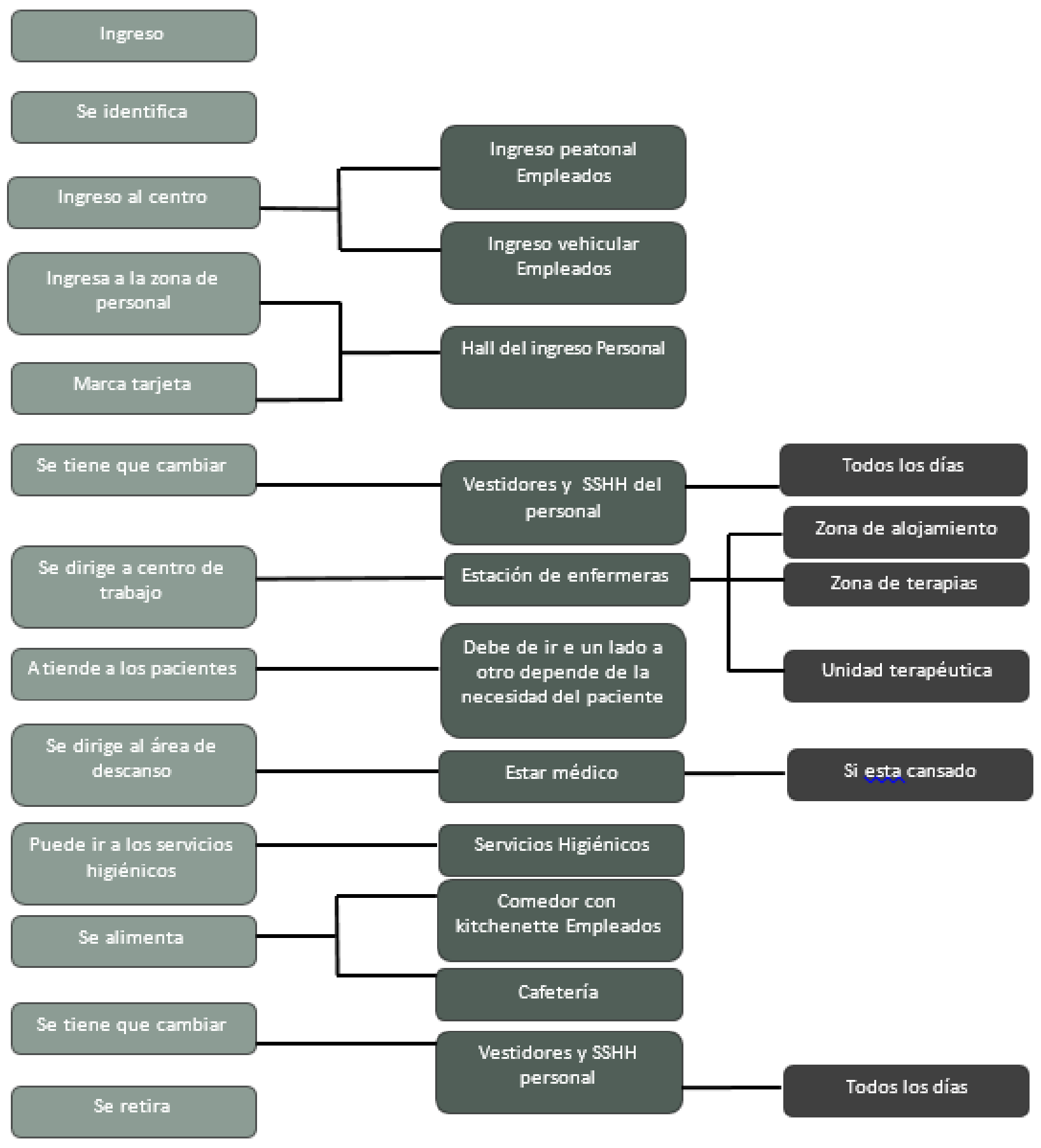

Fuente imagen: Elaboración Propia

- Licenciado en psicología 


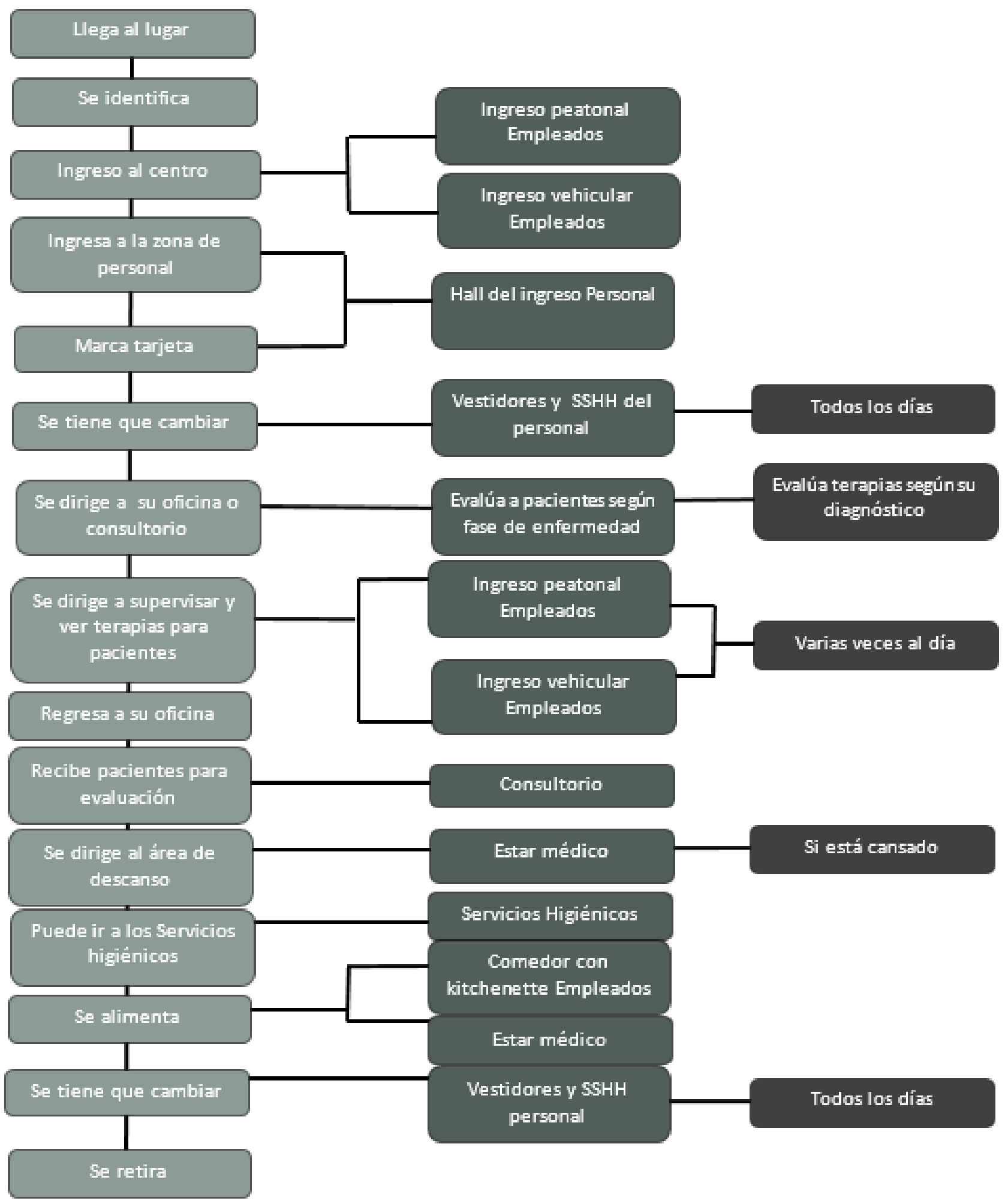

Fuente imagen: Elaboración Propia

- Personal administrativo 


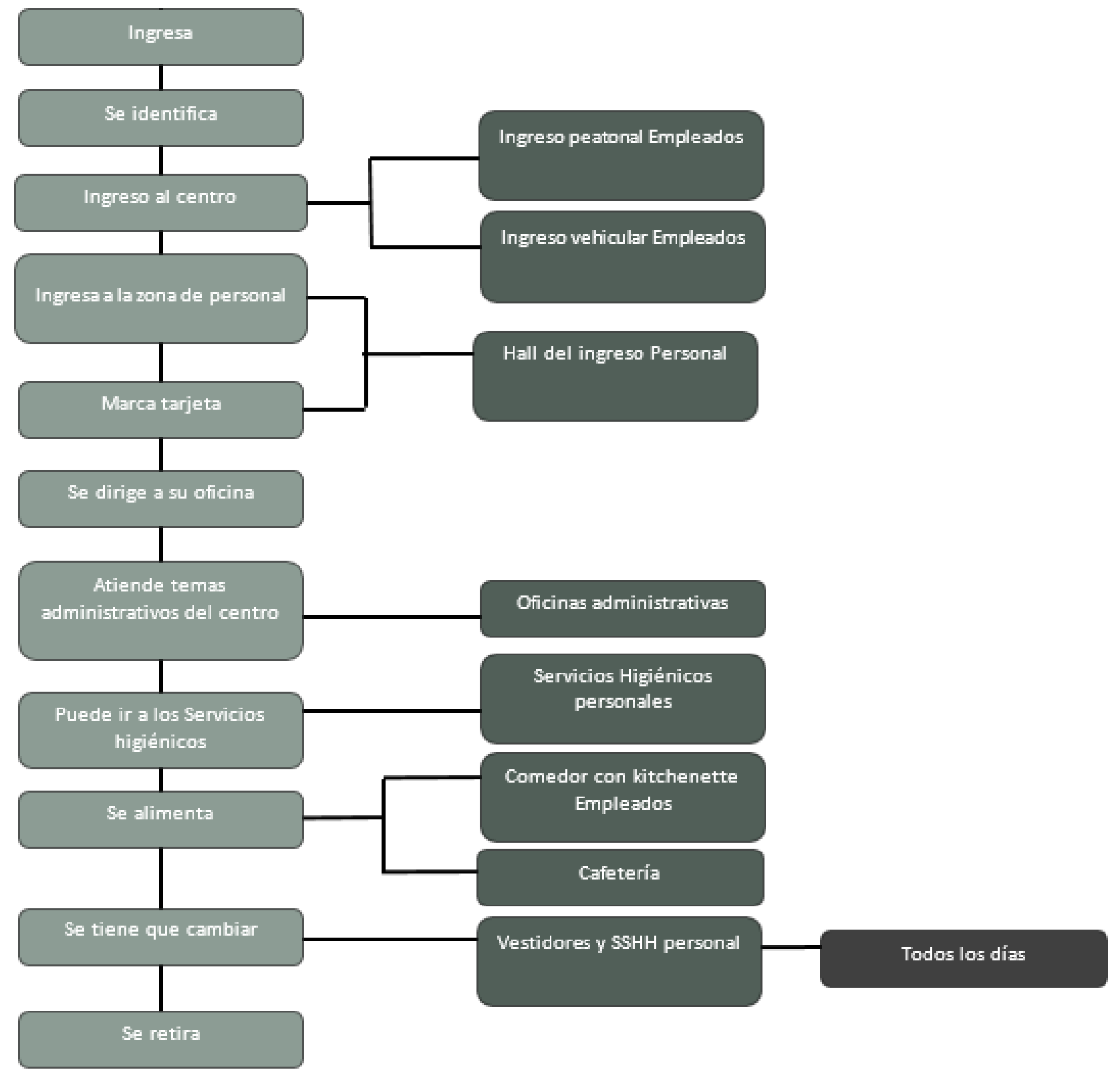

Fuente imagen: Elaboración Propia 


\section{Capítulo 6 : PROGRAMA ARQUITECTÓNICO}

\subsection{Paquetes funcionales}

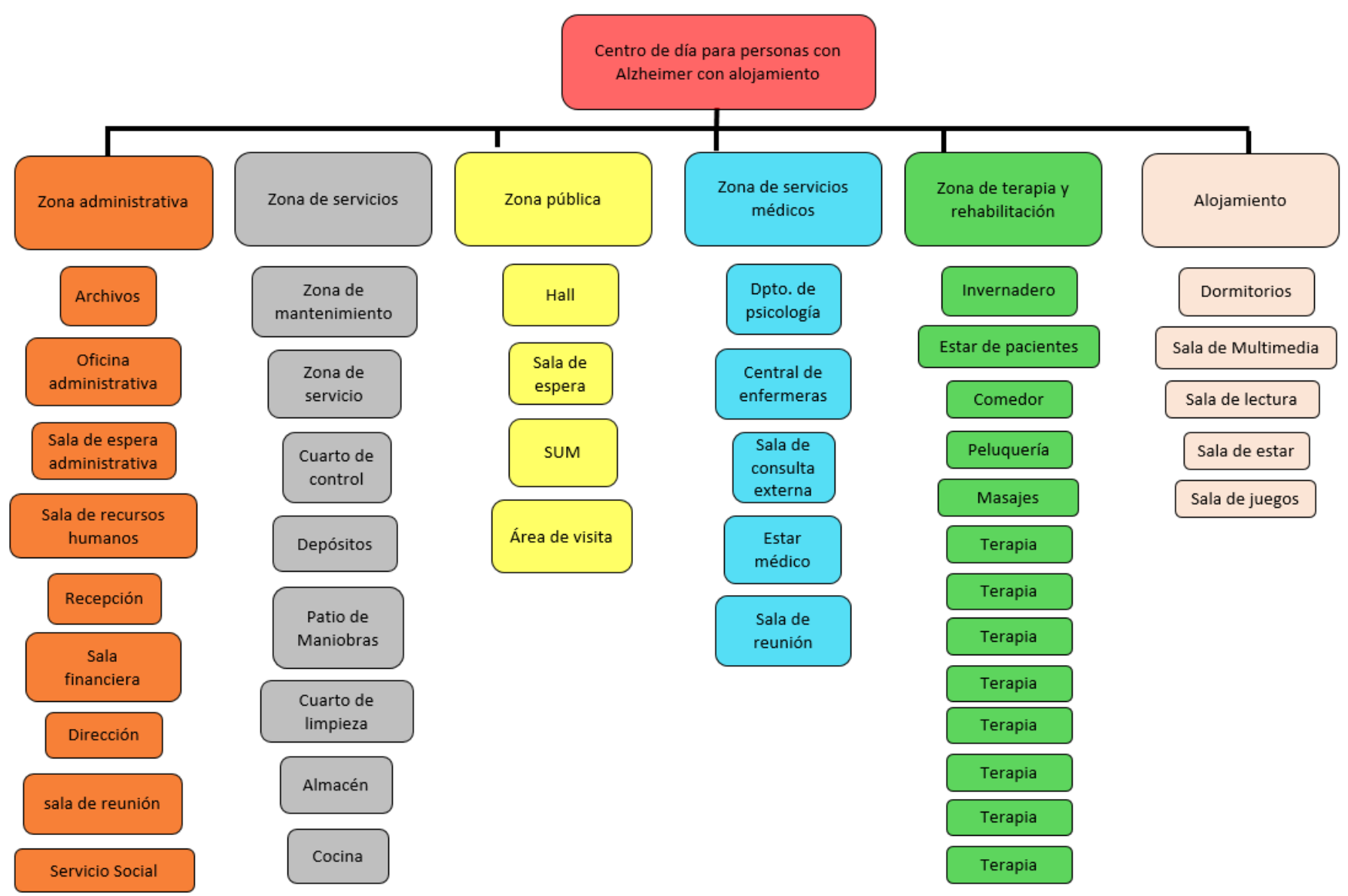

Fuente imagen: Elaboración propia 


\subsection{Diagrama funcional}

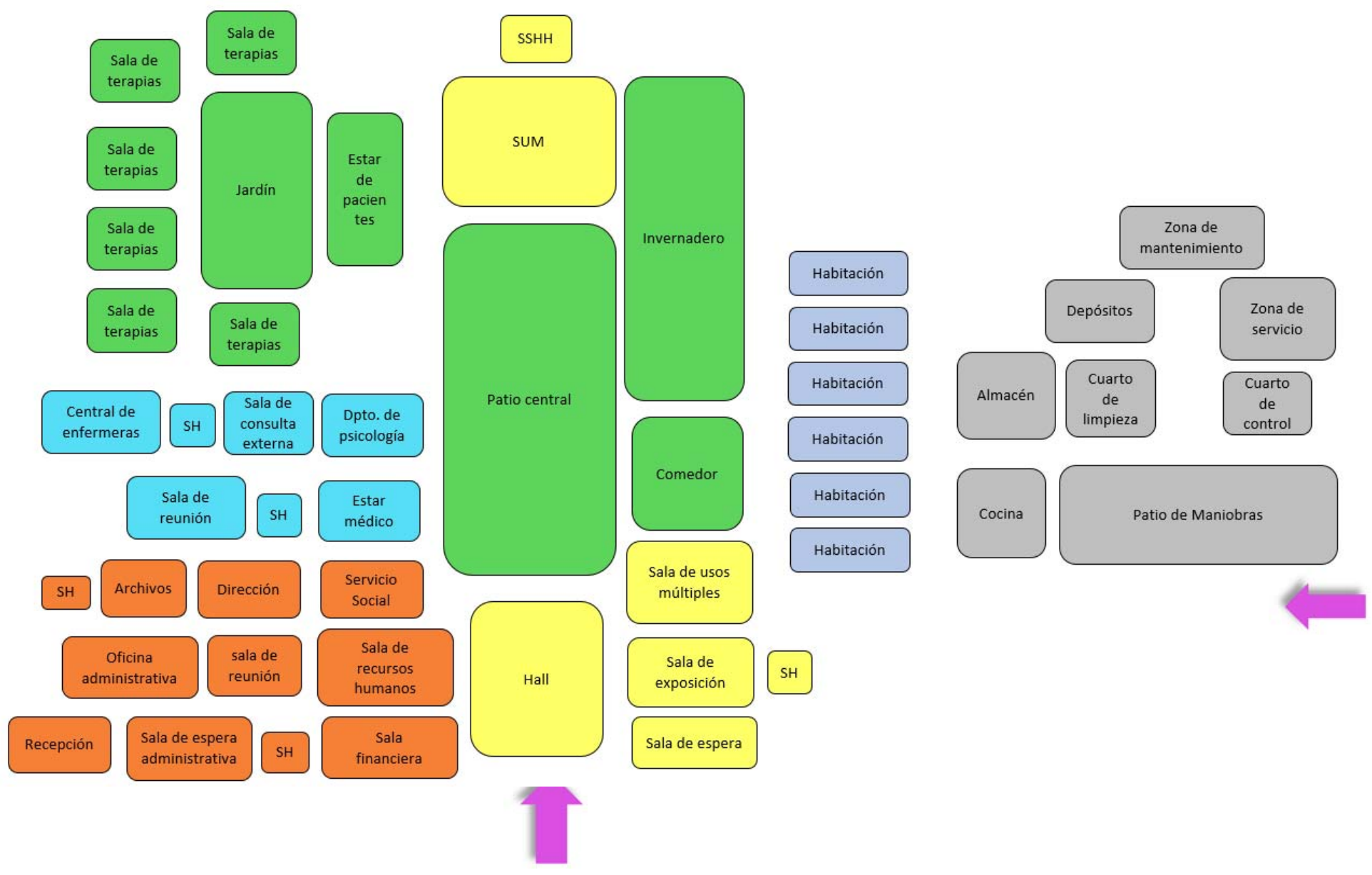

Fuente imagen: Elaboración propia 


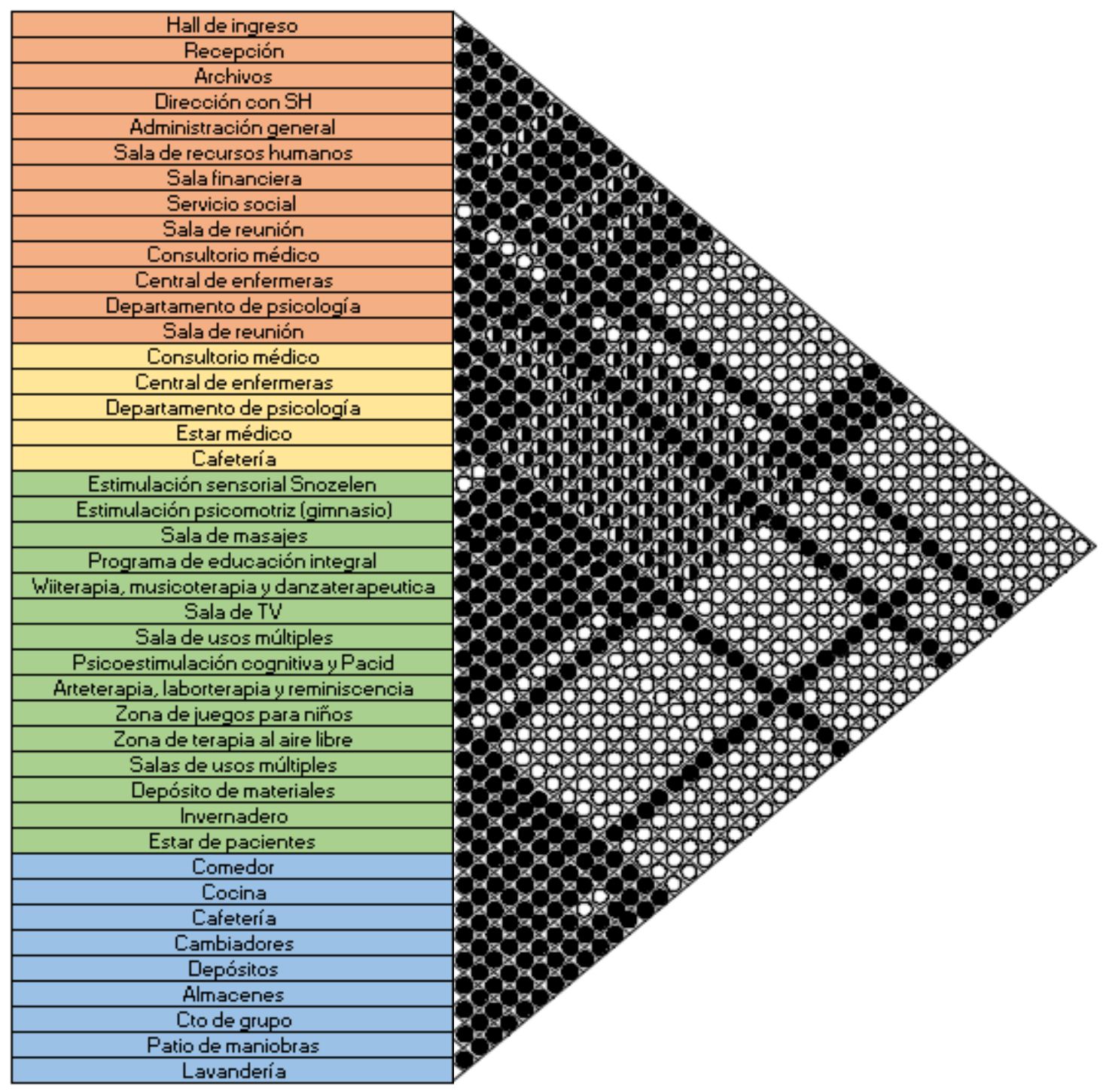

Fuente imagen: Elaboración propia 


\subsection{Dimensiones mínimas de ambientes}

- Consultorio médico
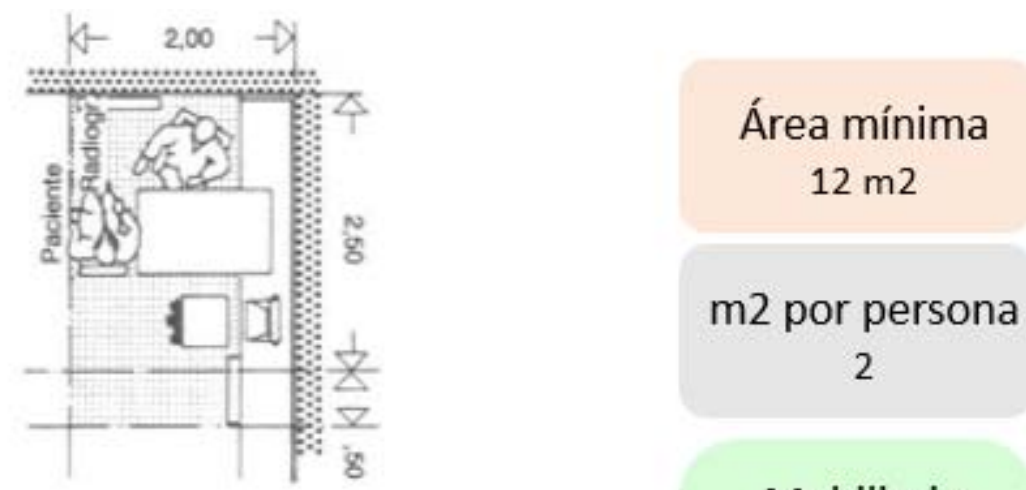

Mobiliario

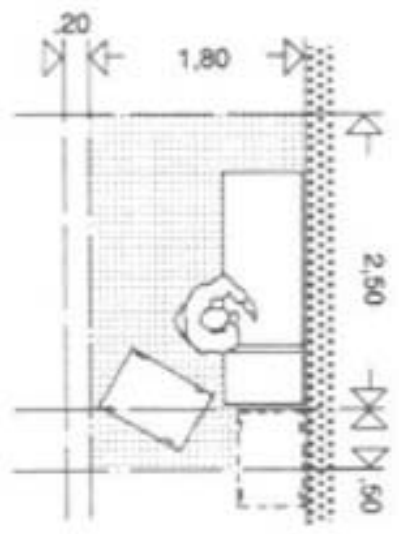

- 1 escritorio

- 3 sillas

- 1 lavamanos

- 1 camilla

Ventilación Natural

Iluminación

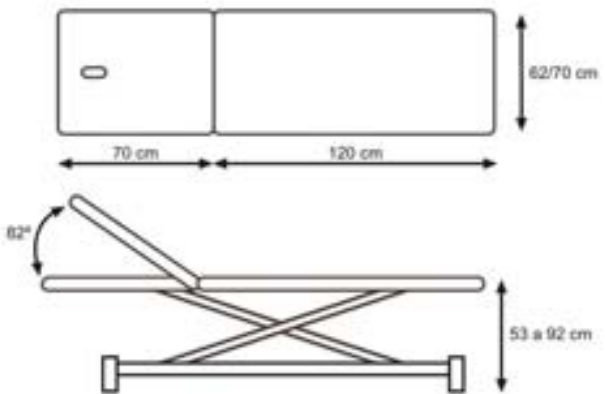

$$
\text { Natural }
$$

Fuente: Neufert 
- Sala de masajes

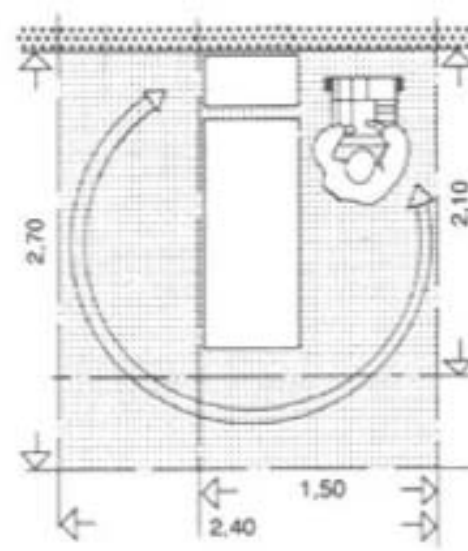

Área mínima

$12 \mathrm{~m} 2$

$\mathrm{m} 2$ por persona

1.50

Mobiliario

- 1 camilla

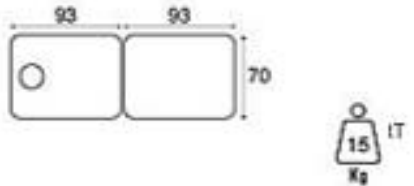

- 3 sillas

- 1 lavamanos

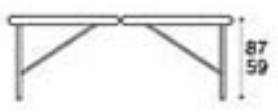

Ventilación

Natural

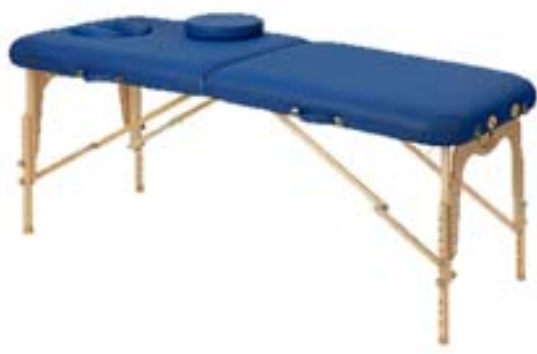

Iluminación

Natural

Fuente: Neufert 
- Sala de Terapias

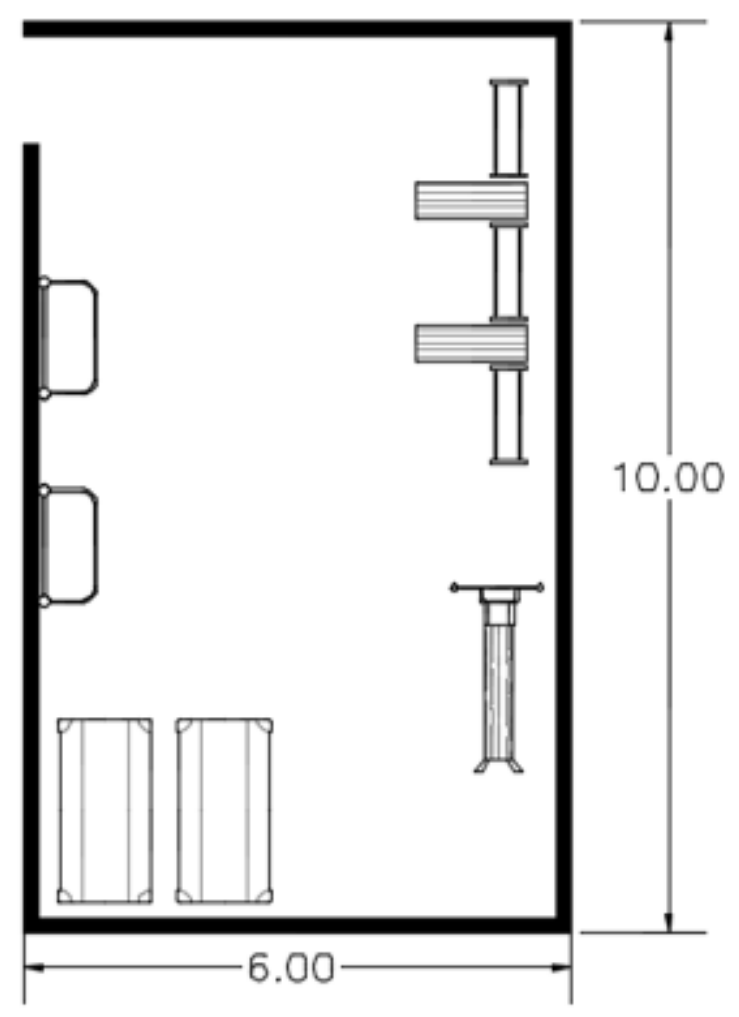

Área mínima

$60 \mathrm{~m} 2$

$\mathrm{m} 2$ por persona

5.3 a $8 \mathrm{~m} 2$

Mobiliario

- Ostáculos

- Colchonetas

- Riel de

equilibrio

- balacines

Ventilación

Natural

Iluminación

Natural

Fuente: MINEDU 
- Dormitorio compartido
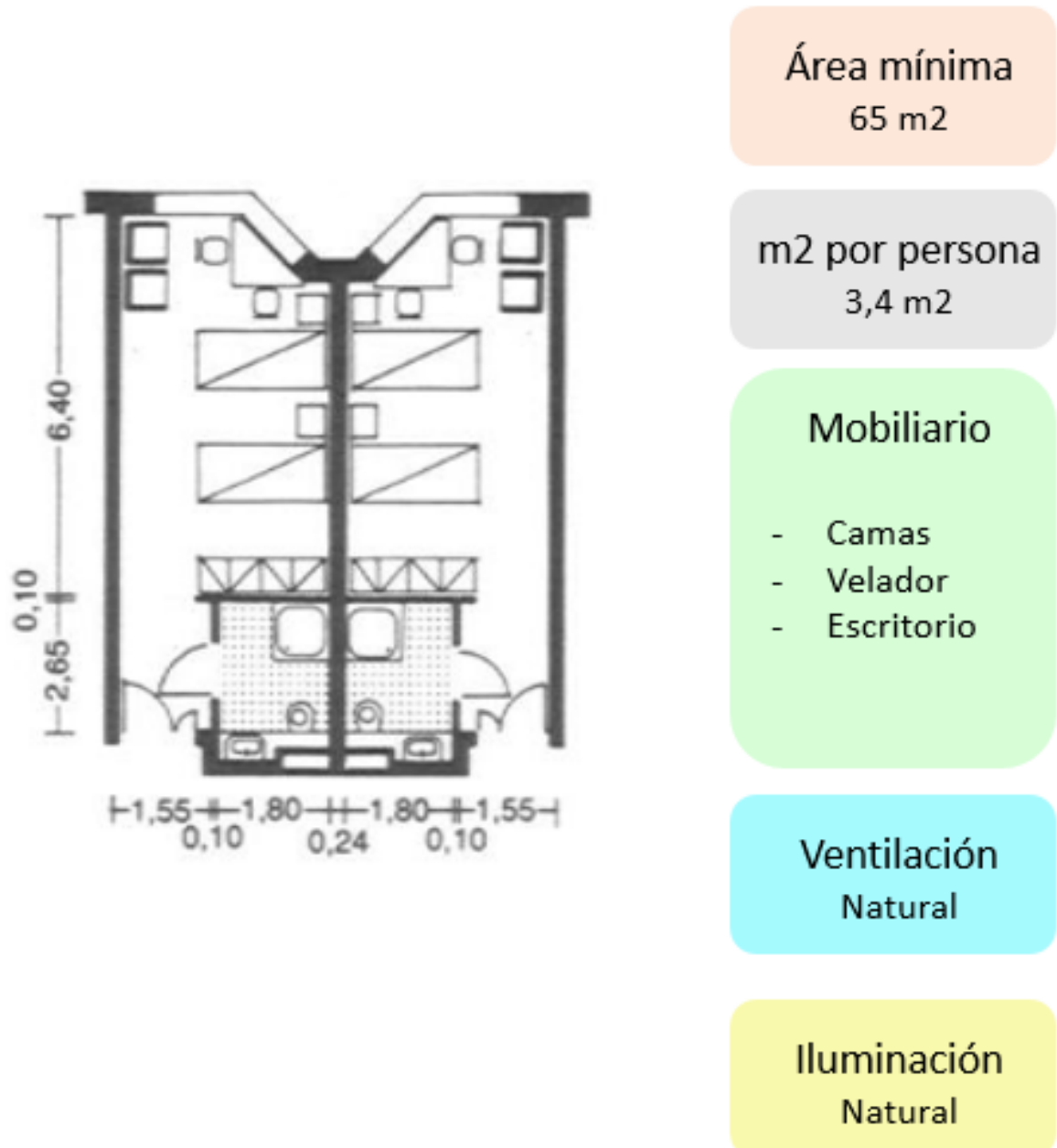

Fuente: Neufert 
- Estar de Pacientes

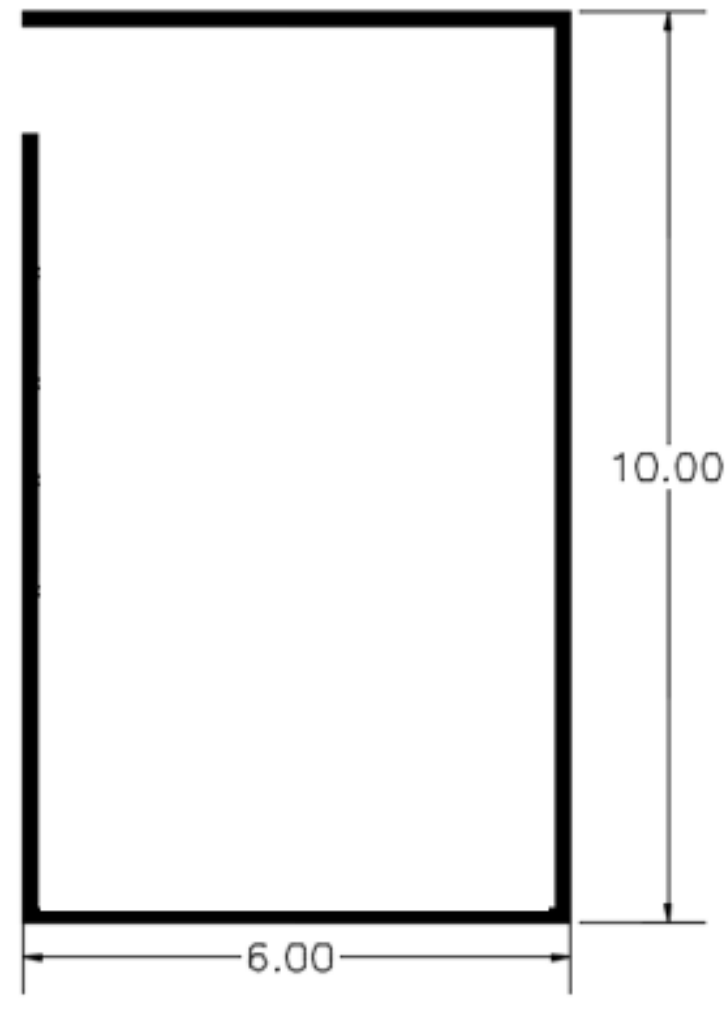

Área mínima

$60 \mathrm{~m} 2$

$\mathrm{m} 2$ por persona

$4 \mathrm{~m} 2$

Mobiliario

- Sillas

- Mesas

- Estante

- Repisa

Ventilación

Natural

Iluminación

Natural

Fuente: Neufert 
- SUM

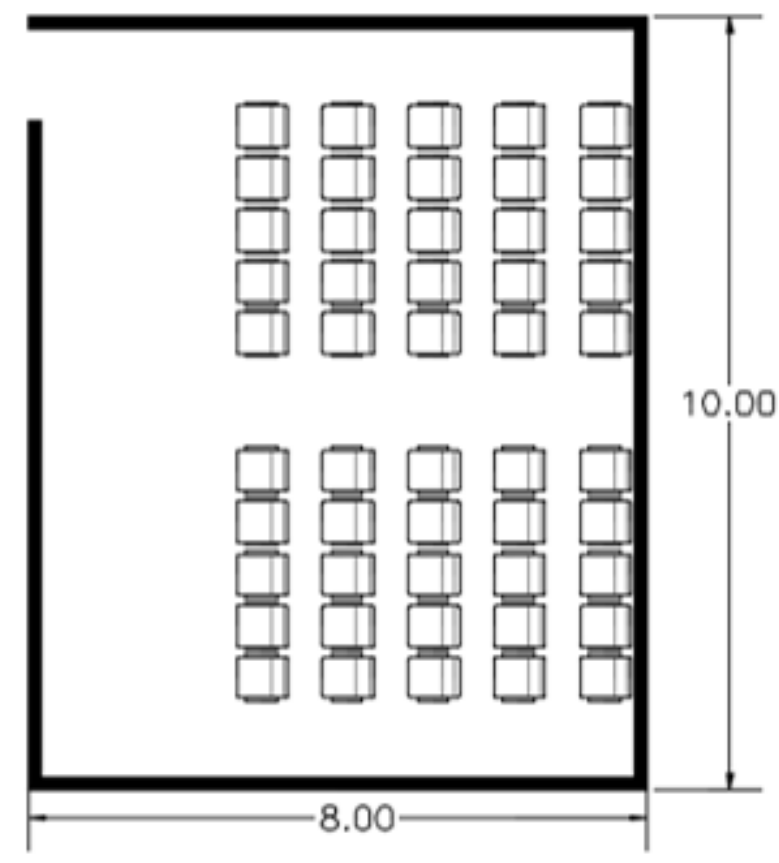

Área mínima

$80 \mathrm{~m} 2$

Aforo

50 personas

Mobiliario

- 50 sillas

Ventilación

Natural

Iluminación

Natural

Fuente: Neufcert 
- Servicios higiénicos para discapacitados
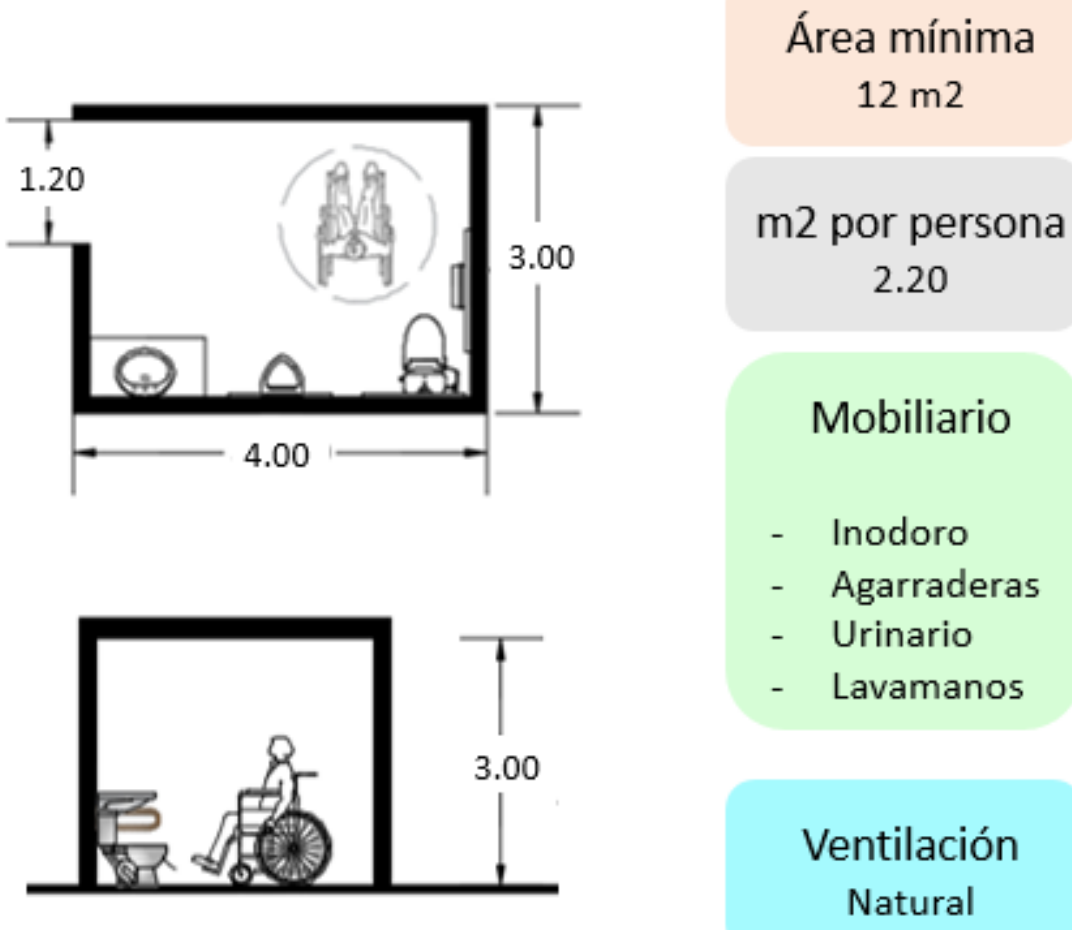

Área mínima $12 \mathrm{~m} 2$

m2 por persona

2.20

\section{Mobiliario}

- Inodoro

- Agarraderas

- Urinario

- Lavamanos

Ventilación

Natural

Iluminación

Natural

Fuente: INAP - España 
- Sala de Reunión

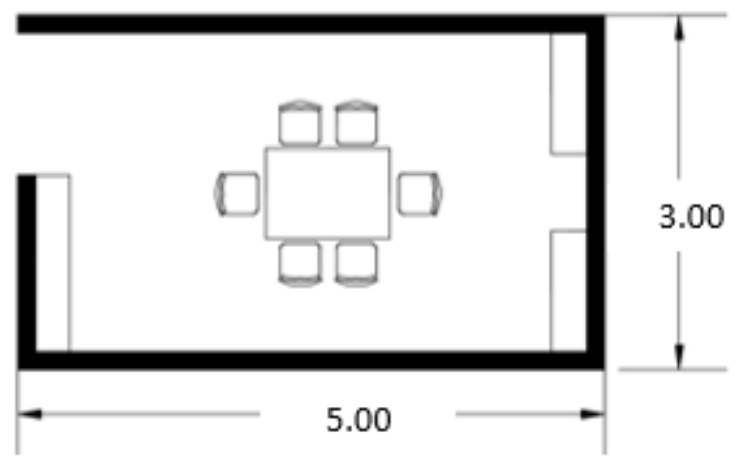

Área mínima

$15 \mathrm{~m} 2$

m2 por persona

2.00

Mobiliario

- 1 Mesa

- Archivadores

- Estantes

- 6 sillas

Ventilación

Natural

Iluminación

Natural

Fuente: Neufcert 
- Enfermería

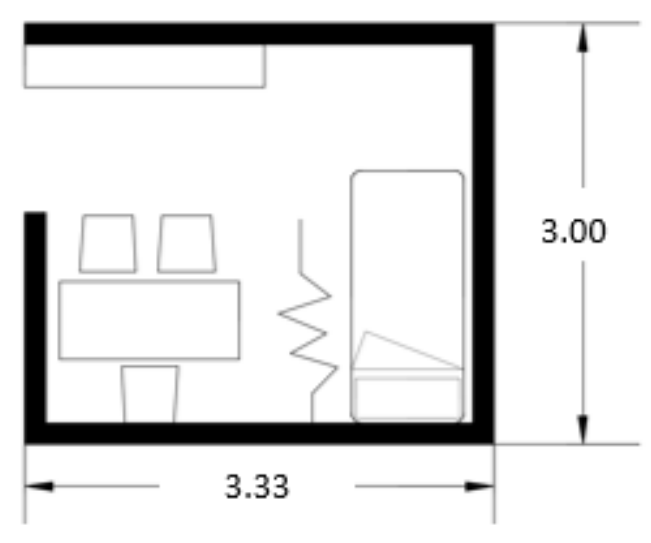

Área mínima

$10 \mathrm{~m} 2$

$\mathrm{m} 2$ por persona

3.00

Mobiliario

- Camilla

- Gabinete básico

- Lavatorio

- 1 Escritorio

- 1 Silla

Ventilación

Natural

Iluminación

Natural

Fuente: Neufcert 
- Comedor

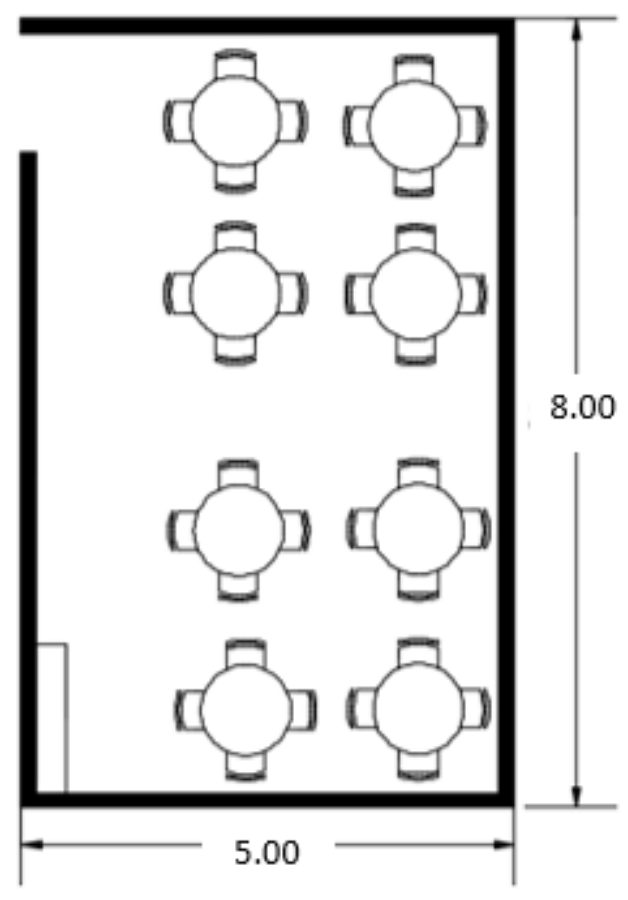

Área mínima $40 \mathrm{~m} 2$

$\mathrm{m} 2$ por persona

2.20

\section{Mobiliario}

- Mesas

- Sillas

- Gabinetes para utensilios

\section{Ventilación}

Natural

Iluminación

Natural 
- Dirección

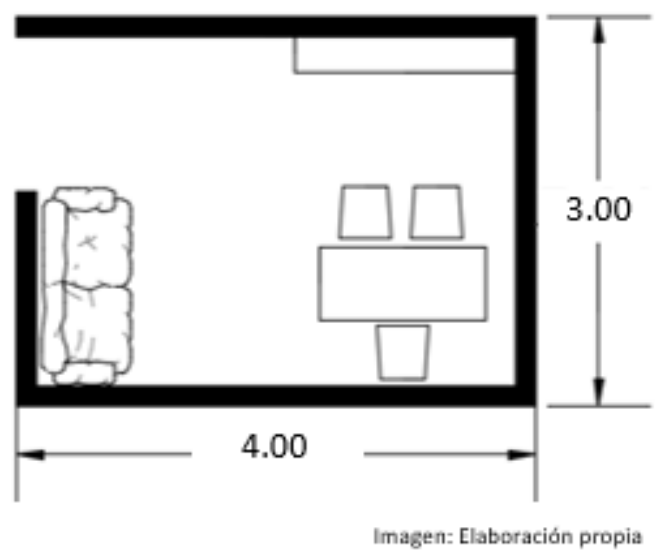

Área mínima

$12 \mathrm{~m} 2$

$\mathrm{m} 2$ por persona

2.00

Mobiliario

- Escritorio

- Silla

- Sillón de visita

- Estante

- Archivador

\section{Ventilación \\ Natural \\ Iluminación \\ Natural}

Fuente: MINEDU 
- Secretaría

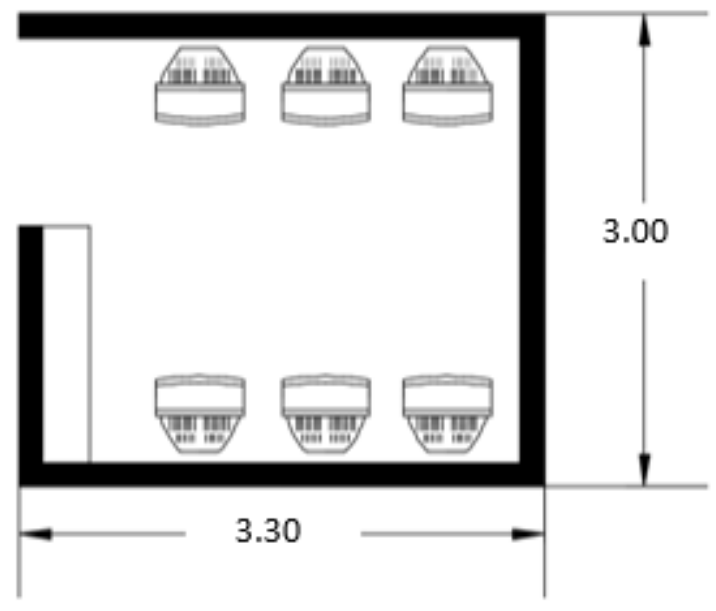

Área mínima

$10 \mathrm{~m} 2$

m2 por persona

2.00

Mobiliario

- Archivadores

- Computadoras

Ventilación

Natural

Iluminación

Natural

Fuente: MINEDU 
- Sala de espera

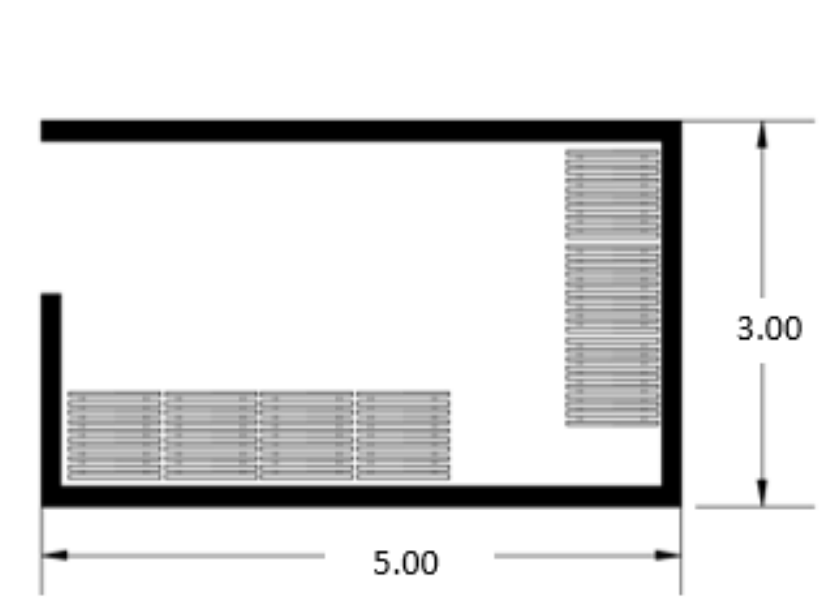

\author{
Área mínima \\ $15 \mathrm{~m} 2$ \\ $\mathrm{m} 2$ por persona \\ 2.00 \\ Mobiliario \\ - Sillas \\ - Bebedero \\ Ventilación \\ Natural \\ Iluminación \\ Natural
}

Fuente: MINEDU 


\subsection{Cuadro de área}

\begin{tabular}{|c|c|c|c|c|c|c|c|c|}
\hline & & \multirow[b]{2}{*}{ AMBIENTE } & \multicolumn{2}{|c|}{ ÁREA } & \multicolumn{4}{|c|}{ DIMENSIDNES } \\
\hline & & & $\begin{array}{l}\text { 总 } \\
\text { 总 } \\
\text { 要 }\end{array}$ & 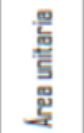 & $\begin{array}{l}\text { 票 } \\
\text { 总 }\end{array}$ & $\begin{array}{l}\text { 틀 } \\
\text { 몹 }\end{array}$ & $\begin{array}{l}\text { 틈 } \\
\text { 믈 }\end{array}$ & 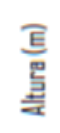 \\
\hline \multirow{10}{*}{ Área de pacientes } & \multirow{10}{*}{$\begin{array}{l}\text { İnternamiento } \\
\text { temporal }\end{array}$} & habitaciones dobles + SH & 9 & 35.00 & 315,00 & 8.33 & 42 & 2.45 \\
\hline & & Manitoreode pacientes alojados & 1 & 15.00 & 15.00 & 4.05 & 3.70 & 2.45 \\
\hline & & Sala de NV & 1 & 27.00 & 27,00 & 4.15 & 6.50 & 2.45 \\
\hline & & Topico & 1 & 16.00 & 16.00 & 4.32 & 3.70 & 2.45 \\
\hline & & D̄epasito de medcinas & i & iōỗō & 10. & $\overline{2.70}$ & $\overline{3}, \overline{7} 0$ & $\overline{2} .4 \overline{4}$ \\
\hline & & Archivos & 1 & 30,00 & 30.00 & 4.55 & 6.60 & 2.45 \\
\hline & & Cuarb de sabanas & 1 & 10.70 & 10.70 & 2.89 & 3.70 & 2.45 \\
\hline & & Cuart de ropa sucia & 1 & 7.00 & 7.00 & 2.59 & 2.70 & 2.45 \\
\hline & & Cuarto de desechos & 1 & 8.60 & 8.60 & 2.61 & 3.30 & 2.45 \\
\hline & & Sh visita (damas y cabaleros) & 2 & 2.70 & 5.40 & 193 & 1,40 & 2.45 \\
\hline \multirow{3}{*}{ Área médica } & \multirow{3}{*}{$\begin{array}{c}\text { Para pacientes } \\
\text { alojados }\end{array}$} & \begin{tabular}{|c|} 
Cambiadores y sh (damas y cabaleros) \\
\end{tabular} & 2 & 20.70 & $4 ., 40$ & 4.60 & 450 & 2.45 \\
\hline & & initarios de tumo de enfermeros (damas y caballent & 1 & 24.00 & 24.00 & 6.67 & 3.60 & 2.45 \\
\hline & & \begin{tabular}{|c|} 
Estarmédico \\
\end{tabular} & 1 & 56.70 & 56.70 & 9.00 & 6.30 & 2.45 \\
\hline \multirow{15}{*}{ Área administrativa } & \multirow{15}{*}{$\begin{array}{l}\text { Jefaturas de áreas } \\
\text { administrativas. } \\
\text { médcas y de } \\
\text { investigacion }\end{array}$} & Control de ingresa & 1 & 400 & 4.00 & 1.82 & 2.20 & 2.45 \\
\hline & & Lactaria & 1 & 9,70 & 9.70 & 2.98 & 3.25 & 2.45 \\
\hline & & Šervicio socia y ysesoriajuridica & $i$ & 13.10 & 13.10 & $32 \overline{28}$ & 4000 & $\overline{2.45}$ \\
\hline & & Sub drección & 1 & 8.50 & 850 & 3.33 & 2.55 & 2.45 \\
\hline & & jefatura enfermeria & 1 & 8.70 & 8.70 & 322 & 2.70 & 2.45 \\
\hline & & Direcciónde asionlogia & 1 & 7.35 & 7.35 & 3.20 & 2.30 & 2.45 \\
\hline & & Oficina de marketing & 1 & 7.50 & 7,50 & 3.26 & 2.30 & 2.45 \\
\hline & & SH (damas, caballeros y discapactadas) & 3 & 8.40 & 25.20 & 3.23 & 2.60 & 2.45 \\
\hline & & Sala de reuniones & 1 & 1700 & 17,00 & 5.67 & 3.00 & 2.45 \\
\hline & & Unidadde estadistica & 1 & 30,00 & 30,00 & 5.83 & 5.15 & 2.45 \\
\hline & & Labarabrio de infornatica & 1 & 35.00 & 35.00 & 6.03 & 5.80 & 2.45 \\
\hline & & Sala de investigación & 1 & 28.00 & 28.00 & 5.83 & 480 & 2.45 \\
\hline & & Oficina de logistica & 1 & 32.50 & 32.50 & 6.02 & 5.40 & 2.45 \\
\hline & & Secretaria direccion & 1 & 1130 & 1130 & 2.83 & 400 & 2.45 \\
\hline & & Direccióngeneral & 1 & 12.50 & 12.50 & 3.13 & 400 & 2.45 \\
\hline \multirow{19}{*}{ Área de terapias } & \multirow{19}{*}{$\begin{array}{c}\text { Rehabilitación y } \\
\text { tratamiento }\end{array}$} & Centralde enfenmeras & 3 & 15.00 & 45.00 & 4.29 & 3.50 & 2.45 \\
\hline & & Estar de pacientes & 3 & 35.00 & 105.00 & 4.07 & 8.60 & 2.45 \\
\hline & & Terraza con vivero & 1 & 80000 & 800,00 & 48.84 & 16.38 & 2.45 \\
\hline & & Comedar & 1 & 143.00 & 143.00 & 16.07 & 8.90 & 2.45 \\
\hline & & Depásito de medicinas & 1 & 10.50 & 10.50 & 3.39 & 3.10 & 2.45 \\
\hline & & Tápico & 1 & 15.30 & 15.30 & 5.19 & 2.95 & 2.45 \\
\hline & & Peluqueria + sh & $i$ & 37.50 & 37.50 & $7.2 i i$ & 5.20 & 2.45 \\
\hline & & SH congletos (damas y cabaleros) + lavamogas & 4 & 8.20 & 32.80 & 2.83 & 2.90 & 2.45 \\
\hline & & Estimulación sensonial Smazelen & 1 & 20.00 & 20.00 & 6.25 & 3.20 & 2.45 \\
\hline & & Estimulación psicamatriz (gimnasio) & 1 & 45.50 & 45.50 & 9.48 & 480 & 2.45 \\
\hline & & Sala de masajes & 1 & 20.90 & 20.90 & 5.10 & 4.10 & 2.45 \\
\hline & & \begin{tabular}{|c|} 
Programa de educación integral \\
\end{tabular} & 1 & 32.10 & 32.10 & 6.7 & 5.20 & 2.45 \\
\hline & & Viterapia musicaterapia y danzaterapeutica + deposit & 1 & 45.80 & 45.80 & 8.81 & 5.20 & 2.45 \\
\hline & & \begin{tabular}{|c|} 
Sala de N \\
\end{tabular} & 1 & 40,00 & 40.00 & 6.90 & 5.80 & 2.45 \\
\hline & & Sab de usas múltiples & 1 & 5470 & 5470 & 11.89 & 460 & 2.45 \\
\hline & & Psicoestimulación cogntiva y Pacid & 1 & 6.50 & 6.50 & 108 & 6.00 & 2.45 \\
\hline & & Arteterapia laborterapia y reniniscencia & 1 & 75.10 & 75.10 & 11.92 & 6.30 & 2.45 \\
\hline & & lona de juegos para rîios & 1 & 73.30 & 73.30 & 1410 & 5.20 & 2.45 \\
\hline & & Zona de terapia al aire libre & 1 & 130.95 & 130.95 & 16.58 & 7.90 & 2.45 \\
\hline
\end{tabular}




\begin{tabular}{|c|c|c|c|c|c|c|c|c|}
\hline & & \multirow[b]{2}{*}{ AMBIENTE } & \multicolumn{2}{|c|}{ ÁREA } & \multicolumn{4}{|c|}{ DIMENSIONES } \\
\hline & & & $\begin{array}{l}\text { 垔 } \\
\text { 長 }\end{array}$ & 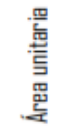 & $\begin{array}{l}\text { 垔 } \\
\text { 总 } \\
\text { 莌 }\end{array}$ & $\begin{array}{l}\text { EE } \\
\text { 嵒 } \\
\text { 严 }\end{array}$ & $\begin{array}{l}\text { 틈 } \\
\text { 믈 }\end{array}$ & 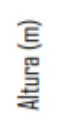 \\
\hline \multirow{10}{*}{ Área admisión } & \multirow{10}{*}{$\begin{array}{l}\text { Admisión y } \\
\text { diagnástico }\end{array}$} & Hall principal e informes & 1 & 150,00 & 150,00 & $\|\|$, & 13,50 & 2.45 \\
\hline & & Sala de exposición de la enfermedad & 1 & 55,00 & 55,00 & 10,78 & 5,10 & 2,45 \\
\hline & & Área de admisión + sala de espera & 1 & 48,00 & 48,00 & 8.42 & 5,70 & 2,45 \\
\hline & & SH públicas (damas, caballeros y discapacitados) & 3 & 8.40 & 25,20 & 3,23 & 2,60 & 2,45 \\
\hline & & Cansultorio médico & 2 & 9,60 & 19,20 & 3.76 & 2,55 & 2.45 \\
\hline & & Consultario psicalógico & 2 & 11,00 & 22,00 & 4.15 & 2,65 & 2,45 \\
\hline & & Sala de reuniones & 1 & 10,80 & 10,80 & 4,15 & 2,60 & 2.45 \\
\hline & & Sala de usas múltiples & 1 & 58.20 & 58.20 & 9,86 & 5,90 & 2.45 \\
\hline & & SH (damas y caballeras) & 2 & 2.80 & 5,60 & 1,47 & 1,90 & 2,45 \\
\hline & & Control de ingreso administrativa y médico & 1 & 6,00 & 6.00 & 1,76 & 3.40 & 2.45 \\
\hline \multirow{12}{*}{ Zona de servicio } & \multirow{12}{*}{ Servicio } & Subestación eléctrica & 1 & 17.00 & 17,00 & 3.78 & 4,50 & 2.45 \\
\hline & & Grupo electrógeno & 1 & 15,90 & 15.90 & 3,79 & 4.20 & 2,45 \\
\hline & & Patio de maniobras + zona de reciclaje & 1 & 164,85 & 164.85 & 24.24 & 6,80 & 2.45 \\
\hline & & Uepósita de basura & i & 4.60 & 4,60 & 3,69 & 2,60 & 2.45 \\
\hline & & Depásito general & 1 & 8,70 & 8.70 & 3.70 & 2,35 & 2.45 \\
\hline & & Cisterna & 1 & 38,60 & 38,60 & 5,68 & 6.80 & 2.45 \\
\hline & & Lavandería & 1 & 22,60 & 22,60 & 4,43 & 5,10 & 2.45 \\
\hline & & Almacen fría y climatizado & 2 & 12,80 & 25,60 & 4,57 & 2,80 & 2,45 \\
\hline & & Cambiadores + sh (damas y caballeras) & 2 & 34,00 & 68,00 & 7,31 & 4.65 & 2.45 \\
\hline & & Andén de descarga & 1 & 22,20 & 22,20 & 2,85 & 7,80 & 2,45 \\
\hline & & Comedor de personal & 1 & 104.15 & 104.15 & [1,36 & 10,05 & 2.45 \\
\hline & & Cocina & 1 & 102,30 & 102,30 & 13,46 & 7,60 & 2.45 \\
\hline \multicolumn{5}{|c|}{ Área parcial } & 3550,60 & & & \\
\hline \multicolumn{5}{|c|}{ Circulación y muras (30\%) } & 1065.2 & & & \\
\hline \multicolumn{5}{|c|}{ Estacionamientas (según número de camas) } & 31 & & & \\
\hline \multicolumn{5}{|c|}{ Área total } & 4615,78 & & & \\
\hline
\end{tabular}

Fuente: Elaboración propia 


\section{Capítulo 7. CRITERIOS DE DISEÑO}

\subsection{Posición}

- Ingresos

El terreno tiene 3 ingresos peatonales por la Av. Canta Callao, y 1 vehicular ubicado en la Calle Huáscar. En la esquina de Calle Huascar y Av. Canta Callao, paralela a la calle Yurumayo.

Está ubicado en el límite del distrito de independencia con SMP. Cerca de Av. Importantes como Faucett, Universitaria, Panamericana Norte, Central, Marñón y San Germán.

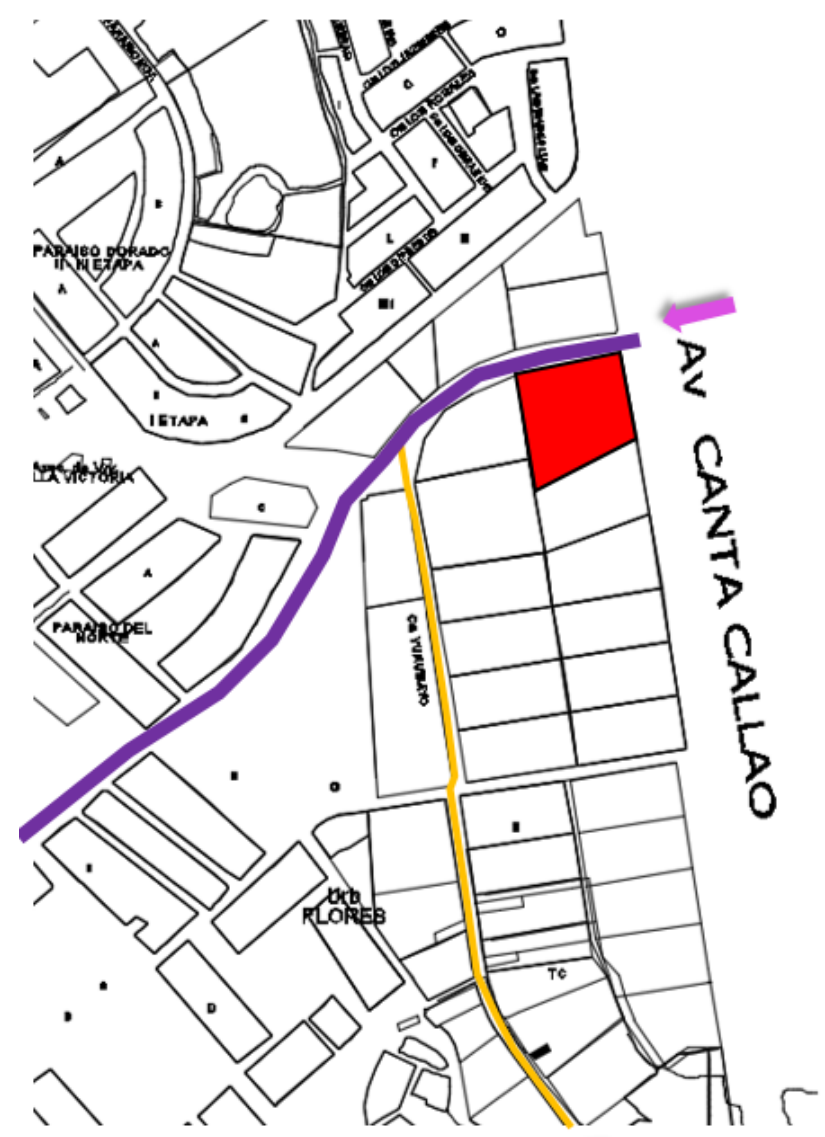

Fuente: Elaboración propia 
- Ruido

El entorno urbano presenta tráfico moderado, lo que significa que no existen excesos de ruidos. A una cuadra de la Calle Huascar se encuentra la Av. Central, un vía colectora importante que une varias avenidas arteriales como la Av. Universitaria, para llevarla hasta la Av. Canta Callao, lo que genera bastante flujo vehicular.

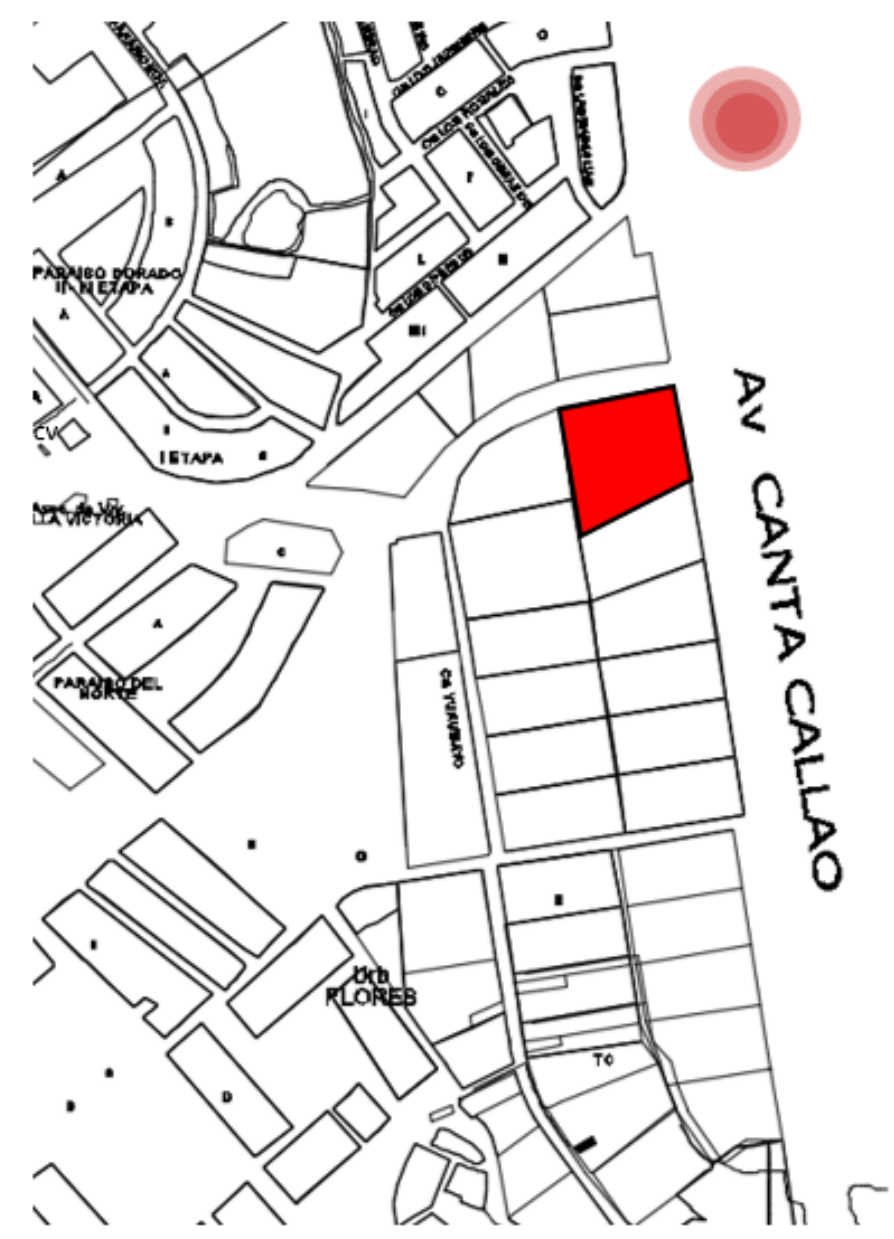

Fuente: Elaboración propia 
- Vegetación

El terreno se ubica en una zona en donde hay varios parques cercanos. Al lado del terreno, hay dos lotes dedicados al cultivo de alimentos y vegetación.

EL terreno deberá tener el $50 \%$ de área libre que será empleado como patios con áreas verdes y un vivero, que es importante para el tratamiento de la enfermedad.

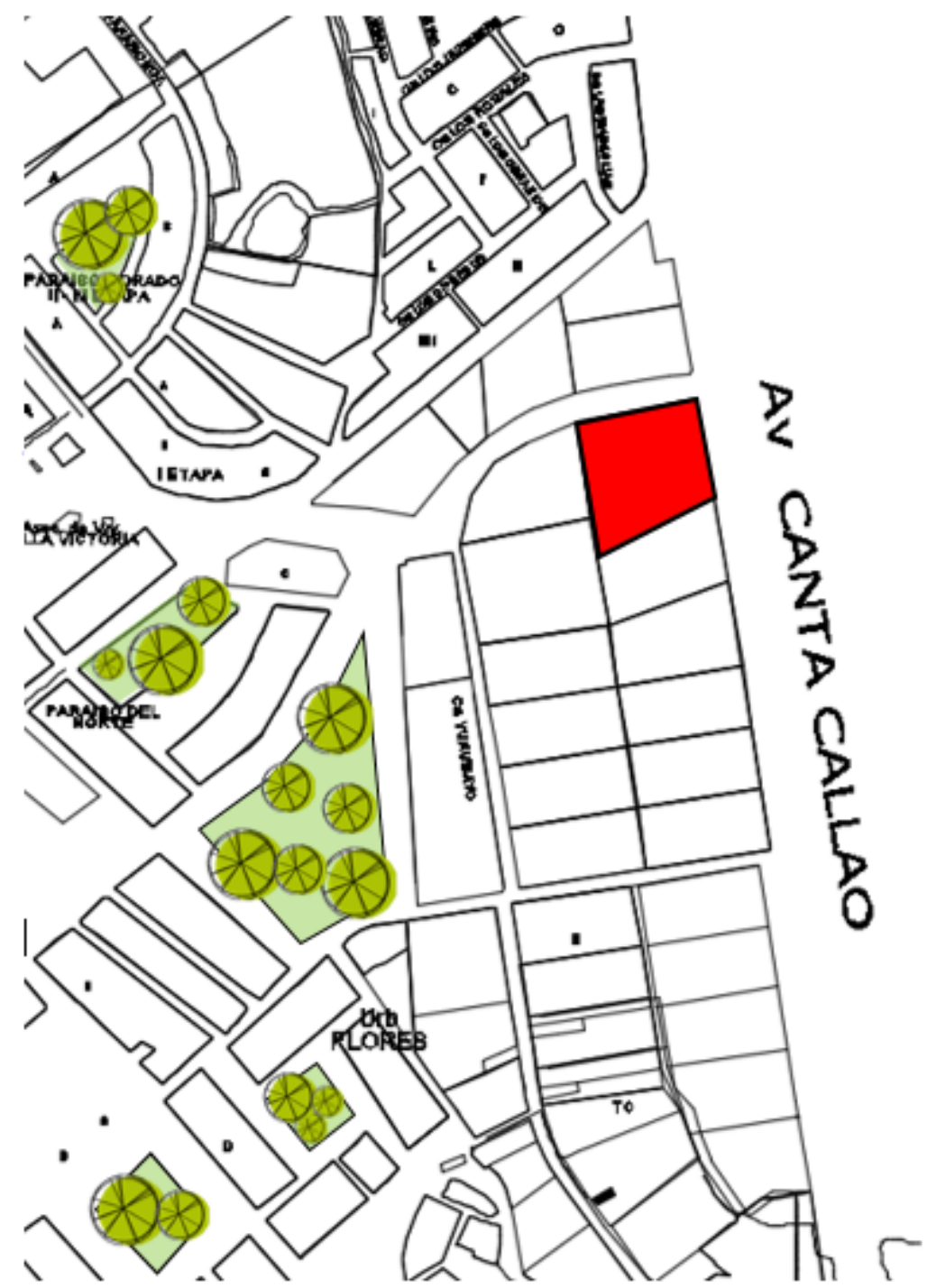

Fuente: Elaboración propia 
- Posición de pabellón

Se propone que los ambientes se desarrollen de manera horizontal para que llegue el sol a todas las salas de rehabilitación. Con excepción de la zona administrativa y de ingreso. Además, contará con patios para el desarrollo de actividades entre los pacientes.

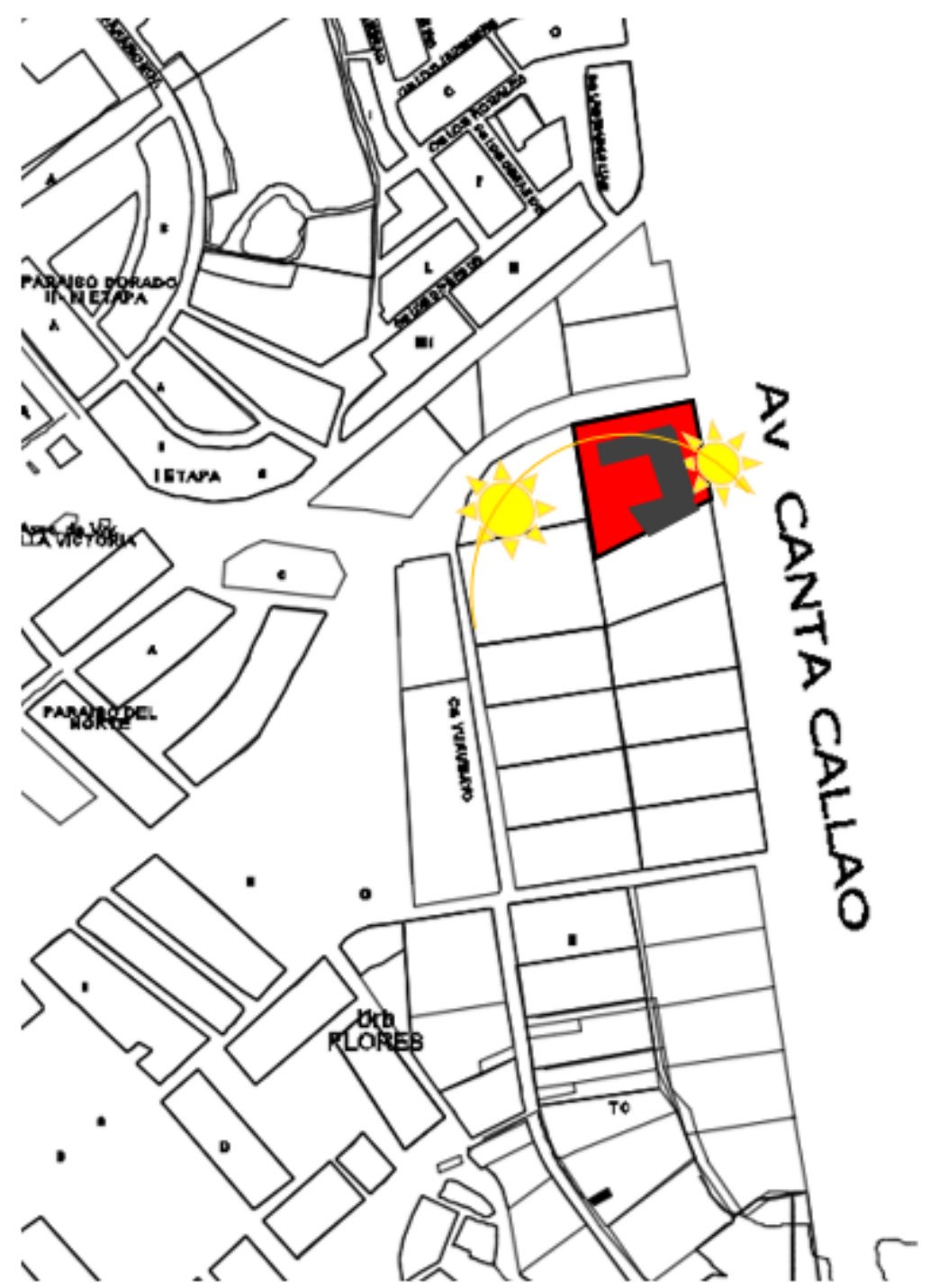

Fuente: Elaboración propia 
- Paisaje prestado

Se toma como paisaje prestado los terrenos aledaños con gran vegetación de cultivos que tienen actualmente. Además, el proyecto contará con un patio en donde habrá mucha vegetación como parte terapeutica, lo que mejorará el ambiente y calidad de tratamiento a los ancianos.

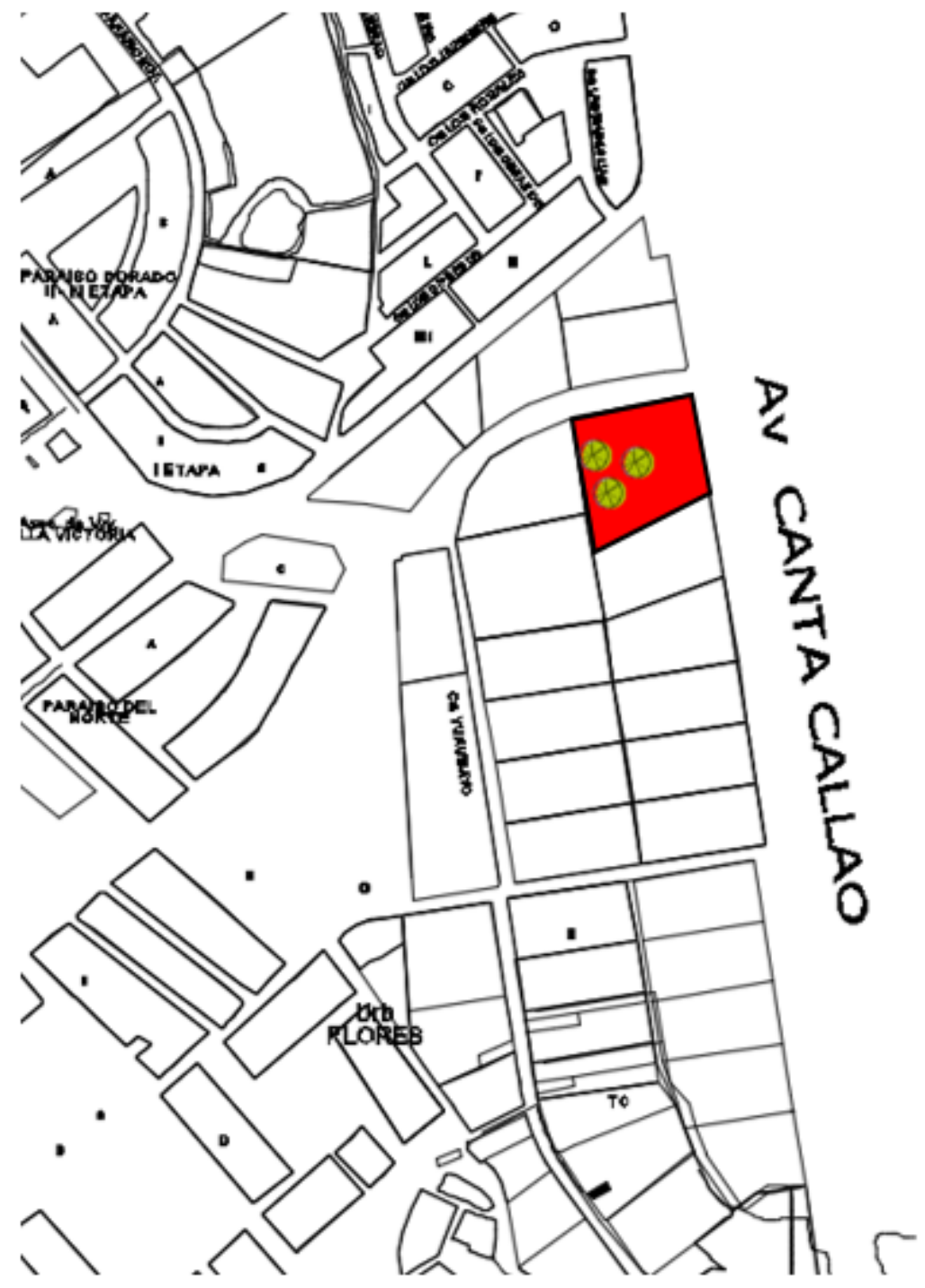

Fuente: Elaboración propia 
El terreno tendrá el ingreso por la avenida Canta Callao, se empleará como paisaje prestado la gran área verde ubicada en el lote vecino. Por otro lado, el terreno es accesible y la futura línea del metro se ubicará muy cerca del terreno ( 3 cuadras) en el cruce de la Av. Central y la Av. Canta Callao. Actualmente, ese cruce es un nodo de trafico lo que genera ruido en la zona. Los pabellones estarán horizontalmente y estarán comunicados por medio de áreas verdes (patios), un vivero y un gran patio central que organizará el centro.

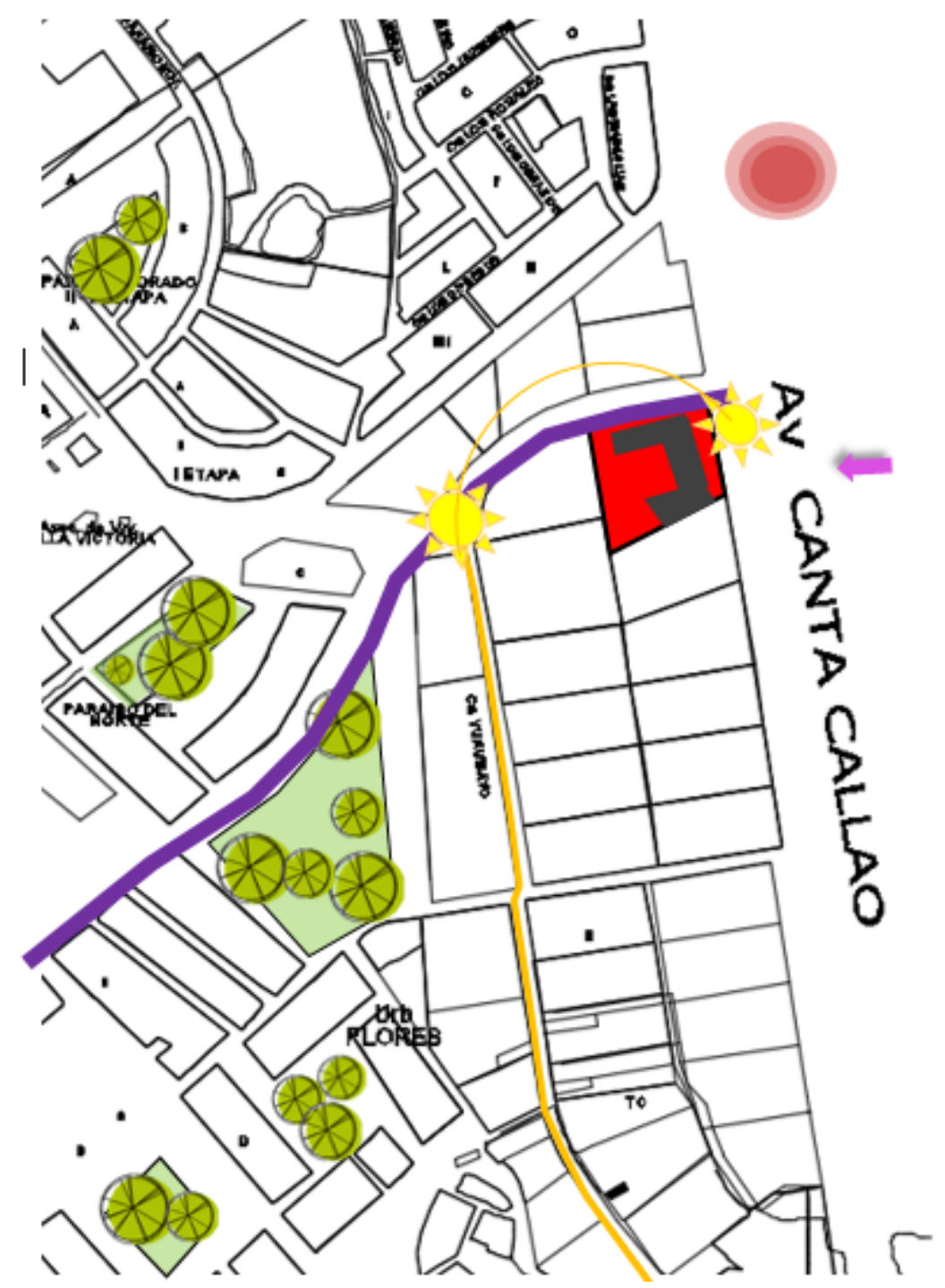

Fuente: Elaboración propia 


\subsection{Posesión}

- Iluminación

El centro de día requiere de iluminación natural, es por eso, que se plantean patios entre cada módulo del centro, que permitirán el ingreso de la luz natural en el día.

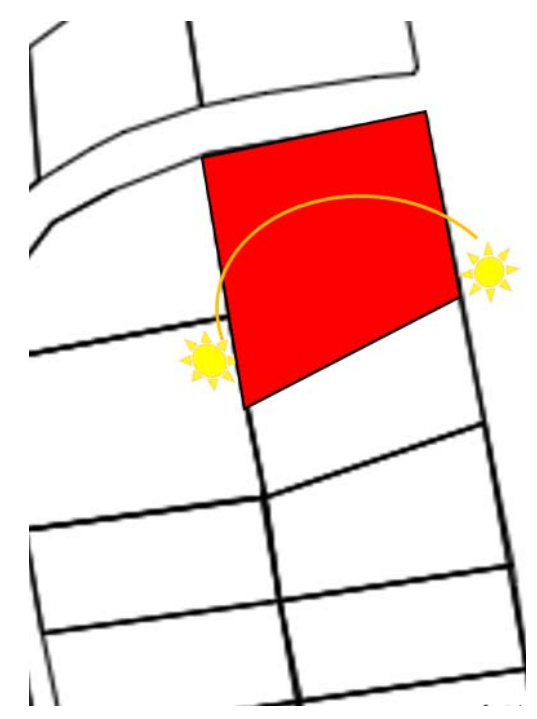

Fuente: Elaboración propia

- Secuencia y espacialidad

Se contará con tres ingresos, uno para la zona de servicio y administrativo, otro para el personal de servicio y abastecimiento del centro y otro para los pacientes. Se tendrá como espacio previo un gran espacio que podrá ser empleado por los familiares y pacientes, ya que, se requiere el 70\% de área libre: $50 \%$ de área verde y $20 \%$ de ampliaciones futuras, según el manual para construcción de edificaciones hospitalarias.

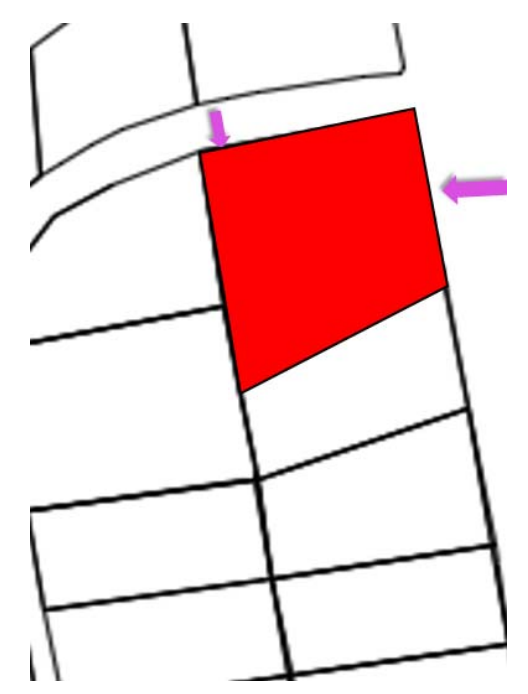

Fuente: Elaboración propia 
- Materiales y sistema constructivo

Se empleará como sistema constructivo el sistema aporticado para proporcionar el ingreso de la luz a través de grandes vanos.

Según la Guía de Centros de Salud de Bolivia Tomo III, se recomienda lo siguiente:

- Pisos: El acabado del piso debe ser resistente para tránsito alto. Los materiales recomendados son piedra pulida, porcelanato, vinilo e alta resistencia (de $3 \mathrm{~mm}$. de espesor) o cerámico de alta resistencia.

- Paredes: En los consultorios y algunas salas de terapia, el mejor material utilizado para los planos verticales es cerámica. Además, se tiene que tomar en cuenta la colocación de revestimientos en las esquinas para evitar los golpes en las paredes. Estos parachoques, pueden servir como elementos de apoyo para los pacientes.

- Cielos rasos: Se recomienda que estén revestidos por estuco con pintura lavable o que sean desmontables.

- Puertas: Deben ser lisas, para poder evitar el polvo y revestidas con una pintura lavable resistente a la limpieza diaria. Sin embargo, debe tener protectores metálicos, uno a $0.20 \mathrm{~m}$. como zócalo para proteger de los golpes de pie y otro a $0.90 \mathrm{~m}$. para que no se dañe la puerta con los golpes de las sillas de ruedas. 


\section{Capítulo 8 : CONCLUSIONES}

El centro de día para personas con el mal de Alzheimer no tiene como finalidad curar la enfermedad, sino brinda atención especializada para retrasar su desarrollo rápidamente. Así mismo, poder alojar a los pacientes para un mayor desarrollo y/o cuidado TEMPORAL.

Actualmente, existe cura contra la enfermedad, según la doctora Mary Newport, una dosis medicada de aceite de coco diariamente, curaría a los afectados.

Se tiene como objetivo desarrollar un centro con las mejores medidas en cuanto a función, mediante la accesibilidad a cada espacio (énfasis), para que los pacientes puedan desplazarse por el centro sin estar vulnerables a cualquier tipo de daños.

El Alzheimer es una enfermedad que requiere muchos tipos de cuidados especializados con personal que sepa sobre el mal y pueda ayudar al desarrollo de cada paciente. Además, el familiar cumple un rol muy importante en el tratamiento, es por eso que se requiere capacitar a ellos también.

Los ancianos no solo se verán beneficiados por las terapias brindadas, si no también, podrán convivir con los demás pacientes que sufren con ese mal, ayudándose y compartiendo conocimientos mutuamente.

El Perú solo tiene centros de Alzheimer en Lima, dentro de ellos, ninguno realiza las terapias suficientes que necesita un paciente con este tipo de mal; ya que, la mayoría brindan charlas sobre el conocimiento de la enfermedad. 
El Centro de día de ubicará en el distrito de San Martín de Porres, en una zona de fácil acceso que incluso será reforzado con la construcción de una línea propuesta a futuro que tendrá un paradero muy cerca al edificio.

La zona tiene también, varias áreas verdes aledañas, lo cual ayuda con el tratamiento para los pacientes. Es por eso, que dentro del centro se tienen espacios verdes de reunión para la interacción del enfermo con la naturaleza. 


\section{Capítulo 9 : EL PROYECTO}

\subsection{Plantas}




Segundo Nivel

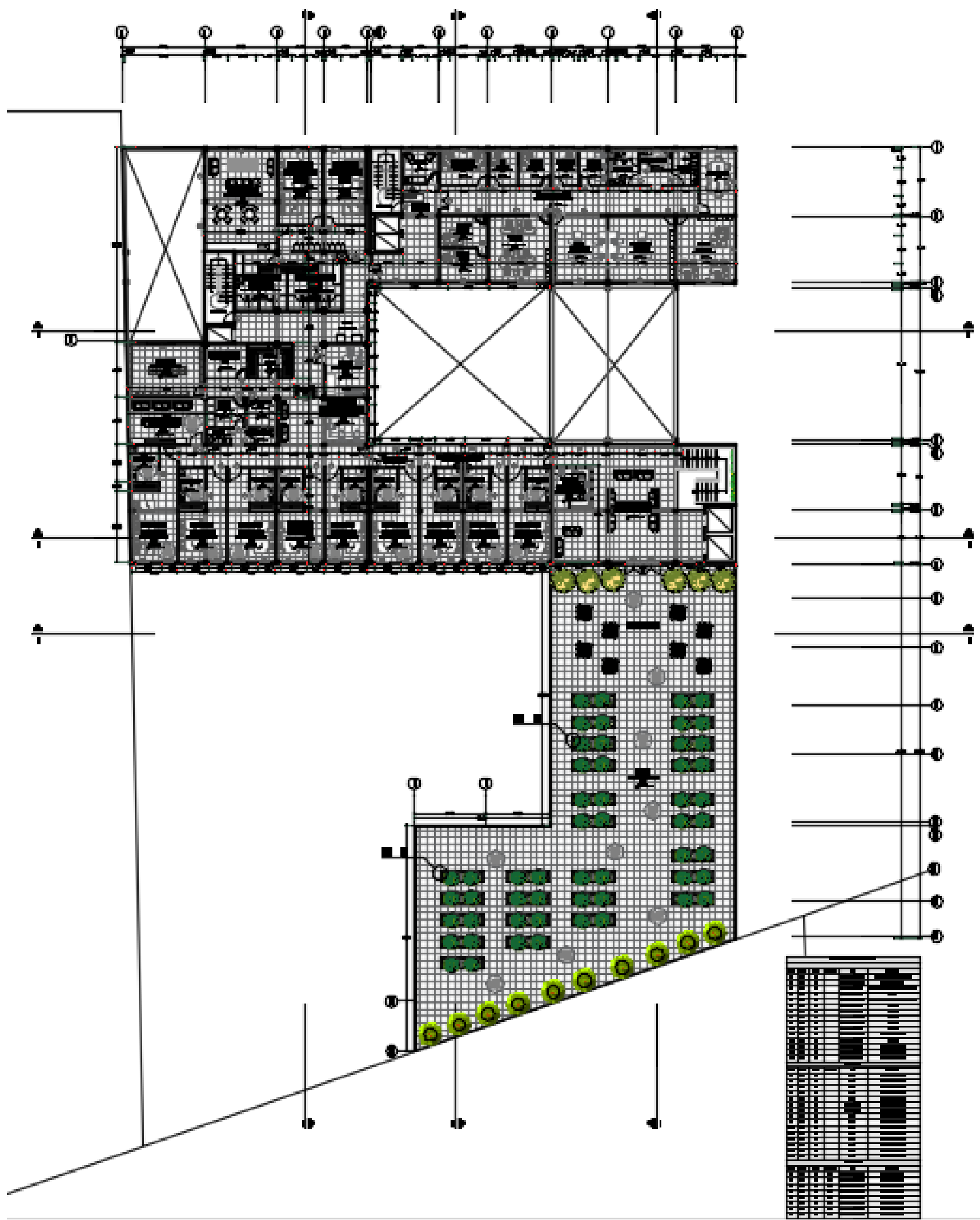




\subsection{Cortes}
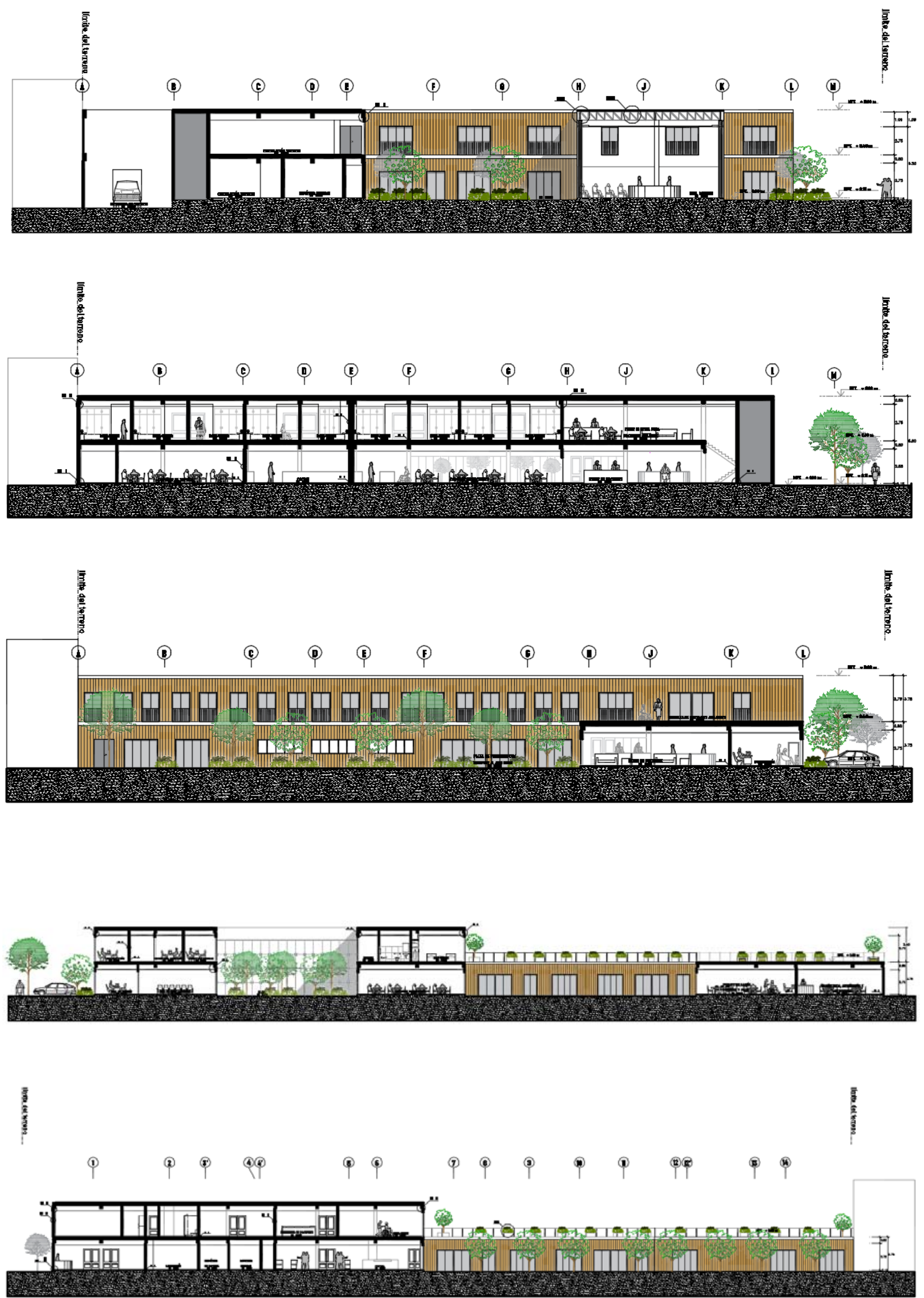


\subsection{Elevaciones}

- Av. Canta Callao

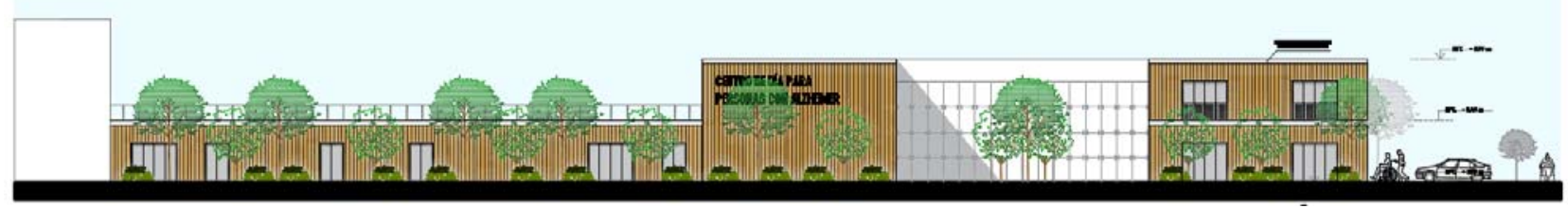

- Calle Huascar

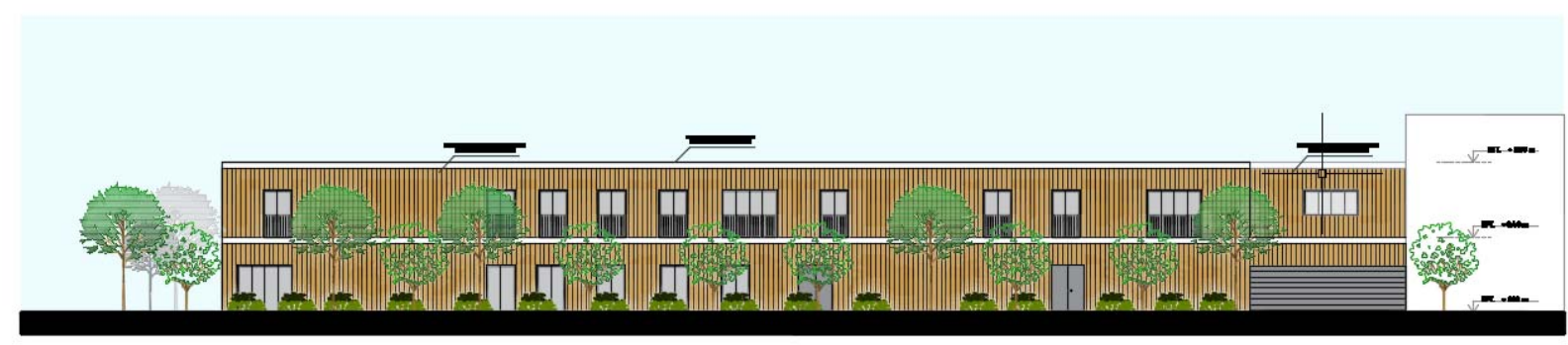




\subsection{Vistas}

Figura 20. Vista exterior : Fachada Av. Canta Callao

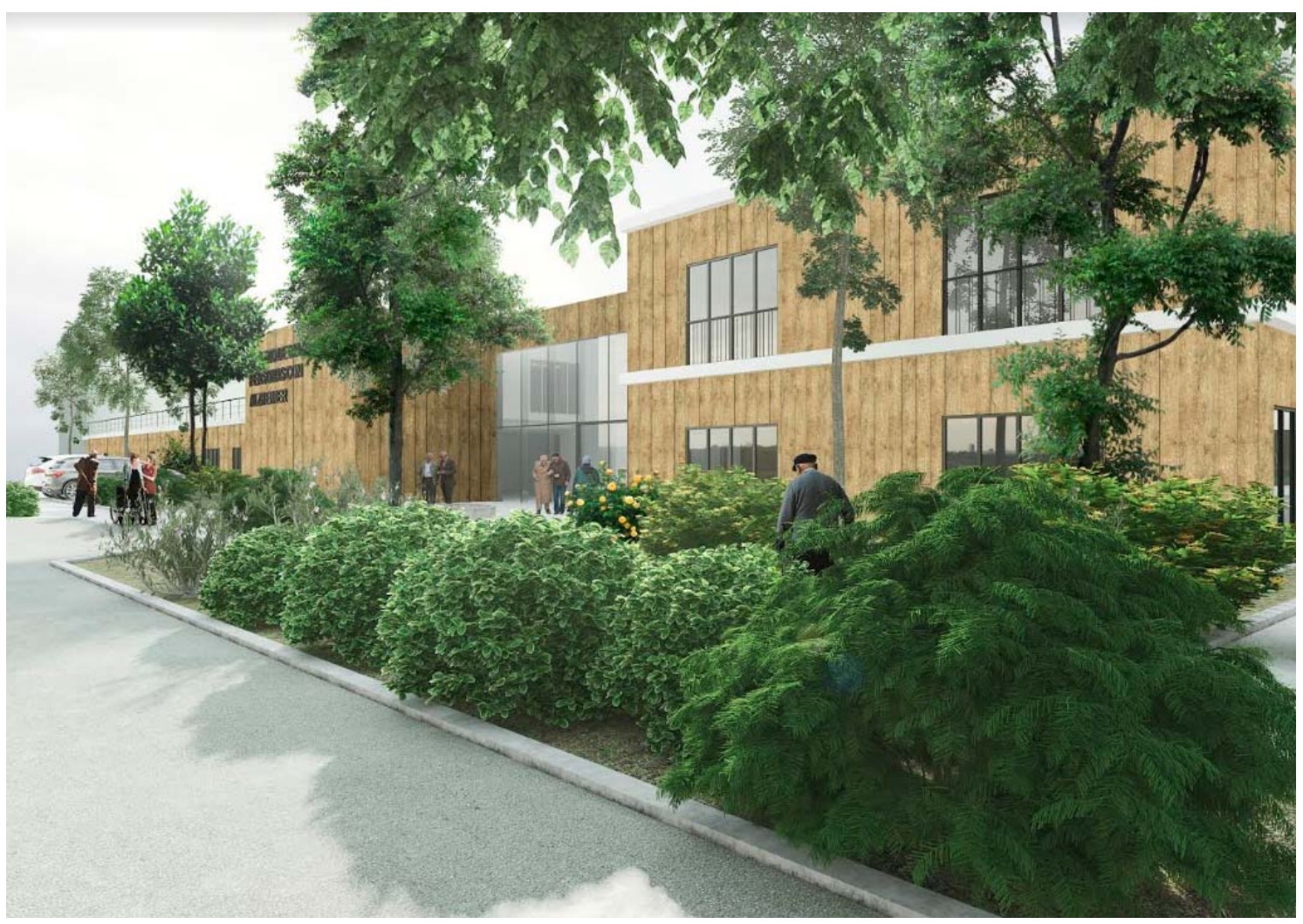

Figura 21. Vista exterior : Fachada calle Huascar

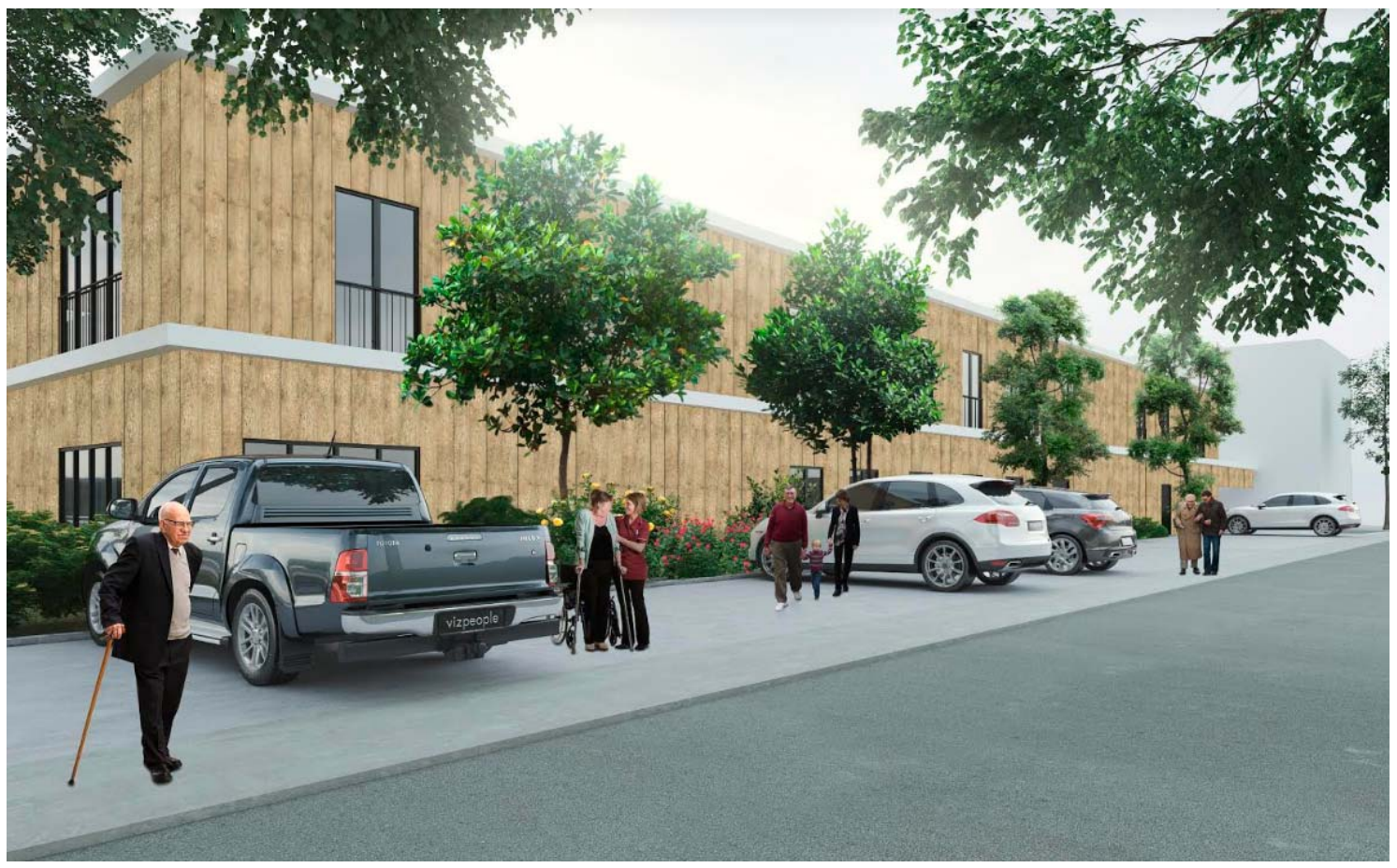


Figura 22. Vista interior : Patio de pacientes

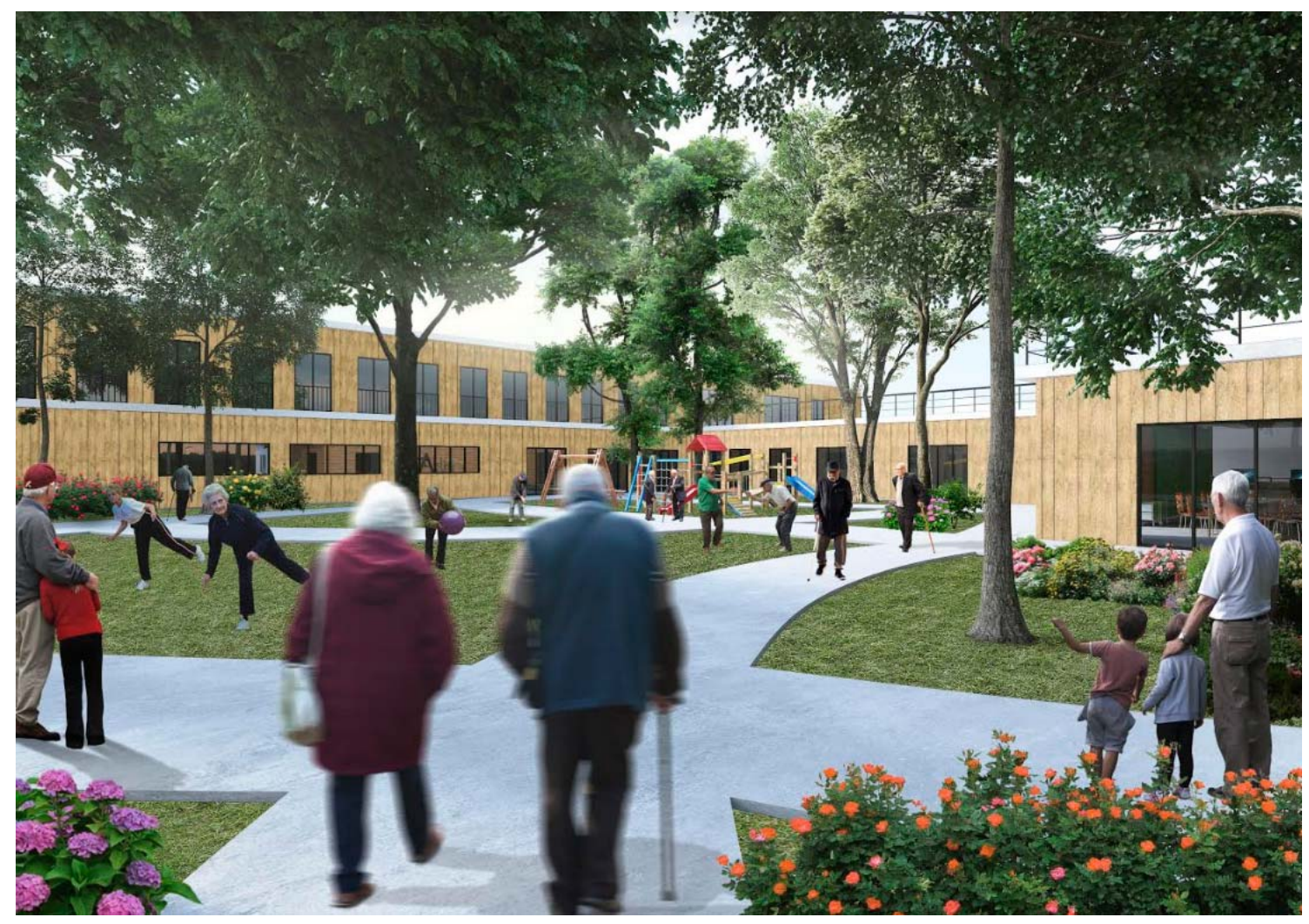

Figura 23. Vista interior : Terraza de pacientes

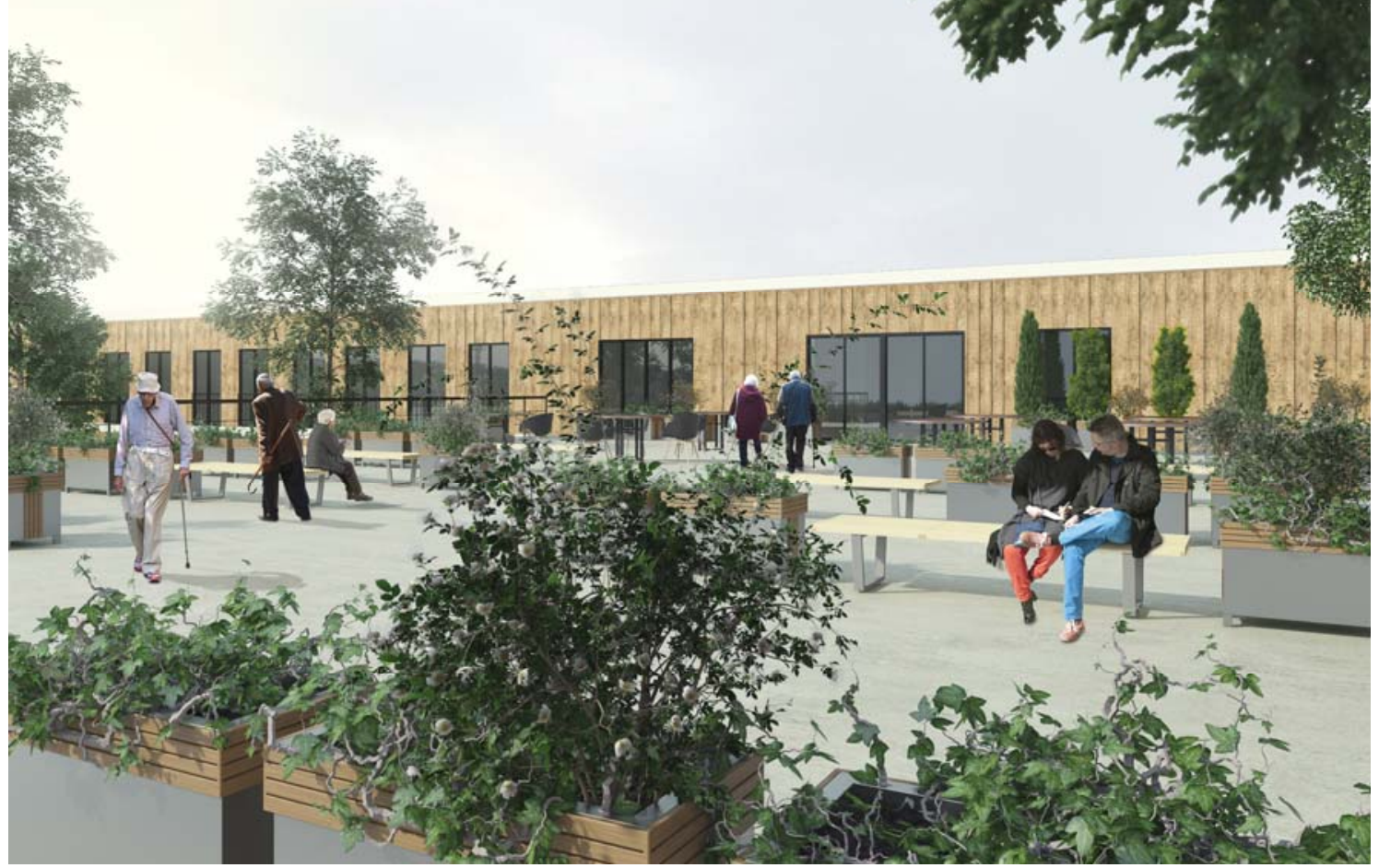


Figura 24. Vista interior : Habitaciones dobles

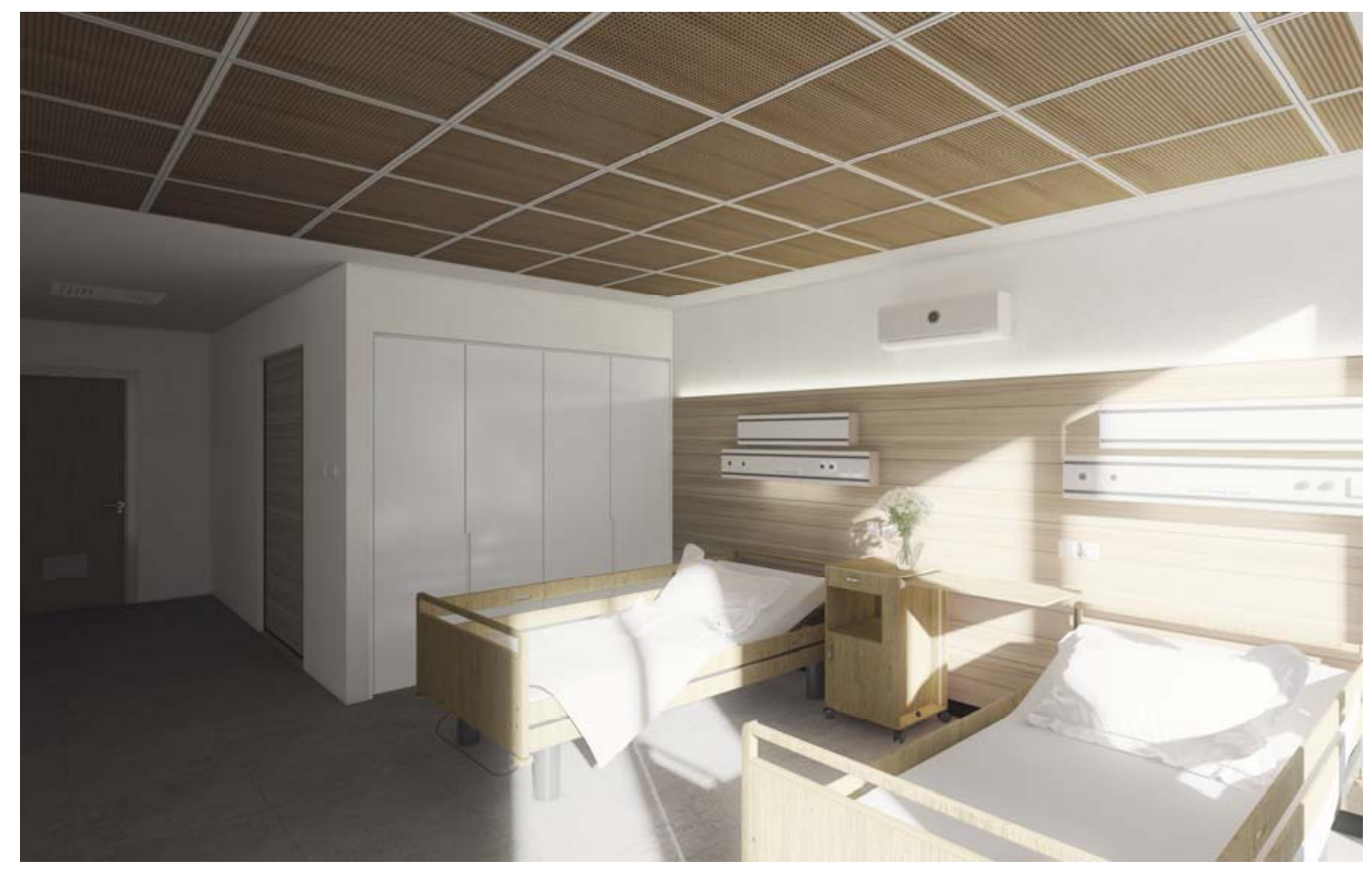

Figura 25. Vista interior: Sala de terapias

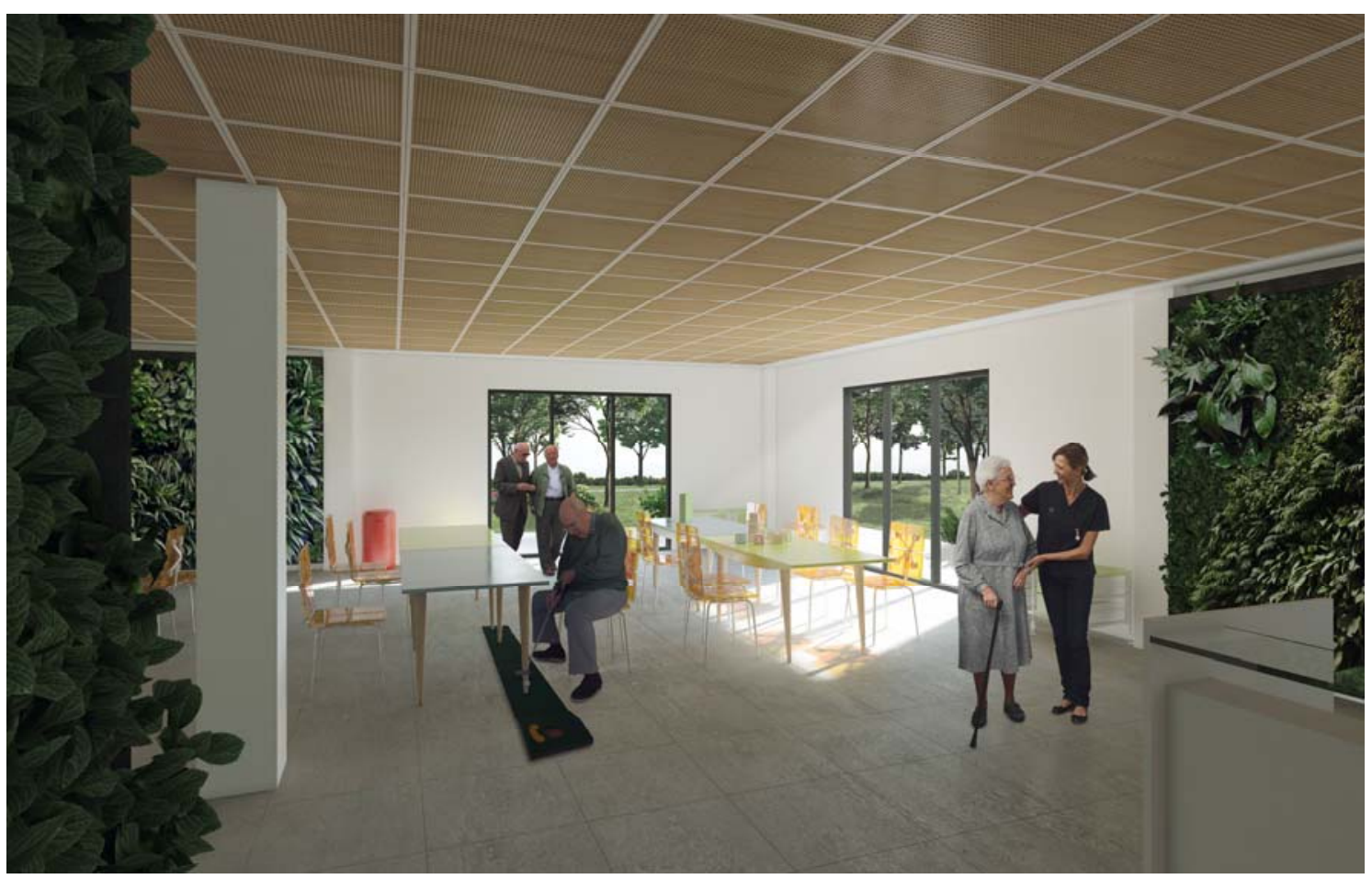




\section{Bibliografía}

80 grados. Prensa sin prisa. (2016). Obtenido de http://www.80grados.net/mejorar-lamemoria-y-reducir-los-riesgos-del-alzheimer/

ADI. (Octubre de 2014). World Alzheimer report 2014. Londres.

Alzheimer. (2016). Obtenido de https://www.alzheimer.com.es/fases-del-alzheimer

Alzheimer Disease International. (2014). World Alzheimer Report 2014: Dementia and Risk Reduction and Analysis of protective and Modifiable Factors.

$\begin{array}{llll}\text { Arquitectura } \quad y \quad \text { empresa } & \text { (2016). Obtenido de }\end{array}$ https://www.arquitecturayempresa.es/noticia/geometria-en-el-terreno-colegiolomas-del-peye-cartagena-colombia

Asociación Peruana de Alzheimer y otras Demencias. (2016, Febrero 9). Visitas diarias al centro de Alzheimer. (F. Ramos, Interviewer)

Atrium. (2016). Obtenido de http://catalogo.artium.org/dossieres/exposiciones/premiospritzker-viaje-por-la-arquitectura-contemporanea/obra-seleccionada-15

Berrocal, F. (2013). Centro de Rehabilitación para discapacitados (Tesis de grado). Lima: Universidad de Ciencias Aplicadas (UPC).

Climate-Data. (2016). Obtenido de https:/es.climate-data.org/location/19726/

Hipocampo. (2016). Obtenido de https://www.hipocampo.org/cruzroja,htm

Huerta, J. (2006). Discapacidad y Accesibilidad. La dimensión desconocida. Comisión Especial de estudio sobre Discapacidad, 189.

INEI. (2008). Perú: Crecimiento y distribución de la población, 2007. Censos Nacionales 2007, 15-30.

INEI. (2014). Proyecciones de Población por Distritos. Lima, Perú.

Information, R. B. (2009). Arte y Cemento . Revista de la Construcción y su entorno, 185-190.

INSM. (2016). Obtenido de http://www.insm.gob.pe/investigacion/articulos/4.html

Instituto de la Memoria. (2016, Febrero 11). Visitas diarias al centro de Alzheimer. (F. Ramos, Interviewer)

Instituto Nacional de Ciencias Neurológicas. (2016, Febrero 9). Visitas diarias en el Centro de Alzheimer. (F. Ramos, Interviewer) 
Martinez, A. (2016). El Alzheimer. España: Consejo Superior de Investigaciones Científicas.

MINEDU. (Agosto de 2006). Normas Tecnicas para el diseño de locales de educación basica especial y programas de intervención temprana . Lima, Perú.

Mostra D'Arquitectura Catalana. (2016). Obtenido de http://www.arquitectes.cat/iframes/mostra_new/visor.php/obra/323?\&lang

MSP. (Junio de 2015). Guia para el diseño y la construcción estructural de establecimientos de salud en la Republica Dominicana .

Muñiz, R., \& Olazarán, J. (2009). Mapa de terápias no Farmacológicas para demencias tipo Alzheimer. Fundación Maria Wolf, 2-5.

Newport, M. (22 de Julio de 2008). What if there was a cure for alzheimer's disease and no one knew? págs. 1-3.

Noguchi", O. O.-H. (2013). Estduio Epidemiologico de salud mental en Lima Metropolitana y el Callao. Anales de Salud Mental , 50-85. Obtenido de http://www.insm.gob.pe/investigacion/archivos/estudios/2012\%20ASM\%20EESM\%20-LM.pdf

Normas Legales. Zonificación de los usos de suelos . (14 de Mayo de 2007). Lima, Perú.

Perez, C. H. (2006). Centro de asistencia diurno para personas enfermas de Alzheimer en la ciudad de Oaxaca. (Tesis doctoral). Universidad Tecnológica de Mixteca, Mixteca.

Planos de Casas. (2016). Obtenido de http://planosdecasas.net/centro-granadino-delalzheimer/

Salud, D. G. (08 de Agosto de 1996). Normas técnicas para proyectos de Arquitectura Hospitalaria. Lima, Perú. Obtenido de http://www.dgiem.gob.pe/wpcontent/uploads/2013/01/pw11_rm482-96-sa-dm.pdf

San Isidro, Ciudad Sostenible . (2016). Obtenido de http://msi.gob.pe/portal/nuestrodistrito/historia-del-distrito/

SINIA. (2016). Obtenido de http://sinia.minam.gob.pe/mapas/mapa-suelos-distritos-lima

Sophia, F. R. (8 de Marzo de 2007). El proyecto Alzheimer de la Reina Sofía. Madrid, España.

Wikiarquitectura. (2016). Obtenido de https://es.wikiarquitectura.com/edificio/Clinicapara-la-Salud-Mental-Lou-Ruvo/

Yanguas, J. (2007). Modelo de atención a las personas con enfermedad de Alzheimer . DOC, 50-60. 
